\title{
Optimizing outcomes \\ of patients with systemic sclerosis
}

\author{
Julia Spierings
}




\section{Julia Spierings}

\section{Optimizing outcomes of patients with systemic sclerosis}

Verbetering van uitkomsten in systemische sclerose

ISBN 978-94-6332-678-0

https://doi.org/10.33540/168

Cover \& layout by Beatrijs Voorneman

Printed by GVO drukkers \& vormgevers B.V.

Financial support by Mw. van de Sanden-Koolen and de Nationale Vereniging voor Lupus, APS, Sclerodermie en MCTD (NVLE) is gratefully acknowlegded. Part of the research described in this thesis was supported by ARCH.

(C) 2020 Julia Spierings

All rights reserved. No part of this publication may be reproduced, stored in a retrieval system, or transmitted, in any form or by any means, electronically, mechanically, by photocopying, recording or otherwise, without the prior written permission of the author. 
Optimizing outcomes of patients with systemic sclerosis

Verbetering van uitkomsten in systemische sclerose

\section{Proefschrift}

ter verkrijging van de graad van doctor aan de Universiteit Utrecht op gezag van de rector magnificus, prof.dr. H.R.B.M. Kummeling, ingevolge het besluit van het college voor promoties in het openbaar te verdedigen op

maandag 12 oktober 2020 des ochtends te 11.00 uur door

\section{Julia Spierings}

geboren op 25 oktober 1985

te Breda 


\section{Promotor:}

Prof. dr. J.M. van Laar

\section{Copromotor:}

Dr. M.C. Vonk 


\title{
Optimizing outcomes of patients with systemic sclerosis
}

\author{
by Julia Spierings
}




\section{table of contents}

Part 1 | Health care and quality of care in Systemic Scerosis in the Netherlands

Chapter 1

General introduction
8-17 Chapter 2

20-37

How do patients with systemic sclerosis experience health care and how should we measure its quality?

Chapter 3

38-61

Optimal care for patients with systemic sclerosis: recommendations from a patient-centered and multidisciplinary mixed-method study and working conference

Chapter 4 $62-73$

Requirements for systemic sclerosis expert centres in the Netherlands: a Delphi consensus study

Chapter 5 $74-79$

Living with systemic sclerosis: exploring its impact on caregivers 
Part 2 | Autologous stem cell

transplantation in systemic sclerosis

Chapter 6

82-93

Chapter 12

146-157

Hematopoietic stem cell transplantation

General discussion

in systemic sclerosis: a review of recent

literature

Summary

158-163

Chapter 7

94-109

Samenvatting

164-169

Treatment decision-making in diffuse

Dankwoord

170-175

cutaneous systemic sclerosis: a patient's

Curriculum vitae

176-179

perspective

List of publications

180-186

Chapter 8

110-113

Choosing a treatment: how can we guide patients through the labyrinth?

Chapter 9

114-119

Second autologous hematopoietic stem cell transplantation in systemic sclerosis - a case report

Chapter 10

$120-131$

From "being at war" to "getting back on your feet": an exploratory qualitative study in patients with systemic sclerosis treated with hematopoietic stem cell transplantation

Chapter 11

A randomized, open-label trial to assess the optimal treatment strategy in early diffuse cutaneous systemic sclerosis: the UPSIDE Study protocol 

chapter 1

General introduction 


\section{Chapter 1}

\section{Systemic sclerosis}

Systemic sclerosis (SSc) is a rare systemic autoimmune connective tissue disease characterized by inflammation, vasculopathy and fibrosis of the skin and internal organs. It is an orphan disease with a spectrum ranging from mild forms to severe and progressive disease. Globally, 1 in 10000 people is diagnosed with SSc (1). In the Netherlands, the reported incidence is 0.77 per 100000 per year (2).

\section{Pathogenesis}

The three key pathological processes in SSc are inflammation, vasculopathy and fibrosis of the skin and visceral organs. Nevertheless, their interplay is poorly understood but probably involves stepwise evolution. Endothelial injury accompanied with pro-inflammatory cytokines are thought to be an initiating event, leading to microvascular changes and oxidative stress (3). Vascular changes are associated with activation of the innate and adaptive immune system early in the disease, which lead to inflammation and formation of autoantibodies (4). These processes eventually result in myofibroblast activation and differentiation resulting in excessive production of extracellular matrix which accumulate in skin, vessels and internal organs (5,6). An overview of the course of disease and pathological processes involved, is provided in Figure 1. Additionally, several genetic associations with SSc are reported and it is believed that a genetic predisposition could develop the disease when exposed to a triggering event such as infection or other environmental factor $(7,8)$. The low concordance among monozygotic twins indicates however that epigenetic rather than genetic components predominate $(9,10)$.

Figure 1. Disease course of systemic sclerosis and pathological processes

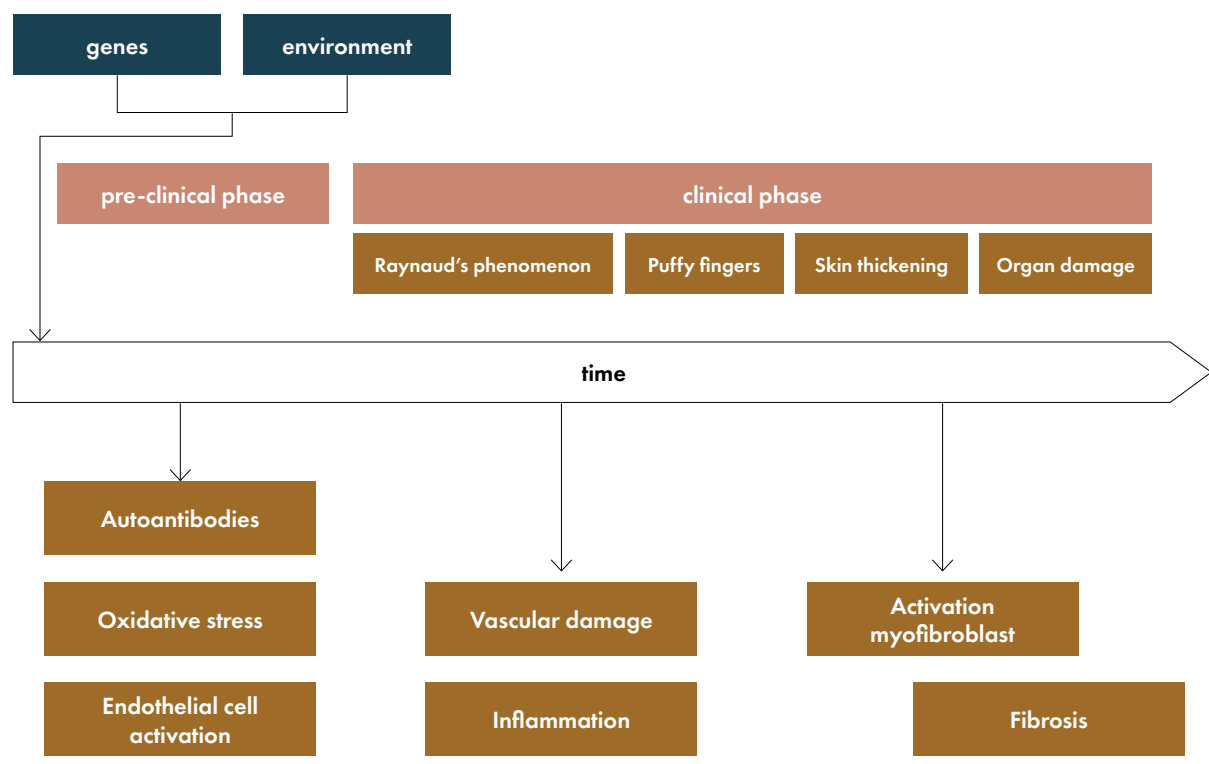




\section{Clinical features}

The clinical presentation of SSc is heterogeneous. Disease manifestations range from limited skin thickening to generalized skin involvement with severe internal organ damage. First symptoms of SSc are often Raynaud's phenomenon and puffy fingers, sometimes accompanied with non-specific features such as gastrointestinal reflux, joint pain and fatigue. These symptoms can be present years before more distinct features appear (11). Thickening of the skin is a characteristic feature. Two clinical subsets can be distinguished: patients with affected skin restricted to the face and the distal part of the arms and legs, distal from the elbows and knees (limited cutaneous systemic sclerosis (lcSSc)) and patients with generalized skin involvement (diffuse cutaneous systemic sclerosis (dcSSc)) (see Figure 2) (12,13). Approximately $75 \%$ of patients can be classified as having lcSSc, $25 \%$ has the diffuse subtype. In patients with dcSSc, major organ involvement (heart, lungs and kidneys) is more common $(14,15)$. Aside from skin involvement, LCSSc and dcSSc can also be differentiated by their auto-antibody profiles.

Figure 2. There are two SSc subtypes:

A. Limited cutaneous systemic sclerosis. Characterized by a long history of Raynaud's phenomenon, distal skin thickening and organ complications at a late-stage. Autoantibodies typically present are anti-centromere antibodies.

B. Diffuse cutaneous systemic sclerosis. Characterized by more rapidly progressive generalized skin thickening and organ involvement. Autoantibodies typically present are anti-topoisomerase I and RNA polymerase III antibodies.
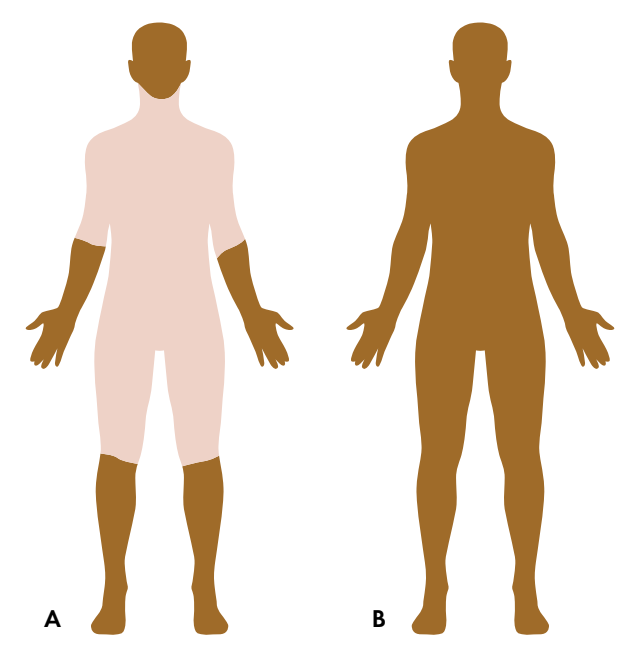

Despite improvement in health care and increased understanding of pathophysiological processes, SSc is still associated with high mortality rates (16). This holds true for dcSSc in particular, with a five-year mortality rate of $27 \%$ (17). Pulmonary fibrosis and pulmonary arterial hypertension are the leading causes of scleroderma associated death(18). The disease course of LCSSc is more indolent though life-threatening organ complications may occur later on in the disease course, e.g. cardiopulmonary organ involvement, leading to a 10 -year mortality of $\sim 19 \%(18,19)$. Complications of the disease with high impact on quality 


\section{Chapter 1}

of life are digital vasculopathy (ulcers, gangrene, calcinosis cutis), digital contractures, gastrointestinal complications, lung fibrosis, cardiac fibrosis, pulmonary hypertension and scleroderma renal crisis (20). Additionally, symptoms like weight loss, arthritis, fatigue, sicca and facial changes are common and can have a major impact on quality of life and daily functioning as well (21). Figure 3 shows an overview of the main clinical manifestations of systemic sclerosis.

Fig 3. Clinical manifestations of systemic sclerosis

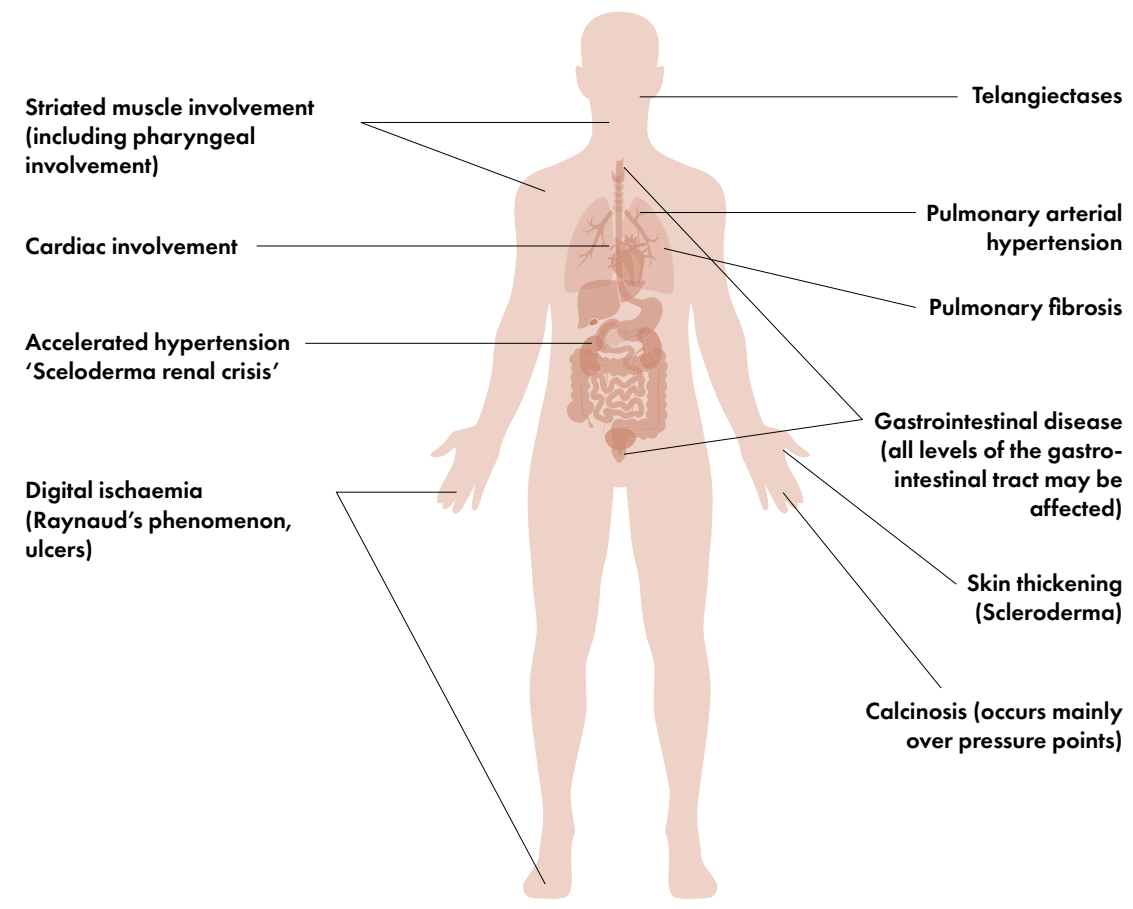

\section{Therapy of SSc}

Treating patients with SSc is challenging, due to the heterogeneous character of the disease, multiorgan involvement and relatively limited treatment options. A key element in clinical management is a systematic follow-up focused on identifying organ involvement in its early stages in order to treat within the window of opportunity. This screening regimen includes at least annually skin involvement evaluation, pulmonary function testing, blood pressure monitoring and cardiac ultrasonography. Treatment strategies are essentially based on organ involvement. Treatments available in SSc can be divided into three categories: immunomodulating therapy, vasoactive medication and other symptomatic treatment.

\section{Immunomodulating treatments}

Immunomodulating therapies are widely used in patients with progressive inflammatory and fibrotic disease. Treatment of progressive skin thickening and arthritis may consist of methotrexate (15-25mg/week) or mycophenolate mofetil (up to 3 grams a day)(22). The efficacy of cyclophosphamide to treat severe skin involvement is supported by evidence (23). 
In progressive interstitial lung disease, which is present in approximately $20-30 \%$ of SSc patients, large clinical trials supported the use of cyclophosphamide (daily oral or monthly pulse therapy) and mycophenolate mofetil $(24,25)$. In recent trials two other immunomodulating treatments that are widely used in other rheumatic conditions, rituximab and tocilizumab, have shown variable results on ILD and skin $(26,27)$ The new agent nintedanib, a tyrosine-kinase inhibitor targeting profibrotic pathways, has demonstrated benefits with regard to pulmonary function and will be available in clinical care soon (28). Furthermore, other new immunomodulating agents are currently evaluated in ongoing studies.

To date, the treatment with the best result to improve survival and stabilize organ function is haemopoietic autologous stem-cell transplantation (HSCT). This is an intensive immunomodulating therapy that can be initiated in patients with progressive dcSSc. HSCT is thought to rebalance the immune system through elimination of pathogenic self-reactive immune cells and reconstitution of a new, tolerant immune system. However, the mechanism of action underlying this reset to tolerance remains largely unknown. In three controlled trials, HSCT was shown to improve survival, quality of life, skin fibrosis and prevented disease progression in dcSSc patients (29-31). This treatment option is however hampered by two aspects: costs and a significant treatment related mortality. Selection of patients that have the best benefit ratio and performance of this treatment in experienced centers is warranted to safely and effectively perform HSCT. Unfortunately, specific guidelines on when to treat with HSCT in the course of dcSSc are currently lacking (32).

\section{Treatment of pulmonary hypertension}

Ten percent of the patients with SSc develop pulmonary arterial hypertension, which is a lethal complication (33). Treatment with endothelin receptor antagonists, prostacyclin analogues and phosphodiesterase- 5 inhibitors as monotherapy or combination therapy have demonstrated to improve life expectancy, exercise capacity and World Health Organization functional class in several trials (34-37).

\section{Symptomatic treatment}

Vasoactive medication is used to treat Raynaud's phenomenon and other vascular complications in SSc. Raynaud's phenomenon and digital ulcers have a large impact on daily functioning, causing severe pain, secondary infections or digital infarction and, subsequently, affect hand function (38). Pharmacological management includes vasodilating therapy with calcium channel blockers, phosphodiesterase-5 inhibitors, intravenous prostanoid therapies or endothelin antagonists (39).

Other symptomatic treatments aim to ameliorate gastrointestinal (GI) problems, which are very common and disturbing i.e. esophageal and gastric dysmotility and gastric antral vascular ectasia in the upper tract and constipation, diarrhea and anorectal incontinence in the lower tract. Treatment of Gl symptoms consists of proton pump inhibitors for reflux, prokinetics and probiotics to improve motility, antibiotics for bacterial overgrowth, dietary measures and symptomatic treatment in case of diarrhea or constipation (40).

At last, non-pharmaceutical treatments are an indispensable complementary facet in SSc care. Exercise programs and physiotherapy can be beneficial in patients with musculoskeletal pain and fatigue (41). Occupational therapy is key in optimizing hand 
function (42), and psychosocial support can help patient cope with the impact of the disease on multiple domains (43).

With regard to psychosocial support, we hypothesize that especially in patients in whom HSCT is indicated or already applied, there is a considerable psychosocial burden. Several studies in patients with hematological malignancies, demonstrated that HSCT has a major physical and psychological impact, even long-time after the treatment (44-46). To date, no studies have been performed to investigate these experiences of HSCT in patients with autoimmune diseases or dcSSc specifically.

In general, determining a certain treatment strategy should be a process in which clinicians share the best available evidence, the preferences of patients are incorporated in the treatment decision. This is defined as shared decision-making (SDM) $(47,48)$. Treatment decision-making in dcSSc in the context of HSCT or other immunomodulating treatments can, however, be a difficult process: although there is evidence for the superior long-term benefits of HSCT, this treatment carries significant risks and there is no evidence on patient selection or optimal timing for HSCT. Therefore, the decision-making process should be optimally supportive for patients. Unfortunately, there is not much experience with regard to SDM and optimal patient education for HSCT in dcSSC.

\section{Organization of SSc in the Netherlands}

In addition to the complex treatment, organization of optimal care in patients with rare, chronic and complex conditions, like SSc, is challenging $(49,50)$. Patients may present with various signs and symptoms at different departments, which can complicate timely diagnosis. Moreover, the high number of hospital visits puts a huge strain on patients, especially on those with functional disabilities (51). Also, with several disciplines involved in the treatment of each single patient, alignment between health care professionals is crucial for safe and optimal patient management.

Although the importance of collaboration and education is broadly recognized, not all patients receive the same high standard of care (52). Earlier studies showed that only a low percentage of SSc patients received adequate multidisciplinary specialist care (53). Furthermore, in other countries, patient report that the diagnostic process and follow-up care need to be optimized. Concluding from the earlier studies evaluating SSc care, even in developed countries with modern health care systems there is room to improve quality of care.

Evaluation of quality of care in SSc in the Netherlands, involving different stakeholders in order to merge various perspectives, will identify aspects for improvement. In addition to the recognition of unmet needs in SSc care, criteria for good health care are needed in order to properly evaluate the quality of care at this moment and in the future. Although two studies focussed on the perspective of physicians $(54,55)$, the patient perspective regarding this issue is still lacking.

In the Netherlands, the Arthritis Research and Collaboration Hub (ARCH), funded by the Dutch Arthritis Association, was started in 2016 as a nationwide effort to improve health care for patients with rare systemic autoimmune diseases, including systemic sclerosis (SSc). ARCH has connected health care professionals, patients and other stakeholders with whom a design for optimal health care was created. Currently, $\mathrm{ARCH}$ is building a national network to improve accessibility of high quality care for rare systemic autoimmune diseases. 


\section{Aims and outline of this thesis}

This thesis aims to contribute to the improvement of outcomes in SSc. It focuses on organization and quality of care and treatment of patients with SSc in the context of HSCT. The goal of the first part was to investigate the organization of Dutch SSc care and its quality from different perspectives and to explore ways to improve quality of care. The goal of the second part was to assess several aspects of HSCT in SSc.

\section{Part 1. Health care and quality of care in SSc in the Netherlands}

In chapter 2, the results of a patient survey evaluating quality of care in thirteen hospitals in the Netherlands are discussed. Also, indicators to evaluate quality of care prioritized by patients are presented. Chapter $\mathbf{3}$ adds the perspectives of health care professionals on quality of SSc care, providing the results of a multidisciplinary mixed-method study and working conference on optimal SSc care in the Netherlands. Chapter 4 describes the outcome of a Delphi consensus study in which a set of requirements for two types of SSc expert centres was established, in order to develop a nationwide structure for an optimal and transparent organization of care. In chapter 5 the impact of SSc on caregivers and their unmet needs are described.

\section{Part 2. Autologous stem cell transplantation in SSc}

Chapter 6 summarizes recent literature on HSCT in SSc. Chapter 7 explores the experiences of treatment decision-making in dcSSc and chapter 8 reflects on treatment decisionmaking and ways to support patients in this process. Chapter 9 describes a case of repeat HSCT. Chapter 10 evaluates patients' experiences during and after HSCT.

A design of a trial assessing the optimal treatment strategy in early dcSSc is presented in chapter 11. Chapter 12 contains a discussion of the main findings of this thesis and recommendations for clinical practice and further research.

\section{References}

1. Bergamasco A, Hartmann N, Wallace L, Verpillat P. Epidemiology of systemic sclerosis and systemic sclerosis-associated interstitial lung disease. Clin Epidemiol. 2019;11:257-273.

2. Vonk MC, Broers B, Heijdra YF, Ton E, Snijder R, Van Dijk APJ, et al. Systemic sclerosis and its pulmonary complications in The Netherlands: An epidemiological study. Ann Rheum Dis. 2009;68(6):961-965.

3. Abraham DJ, Varga J. Scleroderma: From cell and molecular mechanisms to disease models. Trends Immunol. 2005;26(11):587-595

4. Abraham D, Distler O. How does endothelial cell injury start? The role of endothelin in systemic sclerosis. Arthritis Res Ther. 2007;9 Suppl 2(Suppl 2):S2.

5. Jimenez SA. Role of endothelial to mesenchymal transition in the pathogenesis of the vascular alterations in systemic sclerosis. ISRN Rheumatol. 2013;835948.

6. Pattanaik D, Brown M, Postlethwaite BC, Postlethwaite AE. Pathogenesis of systemic sclerosis. Front Immunol. 2015;6:272.

7. Murdaca G, Contatore M, Gulli R, Mandich P, Puppo F. Genetic factors and systemic sclerosis. Autoimmun Rev. 2016;15(5):427-432.

8. Broen JCA, Radstake TRDJ, Rossato M. The role of genetics and epigenetics in the pathogenesis of systemic sclerosis. Nat Rev Rheumatol. 2014;10(11):671-681.

9. Feghali-Bostwick C, Medsger TA, Wright TM. Analysis of systemic sclerosis in twins reveals low concordance for disease and high concordance for the presence of antinuclear antibodies. Arthritis Rheum. 2003;1;48(7):1956-1963. 


\section{Chapter 1}

10. Ramos PS, Zimmerman KD, Haddad S, Langefeld CD, Medsger TA, Feghali-Bostwick CA. Integrative analysis of DNA methylation in discordant twins unveils distinct architectures of systemic sclerosis subsets. Clin Epigenetics. 2019;4;11(1).

11. Bellando-Randone S, Matucci-Cerinic M. From Raynaud's Phenomenon to Very Early Diagnosis of Systemic Sclerosis- The VEDOSS approach. Curr Rheumatol Rev. 2014;20;9(4):245-248.

12. Van Den Hoogen F, Khanna D, Fransen J, Johnson SR, Baron M, Tyndall A, et al. 2013 classification criteria for systemic sclerosis: An American college of rheumatology/European league against rheumatism collaborative initiative. Ann Rheum Dis. 2013;72(11):1747-1755.

13. LeRoy EC, Medsger J. Criteria for the classification of early systemic sclerosis.J Rheumatol. 2001;28(7):1573-1576.

14. Black CM. Scleroderma - clinical aspects. J Intern Med. 1993;234(2):115-118

15. Steen VD. Clinical manifestations of systemic sclerosis. Semin Cutan Med Surg. 1998;17(1):48-54.

16. Nihtyanova SI, Tang EC, Coghlan JG, Wells AU, Black CM, Denton CP. Improved survival in systemic sclerosis is associated with better ascertainment of internal organ disease: a retrospective cohort study. QJM. 2010;103(2):109-115.

17. Ioannidis JPA, Vlachoyiannopoulos PG, Haidich AB, Medsger TA, Lucas M, Michet CJ, et al. Mortality in systemic sclerosis: An International meta-analysis of individual patient data. Am J Med. 2005;118(1):210 .

18. Tyndall AJ, Bannert B, Vonk M, Airò P, Cozzi F, Carreira PE, et al. Causes and risk factors for death in systemic sclerosis: A study from the EULAR Scleroderma Trials and Research (EUSTAR) database. Ann Rheum Dis. 2010;69(10):1809-1815.

19. Ferri C, Sebastiani M, Lo Monaco A, ludici M, Giuggioli D, Furini F, et al. Systemic sclerosis evolution of disease pathomorphosis and survival. Our experience on Italian patients' population and review of the literature. Autoimmun Rev. 2014;13(10):1026-1034

20. Denton CP, Khanna D. Systemic sclerosis. Lancet. 2017;390(10103):1685-1699

21. Almeida C, Almeida I, Vasconcelos C. Quality of life in systemic sclerosis. Autoimmun Rev. 2015;14(12):1087-1096.

22. Herrick AL, Pan X, Peytrignet S, Lunt M, Hesselstrand R, Mouthon L, et al. Treatment outcome in early diffuse cutaneous systemic sclerosis: The European Scleroderma Observational Study (ESOS). Ann Rheum Dis. 2017;1;76(7):1207-1218.

23. Kersten BE, den Broeder N, van den Hoogen FHJ, Knaapen-Hans HAK, van den Ende CHM, Vonk MC. Treatment with cyclophosphamide i.v. pulse therapy is an option for effective treatment of skin fibrosis in patients with early systemic sclerosis. Rheumatology. 2020;59(7):1793.

24. Tashkin DP, Elashoff R, Clements PJ, Roth MD, Furst DE, Silver RM, et al. Effects of 1-year treatment with cyclophosphamide on outcomes at 2 years in scleroderma lung disease. Am J Respir Crit Care Med. 2007;15;176(10):1026-1034.

25. Tashkin DP, Elashoff R, Clements PJ, Goldin J, Roth MD, Furst DE, et al. Cyclophosphamide versus placebo in scleroderma lung disease. N Engl J Med. 2006;22;354(25):2655-66.

26. Khanna D, Denton CP, Jahreis A, van Laar JM, Frech TM, Anderson ME, et al. Safety and efficacy of subcutaneous tocilizumab in adults with systemic sclerosis (faSscinate): a phase 2, randomised, controlled trial. Lancet. 2016;25;387(10038):2630-2640.

27. Jordan S, Distler JHW, Maurer B, Huscher D, Van Laar JM, Allanore Y, et al. Effects and safety of rituximab in systemic sclerosis: An analysis from the European Scleroderma Trial and Research (EUSTAR) group. Ann Rheum Dis. 2015;1;74(6):1188-1194.

28. Distler O, Highland KB, Gahlemann M, Azuma A, Fischer A MM et al. Nintedanib for Systemic SclerosisAssociated Interstitial Lung Disease. New Engl J Med. 2019;380(26):2518-2528.

29. Burt RK, Shah SJ, Dill K, Grant T, Gheorghiade M, Schroeder J, et al. Autologous non-myeloablative haemopoietic stem-cell transplantation compared with pulse cyclophosphamide once per month for systemic sclerosis (ASSIST): An open-label, randomised phase 2 trial. Lancet. 2011;6;378(9790):498506.

30. Sullivan KM, Wigley FM, Denton CP, Van Laar JM, Furst DE. Haemopoietic stem-cell transplantation for systemic sclerosis. Lancet. 2012;379(9812):219-220.

31. Van Laar JM, Farge D, Sont JK, Naraghi K, Marjanovic Z, Larghero J, et al. Autologous hematopoietic stem cell transplantation vs intravenous pulse cyclophosphamide in diffuse cutaneous systemic sclerosis: A randomized clinical trial. JAMA 2014;311(24):2490-2498.

32. Kowal-Bielecka O, Fransen J, Avouac J, Becker M, Kulak A, Allanore Y, et al. Update of EULAR recommendations for the treatment of systemic sclerosis. Ann Rheum Dis. 2017; 1;76(8):1327-1339. 
33. Nihtyanova SI, Schreiber BE, Ong VH, Rosenberg D, Moinzadeh P, Coghlan JG, et al. Prediction of pulmonary complications and long-term survival in systemic sclerosis. Arthritis Rheumatol. 2014;66(6):1625-1635.

34. Mullin CJ, Mathai SC. New insights into the recognition, classification and management of systemic sclerosis-associated pulmonary hypertension. Curr Opin Rheumatol. 2017;29(6):561-567.

35. Galiè N, Humbert M, Vachiery J-L, Gibbs S, Lang I, Torbicki A, et al. 2015 ESC/ERS Guidelines for the Diagnosis and Treatment of Pulmonary Hypertension. Rev Española Cardiol. 2016;69(2):177.

36. Galie N, Barbera JA, Frost AE, Ghofrani HA, Hoeper MM, McLaughlin V V., et al. Initial use of ambrisentan plus tadalafil in pulmonary arterial hypertension. N Engl J Med. 2015; 27;373(9):834-844.

37. Ghofrani HA, Galiè N, Grimminger F, Grünig E, Humbert M, Jing ZC, et al. Riociguat for the treatment of pulmonary arterial hypertension. N Engl J Med. 2013;369(4):330-340.

38. Pauling JD, Hughes M, Pope JE. Raynaud's phenomenon-an update on diagnosis, classification and management. Clin Rheumatol. 2019;38(12):3317-3330.

39. Cappelli L, Wigley FM. Management of Raynaud Phenomenon and Digital Ulcers in Scleroderma. Rheum Dis Clin North Am. 2015;41(3):419-438.

40. Hansi N, Thoua N, Carulli M, Chakravarty K, Lal S, Smyth A et al. Consensus best practice pathway of the UK scleroderma study group: gastrointestinal manifestations of systemic sclerosis. Clin Exp Rheumatol. 2014;32(6):S214-221.

41. Maddali-Bongi S, Del Rosso A. Systemic sclerosis: rehabilitation as a tool to cope with disability. Clin Exp Rheumatol. 2016;34(Suppl 100(5):):162-169.

42. Becetti K, Kwakkenbos L, Carrier M-E, Gordon JK, Nguyen JT, Mancuso CA, et al. Physical or Occupational Therapy Use in Systemic Sclerosis: A Scleroderma Patient-centered Intervention Network Cohort Study. J Rheumatol. 2019;46(12):1605-1613.

43. Malcarne VL, Fox RS, Mills SD, Gholizadeh S. Psychosocial aspects of systemic sclerosis. Curr Opin Rheumatol. 2013;25(6):707-713

44. El-Jawahri AR, Traeger LN, Kuzmuk K, Eusebio JR, Vandusen HB, Shin JA, et al. Quality of life and mood of patients and family caregivers during hospitalization for hematopoietic stem cell transplantation. Cancer. 2015;1;121(6):951-959.

45. Prieto JM, Atala J, Blanch J, Carreras E, Rovira M, Cirera E, et al. Patient-rated emotional and physical functioning among hematologic cancer patients during hospitalization for stem-cell transplatation. Bone Marrow Transplant. 2005;35(3):307-314.

46. McQuellon RP, Russell GB, Rambo TD, Craven BL, Radford J, Perry JJ, et al. Quality of life and psychological distress of bone marrow transplant recipients: The "time trajectory" to recovery over the first year. Bone Marrow Transplant. 1998;1;21(5):477-486.

47. Sandman L, Munthe C. Shared decision-making and patient autonomy. Theor Med Bioeth. 2009;30(4):289-310.

48. Joosten EAG, DeFuentes-Merillas L, De Weert GH, Sensky T, Van Der Staak CPF, De Jong CAJ. Systematic review of the effects of shared decision-making on patient satisfaction, treatment adherence and health status. Psychother Psychosom. 2008;77(4):219-226.

49. Nakayama A, Tunnicliffe DJ, Thakkar V, Singh-Grewal D, O'Neill S, Craig JC, et al. Patients' perspectives and experiences living with systemic sclerosis: A systematic review and thematic synthesis of qualitative studies. J Rheumatol. 2016;1;43(7):1363-1375.

50. Wagner EH, Austin BT, Von Korff M. Organizing care for patients with chronic illness. Milbank Q. 1996;74(4):511-544.

51. Meijs J, Zirkzee EJM, Schouffoer AA, Henquet SM, Caljouw MAA, Stijnen T, et al. Health-care utilization in Dutch systemic sclerosis patients. Clin Rheumatol. 2014;33(6):825-832.

52. Harding S, Khimdas S, Bonner A, Baron M PJ. Best practices in scleroderma: an analysis of practice variability in SSc centres within the Canadian Scleroderma Research Group (CSRG). Clin Exp Rheumatol. 2012;30(2):Suppl 71):S38-43.

53. Johnson SR, Carette S DJ. Scleroderma: health services utilization from patients' perspective.J Rheumatol. 2006;33(6):1123-1127.

54. Khanna D. A standardized core set for systemic sclerosis clinical trials. First step in development of combined response index. Rheumatology. 2008;(47):Suppl 5:v31-32.

55. Khanna D, Kowal-Bielecka O, Khanna PP, Lapinska A, Asch SM, Wenger N, et al. Quality indicator set for systemic sclerosis. Clin Exp Rheumatol. 2011;29(2 Suppl. 65):S33. 
part 1

Health care and

quality of care in

systemic scerosis

in the Netherlands 
part 1 


\section{Abstract}

Objectives. To gain insight in systemic sclerosis (SSc) patients' perspective of quality of care and to survey their preferred quality indicators.

Methods. An online questionnaire about health care setting, perceived quality of care (CQ index) and quality indicators, was sent to 2,093 patients from 13 Dutch hospitals.

Results. 650 patients (mean age 59 years, 75\% women, 32\% limited cutaneous SSc, 20\% diffuse cutaneous SSc) completed the questionnaire. Mean time to diagnosis was 4.3 years (SD 6.9) and was longer in women compared to men (4.8 (SD 7.3) versus 2.5 (SD 5.0) years). Treatment took place in a SSc expert center in 58\%, regional center in $29 \%$ or in both in $39 \%$ of patients. $13 \%$ of patients was not aware if their hospital was specialized in SSc. The perceived quality of care was rated with a mean score of 3.2 (SD 0.5) (range 1.0 - 4.0). There were no relevant differences between expert and regional centers. The three prioritized process indicators were: good patient-physician interaction (80\%), structural multidisciplinary collaboration (46\%) and receiving treatment according to SSc guidelines (44\%). Absence of disease progression (66\%), organ involvement (33\%) and digital ulcers (27\%) were the three highest rated outcome indicators.

Conclusion. The perceived quality of care evaluated in our study was fair to good. No differences between expert and regional centers were observed. Our prioritized process and outcome indicators can be added to indicators suggested by SSc experts in earlier studies and can be used to evaluate the quality of care in SSc.

\section{Key messages}

$\rightarrow$ This study identified the preferred process and outcome indicators to evaluate quality of care in systemic sclerosis from a patient's perspective.

$\rightarrow$ No significant differences in the perceived quality of care between expert centers and regional hospitals in the Netherlands were observed in our study.

$\rightarrow$ Several points for improvement were identified in our study, particularly with regard to patient education, definitions of SSc expert centers and transparency on expertise towards patients. 


\section{chapter 2}

\section{How do patients with systemic sclerosis experience health care and how should we measure its quality?}




\section{Chapter 2}

\section{Introduction}

Providing optimal care for patients with rare, chronic and heterogenous conditions, like systemic sclerosis (SSc), can be challenging. $(2,3)$ Patients may present with different signs and symptoms, and may experience high morbidity as well as increased mortality. Medical treatments are applied with varying results and the patient's journey towards diagnosis and treatment varies greatly among individual patients.

Evaluation of the quality of the currently provided care can help to identify aspects for improvement. Furthermore, it enables comparison of care between centers. In literature, multiple definitions of quality of care exist. In general, it may be defined as the evaluation of values and goals present in the medical care system. $(4,5)$ When quality of care is evaluated, both outcomes of care and the process itself can be assessed. Furthermore, different stakeholders (e.g. patients, physicians, hospital staff and policy makers) can have diverse perspectives on how health care should be evaluated. Ideally, the selection of criteria for good health care should be based on agreement between these groups. So far, no clear consensus has been reached on quality indicators in SSc.(6) Two Delphi exercises with physicians resulted in a list of preferred process indicators. $(7,8)$ This is an important first step in making quality of SSc care tangible. However, criteria for quality of care from the perspective of patients with SSc are still missing and would be of value.

Previous small studies in SSc have identified unmet needs in patient education and organization of hospital visits.(9-13) Patient information, especially about disease progression, and non-pharmacological care was an important unmet need reported by 155 Dutch SSc patients in a previous study.(11) In a qualitative analysis of twenty-five interviews and a cross-sectional study using surveys $(n=77)$, patients reported that they preferred improvement in organization of care with regard to the diagnostic process and follow-up visits. $(9,12)$ Annually, the number of hospital visits is high in SSc patients. (10) This puts a huge strain on patients, especially on those with functional disabilities. Although these studies illustrate patients' experience and preferences on an individual or regional level, none of these studies assessed quality of care nationwide in multiple hospitals or compared quality of care between expert and regional hospitals.

In 2017, as a nationwide effort to improve health care for patients with rare systemic autoimmune diseases, including SSc, the Arthritis Research and Collaboration Hub (ARCH) was initiated in the Netherlands (information about the Dutch health care system in general is provided in Box 1). As a starting point, ARCH evaluated the organization and quality of care in SSc from the perspective of patients and health care professionals. The present study was part of this first ARCH project. The aim of this study was to evaluate the patients' perspective of currently provided health care for patients with SSc and to identify quality indicators from a patients' perspective. 


\section{Box 1. The Dutch National Health System}

The Netherlands is a small but densely populated country. The number of physicians per head is relatively low in comparison to other European countries: 329 per 100000 people. (1) Total expenditure on health as \% of Gross Domestic Product was 10.1\% in 2018 in the Netherlands. The Dutch system is universal. Primary care plays a major role and is characterized by the gatekeeping principle: hospital care requires referral from a general practitioner (GP) (only $7 \%$ of the contacts result in a referral). After receiving a referral, patients can choose in which center they want to be treated. Basic health insurance is mandatory and covers medical care, medicines and hospital stays, including all medical care for SSc. GPs are affiliated with primary health care centers and most medical specialists are working in hospitals. Tertiary hospitals are most often associated with an university. All patients diagnosed with SSc receive medical care in secondary or tertiary centers.

The Dutch National Health System has three managed markets for a universal health insurance package, healthcare purchasing and provision. Health insurers and providers negotiate on price and quality of care. Hospitals are paid through an adapted type of diagnosis-related group system. In most centers, healthcare providers do not financially benefit or loose from an increase in referrals or diagnostic tests.

The government aims to enable patients to make choices between insurers and providers and stresses the importance of transparency with regard to quality of care and the development of reliable quality indicators. Choosing these indicators is also a task of the Dutch scientific organizations.

\section{Patients and Methods}

\section{Study design}

In this cross-sectional study, an online survey was used to gather information from patients with SSc across the Netherlands. Ethical approval was obtained from participating centers and all participants provided written informed consent. The Strengthening the Reporting of Observational Studies in Epidemiology (STROBE) guidelines were followed.(14)

\section{Patients and setting}

Setting and participants

Fifteen physicians in thirteen different hospitals (seven regional hospitals and six expert centers, median number of 150 SSc patients per hospital (range 40-800)) were asked to invite their SSc patients to participate in the study. An information letter about the study was enclosed to the invitation, explaining the aim and methods of the study. By returning a reply card or sending an email, patients received a link to enter the online survey. A total of 2,093 invitations to patients were sent. If patients were treated in two participating hospitals, they could receive this invitation twice. Patients could only take the survey once. The online survey was accessible from 15th of December 2017 till the 21st of February 2018.

Content

The survey was composed by three rheumatologists, one senior researcher and one patient. The questions were discussed in a pilot group, which included three independent researchers, two representatives from the Dutch organization of health professionals 


\section{Chapter 2}

(NHPR), two representatives from the Dutch patient organization for systemic autoimmune diseases (NVLE) and one representative from the Dutch Society of Rheumatology. Next, the survey was tested in five patients with SSc.

\section{Questions per theme:}

Sociodemographic questions included sex, age, status of living (living alone, with partner, with parents, with partner and children, with children, with (a) friend(s)), educational level (primary education and vocational education/university), paid employment (no paid job, less than $12 \mathrm{~h}$ a week, $12 \mathrm{~h}-30 \mathrm{~h}$ a week, more than $30 \mathrm{~h}$ a week).

Disease related questions included the disease subset (limited cutaneous, diffuse cutaneous SSc (lcSSc or dcSSc respectively), other or unknown, disease duration since onset of first symptoms (years) and time since diagnosis (years)).

Multiple-choice questions about health care setting included hospital type (Are you treated in an SSc expert center, regional center? Are you treated in one, two or more than two hospitals for SSc related symptoms?), traveling time to hospital (less than 15 minutes (min), 15-30 min, 30-60 min, longer than $60 \mathrm{~min}$ ), number of hospitals visited for SSc treatment last year (1,2 or more than 2). Expert centers were defined as hospitals were experts in the field of SSc are working, the five expert centers in the Netherlands were mentioned in the survey.

The Consumer Quality Index (CQI) for rheumatoid arthritis was used and adapted to measure the quality of care as perceived by patients. This is an instrument validated in patients with rheumatoid arthritis and has also been used in systemic sclerosis $(15,16)$. Subscales on cooperation, data exchange and interaction with the health care provider are assessed on a five-point Likert scale (never, sometimes, most of the time, always, I don't know), the index has a range from 1.0 to 4.0. Higher CQI scores indicate higher satisfaction with the received health care.

Additional questions were based on the results from three focus group interviews with 23 SSc patients and interviews with twelve rheumatologists and five specialized nurses, that took place in September 2017 (for further details about the methods and results of the focus group interviews see Supplementary 1).

The assessment of unmet needs and preferences included: questions about the burden of disease with regard to traveling time (Do you experience problems with traveling time: yes/ no, if yes because of financial, social, physical or logistical reasons), the choice of location of preferred treatment and out-patient visits. (Do you prefer treatment nearby, in a regional center only, shared care (combined treatment with regional physician and someone from an expert center) or by an expert in an expert center only?).

Questions about patient education and information provision about systemic sclerosis were evaluated by multi-response questions about their main information source and used devices for patient education (leaflet, book, magazine, internet (computer, smartphone, other), internet (website patient organization, website Dutch Arthritis Society, other), physician, specialized nurse, patients with SSc, I never ask/look for information about SSc, 
other). Patients were asked if they received information about

SSc (yes/no), if thisinformation was understandable (yes/no), if there was any information about SSc on the website of the hospital (yes/no) and whether patients were introduced with patient organizations (yes/no).

Process and outcome indicators previously mentioned in the focus groups were prioritized by using multi-response questions, participants could choose a maximum of three options, including an option to add a new item. The choice of process indicators were: good accessibility of health care, satisfaction with interaction between patient and physician, getting the appropriate treatment (defined by receiving treatment according to the Dutch guideline for SSc), number of patients correctly diagnosed, structured multidisciplinary collaboration, collaboration between health care providers, annual evaluation of skin score, annual evaluation of pulmonary function, access to a specialized nurse, percentage of patients informed about non-pharmacological care, or other suggestions (free text option). Listed outcome indicators were: improved quality of life, improved daily functioning, decreased fatigue score, decreased pain, improved hand function, absence of disease progression, absence of organ involvement, absence of digital ulcers, absence of recurrent digital ulcers, or other suggestions (free text option). The option "I do not know" was also available in the multi-response questions about quality indicators.

\section{Data collection and analyses}

Descriptive statistics were used to summarize patient characteristics. Missing data were not imputed. Means and standard deviations were calculated and compared using t-test. Associations between the health care satisfaction (CQI subscales) and treatment in an expert center were investigated. All analyses were performed using Statistical Package for Social Sciences (SPSS) version 25.

\section{Results}

\section{Participants}

650 patients (31\%) (mean age 59 years, 164 (25\%) men and 486 (75\%) women) completed the survey. All characteristics are shown in table 1. LcSSc was reported as disease subset in 207 (32\%) patients and 132 (20\%) had dcSSc. Remarkably, 254 (39\%) patients did not know the subset of their disease. Disease duration was significantly longer in women than in men (mean difference 1.8 years, $\mathrm{p}=0.01$ (95\% Cl 0.4-3.2). The mean time between onset of first symptoms, including Raynaud's phenomenon, and diagnosis was 4.3 years (SD 6.9). Women reported a significantly longer period between onset of symptoms and diagnosis than men ( 4.8 versus 2.5 years respectively, mean difference 2.3 years, $p<0.001$ ( $95 \% \mathrm{Cl} 1.1-3.5$ ). There were no correlations observed between the time to diagnosis and educational level, disease subtype or treatment received in expert centers or regional centers. 
Table 1. Patient characteristics

\begin{tabular}{|c|c|}
\hline & $\mathrm{N}=650$ \\
\hline Age, years; mean (SD) & $59(11)$ \\
\hline Male, $\mathrm{N}(\%)$ & $164(25)$ \\
\hline Living with partner, $\mathrm{N}(\%)$ & $359(55)$ \\
\hline \multicolumn{2}{|l|}{ Educational level, N (\%) } \\
\hline Low & $19(3)$ \\
\hline Medium & $425(65)$ \\
\hline High & $207(32)$ \\
\hline Paid employement $\mathrm{N}(\%)$ & $245(38)$ \\
\hline \multicolumn{2}{|l|}{ SSc subset, N (\%) } \\
\hline LcSSc & $207(32)$ \\
\hline DcSSc & $132(20)$ \\
\hline Other & $65(10)$ \\
\hline Unknown & $250(38)$ \\
\hline Time between onset symptoms and diagnosis, years; mean (SD) & $4.3(7)$ \\
\hline Disease duration after diagnosis, years; SD & $8.0(8)$ \\
\hline \multicolumn{2}{|l|}{ Patients treated in, $N(\%)$} \\
\hline SSc expert centers & $360(58)$ \\
\hline Regional hospitals & $182(29)$ \\
\hline Unknown & $83(13)$ \\
\hline
\end{tabular}

\section{Quality of health care}

\section{Health care setting}

A total of 252 (39\%) patients visited two or more centers for the treatment of SSc. More than half (58\%) of the patients was treated in an expert center. Interestingly, $13 \%$ of patients did not know if treatment took place in an expert center. Traveling time to the hospital was less than 30 minutes in $36 \%$ of the patients and more than one hour in $30 \%$. Traveling time was experienced as a problem by $15 \%$ of the patients, mainly due to physical limitations (64\%). Shared care was the preferred model of care for $49 \%(\mathrm{~N}=159)$ of patients, 332 patients $(51 \%)$ wished to be treated by an SSc expert only.

\section{Patient education}

The main source and provider of information about SSc was the physician in 70\% ( $N=450)$ of patients. Two third of patients $(67 \%, N=427)$ used the internet. The website of the Dutch Arthritis Foundation, the Dutch patient society and other sources were used equally (29\%, $28 \%$ and $27 \%$, respectively). In $48 \%$ of patients, support and education by a specialized nurse was provided. Only $26 \%$ received information from a specialized nurse. There were no significant differences in used information resources and age or level of education. Although a higher percentage of patients with a lower education level used a specialized nurse as main information source compared to high educated patients (42 versus $30 \%$ ). There was no difference between expert centers and regional hospitals with regard to patient education. 


\section{Consumer quality index}

The rating of the perceived quality of care and the differences between patients treated in expert centres and regional hospitals are shown in Table 3. The perceived quality of care provided by the physician was rated with a mean score of 3.2 (S.D. 0.5) (scale 1.0-4.0). The majority of patients thought that their physician took them seriously, listened carefully and provided enough opportunity to ask questions, provided clear explanation and had enough time during hospital visits for them. With regard to follow-up outpatient visits, the quality of care perceived in expert centres was significantly better compared with regional hospitals (mean difference $0.35,95 \% \mathrm{Cl}(-0.49,-0.22), \mathrm{P}<0.01)$. There were no differences between expert and regional centres on the other subscales.

Table 2. Evaluation of quality of health care by patients with SSc

\begin{tabular}{|l|c|c|c|c|c|}
\hline \multicolumn{7}{|c|}{ Mean CQI (SD), range 1.0 - 4.0 } \\
\hline & $\begin{array}{c}\text { Total } \\
\mathrm{N}=640\end{array}$ & $\begin{array}{c}\text { Expert center } \\
\mathrm{N}=357\end{array}$ & $\begin{array}{c}\text { Regional hospital } \\
\mathrm{N}=176\end{array}$ & $\begin{array}{c}\text { Mean difference } \\
\text { (CI) }\end{array}$ & p-value \\
\hline $\begin{array}{l}\text { Care provided by } \\
\text { physician }\end{array}$ & $3.2(0.5)$ & $3.2(0.8)$ & $3.2(0.7)$ & $-0.03(-0.4,0.1)$ & 0.66 \\
\hline & $\mathrm{N}=620$ & $\mathrm{~N}=353$ & $\mathrm{~N}=167$ & & \\
\hline $\begin{array}{l}\text { Outpatients } \\
\text { follow up visits }\end{array}$ & $3.3(0.7)$ & $3.4(0.6)$ & $3.0(0.7)$ & $-0.35(-0.49,-0.22)$ & $<0.01$ \\
\hline & $\mathrm{N}=570$ & $\mathrm{~N}=323$ & $\mathrm{~N}=156$ & & 0.03 \\
\hline Collaboration & $3.0(0.7)$ & $3.0(0.7)$ & $2.9(0.8)$ & $-0.15(-0.29,-0.01)$ & 0.10 \\
\hline $\begin{array}{l}\text { Care provided by } \\
\text { nurse }\end{array}$ & $3.3(0.9)$ & $3.4(0.8)$ & $3.2(1.1)$ & $-0.23(-0.50,0.05)$ & \\
\hline & $\mathrm{N}=323$ & $\mathrm{~N}=193$ & $\mathrm{~N}=76$ & & 0.53 \\
\hline $\begin{array}{l}\text { Care provided } \\
\text { by health } \\
\text { professional }\end{array}$ & $3.3(0.6)$ & $3.2(0.6)$ & $3.1(0.7)$ & $-0.05(-0.22,0.11)$ & \\
\hline
\end{tabular}

Cl, confidence intervals; CQI, Consumer Quality Index; SD, standard deviation, SSc; systemic sclerosis

\section{Quality indicators}

A good patient-physician relationship ( $80 \%, N=513)$, structural multidisciplinary collaboration $(46 \%, \mathrm{~N}=298)$ and receiving adequate treatment $(44 \%, \mathrm{~N}=283)$ were the three highest rated process indicators. No disease progression $(66 \%, \mathrm{~N}=425)$, no organ involvement $(33 \%, N=215)$ and the absence of digital ulcers $(27 \%, N=171)$ were the three highest rated outcome indicators. All results are shown in Figure 1. 


\section{Chapter 2}

\section{Discussion}

This multicenter study evaluated the currently provided health care and quality of care in a large group of SSc patients in the Netherlands and identified quality indicators from a patients' perspective. The overall quality of care evaluated in our study using the CQ index was fair to good. The ratings on care provided by the physician and collaboration were comparable with the rating that was given in a smaller Dutch single center study among 198 SSc patients published five years ago.(15) In our study, aside from a small difference in outpatient follow up visits, the quality of care was not perceived lower in regional hospitals compared to SSc expert centers.

Legend Figure 1. Prioritized quality indicators ( $N=640)$

Results from a multi-response question: Which three outcomes are most appropriate to evaluate the quality of care? $1 \mathrm{~A}$. process indicators, $1 \mathrm{~B}$. outcome indicators

\section{A. Prioritized process indicators}

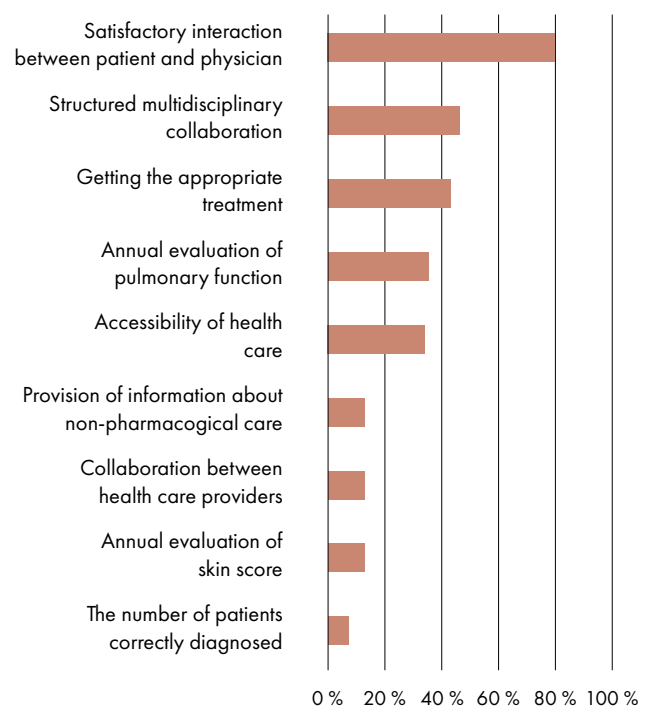

\section{B. Prioritized outcome indicators}

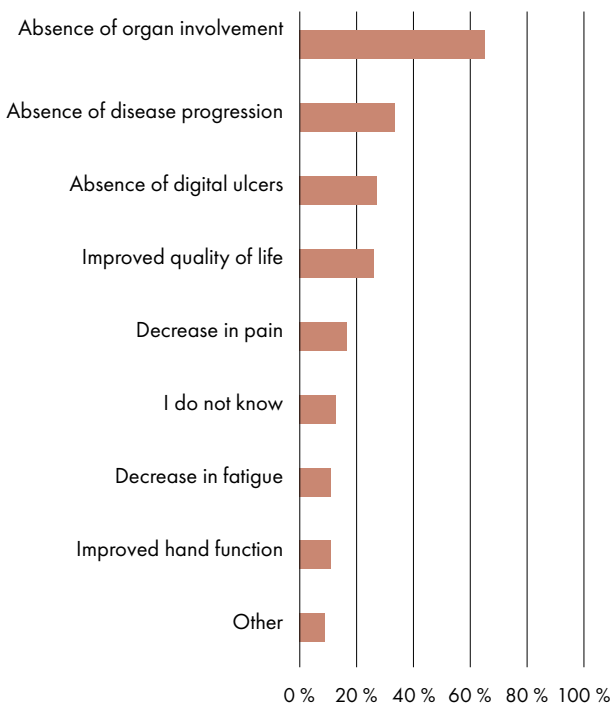

This equality in quality of care of centers could have several reasons. First, the standard of care in general is high in the Netherlands, and all participating centers in our study were large hospitals that offer multidisciplinary care. Patients could therefore experience a similar quality of care, regardless the expert status or performance with regard to SSc care of their hospital. Secondly, $13 \%$ of patients stated that they did not know the expert status of their hospital, despite the definitions provided in our survey. At present, there are several definitions on expert centers in the Netherlands, i.e. the definitions according to university centers, 'top-clinical' hospitals and SSc expert centers defined in the Dutch SSC guideline. This complicates answering this question for patients and limits comparison of results between expert and regional hospitals. The lack of clarity on the definition of expert centers was a point identified in a national and international debate on how to improve care for SSc patients. $(17,18)$ For both patients and physicians it is important that there is one 
single and clear definition on SSc expert centers. Patients prefer to know where expertise is present and are increasingly involved in their own health care nowadays. Moreover, in the Netherlands, patients are able to freely choose in which hospital they want to be treated, so insight in where experts centers for SSc are situated, is important to make that choice. Also, this insight helps physicians finding and consulting expert centers. Future initiatives should therefore focus on reaching agreement on a single definition of SSc expert centers and developing strategies to make the expert status of hospitals across the Netherlands accessible and transparent.

The second objective of our study was to identify indicators relevant from a patient's perspective to evaluate the quality of care in SSc. The three prioritized process indicators were; 1) good patient-physician relationship, 2) structural multidisciplinary collaboration and 3) receiving treatment according to the SSc guidelines. Some of our identified indicators are compatible with the indicators resulted from a Delphi round with SSc experts that took place in 2011.(8) Yearly pulmonary function testing and skin score assessment and adequate treatment were preferred process indicators in both the expert consensusmeeting and the present study.

Additionally, we introduce two new process indicators that meet the values reported in earlier investigations on care from a patient point of view in SSc. Structural multidisciplinary collaboration was reported as important point for improvement by 77 SSc patients.

(12) Secondly, the importance of patient-practitioner relationship was emphasized in a qualitative study in SSc patients.(12) The latter indicator was selected as important process indicator by the vast majority of patients (80\%) in our study. In several studies in primary and secondary care patients, patient-practitioner interaction was also identified as a very relevant dimension of service quality.(19-21)

There are no established disease specific outcome indicators to assess quality of care in SSc. Yet, establishing a few 'hard' SSc specific outcomes could be very useful. In our study, outcome indicators prioritized by patients were: the absence of 1) disease progression, 2) organ involvement and 3) digital ulcers. The results from our study are a valuable addition to the existing list of process indicators selected by physicians and provide suggestions for outcome indicators as well. Furthermore, numerous disease specific PROs are developed for SSc in the last few years, on several domains.(22-24) Our results can help deciding which outcome domains are most relevant for patients in the evaluation of the quality of medical practice. We emphasize the importance of a core set of indicators to evaluate quality of care, which are supported by both patients and physicians.

Several other findings related to quality of care came up in our study. The lack of knowledge among patients about their disease subtype (unknown in respectively $39 \%$ ) was one remarkable observation and could be the result of limited information provision or patient education. Several previous studies have reported on the unmet needs with regard to information in patients with SSc. $(11,18,25)$

Besides general information on the disease, also the need for additional support or counseling on physical and psychological consequences of SSc have been reported.(2, 12 , 26). These unmet needs fall within the scope of health professionals including specialized nurses. In some Dutch centers nurses are already involved in SSc care and satisfaction of this provided care was good in our study. To improve overall care for patients with SSc, access to specialized nurses in all centers seems warranted. 


\section{Chapter 2}

An unexpected finding in our study, was the time to diagnosis, which was found to be longer compared to another large study performed in Canada (mean patient-reported time to diagnosis was 2.4 years, $n=813$ ).(27) Moreover, in our survey the time to establish the diagnosis was twice as long in women compared to men. Further investigation of the diagnostic process in SSc to confirm our findings is needed. In both male and female participants, better recognition of the disease by physicians was indicated as the most important point that should be improved in a cross-sectional survey study we performed in the same group of patients.(18) 'Time to diagnosis' could therefore also be suggested as a relevant process indicator reflecting the quality of care in SSc.

Our study has some limitations. First, there could be selection bias, for both the qualitative part of the study and the survey. Only patients who were willing to discuss their condition with other patients and were able to travel did attend the focus groups. In addition, a relatively large percentage of respondents to the survey received treatment at a specialty center (58\%). It is possible that these patients have different preferences compared to patients in small, local hospitals who did not participate. Secondly, in order to recruit a large group of patients, we could only send patients one invitation without a reminder, which might explain the estimated response rate of 31\%. The response rate will, however be somewhat higher, because patients who are treated in shared care (39\% of patients) could have received the invitation twice if both centers participated in the study. Thirdly, because we could not ask patients in which specific hospital they were treated, due to privacy protection regulations, we do not have data from the non-responders to the invitation, in order to estimate generalizability of our findings. Finally, inherent to a survey study, is that we collected patient reported information. We were not able to check the provided information in medical records, since it was an anonymous questionnaire. Researchers who intend to perform similar studies should consider to offer patients different ways to participate in the study, i.e. online, on paper or at the hospital together with a nurse or patient partner, in order to decrease the risk of selection bias. Also, we suggest include data from medical records on the provided treatment and diagnostic workup. In this way, a broader assessment of quality of care could be accomplished.

\section{Conclusion}

This study provides insight in the currently provided care in SSc patients in the Netherlands and the preferred quality indicators, from a patient point of view. We did not observe relevant differences in the perceived quality of care between patients treated in SSc expert center and regional hospitals. Several points for improvement, particularly with regard to patient education and definition of expertise, were identified. The reported quality indicators added and prioritized by patients to evaluate the quality of health care complement the indicators composed by SSc experts in earlier studies and can be considered in the evaluation of care in SSc.

Funding: This work was supported by the Arthritis Research and Collaboration Hub (ARCH) foundation

Acknowledgements: The authors would like to thank the Dutch Arthritis Foundation (ReumaNederland) for funding the ARCH initiative. 


\section{References}

1. Kroneman M, Boerma W, van den Berg M, Groenewegen P, de Jong J, van Ginneken E. Netherlands: Health System Review. Health Syst Transit. 2016;18(2):1-240.

2. Nakayama A, Tunnicliffe DJ, Thakkar V, Singh-Grewal D, O'Neill S, Craig JC, et al. Patients' Perspectives and Experiences Living with Systemic Sclerosis: A Systematic Review and Thematic Synthesis of Qualitative Studies.J Rheumatol. 2016;43(7):1363-1375.

3. Wagner EH, Austin BT, Von Korff M.Organizing care for patients with chronic illness. Milbank Q. 1996;74(4):511-544.

4. Donabedian A. Evaluating the quality of medical care. 1966. Milbank Q. 2005;83(4):691-729.

5. Donabedian A. The quality of care. How can it be assessed? JAMA. 1988;260(12):1743-1748.

6. Gazi H, Pope JE, Clements P, Medsger TA, Martin RW, Merkel PA, et al. Outcome measurements in scleroderma: results from a delphi exercise. J Rheumatol. 2007;34(3):501-509.

7. Khanna D. A standardized core set for systemic sclerosis clinical trials. First step in development of combined response index. Rheumatology 2008;47 Suppl 5:v31-32.

8. Khanna D, Kowal-Bielecka O, Khanna PP, Lapinska A, Asch SM, Wenger N, et al. Quality indicator set for systemic sclerosis. Clin Exp Rheumatol. 2011;29(2 Suppl 65):S33-39.

9. Schouffoer AA, Zirkzee EJ, Henquet SM, Caljouw MA, Steup-Beekman GM, van Laar JM, et al. Needs and preferences regarding health care delivery as perceived by patients with systemic sclerosis. Clin Rheumatol. 2011;30(6):815-824.

10. Meijs J, Zirkzee EJ, Schouffoer AA, Henquet SM, Caljouw MA, Stijnen T, et al. Health-care utilization in Dutch systemic sclerosis patients. Clin Rheumatol. 2013;33(6):825-832.

11. Schouffoer A, Ndosi ME, Vliet Vlieland TP, Meesters JJ. The educational needs of people with systemic sclerosis: a cross-sectional study using the Dutch version of the Educational Needs Assessment Tool (D-ENAT). Rheumatol Int. 2015;36(2):289-294.

12. Mouthon L, Alami S, Boisard AS, Chaigne B, Hachulla E, Poiraudeau S. Patients' views and needs about systemic sclerosis and its management: a qualitative interview study. BMC Musculoskeletal Disord. 2017;18(1):230.

13. Rubenzik TT, Derk CT. Unmet patient needs in systemic sclerosis. J Clin Rheumatol. 2009;15(3):106-110.

14. von Elm E, Altman DG, Egger M, Pocock SJ, Gotzsche PC, Vandenbroucke JP. The Strengthening the Reporting of Observational Studies in Epidemiology (STROBE) Statement: guidelines for reporting observational studies. Int J Surg. 2014;12(12):1495-149.

15. Willems LM, Kwakkenbos L, Bode C, van den Hoogen FH, van den Ende CH. Health care use and patients perceptions on quality of care in systemic sclerosis. Clin Exp Rheumatol. 2013;31(2 Suppl 76):64-70.

16. Zuidgeest M, Sixma H, Rademakers J. Measuring patients' experiences with rheumatic care: the consumer quality index rheumatoid arthritis. Rheumatol Int. 2009;30(2):159-167.

17. Distler O, Allanore Y, Denton CP, Matucci-Cerinic M, Pope JE, Hinzmann B, et al. Factors influencing early referral, early diagnosis and management in patients with diffuse cutaneous systemic sclerosis. Rheumatology 2018;57(5):813-817.

18. Spierings J, van den Ende C, Schriemer R, de Pundert L, Bernelot Moens HJ, van Laar JM, et al. Optima care for systemic sclerosis patients: recommendations from a patient-centered and multidisciplinary mixed-method study and working conference. Clin Rheumatol. 2019;38(4):1007-1015

19. Hudson Smith M, Smith D. Directing Improvements in Primary Care Patient Experience through Analysis of Service Quality. Health Serv Res. 2018;53(6):4647-4666.

20. Papp R, Borbas I, Dobos E, Bredehorst M, Jaruseviciene L, Vehko T, et al. Perceptions of quality in primary health care: perspectives of patients and professionals based on focus group discussions. BMC Fam Pract. 2014;28;15:128.

21. Schulz LN, Zlatina K, Kent N, Peter J. The doctor-patient relationship and patient resilience in chronic pain: A qualitative approach to patients' perspectives. Chronic Illn. 2018;14(4):256-270.

22. Almeida C, Almeida I, Vasconcelos C. Quality of life in systemic sclerosis. Autoimmun Rev. 2015;14(12):1087-1096.

23. Ingegnoli F, Carmona L, Castrejon I. Systematic review of systemic sclerosis-specific instruments for the EULAR Outcome Measures Library: An evolutional database model of validated patient-reported outcomes. Semin Arthritis Rheum 2017;46(5):609-614.

24. Valentini G, Matucci Cerinic M. Disease-specific quality indicators, guidelines and outcome measures in scleroderma. Clin Exp Rheumatol. 2007;25(6 Suppl 47):159-162.

25. van der Vaart R, Repping-Wuts H, Drossaert CH, Taal E, Knaapen-Hans HK, van de Laar MA et al. 


\section{Chapter 2}

Need for Online Information and Support of Patients With Systemic Sclerosis. Arthritis Care Res. 2017;65(4):594-600.

26. Bassel M, Hudson M, Taillefer SS, Schieir O, Baron M, Thombs BD. Frequency and impact of symptoms experienced by patients with systemic sclerosis: results from a Canadian National Survey. Rheumatology 2010;50(4):762-767.

27. Johnson SR, Carette S, Dunne JV. Scleroderma: health services utilization from patients' perspective.J Rheumatol. 2006;33(6):1123-1127.

\section{Supplementary File}

\section{S1. Survey preparation: A qualitative study}

\section{S1.1 Participants and methods}

To collect information about experiences about health care and to identify treatment goals and indicators, focus group interviews with patients were conducted.

\section{Participants}

Patients fulfilling the diagnostic criteria of SSc were eligible for participation. In order to include patients from different centers distributed nationwide, three rheumatologists from two university hospitals and one from a regional center invited, based on professional judgment, patients who were capable to travel and willing to participate in focus group. Invitations were sent by mail. Health care professionals were selected by the members of the working group, selection was based on a similar number of participants working in regional and university centers. They were invited by e-mail.

\section{Setting}

Between June and September 2017, three focus group interviews were conducted in three different hospitals in the Netherlands (Leiden University Medical Center, Isala Zwolle and Radboudumc Nijmegen). The interviews were led by an independent researcher, female, with a wide experience in focus group interviews (C.H.E). This researcher did not know the participants. The duration of the interviews was 1.5-2 hours. During all interviews, one representative of the Dutch patients' SSc organization (NVLE) was present. All three sessions were recorded

\section{Data collection}

One researcher, one patient and three rheumatologists developed an interview guide. Themes were based on literature findings. The interview comprised open questions and were tested in a pilot group. For details about the interview guide see Supplementary 1.2. The interviews were recorded, transcribed verbatim and coded. The transcriptions were sent to all participants for verification.

\section{Data analysis}

Thematic analysis was performed by two independent investigators. Data saturation was discussed by the researchers. The themes were discussed by two independent investigators. 


\section{S1.2. Interview guide}

\section{Focus group interviews with patients}

Instructions for the interviewer: introduction

1. How did you experience:

a. the diagnostic process?

b. the period after the diagnosis?

2. Experiences during hospital visits:

a. How was the support during routine hospital visits?

b. How did such a visit look like?

c. Was there attention for psychosocial aspects of the disease?

d. Was there any attention on societal, occupational, daily functioning and family?

e. Did you know where to go or whom to contact in case of questions or worsening of symptoms?

3. Did you receive information about the disease, did this meet your expectations?

a. Right after the diagnosis was made

b. Later on in the disease

c. What did you miss?

4. In which way would you prefer to receive education and information?

Instructions for the interviewer: give suggestions / examples: a website with information, animations, meetings, flyers, apps etcetera

5. On which subjects should be paid more attention?

6. Do you have access to your own medical records? How did the collaboration between involved health care professionals go? With;

a. General practitioner

b. Other disciplines

c. Occupational health specialist

d. Nurse

e. Health professional

f. Exchange of medical information between involved health care professionals

7. Which outcome measure do you think is important? What is the most relevant target in treatment?

8. Did you know the patient organization? Are you a member?

9. Is there in your hospital a standardized multidisciplinary assessment program? What are your experiences with this program?

Closing

10. Do you have anything additional to tell us that was not mentioned in the interview? 


\section{Chapter 2}

\section{Rheumatologists and nurses}

Instructions for the interviewer: introduction

\section{Organization}

1. How is SSc care organized in your hospital?
a. Who refers patients?
b. Care after diagnosis? Referral or treatment in your hospital?
c. Division of tasks with other disciplines in your hospital?
d. How often are patients visiting the outpatient clinic?
e. How is the patient education organized?
f. What is your vision about the role of the patient in his/her treatment?
g. Do you have an arrangement with your patients in case of emergencies?

2. Do you collaborate with other health care professionals? Do you know if there are other health care professionals involved in the treatment of your SSc patients? (i.e. general practitioner, occupational health specialist, rheumatologists working in other hospitals, health professionals, nurses

\section{$\underline{\text { Care }}$}

3. Are you aware of the national guideline on SSc care?
a. Do you use the guideline? How do you use it?
b. Do you have a standardized multidisciplinary assessment program?
c. What is the treatment target in SSc? When do you think the treatment is successful?

\section{Patient-centered care}

4. What do you think is most important with regard to health care from a patients' perspective?
a. Why?
b. Do you implement this during your clinical practice?

\section{Quality of care}

5. What are you doing to optimize health care for patients with SSc?
a. Knowledge and education
b. Patient education and facilities for diagnostics and therapy.
c. Multidisciplinary collaboration
d. Do you evaluate the quality of care in your hospital?

\section{Communication}

6. Do your patients have access to their medical records?

7. How do you communicate and exchange information in case of shared care?

8. How do you communicate with other disciplines?

Ideal health care

9. What do you think optimal organization of care for SSc patients will look like? 
a. Which hurdles are there at the moment preventing optimal care?

b. Which changes are needed to improve health care?

$\underline{\text { Indicators }}$

10. Which indicators should be used to evaluate quality of SSc care?

a. Diagnostics and treatment

b. Organization of care

$\underline{\text { Closing }}$

11. Do you have anything additional to tell us that was not mentioned in the interview?

12. Would you like to invite the SSc patients in your hospital for the patient survey?

\section{S1.3. Results}

\section{Participants}

For the focus group interviews, 23 patients were included. There was one group of seven patients and two with eight patients. Twelve rheumatologists and five specialized nurses working in different medical centers in the Netherlands, were interviewed. Characteristics of the participants are shown in tables S1.

\section{Identified themes}

Themes identified from the focus groups were; collaboration; diagnostic process and education of caregivers; patient education; patient empowerment; and nonpharmacological care.

Quality indicators

In the interviews and focus groups several different process and outcome indicators were mentioned to use as quality outcomes in SSc. A list of quality indicators mentioned in the interviews and focus groups is shown in supplementary table $\mathbf{S 2}$. 
Supplementary Table S1.

Table S1.1. Patient characteristics focus group interviews

\begin{tabular}{|l|l|}
\hline & Patients (N=23) \\
\hline Age, years; mean (range) & $49(27-68)$ \\
\hline Male, \% (N) & $30(7)$ \\
\hline $\begin{array}{l}\text { Treated in, \% (N) } \\
\text { Regional hospital } \\
\text { Expert center }\end{array}$ & $35(8)$ \\
\cline { 2 - 2 } & $65(15)$ \\
\hline
\end{tabular}

Table S1.2. Health care professionals' characteristics interviews

\begin{tabular}{|c|c|c|c|}
\hline & $\begin{array}{l}\text { Rheumatologists } \\
(\mathrm{N}=12)\end{array}$ & $\begin{array}{l}\text { Nurses } \\
(\mathrm{N}=5)\end{array}$ & $\begin{array}{l}\text { Total } \\
(N=17)\end{array}$ \\
\hline Age, years; mean (range) & $48(38-58)$ & $43(31-58)$ & $47(31-58)$ \\
\hline Male, \% (N) & $17(2)$ & 0 & (13) 2 \\
\hline \multicolumn{4}{|l|}{ Worksetting, \% (N) } \\
\hline Regional center & $67(8)$ & $80(4)$ & (71) 12 \\
\hline University hospital & $33(4)$ & $20(1)$ & (29) 5 \\
\hline \multicolumn{4}{|l|}{ No hospital } \\
\hline Working in center of expertise, $\%(N)$ & $42(5)$ & $40(2)$ & $(41) 7$ \\
\hline SSc expert, \% (N) & $58(7)$ & $20(1)$ & (53) 8 \\
\hline \multicolumn{4}{|l|}{ SSc patiënts in care $\%(N)$} \\
\hline none & 0 & 0 & 0 \\
\hline$<5$ & 0 & 0 & 0 \\
\hline $5-10$ & $8(1)$ & $20(1)$ & (13) 2 \\
\hline $10-30$ & $16(2)$ & $20(1)$ & (18) 3 \\
\hline $30-50$ & $8(1)$ & & (6) 1 \\
\hline $50-100$ & $22(3)$ & & (18) 3 \\
\hline$>100$ & $38(5)$ & $60(3)$ & (53) 8 \\
\hline
\end{tabular}




\section{Supplementary Table S2. Quality indicators mentioned in the interviews and focus groups}

\section{Table S2.1. Indicators mentioned by patients}

\begin{tabular}{|l|l|}
\hline Process indicators & Outcome indicators \\
\hline Satisfaction about physician-patient interaction & $\begin{array}{l}\text { Shorter time from first symptoms to diagnosis: faster } \\
\text { recognition of SSc }\end{array}$ \\
\hline Access to SSc expertise & Quality of life \\
\hline Access to a specialized nurse for support & No disease progression \\
\hline $\begin{array}{l}\text { Provision of supportive care with regard to } \\
\text { psychological and social consequences of SSc }\end{array}$ & Skin score \\
\hline Annual screening of skin score & Daily functioning \\
\hline Annual screening of pulmonary function & Improvement of fatigue \\
\hline $\begin{array}{l}\text { Provision of supportive care with regard to physical } \\
\text { limitations }\end{array}$ & Decrease in pain \\
\hline Shared decision making & \\
\hline $\begin{array}{l}\text { Provision of health care closer to home, accessibility } \\
\text { of health care in general }\end{array}$ & \\
\hline $\begin{array}{l}\text { Clear information and education about treatment } \\
\text { options, side effects of therapies }\end{array}$ & \\
\hline $\begin{array}{l}\text { Clear and accessible patient information } \\
\text { hospitals and safe exchange of medical data between }\end{array}$ & \\
\hline
\end{tabular}

Table S2.2. Indicators mentioned by health care professionals

\begin{tabular}{|l|l|}
\hline Process indicators & Outcome indicators \\
\hline Patient satisfaction with quality of care & Disease related mortality \\
\hline $\begin{array}{l}\text { Number of hospitals that implemented the Dutch } \\
\text { treatment guidelines of SSc }\end{array}$ & Quality of life \\
\hline Accessibility of health care & No disease progression \\
\hline $\begin{array}{l}\text { Efficient and safe exchange of medical data between } \\
\text { hospitals }\end{array}$ & Skin score \\
\hline Provision of health care closer to home & Mobility \\
\hline Annual screening organ complications & Daily functioning \\
\hline & Number of patients with active digital ulcers \\
\hline & Complication due to treatment of SSc \\
\hline & Improvement of fatigue \\
\hline & Decrease in pain \\
\hline & Compliance \\
\hline
\end{tabular}




\section{Abstract}

Introduction. Systemic sclerosis (SSc) is a chronic autoimmune disease with multi-organ involvement.

Objective. Identify preferences and priorities among patients and health care professionals regarding care for SSc patients in the Netherlands. Develop ideas to improve quality of care.

Methods. A structured approach was followed to collect information from different perspectives to prepare a working conference. Qualitative and quantitative data from patients ( $n=650)$, rheumatologists $(n=167)$, nurses $(n=51)$ and health professionals ( $n=85)$ from regional centers and university hospitals were collected. In February 2018, a working conference was organized. 77 persons (including 10 SSc patients), from different backgrounds discussed the identified themes and survey results. Ideas to improve health care were formulated and prioritised using nominal group technique.

Results. Five key themes were identified: 1 .shared care and multidisciplinary collaboration, 2. medical data exchange, 3. information for all stakeholders, 4. patient empowerment and 5. non-pharmacological care. Shared care was the preferred model of care in $49 \%$ of patients and $82 \%$ of physicians. However, current collaboration structures, especially between hospitals should be improved. Suggestions for improvements were explicitly formulated agreements about referral, clear task division, treatment coordination, and exploration of novel ways to exchange medical records. The creation of a national web-based information hub was highly prioritised.

Conclusion. In this mixed-method study broad-based consensus was achieved and recommendations were developed to improve health care for SSc patients. The approach, recommendations and challenges summarized in this paper can be of use for health care professionals and other actors involved in patients with rare, chronic and multisystem conditions. 
chapter 3

Optimal care for patients with systemic sclerosis: recommendations from a patient-centered and multidisciplinary mixed-method study and working conference 


\section{Introduction}

Systemic sclerosis (SSc) is a complex disease with multi-organ involvement which can have severe physical and psychosocial impact on daily life. (1, 2) Providing optimal care for these patients is challenging, as it requires experienced health care professionals, multicenter collaboration, a multidisciplinary approach and tailored patient education.(3) Although the importance of optimal care, collaboration and education is broadly recognized, not all patients receive the same high standard of care. (4) A Canadian study showed that only a low percentage of SSc patients received adequate multidisciplinary specialist care. (5) Qualitative studies performed in France and Canada showed the need for improvement of diagnostic process and follow-up organization. Furthermore, there were difficulties in accessing information about SSc and finding experts. $(6,7)$

In the Netherlands, the Arthritis Research and Collaboration Hub (ARCH) foundation was started as a nationwide effort to improve health care for patients with rare systemic autoimmune diseases, including systemic sclerosis (SSC). In February 2018, ARCH organized a working conference about the organization of care in SSc. This paper presents the results

Figure 1. Diagram: work streams that led to the recommendations

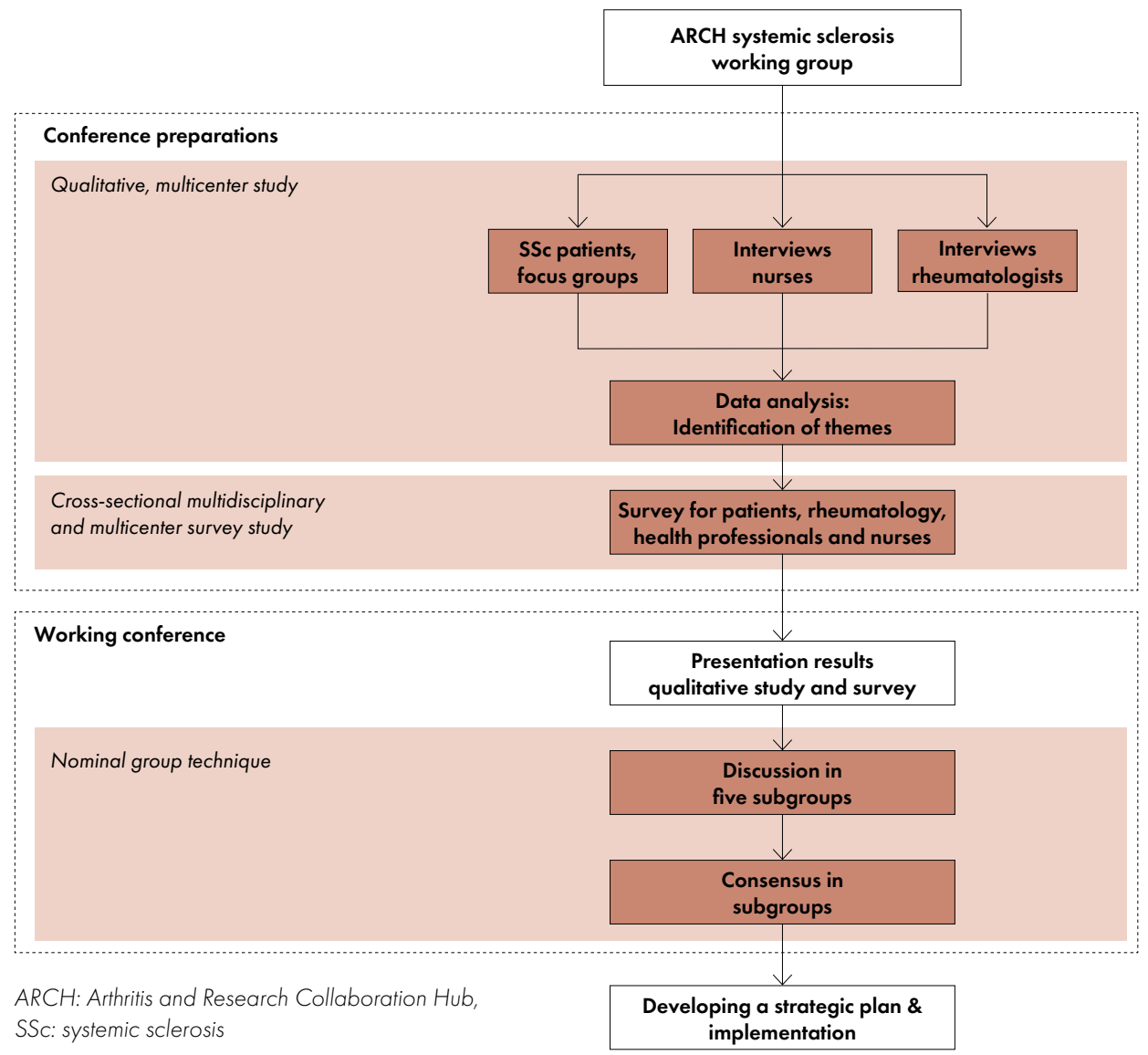


of the interviews and surveys with patients and health care providers performed as a preparation for the working conference, summarizes the results of the meeting and reflects on preferred actions in order to improve the quality of care for patients with SSc.

\section{Methods}

A working group was installed to prepare the working conference. The group was composed of one SSc patient, two health professionals (HPs) and three rheumatologists.

\section{Preparation of the conference: a mixed-method study}

Data collection prior to the working conference comprised interviews and surveys. A structured approach was followed to collect experiences in daily practice, hurdles and unmet needs from the perspective of patients, rheumatologists and HPs in the Netherlands. An overview of the process that led to the recommendations is provided in Figure 1.

Qualitative data were collected in three multicenter focus group interviews. Second, surveys for patients, rheumatologists, nurses and health professionals were developed to evaluate the identified themes from the interviews in a larger group. The survey included open, multiple choice and multi-response questions about current delivery of care, unmet needs and preferences regarding care, rating of collaboration, multidisciplinary care, medical data exchange, patient empowerment, information supply for patients and health care professionals and non-pharmacological care. Theses were assessed on a five-point Likert scale (1: strongly agree, 2: agree, 3: neither agree nor disagree, 4: disagree, 5: strongly disagree), scoring quality of collaboration and medical data exchange was done with a Likert scale (a slider from 0-100). In the multi-response questions used to prioritize items, participants could choose a maximum of three options, including an option to add a new item.

From the $15^{\text {th }}$ of December 2017 till the $21^{\text {st }}$ of January 2018, 2093 patients treated in 13 different hospitals were invited for the online questionnaire whereas HPs were invited through the participating patients. A total of 350 rheumatologists and 264 nurses from regional and university hospitals were invited by e-mail or approached during the annual meeting of the Dutch society of rheumatology at the $28^{\text {th }}$ and $29^{\text {th }}$ of September 2017. For a detailed description of the study methods, see supplementary appendix 1 and 2 , characteristics of the study populations are shown in table S1 and S2. The consolidated criteria for reporting qualitative research (COREQ) were followed and reported in table S4.(8) The Strengthening the Reporting of Observational Studies in Epidemiology (STROBE) guidelines were followed.(9)

\section{Working conference}

Design

An outline of the results of the interviews, focus groups and surveys was presented as a starting point in a plenary session. Then, discussions on different themes were held in five small groups (patient education, patient empowerment, non-pharmacological care and two groups on shared care, multidisciplinary collaboration and medical data exchange), in order to create a constructive action plan that could be used in the $\mathrm{ARCH}$ project the upcoming years. Participants were divided in groups by the working group to ensure a 
diverse composition facilitating a balanced discussion. Nominal group technique (NGT) was used to give every participant the opportunity to share ideas and to reach consensus. $(10,11)$ The NGT process was started with an introduction and explanation about the NGT process. Next, participants were asked to individually and silently generate items and to write these items down on post-its. This was followed by a round-robin collection of all ideas and recording on a flipchart. Ideas were shortly clarified, discussed and either categorized, merged or discarded, if necessary this was done by voting. In each discussion group the remaining ideas were discussed in more detail and prioritised by rating. Discussions were led by a member of the ARCH systemic sclerosis working group and minutes were taken by other $\mathrm{ARCH}$ members. At the end of the meeting, the ideas were presented in a plenary session. The day was led by an independent chair and working group sessions were chaired and recorded by the working group. Ideas with consensus and expected challenges were recorded. A summary of the working conference was verified by the participants afterwards.

\section{Setting and participants}

The meeting took place on the $9^{\text {th }}$ of February 2018 in Utrecht, the Netherlands. Patients and health care professionals who participated in the interviews and focus groups were invited to join the conference. Also, invitations were sent to organizations of health care professionals relevant in SSc (cardiology, pulmonology, dermatology, internal medicine, gastroenterology, physical therapy, occupational therapy and nurses, skin therapy, psychology), patient organizations, insurance companies, governmental institutions, funders of scientific research and other participants in $\mathrm{ARCH}$.

\section{Analysis}

The interviews were analyzed by two independent investigators. Transcripts were read and re-read, using the constant comparative technique. Themes and subthemes were derived from the data by the researchers separately and were discussed until consensus was reached. Descriptive statistics were used to describe characteristics and answering options of respondents from the survey. Means and standard deviations were presented where appropriate. All analyses were performed using SPSS 22.

Results from the group discussions at the conference, which included ideas with consensus and expected challenges, were recorded. A summary of the results from the working conference was made by two independent researchers and was verified by the participants afterwards.

\section{Results}

\section{Participants}

Twenty-three patients participated in the focus group interviews, and 12 rheumatologists and 5 specialized nurses were interviewed individually. 650 patients (estimated $31 \%$ of all Dutch SSc patients), 167 rheumatologists (48\% of all Dutch rheumatologists), 51 specialized nurses (21\% of all Dutch specialized nurses) and 85 health professionals completed the survey on the $21^{\text {st }}$ of January 2018 . The meeting was attended by 77 persons (see Table 1 for details about participants). In Figure 2 one the number of participants is shown at each stage of the study. 
Table 1. Participants working conference

\begin{tabular}{|c|c|}
\hline Participants & Number (overlap)* \\
\hline SSc patients & $10(6)$ \\
\hline $\begin{array}{l}\text { Health care professionals } \\
\text { - Clinical immunologists } \\
\text { - Consultant internal medicine } \\
\text { - Dietitian } \\
\text { - Occupational therapist } \\
\text { - Nephrologists } \\
\text { - Nurses } \\
\text { - Physical therapist } \\
\text { - Pulmonologists } \\
\text { - Rheumatologists } \\
\text { - Skin therapist } \\
\text { - Vascular consultants }\end{array}$ & $\begin{array}{l}2 \\
1 \\
3 \\
1 \\
1 \\
9 \\
6(1) \\
2 \\
12(5) \\
1 \\
1\end{array}$ \\
\hline $\begin{array}{l}\text { Organization representatives } \\
\text { - Dutch Society of Rheumatology } \\
\text { - Dutch Society of Health Professionals } \\
\text { - ParkinsonNet } \\
\text { - Scleroderma Patient-centered Intervention Network }\end{array}$ & $\begin{array}{l}1 \\
1 \\
1 \\
1\end{array}$ \\
\hline $\begin{array}{l}\text { Patient organizations } \\
\text { - Dutch Scleroderma Foundation } \\
\text { - Dutch Siögren's Syndrome Foundation } \\
\text { - Dutch Society for Lupus, APS, Scleroderma and MCTD } \\
\text { - Dutch Vasculitis Foundation }\end{array}$ & $\begin{array}{l}1 \\
1 \\
6(6)\end{array}$ \\
\hline $\begin{array}{l}\text { Providers of health care expertise } \\
\text { - IT companies }\end{array}$ & 2 \\
\hline $\begin{array}{l}\text { Funders of scientific research } \\
\text { - Dutch Arthritis Foundation } \\
\text { - Dutch Organization for Health Research and Development (ZonMW)) }\end{array}$ & $\begin{array}{l}4 \\
1\end{array}$ \\
\hline ARCH members & $15(10)$ \\
\hline
\end{tabular}

ARCH: Arthritis Research and Collaboration Hub, APS: Antiphospholipid Syndrome, IT: Information Technology, MCTD: Mixed Connective Tissue Disease, SSc: systemic sclerosis

*The number of participants that could be categorized in more than one category are reported as "overlap". 
Figure 2. Number of participants at each stage of the study

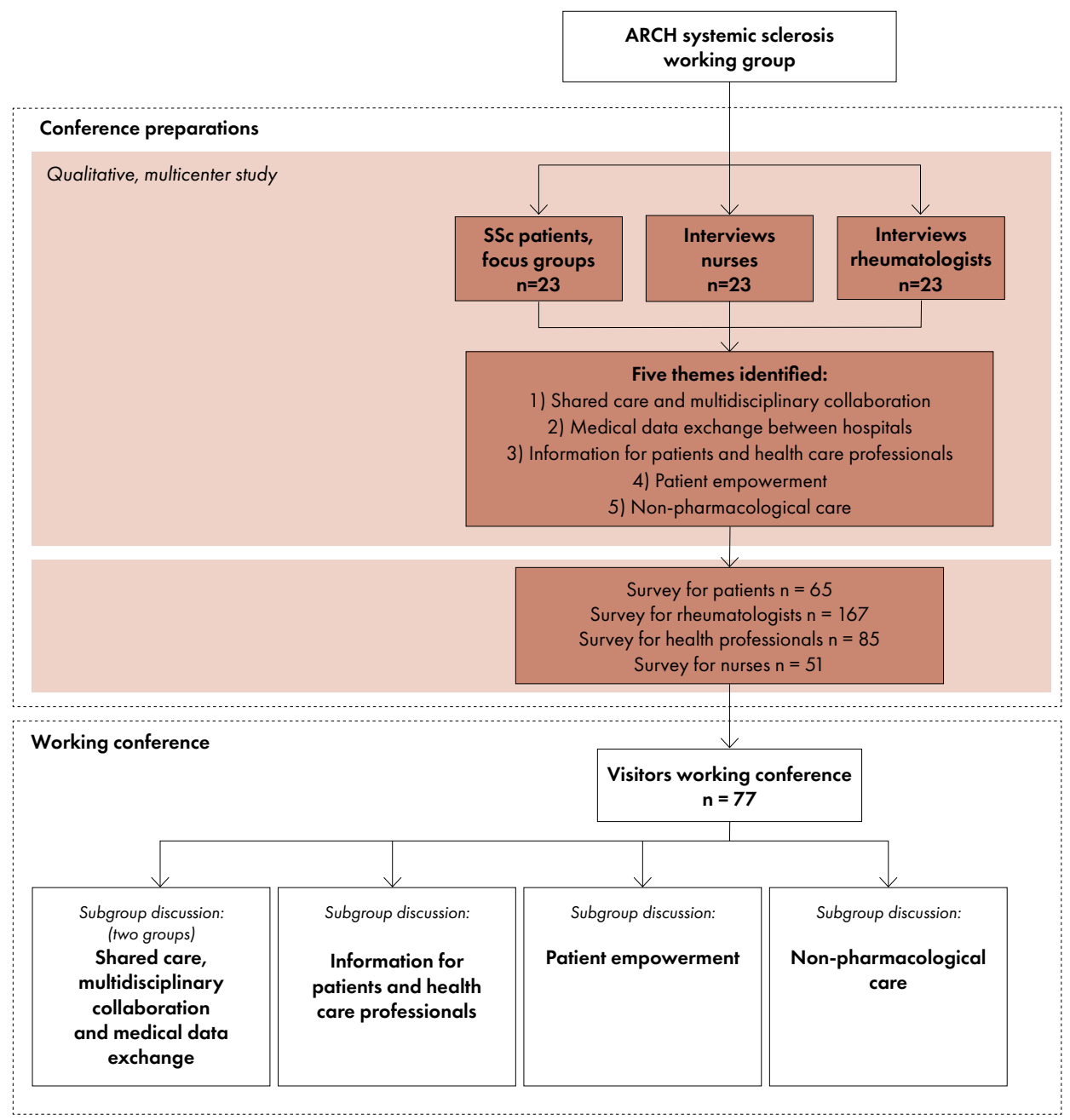

ARCH: Arthritis and Research Collaboration Hub, SSc: systemic sclerosis

\section{Results of the thematic analysis interviews}

Five themes were identified as most important for the quality of care requiring improvement: Shared care and multidisciplinary collaboration, medical data exchange between hospitals and health care professionals, patient education, patient empowerment and nonpharmacological care.

\section{Shared care and multidisciplinary collaboration}

In the interviews, patients preferred to be referred to tertiary expert centers earlier in the disease course, but that treatment closer to home should be made possible too. The lack of widely accepted definitions about SSc expertise and centers of expertise came to light. Furthermore, some interviewed rheumatologists working in regional hospitals, did not know where to find SSc experienced colleagues. The survey results showed that $49 \%$ of 
patients ( $n=314)$ and $82 \%$ rheumatologists $(n=133)$ agreed that shared care between highly specialized (tertiary) centers and regional hospitals, is the preferred model of care. Current quality of collaboration in shared care was rated by the rheumatologists as just sufficient (score of 65 out of 100 (SD 17)). 15\% ( $n=23$ ) of rheumatologists and $27 \%(n=171)$ of patients prioritised this as most important hurdle for optimal care (Table 2 shows the top 3 hurdles that hinder optimal care). Unclear division of responsibilities was addressed an important issue impeding effective collaboration. $44 \%$ of all health care professionals regarded this as the most important obstacle for good quality of care. $76 \%(n=121)$ of rheumatologists agreed with the statement in the survey that treatment goals of all patients should be discussed and agreed upon in multidisciplinary meeting. However, only $48 \%(n=76)$ of rheumatologists currently participates in such meetings. Multidisciplinary teamwork was mentioned as an important challenge in $37 \%(n=59)$ of rheumatologists and $11 \%(n=68)$ of patients. Clear agreements on responsibilities, alignment of treatment-strategies and communication with patients in multidisciplinary collaboration received the highest priority point for improvement among rheumatologists $(45 \%, n=71)$ and patients $(45 \%, n=288)$.

Table 2. Priorities in hurdles that hinder optimal care. Comparison of survey results between patients and health care professionals (multi-response question).

\begin{tabular}{|l|l|l|l|}
\hline & $\mathbf{1}$ & $\mathbf{2}$ & $\mathbf{3}$ \\
\hline $\begin{array}{l}\text { Rheumatologists } \\
\mathbf{( n = 1 5 8 )}\end{array}$ & $\begin{array}{l}\text { No clear division of } \\
\text { tasks between hospitals } \\
\text { (shared care) }(42 \%)\end{array}$ & $\begin{array}{l}\text { Insufficient collaboration } \\
\text { between different } \\
\text { disciplines in one center } \\
(37 \%)\end{array}$ & $\begin{array}{l}\text { Insufficient medical data } \\
\text { exchange between } \\
\text { hospitals in shared care } \\
(27 \%)\end{array}$ \\
\hline $\begin{array}{l}\text { Nurses } \\
(\mathbf{n}=\mathbf{4 9 )}\end{array}$ & $\begin{array}{l}\text { Insufficient number of HPs } \\
\text { with knowledge about } \\
\text { SSc }(45 \%)\end{array}$ & $\begin{array}{l}\text { No clear division of } \\
\text { tasks between hospitals } \\
\text { (shared care) }(29 \%)\end{array}$ & $\begin{array}{l}\text { Patient information does } \\
\text { not fit the needs (27\%) }\end{array}$ \\
\hline $\begin{array}{l}\text { Health professionals } \\
(\mathbf{n}=\mathbf{8 5})\end{array}$ & $\begin{array}{l}\text { Insufficient number of HPs } \\
\text { with knowledge about } \\
\text { SSc (44\%) }\end{array}$ & $\begin{array}{l}\text { No clear division of } \\
\text { tasks between hospitals } \\
\text { (shared care) }(28 \%)\end{array}$ & $\begin{array}{l}\text { Insufficient collaboration } \\
\text { between different } \\
\text { disciplines in one center } \\
(18 \%)\end{array}$ \\
\hline $\begin{array}{l}\text { Patients } \\
(\mathbf{n = 5 3 3 )}\end{array}$ & $\begin{array}{l}\text { Insufficient number of HPs } \\
\text { with knowledge about } \\
\text { SSc (40\%) }\end{array}$ & $\begin{array}{l}\text { Difficulty to find expert } \\
\text { physicians (27\%) }\end{array}$ & $\begin{array}{l}\text { Insufficient medical data } \\
\text { exchange between } \\
\text { hospitals in shared care } \\
(11 \%)\end{array}$ \\
\hline
\end{tabular}

HPs: Health Professionals, SSc: systemic sclerosis

Considerations resulting from the working conference:

In the Netherlands, management of SSc patients is not centralized; patients are treated in regional hospitals or centers of expertise and a relatively small number of patients in both, in the setting of shared care. Participants at the conference stated that shared care enables more patients to receive treatment from experts and shortens overall travel time. Furthermore, this model of care encourages collaboration between centers and increases knowledge sharing. They agreed that shared care should be practiced more in the Netherlands in SSc patients. Networks of hospitals would support shared care and optimal use of experts from several disciplines.

The participants of the conference thought that the initial step should be a consensus on a national level about the minimal requirements of SSc expertise. Next, regional networks need to be formed around these expert centers. The lack of financial incentives could 


\section{Chapter 3}

challenge implementing this model of care. Discussions with insurance companies and governmental organizations are therefore of key importance.

\section{Recommendations:}

$\rightarrow$ Clear criteria for expertise of physicians and health care professionals should be made, including minimal caseloads, required education and composition of multidisciplinary team $\rightarrow$ Regional networks should be formed in order to provide high quality of multidisciplinary (shared) care at reasonable travel distance for the patient.

\section{Exchange of medical data between hospitals}

Patients treated in shared care, reported that they often had to undergo the same diagnostic tests in both centers or had to provide medical data themselves e.g. blood results. By rheumatologists, exchange of medical data between hospitals was reported as a huge hurdle as well. In the survey, current quality of information exchange was rated as just sufficient by both patients (66 out of 100, SD 24) and health care professionals (57 out of 100, SD 19). 84\% $(n=132)$ of rheumatologists agreed that support to improve this is needed. An accessible Electronic Patient Record Systems (EPRS) for all involved physicians was prioritised by $29 \%$ $(n=46)$ of rheumatologists and $23 \%(n=147)$ of patients.

Considerations resulting from the working conference:

In 2011, a national initiative to create an uniform medical record failed because of security and privacy-concerns. Therefore, data exchange is still carried out by fax, mail or phone, which is neither efficient nor secure. Furthermore, when information is missing patient safety is compromised. At the conference, a personal health record managed and shared by patients, accessible EPRS for physicians in expert centers involved in the treatment of individual patients and digital data exchange, were suggested solutions. A personal health record could be efficient since each patient holds their own medical data. It may even increase patient empowerment. However, the management of personal and often complex information is accompanied with a responsibility that probably only can be handled by a select group of patients. The second idea, enabling full access to the EPRS, is a relatively simple intervention and mostly requires agreements between hospitals and patient consent. During further group discussion, this suggestion was nevertheless rejected, because a completely shared EPRS would probably lead to information overload. A shared care medical record would be most efficient but requires new electronic techniques. These techniques should be integrated in existing EPRSs to prevent additional administrative procedures and medical data on several sites. In order to enable uniform data exchange and facilitate connection between different EPRSs, standard forms should be created.

\section{Recommendations:}

$\rightarrow$ A shared care medical record, accessible for the patient and multidisciplinary team involved should be developed, containing medical history, treatment goals, disciplines involved and checklists.

$\rightarrow$ Standardized forms should be agreed upon and developed for data exchange between health care professionals in shared care.

$\rightarrow$ Automatic synchronization of treatment goals and changes in treatment between EPRSs of all physicians involved should be made possible. 


\section{Information for both patients and health care professionals}

The survey showed that over two thirds of patients and health care professionals (70 and $66 \%$ respectively) prioritised a central information hub as their main requirement. More than half of health care professionals and one third of patients desired an online available overview of SSc experts in the Netherlands. An online self-management program was desired by $29 \%$ of patients $(n=184)$ and $36 \%(n=229)$ thought a web-based user-interactive question-answering platform would be an important addition to the current educational propositions. $68 \%$ of nurses and $30 \%$ of all HPs preferred an e-learning about SSc.

Considerations resulting from the working conference:

An overarching idea to improve quality on several themes was the creation of a national information platform for all parties. A list of elements for this platform was established. With regard to patient education, differences in individual needs and level of education should be taken into account. Importantly, consensus should be reached on which organization will be responsible for its development and sustainability.

\section{Recommendations:}

Creation of one website with information for both patients and health care professionals.

This website should offer:

$\rightarrow$ Information about experts and clarification of the organization of care in networks of shared care.

$\rightarrow$ Patient education in both written form as well as animations and pictures.

$\rightarrow$ Self-management program

$\rightarrow$ Information about ongoing national and international research

$\rightarrow$ Essential information about SSc for GPs, HPs and medical specialists not specialized in SSc

$\rightarrow$ The opportunity to join an online network of patients and health care professionals.

\section{Patient empowerment}

In the interviews, patients often felt that their role in their treatment and shared decision making was too small. Also, rheumatologists reported that measures to empower patients are needed. Although $84 \%(n=522)$ of patients in the survey reported that they were involved in treatment decisions, only $63 \%(n=412)$ of patients reported that they actually did receive the care they needed. $18 \%(n=29)$ of rheumatologists prioritised the inability to provide appropriate care as most important hurdle. The patient survey showed that symptoms like fatigue ( $46 \%, n=295)$, Raynaud's phenomenon (31\%, $n=204)$, physical impairment $(30 \%$, $n=192)$, impaired hand function $(27 \%, n=177)$ and arthralgia $(25 \%, n=163)$ deserve more attention during hospital visits.

Considerations resulting from the working conference:

During the conference, participants agreed that patient empowerment could be improved by helping patients navigating the health care system. A case manager could offer this support. The fulfillment of the role of case manager, requires additional training and financial compensation and should be explored further. Secondly, care should be adapted to patients' requirements and preferences. Communication is key in creating a treatment plan that is patient-centered. Consequently, ways to prepare for doctor's visits were discussed in 


\section{Chapter 3}

the groups. The use of applications, checklists or peer support were suggested. A possible disadvantage of peer support is misinformation. Another proposal was the implementation of an annual dialogue between physician and patient to evaluate and discuss the treatment process and the quality of care.

\section{Recommendations:}

$\rightarrow$ In order to deliver patient-centered health care in a complex multicenter and multidisciplinary setting, case managers that coordinate teamwork, exchange of data and patient education are needed.

$\rightarrow$ Measures to improve consultation preparation should be explored, including a checklist and a peer who will join the patient.

$\rightarrow$ Annual evaluation with the emphasis on quality of life, daily functioning, expectations and goals should be implemented.

\section{Non-pharmacological care}

Structural support by a specialized nurse was mentioned in all focus groups as a desirable addition to the current standard of care. Nurses could help patients cope with the daily strains due to functional impairments and offer mental health support. Patients reported that more attention should be paid to non-pharmacological care. The survey revealed that knowledge about where to find HPs with SSc experience is lacking ( $39 \%, n=249$ of patients and $25 \%, n=40$ of rheumatologists, prioritised this as a hurdle for optimal care).

Considerations resulting from the working conference:

Although SSc has a large impact on physical and psychosocial wellbeing, little attention is attributed to non-pharmacological care in both clinical practice and research. In the conference, three elements came forward for further exploration in order to improve this: Increasing awareness, evidence-based guidelines for non-pharmacological care and education. These elements were prioritised. Firstly, physicians and patients might not be aware of the possible benefits of non-pharmacological support. By providing information about available treatment options delivered by HPs, more attention would be given to this theme during doctor's visits. The lack of evidence on non-pharmacological interventions could be partly responsible for the neglect of this theme and, importantly, complicates compensation by insurance policies. Thirdly, education of nurses and HPs will increase the quality of care they provide. As HPs working in private practices treat SSc patients infrequently, a network of HPs with SSc expertise is needed to share experience and knowledge.

\section{Recommendations:}

$\rightarrow$ More information about non-pharmacological support for patients and health care professionals should be provided

$\rightarrow$ Development of a (national) guideline on non-pharmacological support in SSc are needed

$\rightarrow$ Education for HPs to raise awareness, increase knowledge and create a network should be developed. 


\section{Discussion}

In this paper we report the results of interviews, surveys and a working conference among a broad panel of stakeholders aiming to identify consensus based recommendations to improve health care for SSc patients nationwide.

Twelve recommendations were formulated regarding five themes (Box 3). The identified themes in SSc care are in line with themes that were shown to be important in other chronic or rare diseases (12-14). For instance, patients with neuroendocrine tumors (NET) experienced unmet needs in coordination of care and lack of non-pharmacological care. Interestingly, NET patients in shared care were significantly less satisfied, which was attributed to the larger number of physicians involved. A study in SSc found that the number of disciplines involved was associated with a lower rating in care coordination by patients as well.(15) Our study showed that the model of shared care was preferred by physicians and $50 \%$ of the participating patients. (Multidisciplinary) collaboration between centers however was rated just sufficient. Although we did not investigate the actual performance of teams and the extent and quality of collaboration in shared care in practice, we think this rating indicates an important impairment in the currently provided care. Furthermore, it reflects the challenges that are faced in multi-organ orphan diseases demanding a large team of experts. $(3,16)$ In this study, we showed that all stakeholders believe that clear agreements on composition and coordination of multidisciplinary teams could improve the quality of care. Additionally, consensus should be reached on criteria for the appointment of expert centers. Similar efforts were initiated for cystic fibrosis care in the USA.(13) Their strategy also included improvement of leadership of centers and incorporating patients and their families in the improvement effort.

In our study, patients and rheumatologists reported the exchange of medical data as an important hurdle in the collaboration between centers. At the conference, one of the recommendations was a 'shared care record' accessible for the patient and health care professionals involved. Interestingly, in this idea and almost all other ideas that were put forwards on this theme, the patient got a prominent and even active role in holding and keeping own medical data. This might increase patient empowerment and fits in the modern health care ambition of patient-centered care. $(17,18)$

An overarching idea resulting from our study, was the creation of a national information platform. Other studies already showed that current information provision to SSc patients is insufficient in the Netherlands. $(19,20)$ Accessible education improves clinical parameters and therapeutic adherence.(21-23) Importantly, it also increases empowerment and strengthens patients' position in decision making processes.(24-26)

Another way to stimulate continuous, patient-centered care is the introduction of case managers. Case management focusses on the collaborative process, planning and coordination and advocacy for options and services to meet an individual's health needs.

(27) In patients with chronic conditions, case managers facilitated access to the healthcare system and the contact with multiple health care providers. (28) Case managers can also be involved in patient education.(29)

The strength of this study is the diversity of stakeholders and the large number of patients involved. Although we tried to avoid selection of participants, we realize that only a subgroup of patients and health care professionals completed the survey and attended the conference, implicating selection bias. However, this is the first time that quality of care and unmet needs in SSc have been evaluated in a multidisciplinary group of this size on a 


\section{Chapter 3}

nationwide level. In this way, the results from the preparation support the recommendations resulting from the working conference.

\section{Box 3. Recommendations resulting from the working conference}

Shared care and multidisciplinary collaboration

$\rightarrow$ Clear definitions about reference centers and expertise

$\rightarrow$ Concentration of expertise and a regional infrastructure to provide shared care

\section{Exchange of medical data between hospitals}

$\rightarrow$ A 'shared care record', accessible for the patient and all health care professionals

$\rightarrow$ A standardized form with regard to the information requires for information exchange

$\rightarrow$ Automatic synchronization between EPRSs

Information for both patients and health care professionals

$\rightarrow$ One national information hub for all stakeholders

\section{Patient empowerment}

$\rightarrow$ Coordination of care by case managers

$\rightarrow$ Patient led annual dialogue about goals and expectations

$\rightarrow$ Support in preparation of doctors' visit

\section{Non-pharmacological care}

$\rightarrow$ Improved information supply about non-pharmacological support

$\rightarrow$ Development of a guideline on non-pharmacological support in SSc

$\rightarrow$ Development of education for health professionals

EPRSs: Electronic Patient Record Systems, SSc: systemic sclerosis

\section{Conclusion}

This study achieved consensus and developed recommendations to improve quality of care in patients with SSc in the Dutch health care system. The most fundamental recommendations concern the implementation of shared care, development of efficient system to exchange medical data and creation of one hub to educate patients, physicians and HPs. To our knowledge, this is the first time such a multidisciplinary meeting was held with regard to SSc care. Our experiences, approach and results could therefore be of use for policymakers, health insurance companies and other stakeholders in the Netherlands and other countries, that are involved in the care of patients with rare and multisystem conditions.

Funding: This work was supported by the Arthritis Research and Collaboration Hub (ARCH) foundation 
Acknowledgements: The authors would like to thank C.W.Y. Appels, R. Bakker, S. Bazen, F. Bender, H. Berkers, A.E. van der Bijl, E.W.F. Blaas, F. Bonte-Mineur, H. Boerhof, G.W.M. Boerrigter, R. Bos, W.J.W. Bos, C. Bruggink, P.D.M. de Buck, , E. van de Burgt, F.S. Catarinella, S. Denktaș, M. Derksen, T. Dhondai, M. Eimers, R.J. Goekoop, E. van Gorp, L.D.M. Gossens, A. Groenendaal-Boender, R. van der Heijden, M.J. Herenius, J. Hofman, J. Huizer, M. Hulsinga, B. Jilderda, R. Jonkers, S.J. de Jong, C.G.M. Kallenberg, M.A.E. de Kanter, M. van Klei, H. Knaapen-Hans, H. Knaken, I.Koopmans, P. Krop, L.Kwakkenbos, R. Langenhuijsen, S. Leroux, I.C. Lether, M. Limper, M. Lohr, L. van Mourik, D.J. Mulder, A. Muns, S. Otter, S.Persijn, W.F. Peter, J. Potjewijd, B. Rave, H. de Ruiter, C.G. Schoemaker, T.H.M. Schoonbrood, A.A. Schouffoer, M. Soeters, A.J. Stel, J. Stocker, Y.K.O. Teng, E. Ton, A. van Veen, S. Verhaar, P.M.J. Verhoeven, E. Voogt, M. Voortman, Y. de Vries, A.E. Voskuyl, J.E.M. Wijbrans-Roodbergen for attending the working conference. They acknowledge the Dutch Arthritis Foundation (ReumaNederland) for funding the ARCH initiative.

\section{References}

1. Cinar FI, Unver V, Yilmaz S, Cinar M, Yilmaz F, Simsek I, et al. Living with scleroderma: patients' perspectives, a phenomenological study. Rheumatol Int. 2011;32(11):3573-3579.

2. Nakayama A, Tunnicliffe DJ, Thakkar V, Singh-Grewal D, O'Neill S, Craig JC, et al. Patients' Perspectives and Experiences Living with Systemic Sclerosis: A Systematic Review and Thematic Synthesis of Qualitative Studies.J Rheumatol. 2016;43(7):1363-1375.

3. Wagner Eh, Austin BT, Con Korff M. Organizing care for patients with chronic illness. The Milbank Q. 1996;74(4):511-544.

4. Harding S, Khimdas S, Bonner A, Baron M, Pope J. Best practices in scleroderma: an analysis of practice variability in SSc centres within the Canadian Scleroderma Research Group (CSRG). Clin Exp Rheumatol. 2012;30(2 Suppl 71):S38-43.

5. Johnson SR, Carette S, Dunne JV. Scleroderma: health services utilization from patients' perspective.J Rheumatol. 2006;33(6):1123-1127.

6. Mouthon L, Alami S, Boisard AS, Chaigne B, Hachulla E, Poiraudeau S. Patients' views and needs about systemic sclerosis and its management: a qualitative interview study. BMC

Musculoskelet disord. 2017;18(1):230.

7. Milette K, Thombs BD, Maiorino K, Nielson WR, Korner A, Pelaez S. Challenges and strategies for coping with scleroderma: implications for a scleroderma-specific self-management program. Disabil Rehabil. 2019;41(21):2506-2515

8. Tong A, Sainsbury P, Craig J. Consolidated criteria for reporting qualitative research (COREQ): a 32-item checklist for interviews and focus groups. Int J Qual Health Care 2007;19(6):349-357.

9. Von Elm E, Altman DG, Egger M, Pocock SJ, Gotzsche PC, Vandenbroucke JP. The Strengthening the Reporting of Observational Studies in Epidemiology (STROBE) Statement: guidelines for reporting observational studies. Lancet 2007;20;370(9596):1453-1457

10. Delbecq AL, Van de Ven AH. A group process model for problem identification and program planning.J Appl Behav Sci. 1971;7(4):466-491.

11. Delbecq AL, Van de Ven AH, Gustafson DH. Group Techniques for Program Planning: A Guide to Nominal Group and Delphi Processes. Glenview, IL: Scott Foresman Company; 1975.

12. Beesley VL, Burge M, Dumbrava M, Callum J, Neale RE, Wyld DK. Perceptions of care and patient-reported outcomes in people living with neuroendocrine tumours. Support Care Cancer. 2018;26(9):3153-3161

13. Mogayzel, Dunitz, Marrow. Improving chronic care delivery and outcomes: the impact of the cystic fibrosis Care Center Network. BMJ Qual Saf. 2014;23:i3-i8.

14. Epping-Jordan JE, Pruitt SD, Bengoa R, Wagner EH. Improving the quality of health care for chronic conditions. Qual \& Saf Health Care. 2004;13(4):299-305.

15. Willems LM, Kwakkenbos L, Bode C, van den Hoogen FH, van den Ende CH. Health care use and patients' 


\section{Chapter 3}

perceptions on quality of care in systemic sclerosis. Clin Exp Rheumatol. 2013;31(2 Suppl 76):64-70.

16. Bosch M, Faber MJ, Cruijsberg J, Voerman GE, Letherman S, Grol RP et al. Review article: Effectiveness of patient care teams and the role of clinical expertise and coordination: a literature review. Med Care Res Rev. 2009;66:5D-35S.

17. Richards T. Bring outpatients into the 21st century. BMJ 2018;361(k2472).

18. Taylor J, Rayner H, Smith S. Writing letters to patients. Br J Renal Med. 2013;18(1):Supplement P21

19. Schouffoer AA, Zirkzee EJ, Henquet SM, Caljouw MA, Steup-Beekman GM, van Laar JM, et al. Needs and preferences regarding health care delivery as perceived by patients with systemic sclerosis. Clin Rheumatol. 2011;30(6):815-824.

20. Schouffoer A, Ndosi ME, Vliet Vlieland TP, Meesters JJ. The educational needs of people with systemic sclerosis: a cross-sectional study using the Dutch version of the Educational Needs Assessment Tool (D-ENAT). Rheumatol Int. 2015;36(2):289-294

21. Essien O, Otu A, Umoh V, Enang O, Hicks JP, Walley J. Intensive Patient Education Improves Glycaemic Control in Diabetes Compared to Conventional Education: A Randomised Controlled Trial in a Nigerian Tertiary Care Hospital. PloS one. 2017;12(1):e0168835

22. Stenberg U, Haaland-Overby M, Fredriksen K, Westermann KF, Kvisvik T. A scoping review of the literature on benefits and challenges of participating in patient education programs aimed at promoting self-management for people living with chronic illness. Patient Educ Couns 2016;99(11):1759-1771

23. Twigg MJ, Bhattacharya D, Clark A, Patel R, Rogers H, Whiteside H, et al. What do patients need to know? A study to assess patients' satisfaction with information about medicines. Int J Pharm Pract. 2016;24(4):229-236.

24. Voshaar MJ, Nota I, van de Laar MA, van den Bemt BJ. Patient-centred care in established rheumatoid arthritis. Best Pract Res Clin Rheumatol. 2015;29(4-5):643-663.

25. Coulter A, Entwistle VA, Eccles A, Ryan S, Shepperd S, Perera R. Personalised care planning for adults with chronic or long-term health conditions. Cochrane Database Syst Rev. 2015(3):Cd010523.

26. Gionfriddo MR, Leppin AL, Brito JP, Leblanc A, Boehmer KR, Morris MA, et al. A systematic review of shared decision making interventions in chronic conditions: a review protocol. Syst Rev. 2014;3:38.

27. Glettler E, Leen M. The advanced practice nurse as case manager. J Case Manag. 1996; 5(3):121-126

28. Joo JY, Liu MF. Experiences of case management with chronic illnesses: a qualitative systematic review. Int Nursing Review. 2018;65(1):102-113.

29. Sandberg M, Jakobsson U, Midlov P, Kristensson J. Case management for frail older people - a qualitative study of receivers' and providers' experiences of a complex intervention. BMC Health Serv Res. 2014;14:14. 


\section{Supplementary File}

\section{S1. Study Methods}

\section{Qualitative study; focus group interviews}

To identify barriers for optimal care and ideas to improve care, focus group interviews with patients and individual interviews with rheumatologists and specialized nurses were performed. A descriptive phenomenological approach was used.

\section{Participants and setting}

Three focus groups with 23 patients were conducted. Patients from three different regions in the Netherlands were invited through their rheumatologist to participate in the interviews. Patients fulfilling the diagnostic criteria of SSc were eligible for participation.

Rheumatologists from both university hospitals and regional hospitals were approached to invite their SSc patients to participate, in order to include patients from different centers distributed nation-wide. Patients were invited by mail. The sample of participants was based on non-probability judgment sampling. There were no drop-outs, number of patients that refused to participate is not known. Three face-to-face focus group interviews were conducted in three different hospitals (Leiden, Zwolle and Nijmegen) in the Netherlands. The duration of the focus group interviews was in all three groups approximately 1.5-2 hours. All interviews were led by an independent researcher, female, (EE, senior researcher, MD PhD), with a wide experience in focus group interviews in the field of rheumatology, including SSc. This researcher did not know the participants of the interviews.

\section{Data collection}

An interview guide was developed based on literature findings and after discussion with the members of the working group. The interview comprised open questions. For details about the interview guide see Supplementary appendix 2. The questions were pilot tested first. Furthermore, sociodemographic data were collected. There were fieldnotes taken during the (focus group) interviews. The interviews were recorded, transcribed verbatim, transcriptions were sent to all participants for verification and thematic analysis was used and performed by two independent investigators. Data saturation was discussed in group involved in the project.

\section{Data analysis}

Themes and subthemes were derived from the data and were discussed by two independent investigators.

Twelve rheumatologists and five specialized nurses working in different medical centers in the Netherlands, were interviewed. They were selected by the members of the working group, selection was based on a similar number of participants working in regional and university centers. They were invited by e-mail. None refused. For detailed characteristics see table S1 and S2. 


\section{Quantification; cross-sectional online surveys}

The identified themes and other results from the literature study and the interviews were used to create a cross-sectional survey to investigate and prioritize unmet needs in a larger group.

\section{Participants}

To ensure only SSc patients would participate, rheumatologists were asked to invite their patients. The invitation was accompanied by an information letter explaining the aim and methods of the study. By returning a reply card or sending a notification email, patients received a code to enter the online survey or when preferred a paper version of the survey. Informed consent was obtained.

Patients from both regional and university hospitals in the Netherlands were invited through their rheumatologist. Participating hospitals were selected by the working group, to secure a representative patient population from both regional and university hospitals from all regions of the country. From the 15th of December 2017 till the 21 st of February 2018, 2093 patients with SSc were invited for the survey. 650 patients (31\%) completed the survey. For detailed characteristics of the patient population see table S1 and S2.

\section{Assessments}

The survey was created by the seven members of the ARCH Systemic sclerosis working group. Themes identified from the interviews were used. Questions were based on the results of the interviews, in order to investigate current organization of care and preferences in a larger group. The survey was tested and discussed in a pilot group, which included eight persons; three independent researchers, two representatives from the Dutch organization of health professionals (NHPR), two representatives from the Dutch patient organization for systemic autoimmune diseases (NVLE), one representative from the Dutch Society of Rheumatology. Next, the survey was tested in five SSc patients, two nurses, three rheumatologists and two health professionals.

The survey included open, multiple choice and multi-response questions about current delivery of care, unmet needs and preferences regarding care, rating of collaboration, multidisciplinary care, medical data exchange, patient empowerment, information supply for patients and health care professionals and non-pharmacological care. All items mentioned in the interviews and themes prioritized in earlier studies concerning quality of life and quality of care in SSc were included in the survey.

Theses about these items were assessed on a five-point Likert scale (1: strongly agree, 2: agree, 3: neither agree nor disagree, 4: disagree, 5: strongly disagree), scoring quality of collaboration and medical data exchange was done with a Likert scale (a slider from 0-100). In the multi-response questions used to prioritize items, participants could choose a maximum of three options, including an option to add a new item. Consumer Quality (CQ) index (19) was used and sociodemographic data (including age, status of living, educational level, employment) and disease characteristics (disease subset, disease duration) were collected.

The survey included open, multiple choice and multi-response questions about current delivery of care, unmet needs and preferences regarding care, rating of collaboration, multidisciplinary care, medical data exchange, patient empowerment, information supply for patients and health care professionals and non-pharmacological care. 


\section{Setting}

Invitation for an anonymized online questionnaires were sent to the patients via mail.

All Dutch rheumatologists $(n=350)$ and specialized nurses $(n=246)$ were invited for the survey by email by their professional organization. Furthermore, the survey was distributed among rheumatologists and rheumatologists in training during the annual meeting of the Dutch society of rheumatology. 167 (34\%) rheumatologists and 57 (21\%) nurses completed the online survey (details are shown in table $\$ 2$ ). Health professionals were invited through the patients that joined the survey. 90 health professionals invited by these patients completed the survey (details are shown in table S2).

\section{Analyses}

Descriptive statistics were used to describe characteristics and answering options of respondents. Means and standard deviations or median ( $25-75$ quartile's) were presented where appropriate. All analyses were performed using SPSS 22.

\section{Ethics}

Ethics approval was obtained from all participating centers in The Netherlands. All patient participants of the study provided written consent. Participants of the focusgroup interviews were reimbursed for their travelling costs.

\section{S2. Interview guide}

\section{Patients}

Instructions for the interviewer: introduction

1. How did you experience:

a. the diagnostic process?

b. the period after the diagnosis?

2. Experiences during hospital visits:

a. How was the support during routine hospital visits?

b. How did such a visit look like?

c. Was there attention for psychosocial aspects of the disease?

d. Was there any attention on societal, occupational, daily functioning and family?

e. Did you know where to go or whom to contact in case of questions or worsening of symptoms?

3. Did you receive information about the disease, did this meet your expectations?

a. Right after the diagnosis was made

b. Later on in the disease

c. What did you miss?

4. In which way would you prefer to receive education and information? Instructions for the interviewer: give suggestions / examples: a website with information, animations, meetings, flyers, apps etcetera 
5. On which subjects should be paid more attention?

6. Do you have access to your own medical records? How did the collaboration between involved health care professionals go? With;
a. General practitioner
b. Other disciplines
c. Occupational health specialist
d. Nurse
e. Health professional
f. Exchange of medical information between involved health care professionals

7. Which outcome measure do you think is important? What is the most relevant target in treatment?

8. Did you know the patient organization? Are you a member? Is there in your hospital a standardized multidisciplinary assessment program? What are your experiences with this program?

\section{Closing}

9. Do you have anything additional to tell us that was not mentioned in the interview?

\section{Rheumatologists and nurses}

Instructions for the interviewer: introduction

\section{Organization}

1. How is SSc care organized in your hospital?
a. Who refers patients?
b. Care after diagnosis? Referral or treatment in your hospital?
c. Division of tasks with other disciplines in your hospital?
d. How often are patients visiting the outpatient clinic?
e. How is the patient education organized?
f. What is your vision about the role of the patient in his/her treatment?
g. Do you have an arrangement with your patients in case of emergencies?

2. Do you collaborate with other health care professionals? Do you know if there are other health care professionals involved in the treatment of your SSc patients? (i.e. general practitioner, occupational health specialist, rheumatologists working in other hospitals, health professionals, nurses

\section{$\underline{\text { Care }}$}

3. Are you aware of the national guideline on SSc care?
a. Do you use the guideline? How do you use it?
b. Do you have a standardized multidisciplinary assessment program?
c. What is the treatment target in SSc? When do you think the treatment is
d. successful? 


\section{Patient-centered care}

4. What do you think is most important with regard to health care from a patients' perspective?
a. Why?
b. Do you implement this during your clinical practice?

\section{Quality of care}

5. What are you doing to optimize health care for patients with SSc?

a. Knowledge and education

b. Patient education and facilities for diagnostics and therapy.

c. Multidisciplinary collaboration

d. Do you evaluate the quality of care in your hospital?

\section{Communication}

6. Do your patients have access to their medical records?

7. How do you communicate and exchange information in case of shared care?

8. How do you communicate with other disciplines?

\section{Ideal health care}

9. What do you think optimal organization of care for SSc patients will look like?

a. Which hurdles are there at the moment preventing optimal care?

b. Which changes are needed to improve health care?

\section{Indicators}

10. Which indicators should be used to evaluate quality of SSc care?
a. Diagnostics and treatment
b. Organization of care

\section{Closing}

11. Do you have anything additional to tell us that was not mentioned in the interview?

12. Would you like to invite the SSc patients in your hospital for the patient survey? 


\section{Supplementary Table S1. Patient characteristics survey}

\begin{tabular}{|l|l|}
\hline & Survey (N=650) \\
\hline Age, years; mean (SD) & $59(11)$ \\
\hline Male, \% (N) & $25(164)$ \\
\hline SSc Subset, \% (N) & \\
\cline { 2 - 2 } $\begin{array}{l}\text { LCSSc } \\
\text { DcSSc }\end{array}$ Unknown & $20(132)$ \\
\hline Time between onset symptoms and diagnosis, years; mean (SD) & $38(250)$ \\
\hline Disease duration after diagnosis, years; SD & $4(7)$ \\
\hline Living with partner, \% (N) & $8(8)$ \\
\hline Educational level, \% (N) & $55(359)$ \\
\hline \multirow{2}{*}{$\begin{array}{l}\text { Mew } \\
\text { High }\end{array}$} & $3(19)$ \\
\hline Paid employement & $65(425)$ \\
\hline Care in center of expertise, \% (N) & $32(207)$ \\
\hline Number hospital SSc care, \% (N) & $38(245)$ \\
\hline 1 & $56(361)$ \\
\hline 2 & $13(83)$ \\
\hline$>2$ & $61(399)$ \\
\hline & $32(209)$ \\
\hline & $7(43)$ \\
\hline
\end{tabular}




\section{Supplementary Table S2. Health care professionals' characteristics} interviews and survey

\begin{tabular}{|c|c|c|c|c|c|c|}
\hline & \multicolumn{3}{|l|}{ Interviews } & \multicolumn{3}{|l|}{ Survey } \\
\hline & $\begin{array}{l}\text { Rheumatologists } \\
(N=12)\end{array}$ & $\begin{array}{l}\text { Nurses } \\
(N=5)\end{array}$ & $\begin{array}{l}\text { Total } \\
(N=17)\end{array}$ & $\begin{array}{l}\text { Rheumatologists } \\
(\mathrm{N}=167)\end{array}$ & $\begin{array}{l}\text { Nurses } \\
(\mathrm{N}=51)\end{array}$ & $\begin{array}{l}\mathrm{HP} \\
(\mathrm{N}=84)\end{array}$ \\
\hline $\begin{array}{l}\text { Age, years; mean } \\
\text { (range) }\end{array}$ & $48(38-58)$ & $43(31-58)$ & $\begin{array}{l}46.7 \\
(31-58)\end{array}$ & $44(26-65)$ & 50 & 42 \\
\hline Male, \% (N) & $17(2)$ & 0 & 2 & & $10(5)$ & $34(29)$ \\
\hline \multicolumn{7}{|l|}{$\begin{array}{l}\text { Worksetting, \% } \\
\text { (N) }\end{array}$} \\
\hline Regional center & $67(8)$ & $80(4)$ & 12 & $65(102)$ & $68(30)$ & $58(92)$ \\
\hline University hospital & $33(4)$ & $20(1)$ & 5 & $35(55)$ & $32(16)$ & 35 (55) \\
\hline No hospital & & & & & & $7(10)$ \\
\hline $\begin{array}{l}\text { Working in center } \\
\text { of expertise, } \%(N)\end{array}$ & $42(5)$ & $40(2)$ & 7 & $46(72)$ & $36(17)$ & $14(12)$ \\
\hline SSc expert, \% (N) & $58(7)$ & $20(1)$ & 8 & $24(37)$ & & $30(25)$ \\
\hline \multicolumn{7}{|l|}{$\begin{array}{l}\text { SSc patiënts in } \\
\text { care \% (N) }\end{array}$} \\
\hline none & & & & 11 (17) & $14(7)$ & \multirow[t]{2}{*}{$76(64)$} \\
\hline$<5$ & & & & $26(42)$ & $35(18)$ & \\
\hline $5-10$ & $8(1)$ & $20(1)$ & 2 & $31(50)$ & $24(12)$ & $18(15)$ \\
\hline $10-30$ & $16(2)$ & $20(1)$ & 3 & $23(36)$ & $14(7)$ & \multirow[t]{4}{*}{$6(5)$} \\
\hline $30-50$ & $8(1)$ & & 1 & $3(5)$ & $4(2)$ & \\
\hline $50-100$ & $22(3)$ & & 3 & $3(5)$ & $4(2)$ & \\
\hline$>100$ & $38(5)$ & $60(3)$ & 8 & $3(5)$ & $6(3)$ & \\
\hline
\end{tabular}

dcSSc: diffuse cutaneous systemic sclerosis, HP: health professional, IcSSc: limited cutaneous systemic sclerosis. 


\section{Supplementary Table S3. Illustrative responses of patients and healthcare professionals}

\begin{tabular}{|l|l|}
\hline Question & Quote \\
\hline $\begin{array}{l}\text { Did you receive information } \\
\text { about the disease, did this } \\
\text { meet your expectations? }\end{array}$ & $\begin{array}{l}\text { Patient: "I need more information about the prognosis, in what way will SSc } \\
\text { influence my future?" } \\
\text { Patient: "I need a self-management program, I would like to learn how to } \\
\text { cope with fatigue and find a balance in daily activities, and get advice about } \\
\text { nutrition." }\end{array}$ \\
\hline $\begin{array}{l}\text { How did you experience } \\
\text { support and therapy? }\end{array}$ & Patient: "I wished I was more involved in clinical decision making" \\
\cline { 2 - 2 } $\begin{array}{l}\text { What could be improved? } \\
\text { Patient: "More attention should be given to coping and psychological } \\
\text { consequences of the disease. Health care is purely focused on the medical and } \\
\text { somatic issues." }\end{array}$ \\
\hline $\begin{array}{l}\text { How did the collaboration } \\
\text { care professionals go? }\end{array}$ & $\begin{array}{l}\text { Patient: "I feel 'shredded', all caregivers involved in my treatment are focusing } \\
\text { on their own discipline, collaboration and communication is inadequate." }\end{array}$ \\
\hline $\begin{array}{l}\text { How could SSc care be } \\
\text { optimized? }\end{array}$ & $\begin{array}{l}\text { Patient: " All diagnostics and hospital appointments planned on the same day." } \\
\text { Patient: "The general practitioner should have more knowledge about how to } \\
\text { recognize the disease" }\end{array}$ \\
\hline $\begin{array}{l}\text { How do you rate exchange } \\
\text { of medical records and } \\
\text { information about patients? }\end{array}$ & $\begin{array}{l}\text { Rheumatologist: "Referral of patients by other rheumatologists is not going well, } \\
\text { there is no standardized way to do it." }\end{array}$ \\
\cline { 2 - 2 } & $\begin{array}{l}\text { Rheumatologist: "Exchange of medical data in shared care and second } \\
\text { opinions is not going efficiently." }\end{array}$ \\
\hline
\end{tabular}


Optimal care for patients with systemic sclerosis 


\section{Abstract}

Introduction. Systemic sclerosis (SSc) is a rare and complex disease. Optimal management of patients requires knowledge and experience and, importantly, intensive collaboration between hospitals and multidisciplinary teams. Definition and recognition of expert centres in SSc is currently lacking, which complicates collaboration between centres and leaves patients poorly informed. The aim of this study was to develop a set of requirements for two type of SSc centres in order to establish a nationwide structure for an optimal and transparent organization of care.

Methods. A three-round Delphi-study was conducted among a panel of rheumatologists working at university or regional hospitals across the Netherlands. Prior to the final consensus round, a session with a patient panel $(\mathrm{N}=22)$ was held. The results of this meeting were described in the last round for rheumatologists. Criteria were divided in five categories: 1) medical care, 2) case load, 3) collaboration, 4) research, 5) training of staff, 6) other. In the first round, criteria derived from literature were proposed and participants could add criteria that were missing. For every item, participants could indicate if they thought the item should be included for two types of SSc centres: 1) SSc expert centre or 2) SSc treatment centres. Consensus was reached when more than $85 \%$ of the panel agreed.

Results. In total, 47 rheumatologists participated in Delphi round 1, 35 in round 2, and 43 in round 3. Additional suggestions were added by the patient panel $(n=22)$. Consensus was reached for the requirements of SSc expert ( 45 items) and SSc treatment centres (29 items) including minimal caseloads of annual suspected SSc cases and total patients in care.

Conclusion. Requirements of centres for SSc care in the Netherlands were established in this study. Feasibility of certification should be evaluated next. Our proposed list can serve as a model for other countries. 


\section{chapter 4}

Requirements for systemic sclerosis expert centres in the Netherlands: a Delphi consensus study 


\section{Chapter 4}

\section{Introduction}

Systemic sclerosis (SSc) is a rare, chronic and complex connective tissue disease (1). Screening and treatment of disease-related organ and vascular complications and timely referral for advanced therapies can be challenging in this heterogenous group of patients. Therefore, training of staff, interdisciplinary and multicentre collaboration and agreement on organisation of health care services are paramount (2). In order to build such an infrastructure, facilities and expertise available in centres need to be identified. Furthermore, insight in the level of expertise of centres is highly valued by patients.(3) Unfortunately, there is currently no uniform and transparent definition of expert centres for SSc. Consequently, collaboration between centres and multidisciplinary teams is complicated. Also, patients are not able to check whether they are treated in a centre that is engaged in managing this rare condition. In some other orphan diseases, requirements for expert centres have already been defined, are endorsed by scientific organizations, and are applied in clinical practice. The Dutch organisation of pulmonology and European Society of Cardiology for instance, defined requirements for expert centres for interstitial lung disease (4) and pulmonary hypertension (5), respectively. Also care for patients with breast cancer, prostate cancer and rare types of cancer, is already structured according to centres of expertise (6-8). In 2014, the Dutch Society of Rheumatology published a guideline for SSc management and defined recommendations for referral to expert centres (9). Yet, a widely accepted definition of SSc specialist centres is currently lacking. The aim of this study was to develop a set of requirements for SSc expert and treatment centres in order to establish a nationwide structure for an optimal and transparent organization of care.

\section{Methods}

\section{Design}

We used the Delphi technique in order to reach consensus about the requirements for expertise in two types of centres: SSc expert centres and SSc treatment centres. We defined a priori SSc expert centres as highly specialized centres provide a wide range of complex diagnostics and treatments and have deep knowledge about SSc. SSc treatment centres are hospitals that offer a selection of diagnostics and therapies and have dedicated multidisciplinary teams for SSc. SSc expert centres can fulfil the role of SSc treatment centres as well, but not vice versa.

Delphi technique involves a structured series of questionnaires (rounds) to gather information until consensus is attained (10). The number of rounds was set on a maximum of three, based on previous Delphi studies. Between January $6^{\text {th }}$ and April $10^{\text {th }} 2020$, rheumatologists participated in the online questionnaires. After the second round we organized a live session with patients to explore their views on expert centres for SSc, and to discuss the results of the two rounds. The patient panel meeting was held on February $22^{\text {nd }}$ at the University Medical Centre Utrecht. Informed consent was obtained from all participants.

\section{Participants}

A Delphi study was performed across rheumatologists working at both academic and regional hospitals in the Netherlands. We aimed to create a list of requirements that 
is supported by our Dutch colleagues, therefore, we invited all rheumatologists in the Netherlands to participate in the study. We approached them via the monthly newsletter of the Dutch Society of Rheumatology (NVR) and by email via the Dutch organization of systemic autoimmune diseases (SANL). Patients were approached on social media by the Dutch patients organization (NVLE). All patients wanting to participate could join the panel meeting.

\section{Delphi rounds}

In the first Delphi round, background information (sex, age, discipline) was collected. The questionnaire with requirements consisted of 40 items, ordered by categories 1) medical care, 2) case load, 3) collaboration, 4) research, 5) training of staff, and 6) other (see Supplementary Table 1). The items originated from criteria described in literature. This literature search was performed in PubMed and MEDLINE databases using the terms SSc or scleroderma combined with quality assurance, certification, requirements, outcome measures and care facilities. Additionally, international and national SSc guidelines and expert definitions of other conditions were included. All English and Dutch papers were included and screened. Also, the set of requirements for expert centres for systemic autoimmune conditions according to the Dutch Federation of University Medical Centres (NFU), the Dutch society of regional specialist centres (STZ) and European Reference Networks (ERN) were used. One reviewer extracted items and discussed these with three other researchers.

To prevent wrong interpretation of the items, a description was provided for each item. Participants could indicate if they thought that fulfilment of the items was required for SSC expert centre and for SSc treatment centres, using a Likert scale 1) completely agree, 2) agree, 3) disagree, 4) completely disagree. Items about case load were open text fields in the first round and 4-item multiple choice questions in the second and third round. All items needed to be scored in order to complete the questionnaire.

In the first round, participants could suggest additional items in an open text field, these items were added to the second Delphi round (see Supplementary Table 1). Questionnaires were built in the online (c) Calibrum Surveylet software for online Delphi studies. For the last Delphi round (c) SurveyMonkey software was used.

\section{Consensus}

Consensus was defined as agreement of at least $85 \%$ of the participants (completely agree and agree or disagree together with completely disagree). Items on which consensus was reached were removed, remaining items and additional items suggested by participants in the first round were included in the next round. In the second and third round participants were informed about the response of the whole group. In the third round, results from the patient panel discussion were shown for each category.

\section{Patient panel meeting}

After two online questionnaires among rheumatologists, we organized a separate meeting with a patient panel. During this meeting, the patient perspectives on SSc expertise were discussed and items on which no consensus had been reached in the online rounds were addressed. The meeting started with a presentation of the background of the study, followed by the results of the 


\section{Chapter 4}

second Delphi round. Patients were asked to vote on the items that were still subject of debate and could add new items. Results from the discussion and voting were summarized and added to the last Delphi round.

\section{Data analyses}

Characteristics and responses of rheumatologists were analysed using descriptive statistics.

\section{Results}

\section{Participants}

In total, 330 rheumatologists were invited to participate in the study, of which $14 \%(n=47)$ completed the first round. Next, 35 completed the second and 43 the third Delphi-round. Of all participants, 61\% were female and 39\% male, median age was 46 (range 34-63 years) and $89 \%$ of the participants were working as a rheumatologist, $11 \%$ worked as internist.

The patient panel meeting was attended by 22 patients, $86 \%$ was female, median age 56 years (range 29-80 years). The median disease duration was 4 years (range $0.5-24$ years), $50 \%(n=11)$ of patients had the diffuse type of disease, $36 \%(n=8)$ had limited cutaneous systemic sclerosis and $14 \%(n=3)$ did not know the disease subtype. Half of the patients were treated in an academic hospital, two (9\%) in a regional hospital and four patients (18\%) in both (shared care). Supplementary table 2 shows the results of the discussion in the patient panel.

\section{Requirements for SSc expertise}

The panel of rheumatologists reached consensus for the requirements of SSc expert and SSc treatment centres on respectively 45 and 29 items (see Table 1).

With regard to the SSc expert centres, the panel agreed that those centres had to be able to provide all therapies including combination therapy for pulmonary hypertension and autologous stem cell transplantation, and collaborate with multiple disciplines and health professionals. SSc expert centres must have a team including a rheumatologist, pulmonologist, nephrologist, cardiologist, gastroenterologist, dermatologist, rehabilitation expert, psychologist, occupational therapist, specialized nurse, dietician and a social worker engaged in SSc. These collaboratives with specialties do not necessarily need to be present within the centre, but can exist between centres. Multidisciplinary team meetings between specialists and centres involved should, however, take place regularly.

A structured multidisciplinary annual visit had to be offered at these centres. The minimal number of patients with suspected SSc should be 50 (62\% of the participants) annually and $>150$ patients have to be in care (60\%). The requirements regarding patient education, suggested by the patient panel, were adopted by the rheumatologist panel. Furthermore, SSc expert centres should have an expert status from the NFU. There was no agreement on the requirement of expert status according to the ERN ( $55 \%$ pro and $45 \%$ against) or STZ status (45\% pro and $55 \%$ against).

With regard to SSc treatment centres, the panel agreed on 29 items. SSc treatment centres must have a team including a rheumatologist, pulmonologist, nephrologist, cardiologist, gastroenterologist, dermatologist, rehabilitation expert, psychologist, occupational 
Table 1. Consensus: Requirements for SSc Expert and Treatment centres

\begin{tabular}{|c|c|c|c|}
\hline \multicolumn{2}{|l|}{ SSC EXPERT CENTRE } & \multicolumn{2}{|c|}{ SSC TREATMENT CENTRE } \\
\hline \multicolumn{4}{|l|}{ Medical care } \\
\hline Diagnostics & Agreement & & Agreement \\
\hline Immunological tests & $100.0 \%$ & Immunological tests & $97.9 \%$ \\
\hline Nailfold capillaroscopy & $94.8 \%$ & Nailfold capillaroscopy & $95.8 \%$ \\
\hline Pulmonary function test & $99.9 \%$ & Pulmonary function test & $97.5 \%$ \\
\hline Echocardiogram & $99.5 \%$ & Echocardiogram & $85.7 \%$ \\
\hline HR-CT scan & $100.0 \%$ & HR-CT scan & $90.4 \%$ \\
\hline mRSS & $100.0 \%$ & mRSS & $90.5 \%$ \\
\hline MR heart & $90.7 \%$ & & \\
\hline Right heart catheterization & $96.4 \%$ & & \\
\hline \multicolumn{4}{|l|}{ Therapies } \\
\hline Vasoactive medication & $98.5 \%$ & Vasoactive medication & $93.5 \%$ \\
\hline $\begin{array}{l}\text { Immunosuppressive therapy incl. } \\
\text { CYC iv }\end{array}$ & $100.0 \%$ & $\begin{array}{l}\text { Immunosuppressive therapy incl } \\
\text { iv (CYC iv) }\end{array}$ & $92.8 \%$ \\
\hline Combination therapy for $\mathrm{PH}$ & $99.9 \%$ & & \\
\hline $\begin{array}{l}\text { Autologous stem cell } \\
\text { transplantation }\end{array}$ & $85.5 \%$ & & \\
\hline \multicolumn{4}{|l|}{ Facilities } \\
\hline In-patient unit & $100.0 \%$ & In-patient unit & $92.7 \%$ \\
\hline \multirow[t]{2}{*}{ Intensive care unit } & $96.5 \%$ & Intensive care unit & $85.7 \%$ \\
\hline & & Emergency medicine department & $93.3 \%$ \\
\hline \multicolumn{4}{|l|}{ Case load (minimum) } \\
\hline $\begin{array}{l}\text { Annual number of suspected SSc } \\
\text { cases }>50\end{array}$ & $61.9 \%$ & $>10$ & $70.3 \%$ \\
\hline Number of patients in care $>150$ & $59.5 \%$ & $>45$ & $61.0 \%$ \\
\hline \multicolumn{4}{|l|}{ Collaboration } \\
\hline \multicolumn{4}{|l|}{ Health care professionals } \\
\hline Pulmonologist & $99.9 \%$ & Pulmonologist & $97.9 \%$ \\
\hline Cardiologist & $99.8 \%$ & Cardiologist & $95.8 \%$ \\
\hline Gastroenterologist & $96.0 \%$ & Gastroenterologist & $97.6 \%$ \\
\hline Nephrologist & $86.7 \%$ & Nephrologist & $86.8 \%$ \\
\hline Dermatologist & $93.4 \%$ & Dermatologist & $88.0 \%$ \\
\hline Rehabilitation expert & $96.0 \%$ & Rehabilitation expert & $88.1 \%$ \\
\hline Occupational therapist & $88.3 \%$ & Occupational therapist & $87.7 \%$ \\
\hline Psychologist & $87.5 \%$ & Psychologist & $85.3 \%$ \\
\hline Dietitian & $91.1 \%$ & & \\
\hline Social worker & $87.5 \%$ & & \\
\hline Specialized nurse & $99.9 \%$ & & \\
\hline Multidisciplinary meeting & $98.0 \%$ & Multidisciplinary meeting & $98.0 \%$ \\
\hline Annual visit to specialized nurse & $100.0 \%$ & & \\
\hline \multirow{2}{*}{$\begin{array}{l}\text { Structured multidisciplinary annual } \\
\text { visit }\end{array}$} & $88.1 \%$ & & \\
\hline & & Physiotherapist & $85.1 \%$ \\
\hline \multicolumn{4}{|l|}{ Other } \\
\hline Other centres & $100.0 \%$ & Other centres & $92.0 \%$ \\
\hline Participation in ARCH and SANL & $100.0 \%$ & Participation in ARCH and SANL & $90.4 \%$ \\
\hline
\end{tabular}




\begin{tabular}{|c|c|c|c|}
\hline Patient organisations & $98.0 \%$ & Patient organisations & $89.4 \%$ \\
\hline & & General practitioners & $88.0 \%$ \\
\hline \multicolumn{4}{|l|}{ Research } \\
\hline Participation in trials & $97.5 \%$ & & \\
\hline Initiation of trials & $98.8 \%$ & & \\
\hline Participation in registries & $100.0 \%$ & Participation in registries & $100.0 \%$ \\
\hline $\begin{array}{l}\text { Initiation of projects to improve } \\
\text { quality of care }\end{array}$ & $98.0 \%$ & & \\
\hline $\begin{array}{l}\text { Participation in international } \\
\text { studies }\end{array}$ & $88.8 \%$ & & \\
\hline \multicolumn{4}{|l|}{ Training of staff } \\
\hline $\begin{array}{l}\text { Staff is trained in SSc every } 2 \\
\text { years }\end{array}$ & $93.4 \%$ & $\begin{array}{l}\text { Staff is trained in SSc every } 2 \\
\text { years }\end{array}$ & $87.1 \%$ \\
\hline $\begin{array}{l}\text { Staff is trained in nailfold } \\
\text { capillaroscopy }\end{array}$ & $86.6 \%$ & $\begin{array}{l}\text { Staff is trained in nailfold } \\
\text { capillaroscopy }\end{array}$ & $90.5 \%$ \\
\hline Staff is trained in mRSS & $92.6 \%$ & Staff is trained in mRSS & $90.4 \%$ \\
\hline $\begin{array}{l}\text { Experts provide training for other } \\
\text { centres }\end{array}$ & $96.0 \%$ & & \\
\hline \multicolumn{4}{|l|}{ Other } \\
\hline Centre fulfils requirements of NFU & $85.4 \%$ & & \\
\hline $\begin{array}{l}\text { Patient education is integrated in } \\
\text { usual care }\end{array}$ & $100.0 \%$ & & \\
\hline $\begin{array}{l}\text { Patient education is available for } \\
\text { any stage }\end{array}$ & $100.0 \%$ & & \\
\hline $\begin{array}{l}\text { Patient education is provided by } \\
\text { trained staff. }\end{array}$ & $91.4 \%$ & & \\
\hline
\end{tabular}

ARCH: Arthritis and Research Collaboration Hub, CYC: cyclophosphamide, mRSS: modified Rodnan Skin Score, NFU: The Netherlands Federation of University Medical Centres, PH: pulmonary hypertension, SANL: Stichting Autoimmuunziekten Nederland.

therapist and a physiotherapist. Compared to the SSc expert centres, ability to provide highly specialized procedures i.e. right heart catheterization and combination therapy for pulmonary hypertension are not required. Minimal caseload for suspected SSc was 10 annually and 45 for the total number of patients in care. Additionally, an item about collaboration with general practitioners was adopted (see Table 1).

For both types of centres, requirements on training of staff and collaboration with other hospitals in the area and participation in national initiatives such as registries and the ARCH initiatives, were included in the list.

\section{Discussion}

The aim of this study was to reach consensus among rheumatologist on requirements for expert centres for SSc in the Netherlands. Rheumatologists agreed on a set of requirements for two types of SSc centres with different levels of expertise. To our knowledge, this is the first study proposing such a list for SSc.

Establishment of consensus for two different types of SSc centres (SSc Expert centre and SSc Treatment centre) allows the design of a structure for medical services nationwide that fits the Dutch health care system. In this way, care for SSc patients with complex problems 
and/or poor prognosis in need of advanced diagnostic trajectories and intensive treatments can be concentrated in SSc Expert centres. SSc care with low complexity can be done in SSc Treatment centres. Intensive collaboration between these centres is obviously essential, in order to align referrals and shared care. In this way, distribution of patients can be more balanced across the country, which will shorten travelling time to hospital appointments for many patients.

The agreed items for SSc centres are in line with set up requirements in other conditions. In pulmonary hypertension, the composition of multidisciplinary teams, case load and collaborative networks are defined as well in the set of requirements $(5,11)$. The set in our study also includes items about research, training and patient education, which are also adopted in the sets for prostate and breast cancer care $(7,12)$. Similar initiatives which are already implemented in practice in other conditions, have shown to be feasible and wellaccepted, and have let to improvement of quality indicators in 220 centres after five years of follow-up (13-14).

In order to put our work into practice, the list has yet to be acknowledged by the Dutch Society of Rheumatology, and all hospitals in the Netherlands could be evaluated according to our list. Creating a map with the level of SSc expertise in our country will increase transparency and enable patients and health care professionals to navigate the care system. Subsequently, certification of centres should be evaluated regularly.

Our study has some limitations. Firstly, we made a selection of items we included in the questionnaires. This selection was, however, based on literature on existing requirements for centres for other conditions or categories of conditions (i.e. STZ requirements for systemic autoimmune conditions and recommendations for pulmonary hypertension expert centres). Furthermore, we invited participants to add suggestions for the item list in the first Delphi round. Also, we added items suggested by the patient panel. Secondly, representability could be questioned as the response rate after inviting all rheumatologists in the Netherlands was only $14 \%$. Also, we were not able to record work setting of participants. We assume, however, that the study attracted both local and academically working rheumatologists with a special interest in the subject. Furthermore, the response $(\mathrm{N}=47)$ is acceptable for a Delphi consensus study, as the optimal sample for such studies is recommended to be between 10 50 highly engaged participants (10). Another limitation of our study was that the case load acquired for both Expert and Treatment centres has a relative low consensus, which should be further debated before implementation takes place. Lastly, we realise that different healthcare systems may use distinct approaches to organize care for complex and rare conditions like SSc, yet our national template can serve as an example for other countries as well.

In conclusion, our study resulted in a list of requirements that allows defining expert centres for SSc and identifying centres in the Netherlands that fulfil these requirements. In this way, patients and clinicians are better informed on where they can find the care they need.

\section{Funding}

This work was supported by the Arthritis Research and Collaboration Hub (ARCH) foundation.

\section{Acknowledgements}

We would like to acknowledge the Dutch Arthritis Foundation (ReumaNederland) for funding the ARCH initiative. Furthermore, we thank the Dutch patient organization (NVLE) for their efforts with regard to the patient panel session. 


\section{Chapter 4}

\section{References}

1. Denton CP, Khanna D. Systemic sclerosis. Lancet. 2017;390(10103):1685-1699.

2. Spierings J, Van Den Ende C, Schriemer R, de Pundert L, Bernelot Moens HJ, van Laar JM et al. Optimal care for systemic sclerosis patients: recommendations from a patient-centered and multidisciplinary mixed-method study and working conference. Clin Rheumatol. 2019;38(4):: 1007-1015.

3. Spierings J, Van Den Ende CHM, Schriemer RM, Bernelot Moens HJ, van der Bijl EA, Bonte-Mineur F et al. How do patients with systemic sclerosis experience currently provided healthcare and how should we measure its quality? Rheumatology. 2020;59(6):1226-1232.

4. NVALT bestuur. Leidraad voor Kwaliteitsafspraken bij de introductie van nieuwe diagnostiek, medicatie of behandeling waarvoor Concentratie en Spreiding van Zorg wordt overwogen. 2017.

5. Task Force for Diagnosis and Treatment of Pulmonary Hypertension of European Society of Cardiology (ESC); European Respiratory Society (ERS); International Society of Heart and Lung Transplantation (ISHLT), et al. Guidelines for the diagnosis and treatment of pulmonary hypertension. Eur Respir J. 2009;34(6):1219-1263.

6. Wilson AR, Marotti L, Bianchi S, Biganzoli L, Claassen S, Decker T et al. The requirements of a specialist Breast Centre. Eur J Cancer. 2013;49(17):3579-3587.

7. Valdagni R, Albers P, Bangma C, Drudge-Coates L, Magnani T, Moynihan C et al. The requirements of a specialist Prostate Cancer Unit: a discussion paper from the European School of Oncology. Eur J Cancer. 2011;47(1):1-7.

8. Casanueva FF, Barkan AL, Buchfelder M, Klibanski A, Laws ER, Loeffler JS et al. Criteria for the definition of Pituitary Tumor Centers of Excellence (PTCOE): A Pituitary Society Statement. Pituitary. 2017;20(5):489-498.

9. Bonte-Mineur MECJ, Knaapen-Hans HKA, Meijs J, Moolenbrugh JD, Radstake TRDJ, Schouffoer AA et al. Dutch guideline for treatment of systemic sclerosis Dutch Society for Rheumatology. Dutch Soc Rheumatol. 2014.

10. Hasson F, Keeney S, McKenna H. Research guidelines for the Delphi survey technique.J Adv Nurs. 2000 Oct;32(4):1008-1015.

11. National Pulmonary Hypertension Centres of the UK and Ireland. Consensus statement on the management of pulmonary hypertension in clinical practice in the UK and Ireland. Thorax. 2008;63 Suppl 2:ii1-ii41.

12. Biganzoli L, Cardoso F, Beishon M, Cameron D, Cataliotti L, Coles CE et al. The requirements of a specialist breast centre. Breast. 2020;51:65-84.

13. Brucker SY, Bamberg M, Jonat W, Beckmann MW, Kämmerle A, Kreienberg R et al. Certification of breast centres in Germany: proof of concept for a prototypical example of quality assurance in multidisciplinary cancer care. BMC Cancer. 2009;9:228.

14. Brucker SY, Schumacher C, Sohn C, Rezai M, Bamberg M, Wallwiener D; Steering Committee. Benchmarking the quality of breast cancer care in a nationwide voluntary system: the first five-year results (2003-2007) from Germany as a proof of concept. BMC Cancer. 2008;8:358. 


\section{Supplementary 1. List of items}

\section{Presented in the first Delphi round}

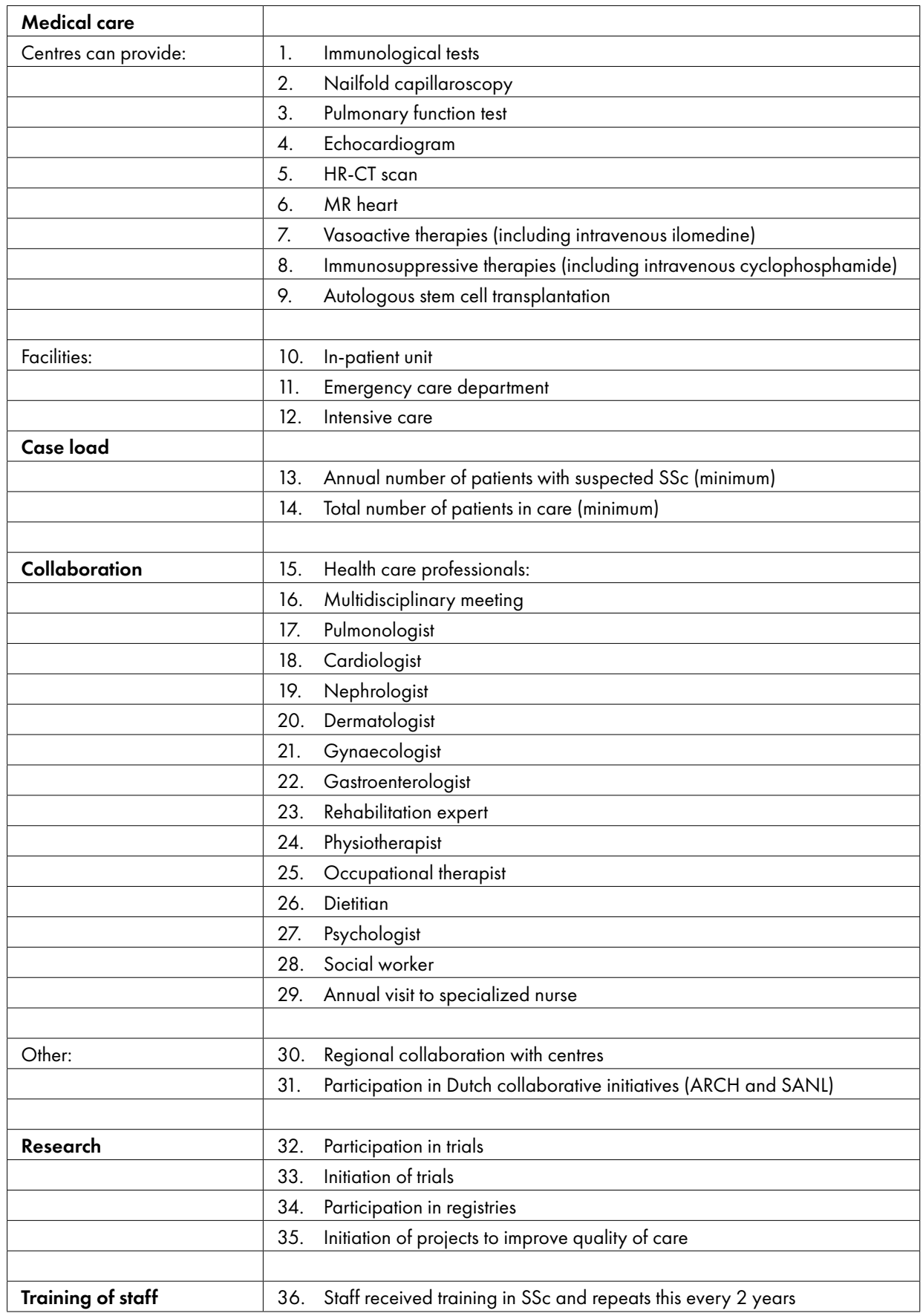




\begin{tabular}{|l|l|}
\hline & 37. Staff received training in nailfold capillaroscopy \\
\hline & 38. Experts provide training for other centres \\
\hline & \\
\hline Other requirements & 39. NFU status (The Netherlands Federation of University Medical Centres) \\
\hline & $40 . \quad$ ERN status (European Reference Networks) \\
\hline & $41 . \quad$ STZ status (Topclinical practices) \\
\hline
\end{tabular}

\section{Items added after the first round}

\begin{tabular}{|l|ll|}
\hline Medical care & 1. & Structured multidisciplinary annual visit \\
\hline & 2. & Dental care \\
\hline & 3. & Specialized nurse \\
\hline Collaboration & 4. & Collaboration with general practitioners \\
\hline Training of staff & 5. & Staff received training in skin score \\
\hline
\end{tabular}

\section{Items added after the patient panel}

\begin{tabular}{|l|ll|}
\hline Patient education & 1. & Patient education is integrated in usual care \\
\hline & 2. & $\begin{array}{l}\text { All patients have access to education at different stages of the disease } \\
\text { course }\end{array}$ \\
\hline Collaboration & 3. & Patient education is provided by trained health care professionals. \\
\hline & 4. & Collaboration with urologist \\
\hline
\end{tabular}

\section{Supplementary 2. Summary of the patient panel discussions}

\section{Expectations of SSc expert centres}

\begin{tabular}{|c|c|}
\hline \multirow[t]{7}{*}{ Collaboration } & Collaboration on a regional and national level \\
\hline & Sharing of knowledge and experience between doctors and centres \\
\hline & Patients should be discussed in a multidisciplinary meeting annually \\
\hline & Experts in other centres should be easily accessible for patients and doctors \\
\hline & Collaboration with rehabilitation medicine should be established \\
\hline & Clear and timely communication between different specialists \\
\hline & Communication with general practitioners \\
\hline \multirow[t]{2}{*}{ Centralisation } & $\begin{array}{l}\text { All disciplines possibly involved in SSc should be present in expert centres: } \\
\text { including at least a cardiologist, pulmonologist, gastroenterologist, } \\
\text { gynaecologist, rehabilitation expert }\end{array}$ \\
\hline & $\begin{array}{l}\text { Provision of all available therapies, including autologous stem cell } \\
\text { transplantation. }\end{array}$ \\
\hline \multirow[t]{3}{*}{ Organisation } & $\begin{array}{l}\text { Care should be organised efficiently, with annual diagnostic tests and } \\
\text { appointments combined }\end{array}$ \\
\hline & Shared care with Treatment centres or local hospitals. \\
\hline & Reachable and accessible $24 / 7$ care \\
\hline
\end{tabular}




\begin{tabular}{|l|l|}
\hline Education & $\begin{array}{l}\text { Deep knowledge about pathogenesis, clinical presentation, symptoms, } \\
\text { therapies, referrals }\end{array}$ \\
\hline & $\begin{array}{l}\text { Clear and uniform information for patients should be available about the full } \\
\text { range of topics that are relevant, also information for loved-ones. }\end{array}$ \\
\hline Donsemination of knowledge among colleagues and patients \\
\hline & $\begin{array}{l}\text { Offer training for health care professionals (physiotherapist, occupational } \\
\text { therapist, psychologists and dietitians) }\end{array}$ \\
\hline Specialised nurse & $\begin{array}{l}\text { Creation of a network with health care professionals for referral for non- } \\
\text { pharmacological care }\end{array}$ \\
\hline & Specialised nurses should be there for support, education, life style advise \\
\hline Research & Specialised nurses should be available as a first contact person for questions \\
\hline Other & Initiation of research (basic, translational and clinical) \\
\hline & Advocate reimbursement of certain therapies with insurance companies \\
\hline & Arrange peer support \\
\hline & Transparency about care that is provided \\
\hline
\end{tabular}

\section{Where should information about expert status be available?}

\begin{tabular}{|l|l|}
\hline Online & $\begin{array}{l}\text { Website of patient organisations, rheumatology sites from Dutch hospitals, } \\
\text { Dutch Arthritis Foundation, initiatives monitoring quality of care (ARHC, } \\
\text { scientific organisations) }\end{array}$ \\
\hline Leaflets/paper work & $\begin{array}{l}\text { Outpatient clinics of rheumatology departments, in magazine of patient } \\
\text { organisation. }\end{array}$ \\
\hline
\end{tabular}





\section{chapter 5}

\section{Living with systemic sclerosis: exploring its}

impact on caregivers

Disabil Rehabil. 2020;42(11):1632-1633.

Schriemer MR, Spierings J, de Vries-Bouwstra JK, de Pundert AJ, van den Ende CH, Vonk MC, On behalf of the ARCH study group. 
We read with great interest the article of Milette and colleagues, which provides valuable insights in the interaction between patients with systemic sclerosis (SSc) and close relatives, from a patient's perspective.(1) Milette et al. observed that it is paramount for patients with SSc to receive emotional, informational, and instrumental support from their social environment, which is in line with results from earlier studies.(2) Furthermore, Milette et al. reported that communication styles and relational factors influenced the way patients were supported. The authors therefore concluded that rehabilitation programs should pay attention to interventions aiming to improve coping with SSc in a collective way.

In addition - and close relation to their conclusions - our study group would like to emphasize the importance of acknowledging the major role close relatives play in daily care for patients with SSc. Moreover, SSc as a rare, chronic and heterogenous disease with an uncertain horizon presents difficulties not only for patients, but also for their social relationships. Therefore, we would like to extend the attention to caregivers and close relatives of patients with SSc. Their experiences were investigated in a qualitative study in the Netherlands last year (2018), which is, to our knowledge, the first time this perspective was explored in SSc.

We conducted interviews in order to gain more insight in the experiences and unmet needs of caregivers for people with SSc. The interviews were audiotaped and transcribed. The participants verified and approved the reports afterwards. Eight caregivers of patients with SSc (four males, four partners, two widowers, one parent and one friend) participated. Six attended a focus group session, two were interviewed over the phone. Participants reported they faced several challenges in daily life living with or caring for a person with SSc. An overview of the themes and related issues brought forward in our study is provided in Table 1. First, coping with the heterogeneous character of SSc and consequently the uncertainties of the prognosis was mentioned as a huge emotional burden. Secondly, the lack of information about treatment options and limitations in treatment modalities worsened the troubled prospective.

Furthermore, the witness of patients' ailing, changing bodies and poor energy levels without being able to provide a cure, was experienced as a huge burden for all participants. Alongside this distress, the personal lives of partners were also affected; future opportunities were cut off, such as starting a family or continuing an active life style and holidays. With regard to providing of support, caregivers experienced large emotional and sometimes physical demands. They became the main support for the patient. Caregivers addressed invalidation and the decrease in support from others due to misjudgment and misconceptions about severity, duration and impact of the illness. They experienced that over time, this lack of understanding and acknowledgment, resulted in a dwindling network of social and emotional support, affecting family-life, relationships and mental health of both patient and caregiver.

In line with the findings reported by Milette et al, caregivers mentioned to struggle with the complex mutual process of coping with and the lack of frank communication about the condition between the partners, towards their social network and the medical staff. Partly, due to the indolent course of the disease, which made it seldomly an explicit part of the conversation, but also, due to fear of what the future would hold and lack of insight in prognosis. Consistent with reports from patients, caregivers as well reported that care provided at the hospital did not actively involve caregivers, nor provided them with the muchneeded references or information with regard to prognosis, long-term treatment plans or daily care. 
In conclusion, our study illustrates the huge impact of SSc on the lives of caregivers and social relations of patients and challenges they face towards supporting their loved-ones. Caregivers should be more involved in the care of patients with SSc. This supports Milette's et al implication that we should not only support people with SSc by encouraging them to seek support from their close social relationships, but also by providing these close relations with accessible information sources and supportive services.

Table 1. Themes and subthemes with quotes

\begin{tabular}{|c|c|c|c|}
\hline Themes & Subthemes & Issues & Quotes \\
\hline \multirow[t]{4}{*}{ Knowledge } & \multirow[t]{4}{*}{$\begin{array}{l}\text { Lack of } \\
\text { information }\end{array}$} & $\begin{array}{l}\text { Uncertainties due to } \\
\text { heterogeneous character } \\
\text { of SSc }\end{array}$ & \multirow{4}{*}{$\begin{array}{l}\text { "There is just so little information about } \\
\text { SSc." } \\
\text { "We were told that there was no treatment } \\
\text { available." } \\
\text { "If you have cancer, it is at least clear what } \\
\text { you can expect." }\end{array}$} \\
\hline & & $\begin{array}{l}\text { Uncertainties due to } \\
\text { unknown prognosis }\end{array}$ & \\
\hline & & $\begin{array}{l}\text { Limited information about } \\
\text { treatment options }\end{array}$ & \\
\hline & & Misunderstanding & \\
\hline \multirow{7}{*}{$\begin{array}{l}\text { Effect of SSc } \\
\text { on personal } \\
\text { life of } \\
\text { caregivers }\end{array}$} & \multirow{2}{*}{$\begin{array}{l}\text { Providing } \\
\text { support }\end{array}$} & Emotional demands & \multirow{7}{*}{$\begin{array}{l}\text { "I have to decide whether to join social } \\
\text { activities, she is confronted with the } \\
\text { condition so often already." }\end{array}$} \\
\hline & & Physical demands & \\
\hline & \multirow[t]{2}{*}{$\begin{array}{l}\text { Less future } \\
\text { opportunities }\end{array}$} & $\begin{array}{l}\text { Adjust work and other } \\
\text { activities/leisure }\end{array}$ & \\
\hline & & Unwanted childlessness & \\
\hline & \multirow[t]{3}{*}{$\begin{array}{l}\text { Decline of social } \\
\text { network }\end{array}$} & $\begin{array}{l}\text { Decrease in support from } \\
\text { others due to misjudgment }\end{array}$ & \\
\hline & & $\begin{array}{l}\text { Complex condition to } \\
\text { explain to others }\end{array}$ & \\
\hline & & Taboo & \\
\hline \multirow{6}{*}{$\begin{array}{l}\text { Changing } \\
\text { relationship }\end{array}$} & \multirow{2}{*}{$\begin{array}{l}\text { Behavioral } \\
\text { changes }\end{array}$} & Protecting the partner & \multirow{6}{*}{$\begin{array}{l}\text { "My wife did not want to be patronized, } \\
\text { although I sometimes do." } \\
\text { "I am taking care of her } 24 / 7 . " \\
\text { "He does not understand how hard it has } \\
\text { been on me in the past year. I experience } \\
\text { stress about his poor health." } \\
\text { "She wants me to accept her condition, yet } \\
\text { she has not accepted it herself." } \\
\text { "For ten years, I was not allowed to tell } \\
\text { anyone about her condition. I did it, } \\
\text { though, I had to talk about it to empty my } \\
\text { head." }\end{array}$} \\
\hline & & Being the main caregiver & \\
\hline & \multirow{2}{*}{$\begin{array}{l}\text { Physical } \\
\text { changes and } \\
\text { disabilities }\end{array}$} & Poor energy levels & \\
\hline & & Changing bodies & \\
\hline & \multirow[t]{2}{*}{ Communication } & $\begin{array}{l}\text { Avoidance of } \\
\text { communication }\end{array}$ & \\
\hline & & $\begin{array}{l}\text { Differences in process of } \\
\text { coping between caregivers } \\
\text { and patients }\end{array}$ & \\
\hline
\end{tabular}




\section{Chapter 5}

\begin{tabular}{|c|c|c|c|}
\hline \multirow[t]{4}{*}{$\begin{array}{l}\text { Support for } \\
\text { caregivers }\end{array}$} & \multirow{2}{*}{$\begin{array}{l}\text { Involvement of } \\
\text { caregivers in } \\
\text { health care }\end{array}$} & $\begin{array}{l}\text { Few interaction between } \\
\text { physician and caregivers }\end{array}$ & \multirow{4}{*}{$\begin{array}{l}\text { "There is no attention for the limitations, } \\
\text { grieving process we have to go through." } \\
\text { "One simple question that could be helpful, } \\
\text { would be: how do you feel, what is going } \\
\text { on in your head." } \\
\text { "I hoped that I was asked how I felt, how } \\
\text { we feel." } \\
\text { "We have a very kind family who ask } \\
\text { about me too." }\end{array}$} \\
\hline & & $\begin{array}{l}\text { Lack of education or } \\
\text { involvement in decision } \\
\text { making }\end{array}$ & \\
\hline & \multirow[t]{2}{*}{$\begin{array}{l}\text { Support for } \\
\text { caregiver }\end{array}$} & $\begin{array}{l}\text { No attention for caregivers } \\
\text { in health care }\end{array}$ & \\
\hline & & $\begin{array}{l}\text { Support provided by social } \\
\text { contacts for caregiver }\end{array}$ & \\
\hline
\end{tabular}

\section{References}

1. Milette K, Thombs BD, Dewez S, Korner A, Pelaez S. Scleroderma patient perspectives on social support from close social relationships. Disabil Rehabil. 2020;42(11):1588-1598

2. Nakayama A, Tunnicliffe DJ, Thakkar V, Singh-Grewal D, O’Neill S, Craig JC, et al. Patients' Perspectives and Experiences Living with Systemic Sclerosis: A Systematic Review and Thematic Synthesis of Qualitative Studies.J Rheumatol. 2016;43(7):1363-1375 
Exploring the impact of systemic sclerosis on caregivers 
part 2

Autologous stem

cell transplantation

in systemic

sclerosis 
part 2

Pa 


\section{Abstract}

Purpose of review. To provide an overview of recently published work on autologous hematopoietic stem cell transplantation (HSCT) in patients with systemic sclerosis (SSc).

Recent findings. Superiority of HSCT versus intravenous cyclophosphamide pulses was demonstrated in the randomized controlled SCOT trial ( $n=75)$, supporting the results from earlier studies. In SCOT, total body irradiation (TBI) was used instead of the nonmyeloablative regimens used in other trials, and considered safe during a follow-up time of 4.5 years. Three small uncontrolled prospective cohorts $(n=4, n=14$ and $n=18)$ and one retrospective analyses ( $n=18)$, using various nonmyeloablative regimens, also showed improvement in skin involvement and lung volumes post-HSCT. Transplant related toxicity and mortality remain an essential issue in HSCT. High treatment related mortality was reported in one prospective cohort $(n=18)$, using alemtuzumab as a conditioning agent. Furthermore, cardiac complications, either treatment or disease related, require special attention. In translational studies, trends are reported in number of regulatory $T$ cells and diversity of $T$ cell receptor repertoire at baseline and post-HSCT correlating with treatment response.

Summary. There is increasing evidence that patients with rapidly progressive SSc may benefit from HSCT. However, optimal patient selection, pre-transplantation workup and post-transplant management, still have to be established. 


\section{chapter 6}

\section{Hematopoietic stem cell transplantation}

in systemic sclerosis: a review of recent literature 


\section{Introduction}

Diffuse cutaneous systemic sclerosis (dcSSc) is a rare, autoimmune disease characterized by multi-organ involvement and is associated with poor outcomes. Autologous hematopoietic stem cell transplantation (HSCT) is the only therapy in SSc that has shown long-term clinical benefit and has been increasingly performed in SSc in the last decades (1). The 2017 update of the European League Against Rheumatism guideline for the treatment of SSc now recommends consideration of HSCT in rapidly progressive SSc at risk of organ damage, a recommendation adopted in various national guidelines (2,3-5). These recommendations were based on the results of the first randomized controlled trials (ASSIST and ASTIS). (6, 7) In these studies, significant improvement in skin involvement and lung function after HSCT were reported. Additionally, the ASTIS trial reported improvement in event-free survival compared to treatment with cyclophosphamide (CYC) only. In the past few years, research has focused on short- and long-term efficacy and safety of HSCT and identification of determinants of clinical response. In this review, we summarize the results of studies published last year and discuss their implications for clinical practice in the context of established evidence.

\section{Mechanism of action and predictors for clinical response}

The exact mechanism of action in HSCT is unknown. Additional evidence was provided last year about parameters that delineated responders from non-responders. A visual summary is provided in Figure 1. In an earlier study, serum titers of circulating anti-topoisomerase I antibodies were associated with skin improvement post-HSCT (8). Subsequently, binding of this autoantibody with several epitopes associated with SSc was assessed and published last year. Although the number of bound antibodies post-HSCT was decreased significantly in 18 transplanted SSc patients, there was no correlation with clinical response (9). Then, the same authors evaluated molecular recognition patterns of anti-topoisomerase I antibodies towards 45 peptides and compared sera from SSc transplant patients with healthy controls and patients with SSc or other connective tissue diseases. (10) A new epitope was identified to be recognized predominantly by anti-topoisomerase I positive sera. The number of antibodies bound to this specific epitope was significantly lower at baseline in responders compared with non-responders.

Thymic size, as a proxy for thymopoiesis, was assessed in a study with ( $\mathrm{N}=28$ ) SSc patients treated with HSCT. Surprisingly, thymic size decreased eleven months post-HSCT, but did not correlate with treatment response (11). This finding is incompatible with previously reported enlargement of the thymus and T cell repopulation after HSCT (12). However, we could not find any sound explanation for this inconsistent observation.

Alterations in telomeres were studied in 25 SSc patients post-HSCT retrospectively. (13) Patients had high rates of homeostatic proliferation, resulting in increased number of senescent and exhausted cells and telomere attritition uptil three years post-HSCT, reflecting physiological immunological reconstitution also reported in other conditions after HSCT. There were no differences between responders and non-responders with regard to telomere length. PD-1+ (programmed death-1 positive) expression on T cells, and the number of CD8(+)CD28(-) cells expressing CD57 and FoxP3 were increased post-HSCT and PD-1 expression on T- and B-cells was higher in responders $(n=19)$. These factors are 
essential for inducing tolerance, and build on the existing evidence that HSCT induces immunological tolerance.

Another important aspect of a recovering immune system, is the T cell receptor (TCR) repertoire, which was associated with clinical response in a few small studies published earlier (9). A recent study with a long follow-up period (median six years) confirmed these findings; post-HSCT, differences in clonality of TCR repertoire were observed between responders and non-responders (14). This observation was also made in one larger study, including 31 patients. (15) This last study sheds some new light on this subject, additionally reporting an increased number to $B$ regulatory cells in responders compared to non-responders. In conclusion, several studies have tried to identify the immunological mechanism most relevant for remission and to find parameters predictive for clinical response, but so far, the relationship between specific parameters such as immune cell counts, auto-antibodies and cytokines and clinical response is unclear. (16) The diversity of the recently reported findings emphasizes the need for hypothesis-generating studies to unravel the mechanism of action of HSCT.

Figure 1. Summary of recently reported factors associated with response

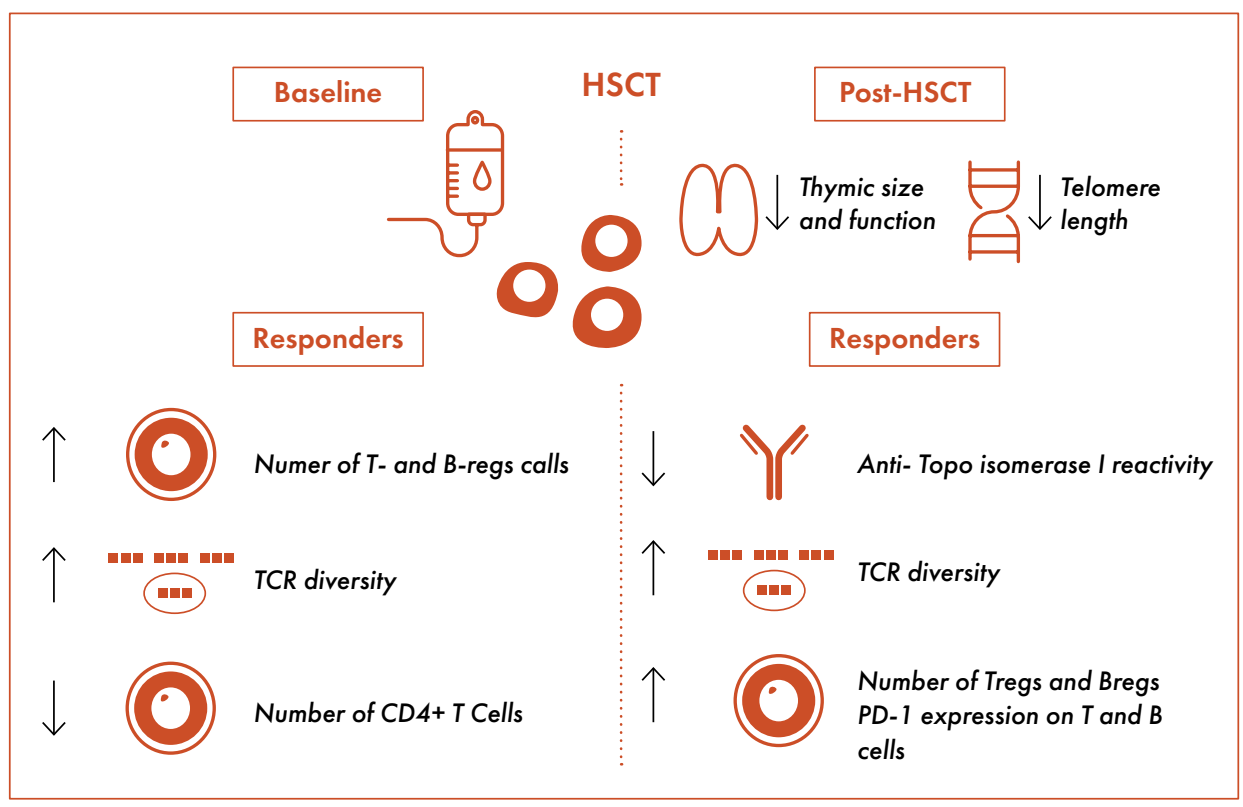

In patients responding to HSCT, numbers of circulating T- and B-regulatory cells were higher and the TCR repertoire was more diverse at baseline and after HSCT, compared with non-responders. The number of CD4+ T cells was lower in responders at baseline. Post-HSCT there was lower reactivity of anti-topoisomerase I against certain epitopes and higher PD- 1 expression on T and B cells in responders. After HSCT thymic function was increased and telomere length was shorter. 


\section{Chapter 6}

\section{Update clinical trials}

In the past year, additional evidence for the beneficial effect of HSCT was reported (Table 1). The studies discussed here also reflect the increased use of HSCT in SSc all over the world and the large variety of conditioning regimens applied.

A small Indian single center study reported the long term results of their first experiences with HSCT in SSc. (17) Four patients with no pre-existing internal organ involvement were treated with a conditioning regimen containing CYC and fludarabine, after which they received unselected autologous stem cells. At four years post HSCT, skin thickening and the frequency of Raynaud's symptoms were significantly decreased in all patients, pulmonary function improved and Gl complaints disappeared. No treatment-related adverse events were reported. A small Japanese uncontrolled clinical trial assessed fourteen patients treated with CYC followed by HSCT. (18) Five patients received a CD34+ selected graft, the other nine received an unselected graft. Patients did not receive rabbit anti-thymocyte globulin (rATG). In the follow-up period of 137 months, overall survival was $93 \%$ and eventfree survival was $40 \%$ at ten years. A relatively high number of six patients (43\%) required additional immunosuppressive treatments due to progression of skin sclerosis and/or interstitial lung disease (ILD) during the follow-up period. This raises the question whether the lack of rATG and CD34+ selection contributed to this high number of relapses and which conditioning regimen is most effective. A Polish prospective cohort study followed $18 \mathrm{dcSSc}$ with a median age of 52 years and disease duration of 14 months. (19) Eleven patients received CYC (median dose $3 \mathrm{~g}$ ) and G-CSF for mobilization, and CYC (median dose 12.3g) and alemtuzumab (median dose, $60 \mathrm{mg}$ ) for conditioning. Two patients received melphalan (140 mg/m2) and alemtuzumab for conditioning, four received CYC and rATG $(7.5 \mathrm{mg} / \mathrm{kg}$ ) and one only received CYC. Eleven patients were alive after a median follow-up of 42 months and experienced a significant decrease in mRSS, but no change in lung function. Unfortunately, 45\% experienced disease progression requiring immunosuppressive therapy.

Secondly, support for the superiority of high-dose immunosuppressive therapy followed by HSCT over CYC alone was provided in two other studies. In an Italian retrospective study, treatment effects of eighteen dcSSc patients treated with HSCT were compared with 36 dcSSc patients treated with CYC ( $n=25,1$ gram monthly for 6 months) or other conventional therapies ( $n=11$, methotrexate, azathioprine and/or methylprednisolone). (20) Again improvement of skin involvement and pulmonary volumes was observed in long-term (60 months) follow-up and diffusing capacity remained stable. There was a survival benefit in the patients who received HSCT.

The long awaited results of the American Scleroderma: Cyclophosphamide or Transplantation Trial (SCOT) underscore the previously demonstrated efficacy of HSCT. Seventy-four dcSSc patients were randomized to undergo either treatment with 12 monthly iv CYC pulses or a myeloablative regimen, using total body irradiation and CYC at a lower than usual dose $(120 \mathrm{mg} / \mathrm{kg})$, followed by HSCT. Thirty-six participants received HSCT and 39 were only treated with CYC pulses (21). Unfortunately, accrual of patients in the study was more difficult than expected, and it was anticipated that the adjusted projected enrollment of patients in this study would not allow analysis using established endpoints, such as eventfree survival and overall survival. Thus, a composite score was composed to compare both treatment groups. The authors conclude that with regard to this global rank composite score (GRCS), myeloablative conditioning followed by HSCT is superior to cyclophosphamide. The use of post-transplantation immunosuppression (DMARDs) was also significantly higher in 
the CYC group (44\% versus $9 \%, P=0.001)$. The use of a different conditioning regimen and different, more stringent criteria for patient selection (all patients with cardiac involvement were excluded in the SCOT trial) complicate comparison with earlier trials. Furthermore, the study was underpowered to draw any firm conclusions with regard to event free survival and overall survival.

Table 1. Overview of recently published clinical studies and results.

\begin{tabular}{|c|c|c|c|c|c|c|c|}
\hline Study & Design, $\mathbf{N}$ & $\begin{array}{l}\text { Median } \\
\text { age } \\
\text { (yrs) }\end{array}$ & $\begin{array}{l}\text { Median } \\
\text { disease } \\
\text { duration } \\
\text { (yrs) }\end{array}$ & $\begin{array}{l}\text { Follow- } \\
\text { up (yrs) }\end{array}$ & $\begin{array}{l}\text { Received } \\
\text { treatment }\end{array}$ & $\begin{array}{l}\text { CD34+ } \\
\text { selection }\end{array}$ & $\begin{array}{l}\text { TRM } \\
n \\
(\%)\end{array}$ \\
\hline \multicolumn{8}{|c|}{ Randomized controlled trials } \\
\hline $\begin{array}{l}\text { Sullivan et } \\
\text { al, } 2018 . \\
\text { USA (21) }\end{array}$ & $\begin{array}{l}\mathrm{RCT} \\
\mathrm{N}=75\end{array}$ & 45.9 & 2.3 & 4.5 & $\begin{array}{l}\text { A. mob: G-CSF. Con: } \\
\text { TBI, CYC ( } 120 \mathrm{mg} / \\
\mathrm{kg}) \text {, rATG }(90 \mathrm{mg} / \\
\mathrm{kg}) \\
\text { B. Monthly CYC }(750 \\
\mathrm{mg} / \mathrm{m} 2 \times 12)\end{array}$ & yes & $1(3)$ \\
\hline \multicolumn{8}{|l|}{ Other } \\
\hline $\begin{array}{l}\text { Del Papa } \\
\text { et al, } 2017 . \\
\text { Italy }(20)\end{array}$ & $\begin{array}{l}\text { Retrospective } \\
\text { study } \\
\mathrm{N}=18 \\
\text { Matched } \\
\text { controls } 36\end{array}$ & 41 & 2.0 & 5 & $\begin{array}{l}\text { HSCT group: Mob: } \\
\text { CYC (2g/m2 2d) + } \\
\text { G-CFS 10ug/kg). } \\
\text { Con: CYC (60mg/ } \\
\mathrm{kg})+\mathrm{rATG}(3.5 \mathrm{mg} / \\
\mathrm{kg}) \\
\text { Control group: } 1 \mathrm{gr} \\
\times 6(\mathrm{~N}=25), M T X \\
\text { AZA and/or MP } \\
(\mathrm{N}=11)\end{array}$ & yes & $\begin{array}{l}1 \\
\text { (5.6) }\end{array}$ \\
\hline $\begin{array}{l}\text { Helbig et } \\
\text { al } 2017 . \\
\text { Poland (19) }\end{array}$ & $\begin{array}{l}\text { Prospective } \\
\text { observational } \\
\text { study } \\
\mathrm{N}=18\end{array}$ & 52 & 1.2 & 3.5 & $\begin{array}{l}\text { HSCT group: } \\
\text { Mob: CYC }(2 \mathrm{~g} / \mathrm{m} 2 \\
2 \mathrm{~d})+\mathrm{G}-\mathrm{CFS} 10 \mathrm{ug} / \\
\mathrm{kg}) . \text { Con: } \\
\text { CYC }(200 \mathrm{mg} / \mathrm{kg})+ \\
\text { alemtuzumab }(\mathrm{med} \\
60 \mathrm{mg})(\mathrm{N}=11), \\
\text { MEL }(140 \mathrm{mg} / \\
\mathrm{m} 2)+ \text { alemtuzumab } \\
(\mathrm{N}=2), \mathrm{CYC}+\mathrm{rATG} \\
(7.5 \mathrm{mg} / \mathrm{kg})(\mathrm{N}=4), \\
\mathrm{CYC} \\
(\mathrm{N}=1)\end{array}$ & yes & $\begin{array}{l}4 \\
(22)\end{array}$ \\
\hline $\begin{array}{l}\text { Nair et al, } \\
2018 \text {, India } \\
\text { (17) }\end{array}$ & $\begin{array}{l}\text { Prospective } \\
\text { observational } \\
\text { study } \\
\mathrm{N}=4\end{array}$ & 30 & 2.8 & 4 & $\begin{array}{l}\text { Mob: CYC }(2 \mathrm{~g} / \\
\mathrm{m} 2)+\mathrm{G}-\mathrm{CFS} \text {. Con: } 2 \mathrm{~d} \\
\text { fludarabine } 30 \mathrm{mg} \text {, } \\
\text { CYC }(60 \mathrm{mg} / \mathrm{kg})+ \\
\text { rATG }(3.5 \mathrm{mg} / \mathrm{kg})\end{array}$ & no & $0(0)$ \\
\hline $\begin{array}{l}\text { Nakamura } \\
\text { et al } 2018 \text {, } \\
\text { Japan (18) }\end{array}$ & $\begin{array}{l}\text { Phase II study } \\
N=14\end{array}$ & 44.5 & 1.8 & 11.4 & unknown & $\begin{array}{l}\text { no } n=9 \\
\text { yes } n=5\end{array}$ & $1(7)$ \\
\hline
\end{tabular}

AZA: azathioprine, Con: conditioning, CYC: cyclophosphamide, D: day, GRCS: global rank composite score, MEL: melphalan, mob: mobilization, MP: methylprednisolone, mRSS: modified Rodnan skin score, MTX: methotrexate, rATG: rabbit anti-thymocyte globulin, RCT: randomized controlled trial, TBl: total body irradiation, yrs: years 


\section{Chapter 6}

No less than three systematic reviews were published last year. (22-24) Two reviews concluded that the high heterogeneity prevented meta-analysis $(23,24)$. Still, one metaanalysis was performed, only including three RCTs and one observational study (total $\mathrm{N}=304$ ). A reduction in all-cause mortality (Risk Ratio (RR) of 0.5 [95\% $\mathrm{Cl} 0.33-0.75]$ ) and significant improvement of pulmonary function and quality of life was reported (24). However, for pulmonary function and quality of life, data from only two RCTs (ASSIST and ASTIS) was pooled.

\section{Safety issues}

Transplant related toxicity and mortality remain an essential issue in HSCT. Interestingly, most of the studies published last year reported lower rates of TRM, compared to previously performed studies. In the small Italian retrospective study TRM was 5,6\% ( $n=1)$ due to interstitial pneumonitis (20). There was a survival benefit in the patients who received HSCT, compared with 36 matched controls. In the Japanese phase two trial, adverse events related to HSCT occurred in six patients (43\%), fatal cardiomyopathy was reported in one patient (18). TRM was highly variable in the meta-analysis (RR 9.00 (95\% Cl, 1.57-51.69])(22). The SCOT trial reported a TRM of $3 \%(n=1, p=0.48)$ at 54 months and $6 \%(n=4)$ at 72 months, as compared with $0 \%$ in the cyclophosphamide group. This relatively low percentage in the HSCT group, could probably partly be attributed to the exclusion of patients with cardiac involvement. Comparison with earlier RCTs is again difficult, because of the relatively small number of patients in the SCOT trial and the low occurrence of TRM in both trials ( 4 in the SCOT, 8 in the ASTIS). Furthermore, it is not clear if definitions for TRM were applied the same in all studies.

In contrast with the reported decreased TRM, the Polish prospective cohort study reported TRM of $22 \%(n=4)$ after median follow-up of 42 months (19). Four patients died early after transplant due to bilateral pneumonia followed by multi-organ failure in three patients and myocardial infarction in one. Authors attribute the high mortality rate to the administration of alemtuzumab causing life-threatening infectious complications.

Overall, toxicity related to treatment can be attributed to the different immunosuppressant treatments used during the mobilization and conditioning prior to HSCT and is mainly caused by cardiotoxicity and infections.

\section{Cardiotoxicity}

The heart is commonly involved in SSc, often subclinically and cardiac failure is an important cause of death in patients with rapidly progressive dcSSc (25). Furthermore, treatment related cardiotoxicity is a major cause of mortality and morbidity, and discussion about cause, treatment and prevention is still ongoing.

Although there are some reports about CYC-induced cardiotoxicity after HSCT in SSc patients, it is not clear how to prevent it or identify patients at risk. No study clearly reported that CYC itself leads to more complications in patients with known cardiac involvement prior to HSCT. Importantly, it cannot always be predicted, as was illustrated by a report describing a case of fatal heart failure post-HSCT in a patient without cardiac disease pre-treatment. (25) The patient developed CYC-induced hemorrhagic pericarditis with an intra-cavity thrombus shortly after the conditioning regimen (histological evidence was obtained after autopsy). 
Still, the risk of cardiac complications in HSCT in patients with decreased cardiac function should be underlined due to the higher cardiac demand in conditions such as transplantrelated fever, neutropenic infection and saline overload during the procedure (figure 2) (26). Furthermore, presence of cardiac disease might reflect extensive organ involvement, longer disease duration and/or a poor overall performance state, which can all be associated with poor outcome.

Thus, probably to prevent complications, in the SCOT trial, all patients with cardiac involvement were excluded, though it was not clear what their definition of "cardiac involvement' was. Also, in a recently published review, extensive cardiac screening before HSCT was recommended, including echocardiogram with tissue Doppler plus dobutamine stress test, cardiac MRI with contrast, cardiac catheterization with fluid challenge and holter.(27) If any of these investigations are abnormal, exclusion from HSCT was suggested. In addition to the invasiveness of the tests and the financial costs of this exhausting screening program, there is insufficient evidence that patient with mildly decreased cardiac function should be excluded for treatment.

Recent literature thus does not shed much light on the quintessential dilemma of which specific patients should be offered the treatment; the adage that treatment risks have to be balanced against the considerable benefits of HSCT remains true. To move the field forward, and provide patients with the best possible treatment, the exclusion of patient groups for whom no other option exists without solid evidence, warrants open discussion.

Figure 2. Causes of cardiac complications during and after HSCT

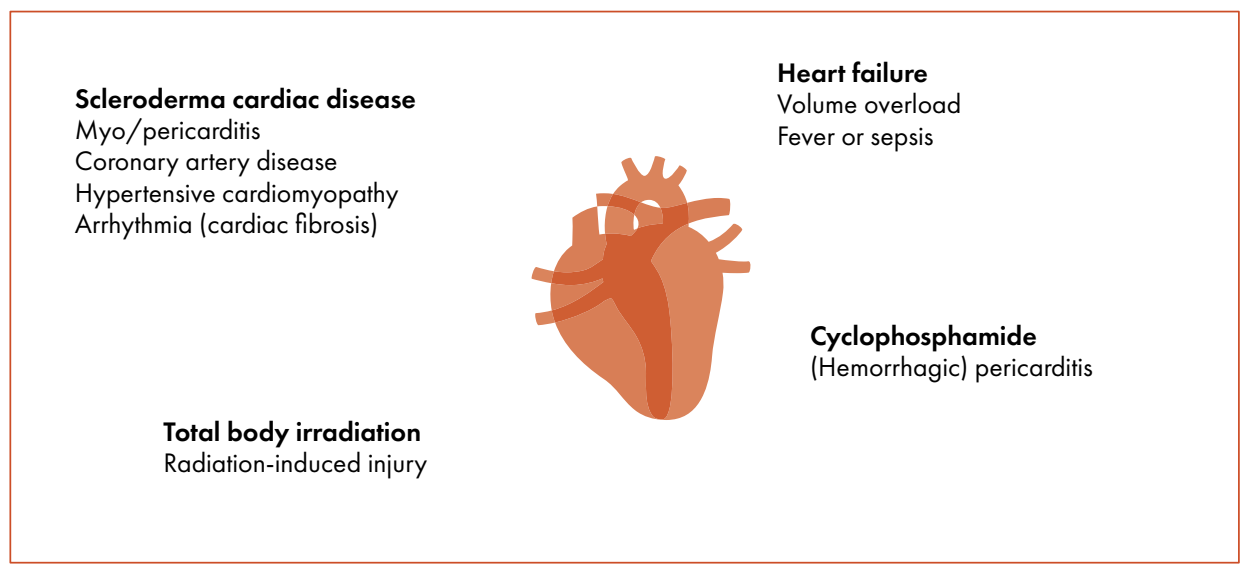

Several factors contribute to the higher risk of cardiac complication during and after HSCT. Scleroderma heart disease is diverse, including myo-and pericarditis and hypertensive cardiomyopathy as a result of scleroderma renal crisis. Furthermore cardiac fibrosis can lead to life-threatening arrhythmia. At last, chronic inflammatory diseases are associated with coronary heart disease. Although rare, toxicity caused by treatment regimens includes injury related to CYC or TBI. In patients with decreased cardiac function, heart failure can develop following the higher cardiac demand in conditions such as fever and saline overload during the procedure. 


\section{Chapter 6}

\section{Infections}

With regard to infectious complications of HSCT, earlier trials mostly reported (mild) viral reactivation (including Epstein-Barr virus (EBV)). In the SCOT trial more severe infections were reported in the HSCT group (rate 0.21 vs. 0.13, $P=0.09$ ). There was one case of fatal enterococcal meningitis. Viral infections included Varicella Zoster infections and cytomegalovirus reactivation occurred more often after transplantation (13 vs. 1 and 5 vs. 0 , respectively) (21). In the retrospective study performed in Italy, five patients developed fever with positive blood culture and three had pneumonia, all treated adequately with antibiotics (20). In the Polish cohort, three patients experienced fatal bilateral pneumonia, early after HSCT (19). Viral infections were seen in $28 \%$ of patients post-HSCT in this study. In this group, 2 (11\%) patients developed EBV-related lymphoproliferative disease. This complication was also reported in a small number of patients in the ASTIS trial. These findings, while not unexpected, emphasize the necessity of adequate antiviral prophylaxis and regular screening for EBV reactivation.

\section{Implications for further research}

Aside from enabling directed research into HSCT in SSc, more insight in the cellular and molecular actors responsible for the beneficial effect of HSCT may aid in predicting response and subsequently providing personalized care, such as pre-emptive post-transplant immunosuppression for patients who are predicted to respond poorly. Post-transplantation progression rate is still remarkably high, further research on optimal post-transplantation management is therefore needed and is currently investigated in two studies (NCT01413100 and NCT02516124). Additionally, given the finding in both ASTIS and SCOT trials that prior treatment with CYC may be associated with worse outcomes after HSCT, it can be questioned whether HSCT should be offered rather as a first-line treatment in early rapidly progressive dcSSc patients. Larger studies comparing different timing of HSCT, different and less toxic conditioning regimens (currently investigated: NCT00622895 and NCT01445821), investigating adapted conditioning regimens for patients with pre-existing cardiac involvement and use of post-HSCT immunosuppression, could support decision making in clinical practice.

\section{Conclusion}

Overall, last year additional evidence was provided confirming the long-term treatment benefits of HSCT in dcSSc. TRM should be weighed against the severity of the disease and remains an important factor in decision making. Small sample sizes, differences in patient selection, follow-up duration and treatment regimens complicate comparison between the studies performed. Further studies should help to identify subgroups in whom HSCT would be most beneficial, optimal cardiac screening and optimal conditioning regimens, especially in patients with cardiac involvement. 


\section{References}

1. Snowden JA, Badoglio M, Labopin M, GiebelS, McGrath E, Marjanovic Z et al. Evolution, trends, outcomes, and economics of hematopoietic stem cell transplantation in severe autoimmune diseases. Blood Adv. 2017;1(27):2742-2755.

2. Kowal-Bielecka O, Fransen J, Avouac J, Becker M, Kulak A, Allanore Y et al. Update of EULAR recommendations for the treatment of systemic sclerosis. Ann Rheum Dis. 2017;76(8):1327-1339.

3. van Rhijn-Brouwer FCC, Vonk MC, van der Velden WJFM, Voskuyl AE, van de Loosdrecht AA, de VriesBouwstra JK et al. Consensusdocument: Autologe hematopoïetische stamceltransplantatie bij ernstige diffuse cutane systemische sclerose. NTvR. 2016;3:17-23.

4. Pugnet G, Castilla-Llorente C, Puyade M, Terriou L, Badoglio M, Deligny C et al. Indications and follow-up for autologous hematopoietic stem cell transplantation in autoimmune and autoinflammatory diseases: Guidelines from the Francophone Society of Bone Marrow Transplantation and Cellular Therapy (SFGM-TC). Bulletin du cancer. 2017;104(12s):S169-s180.

5. Denton CP, Hughes M, Gak N, Vila J, Buch MH, Chakravarty K et al. BSR and BHPR guideline for the treatment of systemic sclerosis. Rheumatology. 2016;55(10):1906-1910.

6. van Laar JM, Farge D, Sont JK, Naraghi K, Marjanovic Z, Larghero J et al. Autologous hematopoietic stem cell transplantation vs intravenous pulse cyclophosphamide in diffuse cutaneous systemic sclerosis: a randomized clinical trial. JAMA. 2014;311(24):2490-2498.

7. Burt RK, Shah SJ, Dill K, Grant T, Gheorghiade M, Schroeder J et al. Autologous non-myeloablative haemopoietic stem-cell transplantation compared with pulse cyclophosphamide once per month for systemic sclerosis (ASSIST): an open-label, randomised phase 2 trial. Lancet. 2011;378(9790):498-506.

8. Tsukamoto H, Nagafuji K, Horiuchi T, Kimoto Y, Akahoshi M, Arinobu Y et al. Analysis of immune reconstitution after autologous CD34+ stem/progenitor cell transplantation for systemic sclerosis: predominant reconstitution of Th1 CD4+ T cells. Rheumatology. 2011;50(5):944-952.

9. Henes J, Glaeser L, Kotter I, Vogel W, Kanz L, Klein R. Analysis of anti-topoisomerase I antibodies in patients with systemic sclerosis before and after autologous stem cell transplantation. Rheumatology. 2017;56(3):451-456.

10. Glaeser L, Henes J, Kotter I, Vogel W, Kanz L, Klein R. Molecular recognition patterns of antitopoisomerase I-antibodies in patients with systemic sclerosis before and after autologous stem cell transplantation. Clin Exp Rheumatol. 2018;36 Suppl 113(4):28-35.

11. Henes JC, Wirths S, Vogel W, Xenitidis T, Kanz L, Horger M. Thymic findings before and after autologous stem cell transplantation for severe systemic sclerosis: a retrospective study using computed tomography in the pre- and post-transplantation setting. Clin Exp Rheumatol. 2017;35 Suppl 104(2):112.

12. Storek J, Zhao Z, Lin E, Berger T, McSweeney PA, Nash RA et al. Recovery from and consequences of severe iatrogenic lymphopenia (induced to treat autoimmune diseases). Clin Immunol. 2004;113(3):285298.

13. Arruda LCM, Lima-Junior JR, Clave E, Moraes DA, Douay C, Fournier I et al. Homeostatic proliferation leads to telomere attrition and increased PD-1 expression after autologous hematopoietic SCT for systemic sclerosis. Bone Marrow Transplant. 2018;53(10):1319-1327.

14. Farge D, Arruda LCM, Brigant F, Clave E, Douay C, Marjanovic Z, et al. Long-term immune reconstitution and $T$ cell repertoire analysis after autologous hematopoietic stem cell transplantation in systemic sclerosis patients. J Hematol Oncol. 2017;19;10(1):21.

15. Arruda LCM, Malmegrim KCR, Lima-Junior JR, Clave E, Dias JBE, Moraes DA, et al. Immune rebound associates with a favorable clinical response to autologous HSCT in systemic sclerosis patients. Blood Adv. 2018;2(2):126-141.

16. van Rhijn-Brouwer FCC, Spierings J, van Laar JM. Autologous hematopoietic stem cell transplantation in systemic sclerosis: a reset to tolerance? Immunol Lett. 2018;195:88-96

17. Nair V, Vasdev V, Kumar A, Shankar S, Nair V, Sharma A. Stem cell transplant in systemic sclerosis: An Indian experience. Int J Rheum Dis. 2018;21(4):859-865.

18. Nakamura H, Odani T, Yasuda S, Noguchi A, Fujieda Y, Kato M et al. Autologous haematopoietic stem cell transplantation for Japanese patients with systemic sclerosis: Long-term follow-up on a phase II trial and treatment-related fatal cardiomyopathy. Mod Rheumatol. 2018;28(5):879-884.

19. Helbig G, Widuchowska M, KoclDga A, KopiDska A, KopeD-MDdrek M, Gaweł WB et al. Safety profile of autologous hematopoietic stem cell mobilization and transplantation in patients with systemic sclerosis. Clin Rheumatol. 2018;37(6):1709-1714. 


\section{Chapter 6}

20. Del Papa N, Onida F, Zaccara E, Saporiti G, Maglione W, Tagliaferri E et al. Autologous hematopoietic stem cell transplantation has better outcomes than conventional therapies in patients with rapidly progressive systemic sclerosis. Bone Marrow Transplant. 2017;52(1):53-58.

21. Sullivan KM, Goldmuntz EA, Keyes-Elstein L, McSweeney PA, Pinckney A, Welch B et al. Myeloablative Autologous Stem-Cell Transplantation for Severe Scleroderma. New Engl J Med. 2018;378(1):35-47.

22. Shouval R, Furie N, Raanani P, Nagler A, Gafter-Gvili A. Autologous Hematopoietic Stem Cell Transplantation for Systemic Sclerosis: A Systematic Review and Meta-Analysis. Biol Blood Marrow Transplant. 2018;24(5):937-944.

23. Host L, Nikpour M, Calderone A, Cannell P, Roddy J. Autologous stem cell transplantation in systemic sclerosis: a systematic review. Clin Exp Rheumatol. 2017;35 Suppl 106(4):198-207.

24. Eyraud A, Scouppe L, Barnetche T, Forcade E, Lazaro E, Duffau P et al. Efficacy and safety of autologous haematopoietic stem cell transplantation in systemic sclerosis: A systematic review of literature. Br J Dermatol. 2018;178(3):650-658.

25. Martin M, Fornecker LM, Marcellin L, Mousseaux E, Hij A, Snowden JA et al. Acute and fatal cardiotoxicity following high-dose cyclophosphamide in a patient undergoing autologous stem cell transplantation for systemic sclerosis despite satisfactory cardiopulmonary screening. Bone Marrow Transplant. 2017;52(12):1674-1677.

26. Burt RK, Oliveira MC, Shah SJ. Cardiac involvement and treatment-related mortality after nonmyeloablative haemopoietic stem-cell transplantation with unselected autologous peripheral blood for patients with systemic sclerosis: a retrospective analysis. Lancet 2013;381(9872):1116-1124.

27. Farge D, Burt RK, Oliveira MC, Mousseaux E, Rovira M, Marjanovic Z et al. Cardiopulmonary assessment of patients with systemic sclerosis for hematopoietic stem cell transplantation: recommendations from the European Society for Blood and Marrow Transplantation Autoimmune Diseases Working Party and collaborating partners. Bone Marrow Transplant. 2017;52(11):1495-1503. 
Stem cell transplantation in systemic sclerosis 


\section{Abstract}

Objectives. To examine the treatment decision-making process of patients with diffuse cutaneous systemic sclerosis (dcSSc) in the context of hematopoietic stem cell transplantation (HSCT).

Methods. A qualitative semi-structured interview study was done in patients before or after HSCT, or patients who chose another treatment than HSCT. Thematic analysis was used. Shared decision-making (SDM) was assessed with the SDM-Q-9.

Results. Twenty-five patients (sixteen male/nine female, median age 47 years (range 27-68)) were interviewed: five pre-HSCT, sixteen post-HSCT and four following other treatment. Whereas the SDM-Q-9 showed the decision-making process was perceived as shared (median score 81/100 (range 49-100)), we learned from the interviews that the decision was predominantly made by the rheumatologist, and patients were often steered towards a treatment option. Strong guidance of the rheumatologist was appreciated because of a lack of accessible, reliable and SSc-specific information, due to the approach of the decision-making process of the rheumatologist, the large consequence of the decision and the trust in their doctor. Expectations of outcomes and risks also differed between patients. Furthermore, more than half of patients felt they had no choice than to go for HSCT, due to rapid deterioration of health and the perception of HSCT as 'the holy grail.'

Conclusion. This is the first study that provides insight in the decision-making process in dcSSc. This process is negatively impacted by a lack of disease-specific education about treatment options. Additionally, we recommend to explore patient's preferences and understanding of the illness to optimally guide decision-making and to provide tailormade information.

\section{Key messages}

$\rightarrow$ Decision-making is strongly guided by the rheumatologist in patients with diffuse cutaneous systemic sclerosis.

$\rightarrow$ Health status, expectations, knowledge and interactions with the rheumatologist and social contacts influence treatment decision-making. $\rightarrow$ The lack of disease-specific and accessible information hinders patients in making a balanced treatment decision. 


\section{chapter 7}

\section{Treatment \\ decision-making in diffuse cutaneous systemic sclerosis: a patient's perspective}

Rheumatology (Oxford). 2020;59(8):2052-2061.

Spierings J, van Rhijn- Brouwer FCC, de Bresser JM, Vonk MC, Voskuyl AE, de Vries-Bouwstra JK, Pieterse AH, Kars MC, van Laar JM. 


\section{Introduction}

Systemic sclerosis (SSc) is a debilitating and incurable autoimmune connective tissue disease. The five-year mortality for diffuse cutaneous SSc (dcSSc) with rapid increase in skin involvement and development of organ fibrosis is approximately $25 \% .(1,2)$ In dcSSc, immunosuppressive or cytotoxic agents such as mycophenolate mofetil, methotrexate and cyclophosphamide are widely used.(3) Autologous hematopoietic stem cell transplantation (HSCT) is often regarded as the last treatment option in dcSSc. HSCT has been shown to lead to superior outcomes with regard to survival, quality of life, skin fibrosis and prevention of disease progression in comparison with intravenous cyclophosphamide.(4-6) HSCT has since been implemented in (inter)national treatment guidelines for dcSSc and is offered in clinical care. $(7,8)$ There are, however, no specific guidelines on patient selection or optimal timing for HSCT, and the value of HSCT as treatment regimen compared to other available immunosuppressive therapies is unclear. Importantly, despite evidence for the superior long-term benefits, HSCT carries a treatment-related mortality between three and 10\% in the first year following treatment.(9) Therefore, treatment choice is primarily based on the preferences of the patient and rheumatologist. It is important that rheumatologists and multidisciplinary teams treating patients with dcSSc, facilitate patients to arrive at a decision that is aligned to his/her preferences.

Shared decision-making (SDM) is defined as 'an approach where clinicians and patients share the best available evidence when faced with the task of making decisions, and where patients are supported to consider options, to achieve informed preferences.(10) SDM is a means to incorporate patient preferences in treatment decisions.(11) Unfortunately, there is not much experience with regard to SDM and optimal patient education for HSCT in dcSSc or other life-threatening autoimmune diseases.(12) The aim of this study was to get insight in and improve understanding of the decision-making process in dcSSc in order to identify ways to support SDM in this group of patients.

\section{Methods}

\section{Design}

In this exploratory qualitative study, interviews were conducted and thematically analysed. $(13-15)$

\section{Patients}

A purposeful sample of patients with dcSSc who were scheduled for HSCT, who had already undergone HSCT, or who chose another treatment than HSCT, were recruited from the four university hospitals in the Netherlands which offer HSCT in dcSSc (University Medical Centre Utrecht, Leiden University Medical Centre, Amsterdam UMC- Vrije Universiteit, Radboud University Medical Centre Nijmegen). Heterogeneity was sought with regard to treatment history, outcomes, participation in a randomized clinical trial, disease duration, marital status, level of education, age and gender. Non-Dutch speaking patients were excluded. Rheumatologists were informed about the sampling criteria, and approached the patients. Consenting patients were invited for an interview at a convenient moment and written informed consent was obtained prior to the interview. This study was classified by the institutional review board as exempt of the Medical Research Involving Human Subjects Act (17-836/C). 


\section{Data collection}

To facilitate the in depth, semi-structured, face-to-face interviews an interview guide with open-ended questions and a topic list was made (see Supplementary appendix S1). (16) Questions aimed to explore the decision-making process, including information provision, patient expectations, patient-physician interaction, and external factors (see Supplementary appendix S1). On the day of the interview, prior to the interview, patients completed a questionnaire assessing sociodemographic and disease characteristics. The extent to which patients perceived that shared decision-making had occurred, was assessed using the SDM-Q-9, which contains nine items scored on a six-point Likert scale from 0 (completely disagree) to 5 (completely agree). Total transformed scores range from 0 to 100 (17); higher scores denote higher perceived SDM (see Supplementary appendix S2). Daily functioning and health-related quality of life (HR-QoL) were assessed using the Scleroderma Health Assessment Questionnaire (SHAQ, range scores: 0-3)(18) and the EuroQoL-5 Dimension-5 Levels (EQ-5D-5L, range scores, 0-1)(19) respectively. Higher scores on the scales denote worse functioning and better health-related quality of life, respectively (see Supplementary appendices S3 and S4). The SDM-Q, EQ5D-5L and SHAQ questionnaires were completed at the same day of the interview. The interview was conducted by one investigator (JS or FR). First, a senior researcher (MK) read and discussed the transcripts of the first two interviews in order to improve the interview style and technique to collect rich data. Interview experiences were shared to foster similarity in how the patients were approached, i.e. the used interviewing techniques and setting of the interview. Prior to the interview, the investigator explained the research goals, and took time to answer questions and make patients feel at ease.(20) At inclusion names of patients were replaced by a code. An independent researcher $(\mathrm{JdB})$ transcribed the interviews verbatim and anonymized the transcripts (e.g. names of persons and hospitals were deleted from the texts).(21) The manuscript was read and evaluated by a representative of the patient sounding board (PM).

\section{Data analyses}

An inductive thematic analysis was performed, themes were identified and described.(14, 22-25) Transcripts were analyzed using the constant comparative technique.(14) The two interviewers independently coded the data, using the software program Nvivo12.(26) Codes are meaningful fragments in relation to the research, it is the first step to sort the data for further interpretation.(14) Contraditories were discussed aimed to reach intersubjective agreement. The different codes were grouped into themes and subthemes. Themes are defined as patterns of meaning resulting from the codes, subthemes are patterns identified within a certain theme. The categorization, definition and refining of themes and subthemes was done by JS and independently checked by FR, JdB and MK.

Saturation was assessed at a conceptual level.(25) FR and JS determined if a new interview added new codes. When data saturation was reached, inclusion of patients was closed. The consolidated criteria for reporting qualitative research (COREQ) were followed.(27) Scores of the questionnaires were calculated according to validated formulas. Quantitative data were analyzed using the Statistical Package for Social Sciences (SPSS) version 21.0. Descriptive statistics (median and range) were used to present socio-economic data and disease characteristics. 


\section{Results}

\section{Patients}

Twenty-six patients were invited to participate in the study. One patient declined participation due to poor health condition. Twenty-five patients were interviewed. Patient characteristics are shown in Table 1. Patients were interviewed face-to-face at the hospital after a scheduled medical appointment $(n=23)$, at their office $(n=1)$, or at their home $(n=1)$.

Table 1. Patient characteristics

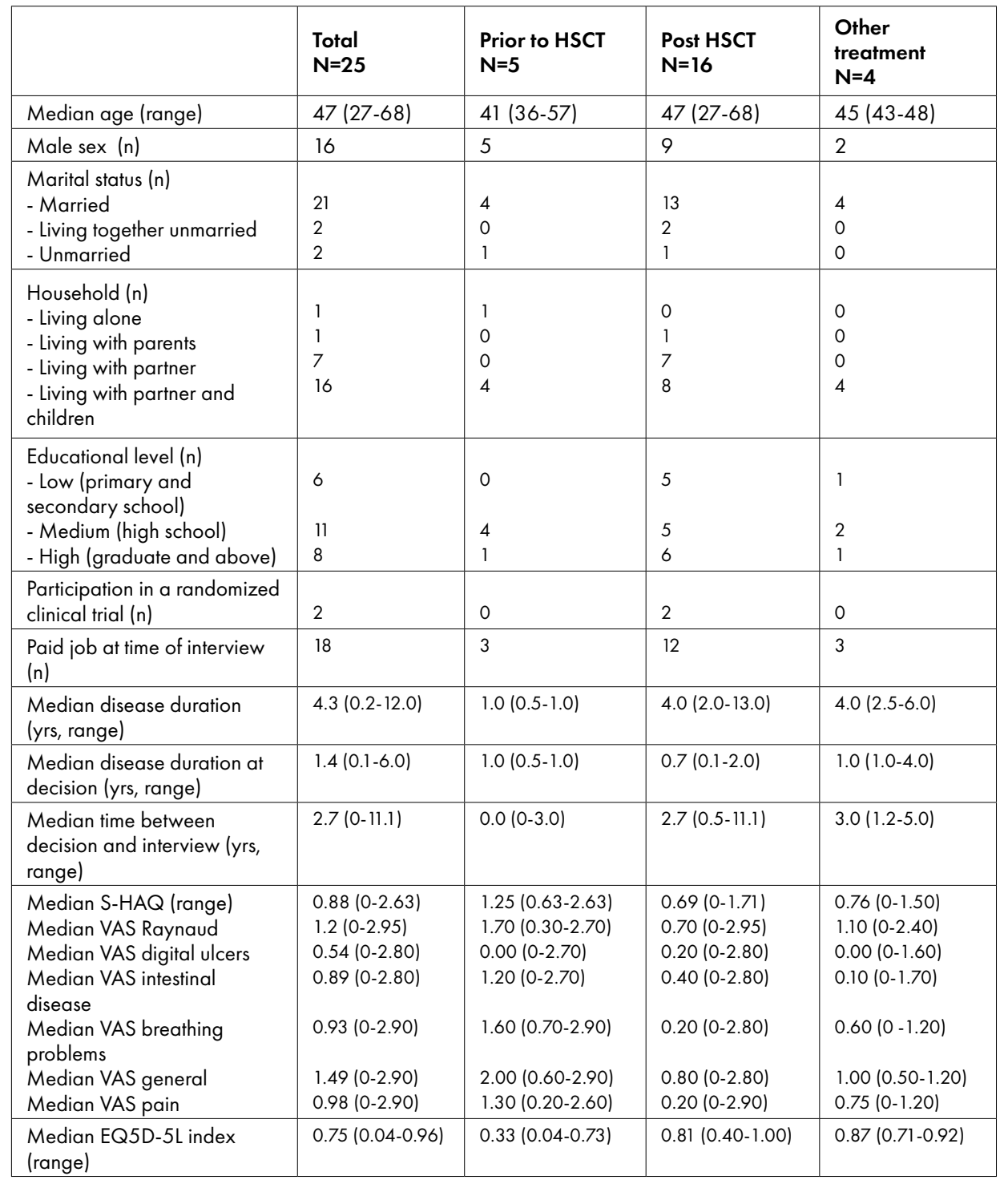

EQ-5D-5L, Euroqol 5 dimensions 5 levels; HSCT, hematopoietic stem cell transplantation; S-HAQ; Scleroderma Health Assessment Questionnaire (range 0-3). VAS, visual analogue scale. VAS scales ranges from 0 (no complaints) - 3 (severe complaints). 


\section{Treatment decision-making approaches}

Three different approaches to decision-making were identified from the patients' stories. Six patients reported that options were presented sequentially, with the next option offered only when the previous option had failed or the patient had declined it (Figure 1A). Nine patients were offered multiple treatment options as part of a stepwise treatment plan, with an a priori preferred order of options (Figure 1B). Ten patients were offered multiple options without an a priori order, which was the preferred approach according to patients (Figure 1C). Four patients who were offered treatment options sequentially, mentioned that they could not see all treatment options in perspective or get a clear overview of alternative treatments. They felt they did not really have a choice.

Across the centres and across rheumatologists, there were differences in approaches, however these differences were not significant.

Figure 1. Three approaches to discuss treatment options and making decisions. Three approaches were identified in discussion of treatment options with patients. Approach A: rheumatologist presents options sequentially. In approach B: a multi-step treatment plan was proposed and in C: rheumatologist presents options concurrently.

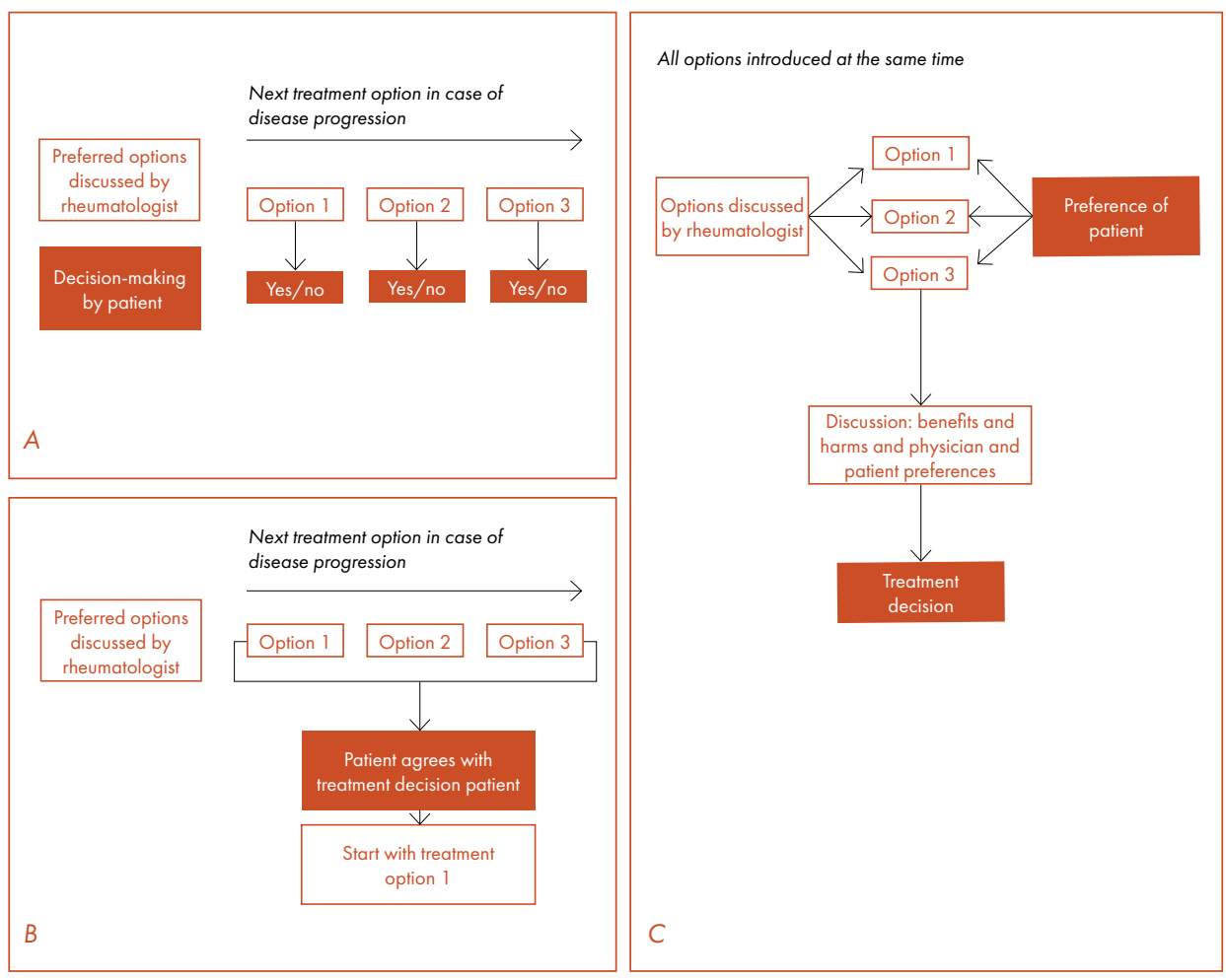




\section{Identified themes in the decision-making process}

Six main themes were identified to play a role in patients' decision-making. The themes with subthemes and associated issues are shown in Table 2. Illustrative quotes are presented in Table 3.

\section{Poor prospects and low quality of life: leaving no other option}

Prior to the decision-making process, most patients $(n=22)$ were shocked to learn that dcSSc has a poor prognosis, especially as none of the patients except one had ever heard of SSc before. Some patients associated the information they received about survival and therapeutic options (i.e., chemotherapy and HSCT) with cancer. They sometimes felt that people in their social networks did not fully understand the burden and severity of their condition, because SSc is unknown, their symptoms are not visible, and other rheumatic diseases are usually associated with less severe and treatable symptoms.

Quality of life and health status were important aspects in decision-making. Patients reported that dcSSc had either a very large negative impact on their quality of life and daily functioning, or their general health was rapidly deteriorating at the time the decision had to be made. Five patients believed that a condition with such a fast-progressing course necessitated high intensity therapy such as HSCT on short notice. Some patients mentioned that they accepted the potential risk of treatment complications, even fatal complications, considering their low quality of life. Some patients had experienced failure of other therapies and therefore thought HSCT was the best, if not the only, option left to commence. Patients who opted for other therapies than HSCT felt they had the time to try alternatives and leave HSCT as last rescue option.

\section{Expectations: maximizing chances for survival?}

Expectations on the outcomes of HSCT varied among patients. Most patients mentioned that they had expected that HSCT provided the best, if not the only, chance for survival. HSCT was regarded by many patients as the ultimate treatment, as "the holy grail".

Some expected that HSCT could completely cure them. Patients hoped to get back to their pre-diagnosis activity level. Return to work was an important consideration in the decisionmaking process. Most patients had to discontinue working due to ill health, with led to loss of financial independence and identity. They anticipated that HSCT was the only way to return to work.

One patient thought the duration and impact of the treatment regimen in HSCT was too intense to combine it with work, and therefore preferred an alternative therapy. Two other patients explained that they were disappointed after being informed about the expected outcomes. One of them thought that it was only worth the risks if HSCT could cure the condition. The other already had experienced improvement after initiating an alternative treatment and thought it was best to keep HSCT as a back-up plan.

\section{Developing a frame of reference that facilitates decision-making: a difficult quest for} knowledge

All patients received information from their rheumatologist and in most cases also from a hematologist and stem cell transplantation nurse. Most information was provided verbally. Patients were informed about the procedures, the expected outcomes, and potential adverse events and risks related to treatment in autologous HSCT in general.

Patients were in need of disease-specific information and personalized treatment risks 
and outcomes to make a decision. They appreciated that the information they received about the prognosis and risks of HSCT was clear and honest. We observed differences in attitudes towards treatment risks. Half of the patients who opted for HSCT thought that $10 \%$ treatment-related mortality was high, but still acceptable. The other half thought the risk was not high or did not know how to relate the risks to their own situation. Furthermore, many patients had positive expectations towards potential risks. Twelve patients, all males, believed they had lower treatment risks compared to other patients. Furthermore, two patients recounted that they had been told that HSCT is always successful, and without risks or complications. One patient could not recall being informed about treatment risks at all. Reliable and SSc-specific patient information about treatment options was not available according to most patients. Two patients reported that they were sufficiently informed about the treatment options, and these were also patients who had participated in a clinical trial. There was no apparent relation between the rating of information provision and time since HSCT. Patients were discouraged by their rheumatologist to use the internet as an information source, because the reliability of the information could not be guaranteed. Some patients did search for additional information on the internet, although they had a difficult time finding reliable and understandable information.

More than half of the patients reported they could not oversee and balance all options, and that they lacked the information to be fully involved in the treatment decision. These patients preferred to be guided by their rheumatologist.

Patients who stated that they had made the decision themselves, could better express their own decision-related health values in the interviews. Moreover, these patients felt sufficiently informed about the pros and cons to make this decision. Nine patients had had contact with a peer who shared their personal experiences about the treatment and decision-making process. This was highly valued as this contact provided more practical information and support, than the patients had received from healthcare professionals. Consultations around family planning and fertility preservation prior to therapy, in collaboration with the gynecologist, were experienced as very distressing and difficult. Patients felt confronted with a sensitive aspect at a time at which they already had to make many tough decisions. They felt they did not have enough time to think about it, which rushed the decision with regard to HSCT and fertility preservation.

\section{Physician-guided and entrusted decision-making}

All patients thought the quality of the relationship and interaction with their rheumatologist was very important. Almost all patients wanted to know the treatment preference of their rheumatologist, and only two patients did not know what treatment their practitioner recommended. Ten patients felt that their rheumatologist made the ultimate decision, with no involvement of them.

The majority of patients described a paternalistic style of decision-making in which patients were strongly guided by their rheumatologist. One patient preferred to receive HSCT, but was directed towards another treatment by his rheumatologist. This led to feelings of rejection and fear, because he felt he did not have the chance to receive the optimal treatment. Patients mentioned that trust was an important factor in accepting guidance from their rheumatologist. This trust was based on a longstanding relationship, the quality of the interaction or the good reputation of the rheumatologist. Having a good reputation was ascribed to having extensive experience or high scientific output. Some patients recounted that the recommended therapeutic plan was first discussed in a (multidisciplinary) team 
before it was introduced to them. These patients experienced this team effort as even more convincing than the individual preference of their rheumatologist. Interdisciplinary collaboration and alignment were valued highly.

Social interactions: protecting loved ones and feeling lonely

Social support during the decision-making process was very important to patients, although at the same time patients thought the interaction with their loved ones was complicated. Patients did not want to bother their family with concerns and believed that they had to make the decision and cope with the disease alone. Many patients reported feelings of loneliness at the very same time, also due to a dwindling social life and because they felt misunderstood by their family and friends. Some patients noticed that the illness put a strain on friendships and their relationship with their partner.

Patients also struggled with sharing information about the treatment and poor prognosis with their family and friends, especially with their children. Others consciously did not tell their children about the risks of treatments and treatment decision. Reasons not to inform children were that they did not want to worry them, or because they felt that it would negatively affect their role as a parent. Furthermore, when explaining the situation to their children, patients felt they really had to face the impact of dcSSc on their lives and the lives of their loved ones.

Some patients however involved their children in the decision-making process, and children were an important reason to opt for a treatment that carried both higher chances of benefit and more risk. For other patients, the high risk of HSCT was a reason not to go for this treatment. During the decision-making process, social contacts, especially partners, provided support and acted as sounding board, for as far as they had been informed. Some patients shared their considerations and thoughts with their family, but made the decision themselves, while others weighted the opinion of others in their final decision.

\section{Shared Decision-Making}

Patients rated the decision-making process with a high score (80.64 out of 100, SD 15.6). There were no differences in rating between non-HSCT patients, HSCT patients, or those scheduled for HSCT; or between age groups ( $<50$ years: 80.9 (range 48.8-100.0), vs $>50$ years: 83.0 (range 62.2-100.0); males or females (mean 78.1 range 86.6-97.8 vs 86.7 range 59.9100.0); or hospitals (UMCU: 89.9 (range 79.9-100.0), Raboudumc 75.7 (range 48.8-100.0), ARC 82.1 (range 77.7-86.6), LUMC 84.6 (range 62.6-97.8)). We did not observe any trend between the approach of the rheumatologist in making the decision and the SDM rating. Three out of four patients that low-rated the decision-making process (SDQ-9<60), reported that they wished that HSCT had been performed earlier than it had been. All patients that were interviewed after HSCT or an alternative treatment, except for one, thought their decision was the right choice. This one person felt his quality of life remained low, because his daily activities were very limited. The two patients that experienced a relapse post-HSCT did not regret their choice for HSCT. 
Table 2. Themes, subthemes and issues important in the decision making process, derived from the interviews

\begin{tabular}{|c|c|c|}
\hline Themes & Subthemes & Issues \\
\hline \multirow{4}{*}{$\begin{array}{l}\text { Poor prospects } \\
\text { and low quality } \\
\text { of life }\end{array}$} & Impact daily life & Limitations in daily functioning \\
\hline & Deterioration health status & Failure of medication \\
\hline & & Fear of dying \\
\hline & Shock about prognosis & Most invasive treatment seems the 'best option' \\
\hline \multirow[t]{17}{*}{ Expectations } & Evaluation different options & Feeling they couldn't see all options in perspective beforehand \\
\hline & & $\begin{array}{l}\text { No other option provided by physician/team, different therapies } \\
\text { offered one by one. }\end{array}$ \\
\hline & $\begin{array}{l}\text { Expectations treatment } \\
\text { outcome }\end{array}$ & Expectation HSCT will stop the disease process \\
\hline & & Expectation HSCT will cure the disease \\
\hline & & Being able to get back to work after HSCT \\
\hline & & Disappointment: HSCT cannot cure SSc \\
\hline & & No memory of expectations before treatment \\
\hline & Expectations side effects & Acceptable side effects given expected effects \\
\hline & & No expectations about side effects \\
\hline & & Lower risk of side effects due to good condition or young age \\
\hline & Expectations complications & More chance to have favorable outcome than other patients \\
\hline & & lgnore risks \\
\hline & & $\begin{array}{l}\text { Symptoms are unbearable or quality of life is very low, so risks } \\
\text { are acceptable }\end{array}$ \\
\hline & & Fear of dying, so risks are acceptable \\
\hline & Employment & $\begin{array}{l}\text { Loss of income, expectations HSCT provides best chance to } \\
\text { return to work }\end{array}$ \\
\hline & & Work defines identity, loss of work means loss of identity \\
\hline & & Work is a distraction from being ill \\
\hline \multirow[t]{3}{*}{ Knowledge } & Information source & Trustworthiness of information on the internet \\
\hline & & Stories from peers: Useful or not applicable to own situation \\
\hline & & $\begin{array}{l}\text { Desire to read and understand scientific literature about HSCT } \\
\text { and therapeutic options }\end{array}$ \\
\hline \multirow{5}{*}{$\begin{array}{l}\text { Interaction with } \\
\text { physician }\end{array}$} & Preference physician & Physician made treatment decision \\
\hline & & Physician tried to leave decision with patient \\
\hline & Trust & Good interaction with physician and team \\
\hline & & $\begin{array}{l}\text { Good reputation of physician (much experience/scientific } \\
\text { output) }\end{array}$ \\
\hline & Rejection & Exclusion for HSCT feels like rejection \\
\hline \multirow[t]{8}{*}{$\begin{array}{l}\text { Social } \\
\text { interaction }\end{array}$} & Support from partner & $\begin{array}{l}\text { Partner plays important role in decision-making and } \\
\text { coping with emotions. }\end{array}$ \\
\hline & Parents / family & Balancing sharing information, discussing risks \\
\hline & Children & $\begin{array}{l}\text { Children gave purpose during decision making and } \\
\text { treatment }\end{array}$ \\
\hline & & $\begin{array}{l}\text { Difficulties telling children about condition and } \\
\text { treatments }\end{array}$ \\
\hline & Loneliness & Feeling misunderstood \\
\hline & & Struggling to cope with condition \\
\hline & & Feeling isolated \\
\hline & & Loss of friends \\
\hline
\end{tabular}


Table 3. Illustrative quotes from patients in the in-depth interviews

\author{
Decision-making approaches \\ P2 "I was offered three treatment options; oral therapy (mycophenolate), monthly chemotherapy \\ (cyclophosphamide) or autologous stem cell transplantation. I felt I had a choice." \\ P4 "They told me I could go for stem cell treatment and that I would die if I did not go this treatment, no alternatives \\ were provided." \\ P6 "They mentioned that stem cell transplantation was an option, but I first had to try chemotherapy."
}

\title{
Poor prospects and health status: leaving no other option
}

P6: "I did not have a choice; my health was only getting worse. It was a sword of Damocles hanging above my head." P4: "I was desperate, I was at war with myself."

\section{Expectations: maximizing chances for survival?}

P3: "I preferred to be treated with HSCT, because I read on the internet that this is the only treatment that could cure dcSSc."

P11: "I only would have taken the risk if HSCT could have cured the disease."

P2: "The most positive scenario would be stabilization of the disease."

P4: "The only thing I could think of, was that I was going to die. If I did not choose HSCT, this was really going to happen."

P3: "I just want back to work, back to my normal life, get some distraction."

Knowledge: the difficult quest for reliable and relevant information

P6: "I was shocked to hear about chemotherapy, I thought this was only needed when you have cancer."

P1: "I was young and until recently in good health, I think I will have lower risks compared to older patients."

P20: "My rheumatologist told me not to Google, but of course I did Google. The information I found was confusing and did not make sense."

P6: "I found it very hard to apply the information to my own personal situation, which led to even more uncertainty and fear about what to expect."

P19: "Nobody really knows how it is and what to expect from stem cell transplantation, it really helped to talk to a peer".

P16: "It was hard to talk about fertility and family planning, about new life, while I was not even sure I would survive."

\section{Interaction with physician: guided decision-making}

P1: "My rheumatologist told me it was my decision and did not want to disclose his preferences. Yet, I preferred his opinion as an expert in this field."

P3: "My rheumatologist decided not to opt for HSCT. I was very upset about this. However, I believe it was the right decision eventually."

P22: "I fully relied on my doctors."

P24: "I always thought I was in good hands at this hospital. I experienced that a whole team of healthcare professionals was there to support me."

Social interactions: involving loved ones and a tendency towards feeling lonely

P16: "My family was very much involved, they supported me a lot."

P2: "I felt obliged to my children to discuss the risks with them and to make the decision together."

P8: "I had to decide to continue with treatments because of my children. I could not leave them."

P20: "I thought it was more difficult to tell my children about the condition and prognosis, than to hear and undergo the situation myself."

P15: "I wanted to protect my children, because there was so much uncertainty."

P1: "I used a booklet about stem cell transplantation in children to explain the procedure to my kids. They could read it themselves and look at the pictures, if they wanted more information."

P2: "Although I was surrounded by many people, I always felt alone." 


\section{Discussion}

This study provides important insights into the treatment decision-making process in dcSSc from a patients point of view. We identified several aspects that play an important role in shared decision-making, including health status and prospects, expectations, knowledge, patient-physician interaction and social interaction. The patients in our study were generally satisfied with the process, which was mainly based on confidence in their rheumatologist. We found that patients perceived the decision-making as 'shared' overall, even though e.g. the rheumatologist steered them towards one or another option. Other studies made similar observations; patients defined the process as having been shared when they were satisfied with the interaction with their physician, notwithstanding that the decision had not been made conjointly.(28) Aspects like trust and feeling 'heard', might thus be more important for patients in appraising their involvement in decision making than making the actual decision themselves or together with their rheumatologist. Nevertheless, patients in our study stressed essential SDM features, such as desiring more information i.e. written information about alternative therapies, clear overview of pros and cons of therapies, what to expected after HSCT. They mentioned, additionally, that being made a partner in the decision contributed to trusting their rheumatologist. It was noteworthy that patients often did not mind being 'steered'. Implicit persuasion was previously shown to commonly occur in decision-making when more than one treatment option is available. $(29,30)$ Yet, the way in which patients are able to participate in decision-making differed per individual. The approach in which the patients are involved in the decision-making process should therefore be carefully tailored to the individual. Also, encouraging patients who were not forthcoming in becoming involved in decision-making, had a positive effect on their satisfaction with the process.(31) Importantly, patients should not be forced to make the decision; ultimately it is for their rheumatologist to elicit enough information from patients to take into account the patients' values and preferences when balancing the pros and cons of treatment options. In our study, patients mentioned a lack of SSc-specific information about treatment options as an impairment for shared decision-making. Indeed, general information about HSCT in autoimmune diseases was published only recently (32), but is not fully applicable to dcSSc, as treatment risks are much higher. The health status at the time of decision-making had a major impact on how patients viewed information about HSCT. As patients further deteriorated, higher treatment risks were deemed more acceptable, which is in line with patients' evaluations in other conditions with a similar impact on quality of life, such as stroke or (33) rheumatoid arthritis.(34) Also, the health status probably influenced the way rheumatologist explained the treatment options.

Secondly, fertility preservation had a huge emotional impact. In oncology, where similar experiences have been reported (35), guidelines have been developed in order to optimize timing of fertility counseling, and in this way optimizing treatment decision-making about oncological therapy.(36) Thirdly, patients' expectations about risks differed. Remarkably, male patients in our study believed they had lower risks of complications compared to other patients with dcSSc. This optimism bias might be a coping strategy, and is also described in other conditions, albeit not specifically in males.(37) To limit the extent of optimism bias, tailored information materials about risks of treatment-related complications, could aid patients in assessing their personal risk. Currently, there are no such risk prediction 


\section{Chapter 7}

scores for HSCT in dcSSc. Taken together, these observations highlight the importance of SSc-specific and personalized patient education about HSCT, if possible at a time when they do not yet experience 'urgency' (advanced care planning).(38) Based on our results, we formulated a number of recommendations for clinicians (see Box 1).

Our study has some limitations. For some patients, the decision-making process happened several years ago, which could lead to recall bias. Also, health status can influence the ability to recall the process correctly. Furthermore, the perception of the process could be influenced by their current condition. The small number of patients who are being offered HSCT in the Netherlands, however, strongly limited the possibility to include larger numbers of recently-diagnosed patients. A strength of this study is that we included a relatively large and diverse group of patients.

In conclusion, our study shows that in general, therapeutic decision-making in dcSSc where HSCT is considered, is judged as shared by patients. Still this study also emphasizes that making therapeutic choices remains a challenge in dcSSc. We call for further research on how the attitude of rheumatologists governs the process of involving patients in decisionmaking in this population and how this might influence the patient. Secondly, studies should focus on the development of risk stratification models to provide patients with individualized information, and for SSc-specific information about HSCT, in order to further improve care.

\section{Box 1. Recommendations}

$\rightarrow$ Physicians should make a deliberate choice regarding the approach they use to facilitate decision making

$\rightarrow$ Aim to provide clear, individualized information about the risks and benefits of all treatment options at an early stage

$\rightarrow$ Encourage the patient to participate in the decision-making process

$\rightarrow$ Take into account the patient is part of a complex system (family, work, social) and that they might have unaddressed needs in one of these areas that are relevant to making the decision

$\rightarrow$ Fertility / family planning needs to be addressed in advance and during follow-up

$\rightarrow$ Offer to arrange contact with patient peers

$\rightarrow$ Clear, SSc-specific information about HSCT and alternative treatments need to be developed and provided.

\section{Research agenda}

$\rightarrow$ Gain more insight in the perceptions of rheumatologists towards shared decision-making in dcSSc

$\rightarrow$ Develop risk stratification models to provide patients with individualized information

\section{Acknowledgements}

We thank the patients for their time and valuable contributions to this research project. 


\section{References}

1. Elhai M, Meune C, Boubaya M, Avouac J, Hachulla E, Balbir-Gurman A et al. Mapping and predicting mortality from systemic sclerosis. Ann Rheum Dis. 2017;76(11):1897-1905.

2. Ioannidis JP, Vlachoyiannopoulos PG, Haidich AB, Medsger TA, Lucas M, Michet CJ et al. Mortality in systemic sclerosis: an international meta-analysis of individual patient data. Am J Med. 2005;118(1):210.

3. Fernandez-Codina A, Walker KM, Pope JE. Treatment Algorithms for Systemic Sclerosis According to Experts. Arthritis Rheumatol. 2018;70(11):1820-1828.

4. Burt RK, Shah SJ, Dill K, Grant T, Gheorghiade M, Schroeder J et al. Autologous non-myeloablative haemopoietic stem-cell transplantation compared with pulse cyclophosphamide once per month for systemic sclerosis (ASSIST): an open-label, randomised phase 2 trial. Lancet. 2011;378(9790):498-506.

5. van Laar JM, Farge D, Sont JK, Naraghi K, Marjanovic Z, Larghero J et al. Autologous hematopoietic stem cell transplantation vs intravenous pulse cyclophosphamide in diffuse cutaneous systemic sclerosis: a randomized clinical trial. JAMA. 2014;311(24):2490-2498.

6. Sullivan KM, Goldmuntz EA, Keyes-Elstein L, McSweeney PA, Pinckney A, Welch B et al. Myeloablative Autologous Stem-Cell Transplantation for Severe Scleroderma. N Engl J Med. 2018;378(1):35-47.

7. Kowal-Bielecka O, Fransen J, Avouac J, Becker M, Kulak A, Allanore Y et al. Update of EULAR recommendations for the treatment of systemic sclerosis. Ann Rheum Dis. 2017;76(8):1327-1339.

8. Denton CP, Hughes M, Gak N, Vila J, Buch MH, Chakravarty K et al. BSR and BHPR guideline for the treatment of systemic sclerosis. Rheumatology. 2016;55(10):1906-1910.

9. Spierings J, van Rhijn-Brouwer FCC, van Laar JM. Hematopoietic stem-cell transplantation in systemic sclerosis: an update. Curr Opin Rheumatol. 2018;30(6):541-547.

10. Sandman L, Munthe C. Shared decision-making and patient autonomy. Theor Med Bioeth. 2009;30(4):289-310.

11. Joosten EA, DeFuentes-Merillas L, de Weert GH, Sensky T, van der Staak CP, de Jong CA. Systematic review of the effects of shared decision-making on patient satisfaction, treatment adherence and health status. Psychother Psychosom. 2008;77(4):219-226.

12. Harter M, Moumjid N, Cornuz J, Elwyn G, van der Weijden T. Shared decision making in 2017: International accomplishments in policy, research and implementation. Z Evid Fortbild Qual Gesundhwes. 2017;123-124:1-5.

13. Marshall MN. Sampling for qualitative research. Fan pract. 1996;13(6):522-525.

14. Corbin J SA. Basics of qualitative research: Techniques and procedures for developing grounded theory. Third ed. Thousand Oaks: Sage; 2008.

15. Guest G, Bunce A, Johnson L. How many interviews are enough? An experiment with data saturation and variability. Field Methods. 2006 (18):59-82.

16. Charmaz. Constructing grounded theory. A practical guide through qualitative analysis. London: Sage; 2006.

17. Rodenburg-Vandenbussche S, Pieterse AH, Kroonenberg PM, Scholl I, van der Weijden T, Luyten GPM, et al. Dutch Translation and Psychometric Testing of the 9-Item Shared Decision Making Questionnaire (SDM-Q-9) and Shared Decision Making Questionnaire-Physician Version (SDM-Q-Doc) in Primary and Secondary Care. PloS one. 2015;10(7):e0132158.

18. Poole JL, Steen VD. The use of the Health Assessment Questionnaire (HAQ) to determine physical disability in systemic sclerosis. Arthritis Care Res. 1991;4(1):27-31.

19. van Reenen M JB. EQ-5D-5L User Guide. EuroQol Research Foundation 2015.

20. de Boer ME, Depla M, WojtkowiakJ, Visser MC, Widdershoven GA, Francke AL et al. Life-and-death decision-making in the acute phase after a severe stroke: Interviews with relatives. Pall Med. 2015;29(5):451-457.

21. Bailey J. First steps in qualitative data analysis: transcribing. Fam Pract. 2008;25(2):127-31.

22. Morgan DL. Practical strategies for combining qualitative and quantitative methods: applications to health research. Qual Health Res. 1999;8(3):362-376.

23. Johnson SR, O'Brien KK. Qualitative Methods in Systemic Sclerosis Research. J Rheumatol. 2016:12651267.

24. Salt E, Peden A. The complexity of the treatment: the decision-making process among women with rheumatoid arthritis. Qual Health Res. 2010;21(2):214-222.

25. B Dierckx de Casterle CG, E Bryon, Y Denier. QUAGOL: A guide for qualitative data analysis. Int J Nurs Stud. 2012;49(3):360-371. 


\section{Chapter 7}

26. Ltd. QIP. NVivo qualitative data analysis Software (computer program). v10, 2012.

27. Tong A, Sainsbury P, Craig J. Consolidated criteria for reporting qualitative research (COREQ): a 32-item checklist for interviews and focus groups. Int J Qual Health Care. 2007;19(6):349-357.

28. Kasper J, Heesen C, Kopke S, Fulcher G, Geiger F. Patients' and observers' perceptions of involvement differ. Validation study on inter-relating measures for shared decision making. PloS One. 2011;6(10):e26255.

29. Engelhardt EG, Pieterse AH, van der Hout A, de Haes HJ, Kroep JR, Quarles van Ufford-Mannesse P et al. Use of implicit persuasion in decision making about adjuvant cancer treatment: A potential barrier to shared decision making. Eur J Cancer. 2016;66:55-66.

30. Karnieli-Miller O, Eisikovits Z. Physician as partner or salesman? Shared decision-making in real-time encounters. Soc Sci Med. 2009;69(1):1-8.

31. van Stam MA, Pieterse AH, van der Poel HG, Bosch J, Tillier C, Horenblas S, et al. Shared Decision Making in Prostate Cancer Care-Encouraging Every Patient to be Actively Involved in Decision Making or Ensuring the Patient Preferred Level of Involvement? J Urol. 2018;200(3):582-589.

32. Jessop H, Farge D, Saccardi R, Alexander T, Rovira M, Sharrack B et al. General information for patients and carers considering haematopoietic stem cell transplantation (HSCT) for severe autoimmune diseases (ADs): A position statement from the EBMT Autoimmune Diseases Working Party (ADWP), the EBMT Nurses Group, the EBMT Patient, Family and Donor Committee and the Joint Accreditation Committee of ISCT and EBMT (JACIE). Bone Marrow Transplant. 2019;54(7):933-942

33. Murtagh MJ, Burges Watson DL, Jenkings KN, Lie MLS, Mackintosh JE, Ford GA, et al. Situationallysensitive knowledge translation and relational decision making in hyperacute stroke: a qualitative study. PloS One. 2012;7(6):e37066.

34. Verburg RJ, Mahabali SD, Stiggelbout AM, Sont JK, van Laar JM. High dose chemotherapy and hematopoietic stem cell transplantation: a study of treatment preference in patients with rheumatoid arthritis and rheumatologists. J Rheumatol. 2002;29(8):1653-1658.

35. Jones G, Hughes J, Mahmoodi N, Smith E, Skull J, Ledger W. What factors hinder the decision-making process for women with cancer and contemplating fertility preservation treatment? Hum Reprod Update. 2019;23(4):433-457.

36. Lee SJ, Schover LR, Partridge AH, Patrizio P, Wallace WH, Hagerty K et al. American Society of Clinical Oncology recommendations on fertility preservation in cancer patients. J Clin Oncol. 2006;24(18):29172931.

37. Stoff BK, Swerlick RA. Reframing risk part II: Methods for improving medical risk communication. J Am Acad Dermatol. 2013;69(4):637-639.

38. Fahner JC, Beunders AJM, van der Heide A, Rietjens J, Vanderschuren MM, van Delden J et al. Interventions Guiding Advance Care Planning Conversations: A Systematic Review. J Am Med Dir Ass. 2019;20(3):227-248. 
Decision-making in diffuse cutaneous systemic sclerosis 


\section{chapter 8}

Choosing a treatment:

how can we guide patients through the labyrinth? 


\section{Chapter 8}

Diffuse cutaneous systemic sclerosis (SSc) is a subtype of SSc, a rare autoimmune connective tissue disease characterised by inflammation, fibrosis, and vasculopathy, resulting in generalised skin thickening and organ damage.(1) The disease can be rapidly progressive leading to severe morbidity and premature death. Although diffuse cutaneous SSc is incurable, disease progression can be suppressed if treatment is started early. $(2,3)$ The following treatment options are generally considered in progressive stages of the disease: methotrexate, mycophenolate mofetil, cyclophosphamide, or autologous hematopoietic stem cell transplantation (AHSCT), (4) all differing in tolerability, risk-benefit, and costs. For instance, AHSCT has been shown to improve survival, function ability, and quality of life in patients with progressive diffuse cutaneous SSc; however, AHSCT is also associated with increased treatment-related mortality in the first years after treatment compared with intravenous cyclophosphamide. $(3,5)$ Still, outcomes and risks remain rather unpredictable in individual patients with diffuse cutaneous SSc, and there are no sufficiently detailed international guidelines on timing and patient selection for the available treatments. Therefore, clinical decision making is based on the preference of patients and their doctors. Making this decision can be very difficult for patients with progressive disease and their relatives, and for this reason, understanding the patients' needs at this stage is crucial.

In a qualitative study of patients with diffuse cutaneous SSc, (6) several factors were identified that influenced patient decision-making in the context of AHSCT, including health status. Those who had experienced a rapid deterioration of health consequently believed that they had poor prospects and wanted the most intensive treatment available, regardless of the risks involved. A better understanding of their disease and treatment options, and expectations about risks and benefits, were also important elements in making treatment decisions.

In addition, social context and individual values played a large part. Some patients preferred cyclophosphamide pulse therapy rather than AHSCT, as they thought that hospital admission and recovery from AHSCT would take too long or it would be impossible to combine this treatment with the care for their children or jobs. Others mentioned that they accepted the risks associated with AHSCT to get the best chance of survival so that they could see their children grow up. Finally, patient-doctor interaction influenced the decision. Patients regarded their doctors as the expert and respected their advice, but they also felt dependent on them. Remarkably, most patients in this study reported that they felt their doctor made the definite decision, which was largely considered acceptable because of trust in the doctor, but importantly because patients did not feel that they had sufficient information and knowledge of all possible treatment options. From this study, it was concluded that patients with diffuse cutaneous SSc should be involved more in decision making and that there is an urgent need for uniform and clear information about available treatment options.

Providing leaflets and verbal information to patients is probably not sufficient in the context of a complex decision process where a patient's outcome and treatment risk are to a large extent unpredictable. Furthermore, there is a risk of information overkill and, conversely, of bias if a physician were to only provide information on treatment options they believe are relevant, ignoring the patient's expectations, values, and social context.(7) Accordingly, information priorities of patients and doctors need to be investigated and unmet 
information needs should be identified before developing information materials. Another potential source of information for patients, which can help them weigh all treatment options, are patient peers. In oncology, where peer advice is already embedded in care, studies have shown that peers can provide social support, set realistic expectations, and advise on selfcare, which is highly valued by most patients.(8) In HIV care, peer support has led to improved adherence and even viral suppression.(9) On the other hand, the content of information and the support provided by peers can be variable and subjective depending on the peers' own experience. Supporting patients can be demanding for peers and therefore, before implementing such strategies, peer supporters should be trained.

Apart from patient education, we should be more aware of how we, as doctors, interact with patients, considering the large effect this has on their decisions.

Previous studies in rheumatology have taught us that doctors perceive shared decisionmaking differently and often struggle to optimally facilitate it.(10) Therefore, training in a structured decision-making process and communication can be helpful for doctors. In conclusion, decision-making in diffuse cutaneous SSc can be a labyrinth and to fully engage our patients in this process, we must guide them. There is room for improvement regarding the structure of the decision-making process, clear patient education, and access to trained peers for support and information.

\section{References}

1. Denton CP, Khanna D. Systemic sclerosis. Lancet. 2017; 390: 1685-1699.

2. Herrick AL, Pan X, Peytrignet S, Lunt M, Hesselstrand R, Mouthon L, et al. Treatment outcome in early diffuse cutaneous systemic sclerosis: the European Scleroderma Observational Study (ESOS). Ann Rheum Dis. 2017; 76:1207-1218.

3. van Laar JM, Farge D, Sont JK, Naraghi K, Marjanovic Z, Larghero J et al. Autologous hematopoietic stem cell transplantation vs intravenous pulse cyclophosphamide in diffuse cutaneous systemic sclerosis: a randomized clinical trial. JAMA. 2014;311:2490-2498.

4. Fernandez-Codina A, Walker KM, Pope JE. treatment algorithms for systemic sclerosis according to experts. Arthritis Rheumatol. 2018; 70: 1820-1828.

5. Sullivan KM, Goldmuntz EA, Furst DE. Autologous stem-cell transplantation for severe scleroderma. N Engl J Med. 2018;378:1066-1067.

6. Spierings J, van Rhijn-Brouwer FCC, de Bresser CJM, Mosterman PTM, Pieterse AH, Vonk MC, et al. Treatment decision-making in diffuse cutaneous systemic sclerosis: a patient's perspective. Rheumatology. 2020; 59(8): 2052-2061.

7. Mattukat K, Boehm P, Raberger K, Schaefer C, Keyszer G, Mau W. How much information and participation do patients with inflammatory rheumatic diseases prefer in interaction with physicians? Results of a participatory research project. Patient Prefer Adherence. 2019; 13: 2145-2158.

8. Graham-Wisener L, Dempster M. Peer advice giving from posttreatment to newly diagnosed esophageal cancer patients. Dis Esophagus. 2017;30:1-7.

9. Cunningham WE, Weiss RE, Nakazono T, Malek MA, Shoptaw SJ, Ettner SL et al. Effectiveness of a peer navigation intervention to sustain viral suppression among HIV-positive men and transgender women released from jail: the LINK LA randomized clinical trial. JAMA Intern Med. 2018; 178: 542-553.

10. Mathijssen EGE, VriezekolkJE, Popa CD, van den Bemt BJF. Shared decision making in routine clinical care of patients with rheumatoid arthritis: an assessment of audio-recorded consultations. Ann Rheum Dis. $2020 ; 72: 170-175$. 


\section{chapter 9}

\section{Second autologous}

hematopoietic stem

cell transplantation in

systemic sclerosis - a

case report

Rheumatology 2019;58(7):1305-1307. 
Sir, autologous hematopoietic stem cell transplantation (HSCT) is an effective treatment in patients with progressive diffuse cutaneous systemic sclerosis (dcSSc)(1,2). Unfortunately, a proportion of patients experiences a relapse, which can be managed with conventional immunosuppressants in most cases. In refractory cases a second HSCT may be considered, however, data on safety and efficacy are lacking. Here, we present the case of a dcSSc patient who underwent a second HSCT and discuss our management of the patient in light of current evidence.

A 35-year old woman with a history of Raynaud's phenomenon for one year, presented with rapidly progressive skin thickening despite treatment with mycophenolate mofetil (MMF). Physical examination showed anterior tibial tendon friction rubs (TFRs) and generalised skin involvement with a Modified Rodnan Skin Score (mRSS) of 26. Nailfold capillaroscopy revealed an early scleroderma pattern. Immunology showed a positive ANA and anti SSA-52 autoantibodies. The diagnosis of dcSSc was made. There was no visceral involvement. Taking into consideration the poor prognosis of this patient (progressive skin involvement, TFRs) and non-responsiveness to MMF, she was counseled about available treatment options and the decision to perform HSCT was made. Mobilization and pre-transplant conditioning were conducted according to the ASTIS Trial protocol (1). After conditioning with intravenous cyclophosphamide and rabbit antithymocyte globulin (rATG), 315*106 CD34+ cells were infused $\left(5.25 * 10^{6} / \mathrm{kg}\right.$ bodyweight). There were no adverse events during the procedure apart from a self-limiting viral respiratory tract infection.

Skin thickening significantly decreased after HSCT (Figure 1). However, almost twelve months post-HSCT, the patient developed clinical signs of a relapse; the mRSS had increased to 22, and tibial TFRs had returned. The patient developed severe itching, which was refractory to standard supportive and pharmacological treatment. Pulmonary function tests were unchanged, but an ECG revealed new onset of a first degree AV block. MMF, methotrexate and rituximab were initiated but were not effective.

There is little evidence to guide treatment decisions in relapse of SSc after HSCT. Data from clinical trials shows that most relapses can be treated with oral methotrexate and MMF (1). Additionally, a small study suggested that rituximab could be used to manage post-HSCT relapse in rheumatoid arthritis (3). Unfortunately, none neither methotrexate nor rituximab were effective in our patient.

Given that symptoms recurred with T cell repopulation (see Figure 1), and the brief but very favorable response on the first HSCT, a second autologous HSCT was considered. Information on both the efficacy and safety of second HSCT is scarce (4). The European Group for Blood and Marrow Transplantation Working Party on Autoimmune Diseases reports 9 second HSCTs, but no clinical outcome data were presented (5). A single casereport described a second HSCT in SSc, which induced clinical remission, but long term follow-up data on safety was not available (6). Therefore, we extensively counseled the patient about the possible risks of a second HSCT, which include secondary malignancy and cardiotoxicity as a complication of high dose cyclophosphamide administration. Other important considerations were anticipated difficulties with stem cell mobilization, and possible sensitization to ATG. It was decided to start immune suppression with ciclosporin and MMF immediately post-HSCT to maintain T cell suppression after immunological reconstitution.

The second HSCT was initiated at 18 months after the first HSCT, using the same protocol as the first HSCT. The mobilization was uneventful; changes to the mobilization regimen were needed to harvest the required number of CD34+ cells through leukapheresis. Similarly, no 
adverse events occurred during the conditioning with cyclophosphamide and rATG. $315 * 10^{6}$ cells were infused $\left(2.93 * 10^{6} / \mathrm{kg}\right.$ bodyweight). During the neutropenic phase after graft infusion, the patient developed an infected digital ulcer complicated with osteomyelitis, which was successfully treated with intravenous antibiotics.

At eighteen months after the second HSCT, skin thickening has almost disappeared (mRSS of 4) and no new visceral involvement has occurred. Despite the favorable outcome on these aspects of the disease, the patient still experiences significant disability due to severe Raynaud's phenomenon.

The pathophysiology of post-HSCT relapse is unclear, but the temporal relationship of the relapse in our patient with immune reconstitution suggests a relationship with reemergence of autogenic clones (Figure 1).

Figure 1. Immunological reconstitution and the mRSS: After HSCT, the mRSS rapidly decreased, to increase again at the onset of relapse. This coincided with immunological reconstitution. After the second HSCT, the mRSS remained low, despite reconstitution of the $\mathrm{T}$ cell compartment.

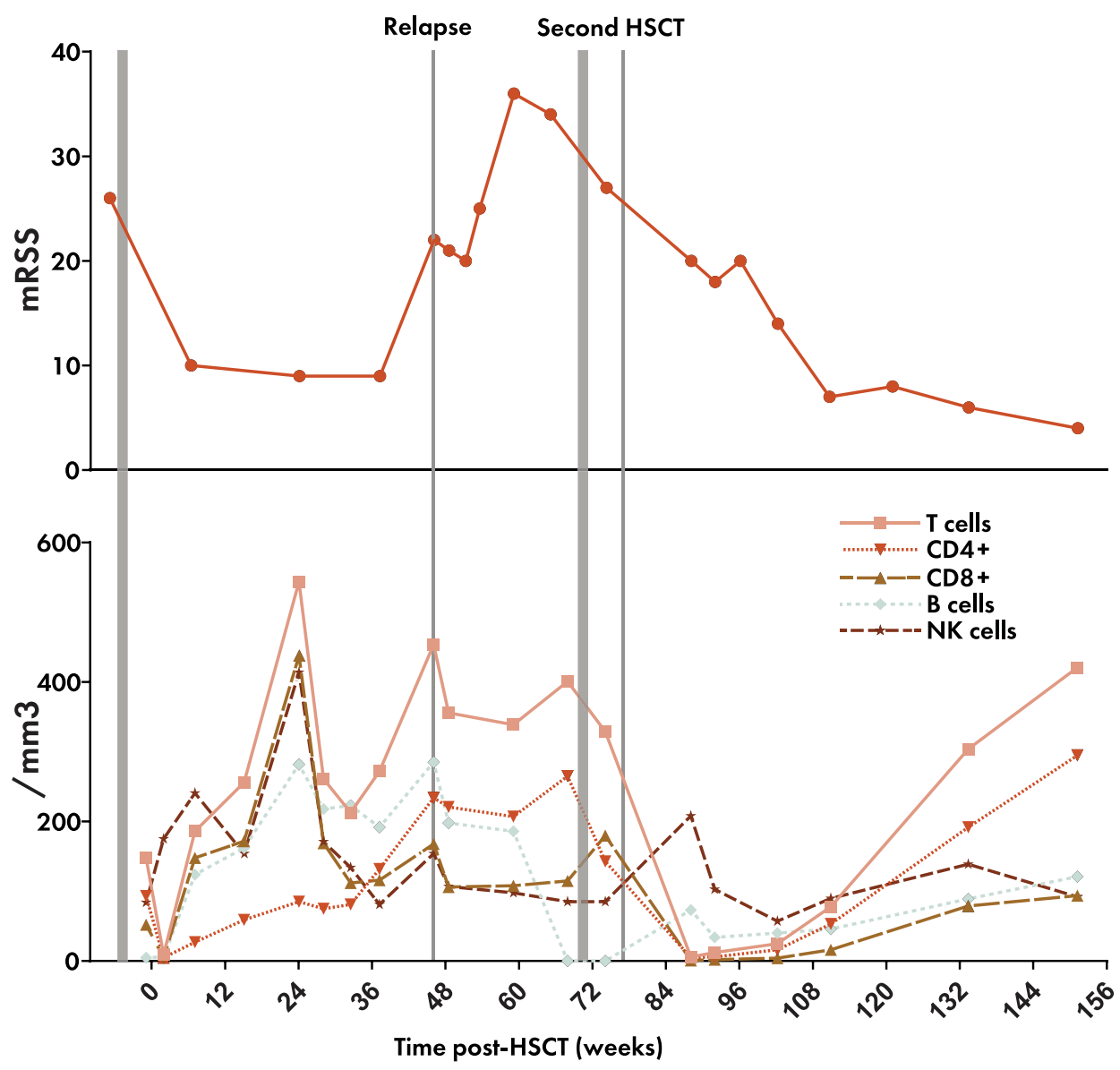


Studies regarding correlations between immunological parameters and relapse after HSCT for dcSSc are conflicting (7). At baseline, our patient had a positive anti-nuclear antibody (ANA) test (1:100) and anti-SSA-antibodies. Anti-SSA-antibodies disappeared after the first HSCT and remained absent during the relapse, though the ANA test remained positive (granular staining pattern).

In conclusion, our case underscores the potential benefit of a second HSCT with post-HSCT immunosuppression in SSc patients who relapse after HSCT. However, caution should be taken regarding possible toxicity and long-term side-effects and a careful screening procedure remains essential, as described by us recently (8). Ultimately, the decision to perform a second HSCT requires good multidisciplinary support as well as shared decision making with the patient.

\section{References}

1. van Laar JM, Farge D, Sont JK, Naraghi K, Marjanovic Z, Larghero J, et al. Autologous Hematopoietic Stem Cell Transplantation vs Intravenous Pulse Cyclophosphamide in Diffuse Cutaneous Systemic Sclerosis. JAMA. 2014; 25;311(24):2490.

2. Kowal-Bielecka O, Fransen J, Avouac J, Becker M, Kulak A, Allanore Y, et al. Update of EULAR recommendations for the treatment of systemic sclerosis. Ann Rheum Dis. 2017; 9; 76(8):1327-1339.

3. Moore J, Ma D, Will R, Cannell P, Handel M, Milliken S. A phase II study of Rituximab in rheumatoid arthritis patients with recurrent disease following haematopoietic stem cell transplantation. Bone Marrow Transplant. 2004; 34(3):241-247.

4. Naumann-Winter F, Greb A, Borchmann P, Bohlius J, Engert A, Schnell R. First-line tandem high-dose chemotherapy and autologous stem cell transplantation versus single high-dose chemotherapy and autologous stem cell transplantation in multiple myeloma, a systematic review of controlled studies. Cochrane database Syst Rev. 2012; 10:CD004626.

5. Farge D, Labopin M, Tyndall A, Fassas A, Mancardi GL, Van Laar J, et al. Autologous hematopoietic stem cell transplantation for autoimmune diseases: an observational study on 12 years' experience from the European Group for Blood and Marrow Transplantation Working Party on Autoimmune Diseases. Haematologica. 2010; 95(2):284-292.

6. Hou Y, Li H-J, Li M-T, Xu D, Zhou D-B, Zeng X-F. A successful case of second autologous haematopoietic stem cell transplantation for post-transplant systemic sclerosis relapse. Clin Exp Rheumatol. 2016; 34 Suppl 100(5):207

7. van Rhijn-Brouwer FCC, Spierings J, van Laar JM. Autologous hematopoietic stem cell transplantation in systemic sclerosis: a reset to tolerance? Immunol Lett. 2018; 195:88-96.

8. Swart JF, Delemarre EM, van Wijk F, Boelens J-J, Kuball J, van Laar JM, et al. Haematopoietic stem cell transplantation for autoimmune diseases. Nat Rev Rheumatol. 2017; 13(4):244-256. 
Second stem cell transplantation in systemic sclerosis 


\section{Abstract}

Objectives. To gain insight into the experiences of patients with diffuse cutaneous systemic sclerosis during and after autologous hematopoietic stem cell transplantation.

Methods. Semi-structured interviews were conducted with patients who underwent hematopoietic stem cell transplantation in four university hospitals in the Netherlands. Interviews were transcribed verbatim and thematically analyzed.

Results. Nine male and seven female patients were interviewed, median age 47 years (range: 27-68). Patients mentioned their life was severely disrupted before hematopoietic stem cell transplantation and remained unsettled a long time after treatment. Uncertainty because of disease progression, loss of control over health and the sense of time and fear of treatmentrelated adverse events were common during hospitalization. After hematopoietic stem cell transplantation, patients experienced more physical limitations than they had expected, and recovery took longer and was mentally taxing. Going back to work and finding a new balance in personal relations and social life was complicated. Patients described various strategies to deal with challenges. Family and friends provided essential support, although many experienced a dwindling social circle. Most patients also appreciated peer support. All patients were satisfied with the low threshold for contact with physicians and nurses during hospitalization. However, aftercare focused on medical aspects rather than on psychological well-being and social issues. Moreover, patients would have preferred to be better prepared on what to expect after discharge, and lacked information about self-management, prognosis, optimal recovery, work, sexuality, and family planning.

Conclusion. Hematopoietic stem cell transplantation has a major physical and psychological impact on patients with diffuse cutaneous systemic sclerosis. The course of recovery after this intensive therapy was unexpectedly long for some patients and offer of support was far less pro-active post-HSCT compared to pre-HSCT and during HSCT. 


\section{chapter 10}

\section{From "being at war" to}

"getting back on your feet": an exploratory qualitative study in patients with systemic sclerosis treated with hematopoietic stem cell transplantation 


\section{Introduction}

Diffuse cutaneous systemic sclerosis (dcSSc) is a progressive, systemic autoimmune disease associated with high morbidity and decreased life expectancy.(1-3) Treatment with autologous hematopoietic stem cell transplantation (HSCT) improves survival, quality of life, skin fibrosis, and prevents disease progression.(4-6) Even so, HSCT carries a high risk of complications, including infections and cardiac toxicity, and treatment-related mortality in the first year following treatment is three to ten percent. In recent years, HSCT has been increasingly performed in dcSSc (7). However, no studies have explored the experiences of patients with dcSSc during and after this treatment.

HSCT is indicated in patients with a progressive disease course, and patients are therefore usually severely ill when the treatment procedure is initiated. In addition, it is an intensive therapy, and severe side-effects from the drugs administered throughout the course of treatment can be experienced during hospitalization. Therefore, it is important to optimally support dcSSc patients during and after this treatment.

Several studies have demonstrated a major physical and psychological impact of HSCT in patients undergoing HSCT for hematological malignancies. Throughout hospitalization, an increase in depression rate and deterioration of quality of life were observed (8,9). After HSCT, psychosocial distress was increased and daily functioning and quality of life were impaired up to one year after therapy.(10) In oncology practices, psychosocial interventions before and after therapy have therefore been implemented to optimally prepare and support patients.

Yet, no studies have been performed to investigate the experiences of HSCT in patients with autoimmune diseases or dcSSc in specific. Compared to patients with hematological malignancies, dcSSc patients have a different disease course, symptoms and prospects. Hence, more insight in the perceptions of patients with dcSSc who are undergoing HSCT could provide opportunities to improve patient health-related quality of life. In this study, we collected data from patients in the four Dutch expert centers that perform HSCT. We investigated the experiences during and after HSCT of patients that underwent HSCT. We were particularly interested in whether there were unmet needs with regard to supportive care and rehabilitation, the impact of the treatment on social contacts, and whether patients were sufficiently informed about the implications of the treatment.

\section{Methods}

\section{Design}

An exploratory, qualitative study using thematic analysis was conducted.

\section{Patients}

Patients with dcSSc who had undergone HSCT between January 2008 and January 2019, were recruited from the four Dutch university hospitals where HSCT is offered for this condition (University Medical Center Utrecht, Leiden University Medical Center, Amsterdam UMC, location VUmc, Radboudumc Nijmegen). To gain an understanding of the diversity in patient experiences, and in line with qualitative research strategies (11-13), maximum variation was sought with respect to center, treatment outcomes, disease duration, marital status, level of education, age and gender. The researchers discussed the selection 
of patients with participating rheumatologists in order to achieve this group variation. Patients were informed about the study by their rheumatologist. If they were interested in participation, contact details were shared with the researcher (JS), who then contacted the patients and scheduled an interview, preferably after a routine appointment at the hospital. Patients who did not speak Dutch were excluded from the study. The study was evaluated by the institutional review board of all centers and classified as exempt of the Medical Research Involving Human Subjects Act (17-836/C). Prior to the interview, the goals of the study were reiterated, patients were informed about the nature of the questions, and written informed consent was obtained.

\section{Data collection}

Two investigators (JS, FvR) conducted the in-depth, semi-structured interviews. The interviews were recorded, transcribed verbatim and pseudonymized (14). Interviews were evaluated and discussed between the two investigators in order to ensure a similar approach.

An interview guide with open-end questions was developed by members of the project team with backgrounds in rheumatology and psychology.(15) This interview guide included questions about the patient's experiences during hospitalization for HSCT and after discharge (Supplementary file 1). Sociodemographic variables and disease characteristics were collected through a short questionnaire. We hypothesized that quality of life and functional impairment at the time of the interview could influence the perceptions of the treatment and recovery process. Health-related quality of life (HR-QOL) was therefore evaluated with the validated EuroQol-5D-5L (EQ-5D-5L). This survey assesses if patients experience any limitations on five domains (mobility, usual activities, selfcare, pain and discomfort, and anxiety and depression) and using five response categories ( $1=$ no problem, 2 =slight problem, $3=$ some problem, $4=$ moderate problem, $5=$ extreme problem). The five dimensional scores can be calculated as an overall utility score ranging from 0 (worst) to 1 (best; no problems in any of the dimensions)(16). Daily functioning was further assessed with the validated Scleroderma Health Assessment Questionnaire (SHAQ, range scores, 0 (no disability) to 3 (maximal disability)(17). Both surveys were taken on the day of the interview.

\section{Data analyses}

Qualitative analysis of the transcripts was done using thematic analysis. $(18,19)$ Open coding was the first step to sort the data for further interpretation. Codes are segments that simultaneously relate to each piece of data. Two researchers (JS, CB) first read and re-read the transcripts to familiarize themselves with the data. They then independently coded the first four transcripts. They frequently met to discuss coding during the process, until consensus was reached. They developed a code list inductively, which was used for all subsequent interviews. Codes were added or renamed whenever needed. Next, the different codes were sorted into themes, based on the labels of codes and the underlying text fragments. Themes were defined, grouped, and refined as necessary, and in consensus. Subthemes are defined as recurrent themes related to bigger themes. Data saturation was assessed on a conceptual level. The analysis was supported by the software program Nvivo12 (20). The consolidated criteria for reporting qualitative research (COREQ) were used. (21) An audit trail was kept of the qualitative analysis, codes and themes. Statistical Package for Social Sciences (SPSS) 25.0 was used for descriptive data analyses (median, range and percentage) of the socio-economic and disease characteristics. 


\section{Results}

\section{Sample characteristics}

Nine male and seven female patients were invited to the study and all agreed to participate. Median time between HSCT and the interview was 2.0 years (range 0.4-11.0 years; see Table 1). The median reported S-HAQ was 0.69 (range 0-1.71) and median HR-QoL index 0.92 (range 0.4-1.0).

Table 1. Patient characteristics

\begin{tabular}{|c|c|}
\hline & $N=16$ \\
\hline Median age (range) & $47(27-68)$ \\
\hline Women/men (n) & $7 / 9$ \\
\hline $\begin{array}{l}\text { Marital status ( } \mathrm{n} \text { ) } \\
\text { - Married } \\
\text { - Living together unmarried } \\
\text { - Single }\end{array}$ & $\begin{array}{l}13 \\
2 \\
1\end{array}$ \\
\hline $\begin{array}{l}\text { Household (n) } \\
\text { - Living alone } \\
\text { - Living with parents } \\
\text { - Living with partner } \\
\text { - Living with partner and children }\end{array}$ & $\begin{array}{l}0 \\
1 \\
7 \\
8\end{array}$ \\
\hline $\begin{array}{l}\text { Educational level ( } n \text { ) } \\
\text { - Low (primary and secondary school) } \\
\text { - Medium (high school) } \\
\text { - High (graduate and above) }\end{array}$ & $\begin{array}{l}5 \\
5 \\
6\end{array}$ \\
\hline Relapse or immunosuppressive agents post-HSCT (n) & 2 \\
\hline Paid job at time of interview (n) & 12 \\
\hline Median disease duration at interview (yrs, range) & $4.0(1.8-13.0)$ \\
\hline Median disease duration at HSCT (yrs, range) & $1.0(0.2-3.0)$ \\
\hline Median time between HSCT and interview (yrs, range) & $2.0(0.4-11.0)$ \\
\hline $\begin{array}{l}\text { Median S-HAQ (range) } \\
\text { Median VAS Raynaud } \\
\text { Median VAS digital ulcers } \\
\text { Median VAS intestinal disease } \\
\text { Median VAS breathing problems } \\
\text { Median VAS general } \\
\text { Median VAS pain }\end{array}$ & $\begin{array}{l}0.69(0-1.71) \\
0.70(0-3.00) \\
0.20(0-1.30) \\
0.40(0-2.80) \\
0.20(0-2.80) \\
0.80(0-2.90) \\
0.15(0.2 .50)\end{array}$ \\
\hline Median EQ5D-5L index (range) & $0.92(0.4-1.0)$ \\
\hline
\end{tabular}

EQ-5D-5L, Euroqol 5 dimensions 5 levels; S-HAQ; Scleroderma Health Assessment Questionnaire (range 0-3). VAS, visual analogue scale. VAS scales ranges from $\mathrm{O}$ (no complaints) - 3 (severe complaints).

\section{Qualitative results}

The analysis of the interviews yielded two key themes: disruption and control. Themes and subthemes (patterns related to the themes) are presented below and shown in table 2. 


\section{Disruption}

Physical impairments and the psychological impact of the disease led to the disruption of daily life. Patients experienced great uncertainties about their future, loss of control over their lives, loneliness, and existential challenges from the moment they received their diagnosis, and this went on during treatment. Problems were mostly related to living with illness instead of undergoing treatment.

P9: "My life was paused."

P15:"I was at war, nothing else mattered."

\section{Expectations about treatment, outcomes, and physical recovery}

Information provided to the patients did not entirely meet the needs of all patients. The patients felt insufficiently prepared for the impact of the treatment, despite having received comprehensive counseling prior to HSCT. Some of the patients preferred more realistic and more practical information from a patient point of view, e.g., provided by a peer. Furthermore, some reported too much emphasis on the theoretical risks and side-effects associated with treatment. They would have preferred a more optimistic and empowering tone of counseling. The patients tried to focus on positive outcomes to cope with insecurity. Subsequently, some felt annoyed or distressed by healthcare professionals who focused on treatment risks.

\section{P7: "I expected that HSCT would save me"}

P16: "The clinicians and nurses focused so much on the negative sides of HSCT".

The patients' expectations regarding treatment outcomes and side-effects differed widely. Some patients were relieved because they experienced fewer side-effects than they had expected. Others felt overwhelmed by the side-effects of the treatment.

P2: "I felt really ill, I was not prepared for that"

P5: "It was easier than I had foreseen, I had no side-effects."

P10: "After (stem cell) mobilization, my skin was improving already, I did not expect that."

The patients experienced more physical limitations after HSCT and their recovery took longer than they had expected. The rehabilitation process was mentally taxing, partly due to uncertainty with regard to the level of improvement. Moreover, patients felt disappointed or insecure because of persistent symptoms and limitations, like low energy levels, limited hand function and Raynaud's phenomenon. These symptoms affected return to work as well. Patients with high S-HAQ scores ( $>1.50)$ and low HR-QoL $(<0.75)$ reported unfulfilled expectations from the treatment effects and limitations in rehabilitation more often compared to patient with high HR-QoL and low S-HAQ scores.

P3: "It was a major setback: I could not even climb the stairs."

$P 7:$ "It took long to notice effects of the therapy." 


\section{Emotional recovery is a long-term process: loss of control and loneliness}

During the HSCT procedure and hospitalization, patients felt they had no/little control over their body. They further mentioned that they had lost their sense of time during treatment. Some had no memory of the events during hospitalization. Patients searched for support in processing the events, and some kept a diary or took photos during hospitalization for that purpose.

P9: "Talking to peers is easier, they understand me."

P13: "Some events, I cannot recall at all."

P14: "Support from a nurse during the admission and afterwards helped me a lot."

In addition, many patients felt lonely and sometimes misunderstood by family and friends, which even led to loss of friendships. Some patients deliberately kept their loved ones, particularly their children, at distance to stay focused, and because they did not want them to worry.

P6: "They expect that I can participate in all social events, but I often feel exhausted." P8: "I felt lonely, also with friends around. Nobody can really imagine how it feels." P9: "It is hard sometimes, we both have to process it in our own way."

Loss of control and insecurity were recurrent themes at the end of the long hospitalization period. Most patients did not know beforehand when the discharge day would be, because this depended on the repopulation of the bone marrow or the management of complications. Therefore, the time of discharge often came as a surprise. The patients who experienced complications felt particularly insecure and feared to contract infections, and that the disease would relapse. Moreover, they did not feel prepared to go home.

P10: "There is sufficient information about risks and procedures, but nobody tells you what to expect afterwards, you just go home."

P11: "Things went so fast, still after years I need to process all that has happened." P15: "After I had been so ill, I suddenly had to go home, I was terrified!"

Uncertainty about the future complicated reintegration in society and work, and family planning. It also put a strain on relationships of some patients. Some struggled to find purpose or to redefine their role in their family or in relationships. Half of patients sought psychological support in the first year after HSCT. Most patients were not interested in psychological support before and during treatment. Furthermore, patients desired to be better informed about what to expect with regard to physical or mental rehabilitation, about the time needed to recover, relapse rates and non-medical information including work, social contacts, sexuality and family planning.

P2: "I live by the day and make no further plans, because it is uncertain."

P7: "It was difficult to find my place in society again." 


\section{(Re)Gaining control}

Family and friends provided support and this was of key importance, although some patients thought it also complicated the relationship. Therefore, patients also appreciated help from persons who were not "emotionally involved", such as a specialized nurse or peer support from other patients. Patients much appreciated the easy access to nurses and physicians during hospitalization.

Participants described various strategies to deal with the challenges outlined above. Half of the patients mentioned that they focused on positive outcomes and tried to avoid negative aspects. Secondly, taking action to recover by adhering to a diet and doing sports during and after admission helped patients to find distraction and regain control over their lives.

Others ways to regain control were setting new goals together with their family, or with regard to work.

In the first years after HSCT, the majority of patients stayed away from social events to avoid confrontation with the outside world and because they felt pressured to justify to others that they were not fully recovered yet. On the long-term, most patients managed to cope with these issues and (partly) returned to their "old life".

P9: "Slowly I got back on my feet, except it was not the same life I had before I got ill." P9: "We had plans, and then I got sick. Now we try to make new plans,"

P12: "Fortunately, I could easily get back to my old job after the therapy."

Table 2. Themes and subthemes derived from patients' responses in the interviews

\begin{tabular}{|l|l|l|}
\hline Theme & Subthemes & Recurrent experiences \\
\hline Disruption & Expectations & The real impact of the treatment was felt during admission \\
\hline & & Expectation HSCT will stop or cure the disease \\
\hline & & Expectation to get back to work after HSCT \\
\hline & & Relief: recovery went faster than expected and uneventful. \\
\hline & Persistent fatigue and Raynaud's phenomenon \\
\hline & No idea what to expect post HSCT \\
\hline & Post-HSCT: Concerns about relapse \\
\hline & Sufficient information pretreatment about the procedure and risks \\
\hline & Much emphasis on complications and side-effects \\
\hline & No information about post-transplant period \\
\hline & Emotional impact & Feelings of losing control over health and time \\
\hline & & $\begin{array}{l}\text { Feelings of loneliness: misunderstanding from social contacts, keep social } \\
\text { contacts at distance (protection) }\end{array}$ \\
\hline & Frustration about timing, HSCT should have been done earlier \\
\hline & & Feeling insecure: Going back home after long admission \\
\hline & &
\end{tabular}




\begin{tabular}{|c|c|c|}
\hline & & $\begin{array}{l}\text { Processing events and impact of diagnosis and treatment is happening } \\
\text { mostly after treatment }\end{array}$ \\
\hline & & Concerns about contracting infections \\
\hline & & Uncertainty about future: worrying about relapse \\
\hline & & $\begin{array}{l}\text { Regain confidence in the future: make plans, find new jobs, family } \\
\text { planning }\end{array}$ \\
\hline & & Feeling misunderstood \\
\hline & & Feeling isolated \\
\hline & & Loss of friendships \\
\hline & & Memory loss about the time of hospitalization \\
\hline & & $\begin{array}{l}\text { Mutual coping and communication with partner: uncertainty about future, } \\
\text { remaining limitations, doubts about family planning, sexuality }\end{array}$ \\
\hline \multirow[t]{8}{*}{$\begin{array}{l}\text { Regaining } \\
\text { control }\end{array}$} & Support & Partner plays important role in coping with emotions. \\
\hline & & Balancing sharing information \\
\hline & & Peer support \\
\hline & & Psychosocial support from nurse \\
\hline & Coping strategies & $\begin{array}{l}\text { Protection of children: not sharing all details about prospects and risks. } \\
\text { No hospital visits. }\end{array}$ \\
\hline & & Keeping social contacts at distance: focus on therapy \\
\hline & & Continue with work, as a distraction \\
\hline & & Writing about feelings and experiences, collect pictures \\
\hline
\end{tabular}

\section{Discussion}

HSCT is an effective but risky treatment option for patients with poor prognosis dcSSc. Hitherto it was unknown how patients who have undergone the treatment have experienced the process and their recovery. In this study, we investigated experiences of HSCT and process of recovery using in-depth interviews in sixteen patients who have undergone HSCT. We observed that HSCT has a major physical and psychological impact both during hospitalization and still a long time after discharge, but also that patients eventually found a way to set forth their lives. In particular they lacked information on what to expect with regard to treatment outcomes and prognosis, and needed more time than they had expected to process everything that had happened and to recover physically. They had difficulties with resuming social contacts and work, and patients sometimes faced problems in their relationships and with their sexual health.

We identified major stressors and various coping mechanisms during hospitalization. A major stressor was the uncertainty about treatment outcome and prognosis. Half of the patients used positive coping and "made a positive story" to hold on to. Healthcare professionals' focus on risks of complications did not fit with this coping strategy and patients therefore did not appreciate it. Problem-focused strategy was used in more than half of the patients. Many patients focused on their lifestyle, so they felt they could contribute to a better treatment outcome. Another coping strategy was distancing themselves from their current health problems, to avoid being confronted with emotions and fears, and to keep control of the situation. Some patients found distraction by engaging in other activities. This strategy was also described after HSCT, i.e., patients stayed away from social events to avoid being confronted with remaining limitations or the slow recovery 
process. Others, on the other hand, sought social support to help them cope.

Identification of these stressors could help health care professionals to improve support of patients in clinical practice. The diversity of experiences and needs of patients we observed in the interviews, however, points out that there will not be one approach that fits all.

Preferably, patients' needs should be evaluated on an individual level. Additionally, family members may have to be involved more, in order to reduce the risk of patients feeling lonely and getting into relationship problems, and to support mutual coping.

In line with our findings, other studies in patients undergoing HSCT for hematological malignancies have also reported the high physical and psychological burden of HSCT, even a long time after completing therapy. $(10,23)$ Patients with dcSSc might experience even more physical complaints post-HSCT, because of the involvement of multiple organs in this condition. Coping strategies during and after HSCT, similar to the ones we identified, have been described in patients with hematological malignancies.(24) Moreover, the use of active and avoidant coping styles was associated with more distress during and after the first months after HSCT $(25,26)$. Psychological interventions to help reduce distress, have therefore been implemented in oncology practice, and indeed have shown to help alleviate distress in patient undergoing HSCT (27). Of note, most patients in our study reported that they initially felt no need for psychological support before or during the therapy, but many sought psychological help after treatment.

Rehabilitation therapy following HSCT was not routinely offered to the patients in our study. Half of the patients referred themselves to a physiotherapist, psychologist, or occupational therapist, showing an unmet need in these patients. In a study among 201 patients who were treated with HSCT at a hematology department in the United States, 26\% received rehabilitation therapy early after transplantation.(28) These patients had worse functional scores prior to HSCT compared to the patients who were not referred to this type of therapy. Their functional performance increased significantly after the rehabilitation intervention. The beneficial effects of rehabilitation interventions on fatigue and social health in hematologic patients who underwent HSCT, were shown in a cross-sectional study $(n=171)$ (29). Rehabilitation therapy prior to HSCT was further demonstrated to be safe and effective in a pilot study including 29 patients (30). Altogether, provision of more extensive supportive care in hematology patients has shown its benefits, and the problems identified in the present study suggest that more extensive support may also be beneficial to patients with dcSSc who are undergoing HSCT. Further research is needed to determine if, and what sort of, strategy could help optimize physical and mental recovery after HSCT, and support coping with (temporary) disabilities post-HSCT.

Our study has some limitations. First, there is a risk of recall bias. For some patients, HSCT took place several years ago. Second, perceptions may be colored by current health status and HR-QoL, which was remarkably good in most patients. Third, healthcare provision in general has changed over the years, so problems reported from experiences a decade ago might already have been be addressed in current care. In this rare condition, however, it was not possible to include more patients who recently underwent HSCT. A strength of this study is that we included a relatively large group of patients from different hospitals and in different health states. Moreover, it is, to our knowledge, the first study addressing the patient experience of HSCT.

In conclusion, our study provides insight in the experiences of patients with regard to HSCT and recovery phase after hospitalization. HSCT clearly has a major impact on daily 
functioning and quality of life. Patients should be better informed about the course of recovery after this intensive therapy and the psychosocial impact of it. Diverse ways of support (i.e. peer contacts, a rehabilitation program, or job coach) should be offered proactively during and after HSCT. The identified unmet needs in our study can be used as a starting point to develop strategies to optimally support patients.

\section{Acknowledgements}

We gratefully acknowledge all the patients who participated in this study.

\section{References}

1. Elhai M, Meune C, Boubaya M, Avouac J, Hachulla E, Balbir-Gurman A, et al. Mapping and predicting mortality from systemic sclerosis. Annals of the rheumatic diseases. 2017; 76(11):1897-1905.

2. Ioannidis JP, Vlachoyiannopoulos PG, Haidich AB, Medsger TA, Lucas M, Michet CJ et al. Mortality in systemic sclerosis: an international meta-analysis of individual patient data. Am J Med. 2005; 118(1):210.

3. Denton CP, Black CM, Abraham DJ. Mechanisms and consequences of fibrosis in systemic sclerosis. Nature Clin Pract Rheumatol. 2006; 2(3):134-144.

4. Burt RK, Shah SJ, Dill K, Grant T, Gheorghiade M, Schroeder J et al. Autologous non-myeloablative haemopoietic stem-cell transplantation compared with pulse cyclophosphamide once per month for systemic sclerosis (ASSIST): an open-label, randomised phase 2 trial. Lancet. 2011; 378(9790):498-506.

5. Sullivan KM, Goldmuntz EA, Keyes-Elstein L, McSweeney PA, Pinckney A, Welch B, et al. Myeloablative Autologous Stem-Cell Transplantation for Severe Scleroderma. New Engl J Med. 2018; 378(1):35-47.

6. van Laar JM, Farge D, Sont JK, Naraghi K, Marjanovic Z, Larghero J, et al. Autologous hematopoietic stem cell transplantation vs intravenous pulse cyclophosphamide in diffuse cutaneous systemic sclerosis: a randomized clinical trial. JAMA. 2014;311(24):2490-2498.

7. Snowden JA, Badoglio M, Labopin M, Giebel S, McGrath E, Marjanovic Z, et al. Evolution, trends, outcomes, and economics of hematopoietic stem cell transplantation in severe autoimmune diseases. Blood Adv. 2017; 1(27):2742-2755.

8. El-Jawahri AR, Traeger LN, Kuzmuk K, Eusebio JR, Vandusen HB, Shin JA, et al. Quality of life and mood of patients and family caregivers during hospitalization for hematopoietic stem cell transplantation. Cancer. 2015;121(6):951-959.

9. Gastó JMP, Atala J, Blanch J, Carreras E, Rovira M, Cirera E. Patient-rated emotional and physical functioning among hematologic cancer patients during hospitalization for stem-cell transplantation. Bone Marrow Transplant. 2005; 35(3):307.

10. McQuellon RP, Russell GB, Rambo TD, Craven BL, Radford J, Perry JJ, et al. Quality of life and psychological distress of bone marrow transplant recipients: the 'time trajectory' to recovery over the first year. Bone Marrow Transplant. 1998; 21(5):477-486.

11. Marshall MN. Sampling for qualitative research. J Fam Prac. 1996;13(6):522-5.

12. Corbin J SA. Basics of qualitative research: Techniques and procedures for developing grounded theory. Third ed. Thousand Oaks: Sage; 2008.

13. Guest G, Bunce A, Johnson L. How many interviews are enough? An experiment with data saturation and variability. Field Methods. 2006 (18):59-82.

14. Bailey J. First steps in qualitative data analysis: transcribing. J Fam Prac. 2008; 25(2):127-31.

15. Charmaz. Constructing grounded theory. A practical guide through qualitative analysis. London: Sage; 2006.

16. van Reenen M JB. EQ-5D-5L User Guide. EuroQol Research Foundation. 2015.

17. Poole JL, Steen VD. The use of the Health Assessment Questionnaire (HAQ) to determine physical disability in systemic sclerosis. Arthritis Care Res. 1991; 4(1):27-31.

18. Morgan DL. Practical strategies for combining qualitative and quantitative methods: applications to health research. Qual Health Res. 1999; 8(3):362-376.

19. Johnson SR, O'Brien KK. Qualitative Methods in Systemic Sclerosis Research. J Rheumatol. 2016; 43(7):1265-1267.

20. Ltd. QIP. NVivo qualitative data analysis Software (computer program). Version 10, 2012 ed. 
21. Tong A, Sainsbury P, Craig J. Consolidated criteria for reporting qualitative research (COREQ): a 32-item checklist for interviews and focus groups. Int J Qual Health Care. 2007; 19(6):349-357.

22. Lincoln Y GE. Naturalistic Inquiry. Newbury Park, CA: Sage Publications 1985.

23. Amonoo HL, Massey CN, Freedman ME, El-Jawahri A, Vitagliano HL, Pirl WF, et al. Psychological Considerations in Hematopoietic Stem Cell Transplantation. Psychosomatics. 2019; 60(4):331-342.

24. Farsi Z, Dehghan Nayeri N, Negarandeh R. Coping strategies of adults with leukemia undergoing hematopoietic stem cell transplantation in Iran: a qualitative study. Nurs Health Sci. 2010; 12(4):485492.

25. Baliousis M, Rennoldson M, Dawson DL, Mills J, das Nair R. Perceptions of Hematopoietic Stem Cell Transplantation and Coping Predict Emotional Distress During the Acute Phase After Transplantation. Oncol Nurs Forum. 2017; 44(1):96-107.

26. Wells KJ, Booth-Jones M, Jacobsen PB. Do coping and social support predict depression and anxiety in patients undergoing hematopoietic stem cell transplantation? J Psych Oncol. 2009; 27(3):297-315.

27. Baliousis M, Rennoldson M, Snowden JA. Psychological interventions for distress in adults undergoing haematopoietic stem cell transplantation: a systematic review with meta-analysis. Psycho-oncology. 2016; 25(4):400-411.

28. 2Laine J, D’Souza A, Siddiqui S, Sayko O, Brazauskas R, Eickmeyer SM. Rehabilitation referrals and outcomes in the early period after hematopoietic cell transplantation. Bone Marrow Transplant. 2015; 50(10):1352-1357.

29. Park J, Wehrlen L, Mitchell SA, Yang L, Bevans MF. Fatigue predicts impaired social adjustment in survivors of allogeneic hematopoietic cell transplantation (HCT). Support Care Cancer. 2019; 27(4):1355-1363.

30. van Haren I, Staal JB, Potting CM, Atsma F, Hoogeboom TJ, Blijlevens NMA, et al. Physical exercise prior to hematopoietic stem cell transplantation: A feasibility study. Physiother Theory Pract. 2018; 34(10):747-756. 


\section{Abstract}

Introduction. Systemic sclerosis (SSc) is a chronic, autoimmune connective tissue disease associated with high morbidity and mortality, especially in diffuse cutaneous SSc (dcSSc). Currently there are several treatments available in early dcSSc that aim to change the disease course, including immunosuppressive agents and autologous hematopoietic stem cell transplantation (HSCT). HSCT has been adopted in international guidelines and is offered in current clinical care. However, optimal timing and patient selection for HSCT is still unclear. In particular, it is unclear whether HSCT should be positioned as upfront therapy or rescue treatment for patients refractory to immunosuppressive therapy. We hypothesise that upfront HSCT is superior and results in lower toxicity and lower long-term medical costs. Therefore, we propose this randomized trial aiming to determine the optimal treatment strategy for early dcSSc by comparing two strategies used in standard care: A. upfront autologous HSCT versus B. immunosuppressive therapy (intravenous cyclophosphamide pulse therapy followed by mycophenolate mofetil) with rescue HSCT in case of treatment failure.

Methods and analysis. The UPSIDE (Upfront autologous hematopoietic Stem cell transplantation versus Immunosuppressive medication in early DiffusE cutaneous systemic sclerosis) study is a multicentre, randomized, open label, controlled trial. In total, 120 patients with early dcSSc will be randomized. The primary outcome is event free survival at two years after randomisation. Secondary outcomes include serious adverse events, functional status, and health related quality of life. We will also evaluate changes in nailfold capillaroscopy pattern, pulmonary function, cardiac MR and High Resolution-CT of the chest. Follow-up visits will be scheduled 3-monthly for 2 years and annually in the following 3 years.

Ethics and dissemination. The study was approved by the Dutch Central Committee on Research Concerning Human Subjects (NL72607.041.20). The results will be disseminated through patient associations and conventional scientific channels.

Trial registration number. NCT04464434, trial NL 8720

\section{Strengths and limitations of this study}

$\rightarrow$ This study is a multicentre, randomized, controlled and open-label trial aiming to determine whether upfront autologous stem cell transplantation (HSCT) is superior to standard immunosuppressive treatment (with rescue HSCT for those who progress), in early diffuse cutaneous systemic sclerosis (dcSSc).

$\rightarrow$ Event free survival is the primary outcome measure and is defined as the time in days from randomisation until death due to any cause or the development of persistent major organ failure (heart, lung, or kidney).

$\rightarrow$ This clinical trial has the potential to change clinical practice in early dcSSc worldwide 


\section{chapter 11}

\section{A randomized, open-}

label trial to assess

the optimal treatment strategy in early diffuse cutaneous systemic sclerosis: the UPSIDE Study protocol 


\section{Introduction}

Systemic sclerosis (SSc) is a debilitating and incurable autoimmune connective tissue disease. Clinical features include vasculopathy, fibrosis and inflammation of skin and internal organs (1). Presentation and disease course are very heterogenous. In the diffuse cutaneous subset of SSc (dcSSc) there is generalized skin thickening and often multiorgan involvement (2-4). Due to its progressive character, the median 5 and 12 -year mortality for dcSSc is $\sim 25 \%$ and $70 \%$ respectively $(5,6)$. To prevent progression and death in SSc patients, it is key to identify individuals at risk at an early stage of the disease and initiate immunomodulating treatment. Methotrexate, mycophenolate mofetil and cyclophosphamide are commonly used in dcSSc, dependent on the organ system involved.

In three randomized controlled trials (RCT) in dcSSc, treatment with autologous hematopoietic stem cell transplantation (HSCT) improved survival, quality of life, skin fibrosis and prevented disease progression in dcSSc patients, when compared to cyclophosphamide pulse therapy (7-9). Additionally, three systematic reviews were published on the efficacy and safety of HSCT in SSc.(10-12) In all reviews it was concluded that HSCT provided a survival benefit, improved skin involvement and stabilized pulmonary function compared to intravenous cyclophosphamide for 12 months. Heterogeneity between studies, however, prevented meta-analysis, yet a trend towards better outcome was observed in patients with a shorter disease duration prior to HSCT. HSCT has since been implemented in (inter)national treatment guidelines for SSc, made its way into regular clinical care and is reimbursed in several European countries (13,14). However, recommendations regarding the optimal use and especially the preferred timing of HSCT and the efficacy of other therapies in the course of dcSSc are lacking. Particularly, it is unclear whether HSCT should be positioned as upfront or as rescue treatment for patients not responding to immunosuppressive therapy such as MMF or intravenous pulse CYC. HSCT as upfront treatment might result in better outcomes, because the disease process is effectively targeted early in the disease at a time when there is less irreversible organ damage. On the other hand, HSCT is a treatment associated with a higher risk of adverse events compared to other treatments, as it is associated with a treatment related mortality of approximately $10 \%(8,15)$. However, there might be fewer transplant related adverse events due to the better health status of patients and limited immunosuppressive premedication if HSCT is commenced early, compared to the patients that need rescue HSCT after months or even years of other immunocompromising agents. So, in order to determine the optimal treatment strategy in early dcSSc, further investigation is needed.

This manuscript describes the protocol of the UPSIDE study (Upfront autologous hematopoietic Stem cell transplantation versus Immunosuppressive medication in early DiffusE cutaneous systemic sclerosis). The UPSIDE study is a multicentre randomized open-label controlled trial that aims to compare two treatment strategies used in standard care of adult patients with early dcSSc: upfront autologous HSCT versus intravenous cyclophosphamide pulse therapy followed by oral mycophenolate mofetil and rescue HSCT in case of treatment failure. Efficacy, safety, survival and cost-effectiveness will be evaluated.

\section{Aims and objectives}

The UPSIDE study aims to investigate the optimal timing of HSCT in early dcSSc by comparing two treatment strategies: the effect of HSCT as upfront therapy compared with that of immunosuppressive medication and HSCT in case of failure, with respect to (event- 
free) survival and prevention of major organ failure, safety and the impact on skin thickening, visceral involvement, functional status, and quality of life.

Secondary goals are to evaluate (in both treatment arms) whether disease activity correlates with immunological parameters, including immunopathology of skin, immune reconstitution, and autoantibodies. Cost-effectiveness of both therapeutic options and factors associated with response to treatment will also be examined.

\section{Methods and analysis}

\section{Study design and setting}

The UPSIDE study is a randomized controlled, multicentre, open-label trial.

$\mathrm{SSc}$ is a rare condition and stem cell mobilisation after intravenous cyclophosphamide administration, and HSCT are treatments only performed in experienced tertiary treatment centres. Therefore, national and international collaboration is of key importance to include the necessary number of patients. Participants will be recruited from fourteen participating centres from The Netherlands, Belgium, Germany, Italy, Sweden, Switzerland and Croatia (Table 1). Multidisciplinary expert teams in the field of SSc and HSCT are involved in each centre.

Table 1. Participating centres

\begin{tabular}{|l|l|}
\hline Country & Centres and affiliated networks \\
\hline The Netherlands & $\begin{array}{l}\text { Amsterdam UMC } \\
\text { Leiden University Medical Centre } \\
\text { Radboudumc Niimegen } \\
\text { University Medical Centre Utrecht (coordinating centre) } \\
\text { National scleroderma network: } \\
\text { Arthritis Research and Collaboration Hub (ARCH) }\end{array}$ \\
\hline Belgium & $\begin{array}{l}\text { University Hospital Ghent } \\
\text { University Hospital Leuven }\end{array}$ \\
& $\begin{array}{l}\text { National scleroderma network: } \\
\text { Belgian Scleroderma Cohort. }\end{array}$ \\
\hline Germany & $\begin{array}{l}\text { Ruhr University Bochum } \\
\text { University Hospital Freiburg } \\
\text { Universitats Klinikum Tuebingen } \\
\text { Universitats Klinikum Wurzburg }\end{array}$ \\
\hline Sweden & $\begin{array}{l}\text { Karolinska University Hospital Stockholm } \\
\text { Skåne University Hospital Lund }\end{array}$ \\
\hline Switzerland & University Hospital Basel \\
\hline Italy & ASST Pini-CTO, Milano \\
\hline Croatia & University Hospital Zagreb \\
\hline
\end{tabular}


Table 2. Inclusion and exclusion criteria

\begin{tabular}{|c|c|}
\hline Inclusion criteria & Exclusion criteria \\
\hline Age between 18 and 65 years. & $\begin{array}{l}\text { Pregnancy or unwillingness to use adequate } \\
\text { contraception during study. }\end{array}$ \\
\hline $\begin{array}{l}\text { Fulfilling the } 2013 \text { ACR-EULAR classification criteria for } \\
\text { dcSSc }\end{array}$ & $\begin{array}{l}\text { Poor compliance of the patient as assessed by the } \\
\text { referring physicians. }\end{array}$ \\
\hline $\begin{array}{l}\text { Disease duration } \leq 2 \text { years (from onset of first non- } \\
\text { Raynaud's symptoms) } \\
\text { 1. mRSS } \geq 15 \text { (diffuse skin pattern) and/or } \\
\text { 2. clinically significant organ involvement as defined } \\
\text { by either: } \\
\text { a. respiratory involvement = } \\
\text { i. DLCO and/or (F)VC } \leq 85 \% \text { (of predicted) and } \\
\text { evidence of interstitial lung disease on HR-CT scan with } \\
\text { clinically relevant obstructive disease and emphysema } \\
\text { excluded. } \\
\text { ii. Patients with a DCLO and/or FVC }>85 \% \text {, but with } \\
\text { a progressive course of lung disease: defined as } \\
\text { relative decline of } \geq 10 \% \text { in FVC predicted and/or } \\
\text { TLC predicted, or } \geq 15 \% \text { in DLCO predicted within } 12 \\
\text { months. Intercurrent infections excluded. } \\
\text { b. renal involvement = any of the following criteria: } \\
\text { hypertension (two successive BP readings } \\
\text { of either systolic } \geq 160 \text { mm Hg or diastolic }>110 \\
\text { mm Hg, at least } 12 \text { hours apart), persistent urinalysis } \\
\text { abnormalities (proteinuria, haematuria, casts), } \\
\text { microangiopathic haemolytic anaemia, } \\
\text { new renal insufficiency (serum creatinine > upper limit of } \\
\text { normal); non-scleroderma related } \\
\text { causes (e.g. medication, infection etc.) must be } \\
\text { reasonably excluded. } \\
\text { c. cardiac involvement = any of the following criteria: } \\
\text { reversible congestive heart failure, atrial or ventricular } \\
\text { rhythm disturbances such as atrial fibrillation or } \\
\text { flutter, atrial paroxysmal tachycardia or ventricular } \\
\text { tachycardia, } 2 \text { nd or } 3 \text { rd degree AV block, pericardial } \\
\text { effusion (not leading to hemodynamic problems), } \\
\text { myocarditis; non-scleroderma related causes must have } \\
\text { been reasonably excluded }\end{array}$ & 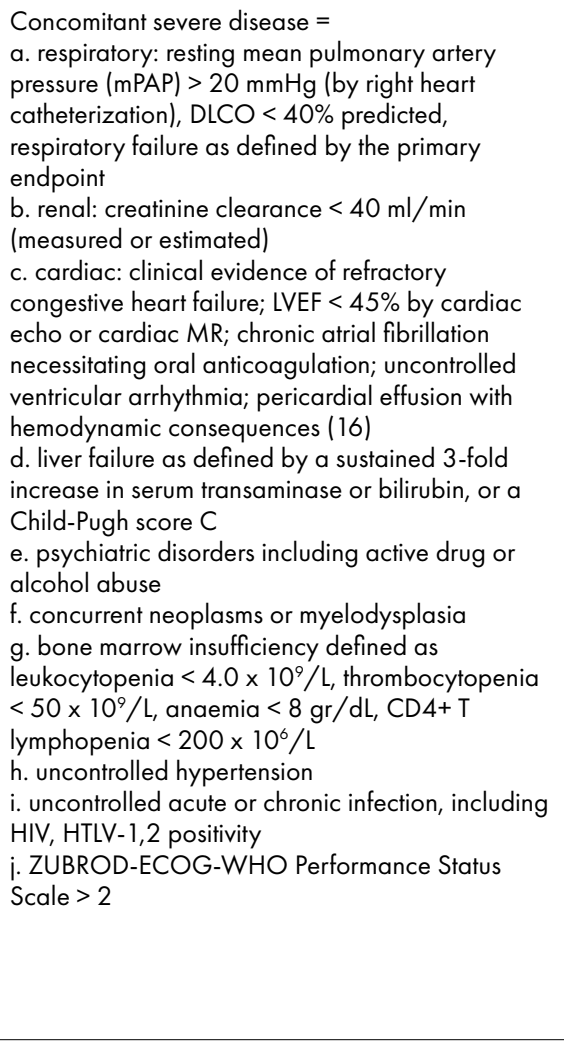 \\
\hline \multirow[t]{4}{*}{ Written informed consent } & $\begin{array}{l}\text { Previous treatments with immunosuppressants } \\
>6 \text { months including mycophenolate mofetil, } \\
\text { methotrexate, azathioprine, rituximab, tocilizumab, } \\
\text { glucocorticoids. }\end{array}$ \\
\hline & $\begin{array}{l}\text { Previous treatments with TLI, TBI or alkylating agents } \\
\text { including cyclophosphamide. }\end{array}$ \\
\hline & $\begin{array}{l}\text { Significant exposure to bleomycin, tainted } \\
\text { rapeseed oil, vinyl chloride, trichlorethylene or } \\
\text { silica }\end{array}$ \\
\hline & $\begin{array}{l}\text { Eosinophilic myalgia syndrome; eosinophilic } \\
\text { fasciitis, morphea. }\end{array}$ \\
\hline
\end{tabular}




\section{Study population and eligibility criteria}

We will include 120 patients with early dcSSc who fulfil the inclusion criteria (table 2). These criteria are designed to select patients in an early stage of the disease, but at high risk of disease progression and subsequent death. We anticipate the accrual time will be 4 years. Baseline assessment prior to randomisation includes complete blood count, liver function, kidney function, urine portion analysis, viral serology tests, 12-lead ECG, cardiac ultrasound, cardiac MRI, right heart catheterization, lung HR-CT and pulmonary function tests.

\section{Randomisation}

Eligible patients who provided informed consent will be randomised 1:1 (variable block randomisation) using the validated algorithm within Castor, the Electronic Data Capture program used for the study. Blocks of 2, 4, or 6 patients will be randomly and blindly assigned, stratified by participating centre. The two treatment are: strategy arm A: upfront high dose non-myeloablative autologous HSCT or strategy arm B: intravenous pulse therapy with cyclophosphamide followed by at least 12 months oral mycophenolate mofetil daily and thereafter HSCT as rescue option. The treatment allocation will be coordinated by the principal investigator of the study site. The investigators and participants are not blinded to treatment allocation.

\section{Interventions}

A. Upfront autologous HSCT

Autologous, non-myeloablative HSCT comprises the following consecutive steps:

a. Mobilisation: PBSCs will be mobilised using a regimen consisting of infusion of cyclophosphamide $2 \mathrm{~g} / \mathrm{m}^{2}$ for 1 day. Hyperhydration, alkalinisation of the urine and Mesna will be given in order to prevent haemorrhagic cystitis. The patients will receive filgrastim (G-CSF) $5 \mu \mathrm{g} / \mathrm{kg} /$ day subcutaneously once or twice a day for 5 days (or more when necessary) according to local practice. Administration of filgrastim starts 5 days after the last cyclophosphamide infusion. Mobilisation can be done either at a day care unit or inpatient admission, according to local practice.

b. Leukapheresis: Start of leukapheresis is required at a CD34+ cell count of $\geq 10-20 / \mu \mathrm{L}$, according to local practice. This is expected to occur on day 5 or 6 of filgrastim treatment. Leukapheresis will be performed with the goal to obtain at least $6 \times 10^{6} \mathrm{CD} 34+$ cells per kilogram body weight. The primary goal is to obtain a target dose of $6 \times 10^{6} \mathrm{CD} 34+\mathrm{cells} / \mathrm{kg}$, but a minimum of $2 \times 10^{6} \mathrm{CD} 34+$ cells/kg after CD34+selection. The apheresis product will be 4-5 $\log T$ cell depleted. The CD34+ selected cells will be cryopreserved and stored in liquid nitrogen until reinfusion. In case of mobilisation failure, the patient will be treated with daily s.c. filgrastim upto $20 \mu \mathrm{g} / \mathrm{kg}$.

c. Prior to conditioning: Echocardiography should be repeated prior to conditioning to evaluate possible subclinical cardiac toxicity caused by cyclophosphamide administered during mobilisation. Conditioning can be initiated if LVEF > $45 \%$ or has not decreased with $>15 \%$ compared to pre-mobilisation, and there are no uncontrolled arrhythmias (16).

d. Conditioning: Conditioning is to be initiated preferably within 6 weeks after successful harvest. The conditioning regimen consists of cyclophosphamide $50 \mathrm{mg} / \mathrm{kg} / \mathrm{day}$ intravenously for 4 consecutive days (total $200 \mathrm{mg} / \mathrm{kg}$ ) and rabbit antithymocyte globulin (rbATG, Thymoglobulin $\AA$ ). The first dose of cyclophosphamide will be given on day -5 (day $0=$ day of infusion of PBSC). Hyperhydration, alkalinisation of the urine and Mesna will be given in order to prevent haemorrhagic cystitis. A total dose of $7.5 \mathrm{mg} / \mathrm{kg}$ intravenous rbATG will be 
administered over three days. Intravenous methylprednisolone $2 \mathrm{mg} / \mathrm{kg}$ will be given on the days ATG will be administered, to improve tolerability of the ATG.

e. Peripheral stem cell infusion: The interval between the last dose of cyclophosphamide and infusion of the graft will be at least 48 hours. On day 0, CD34+ selected stem cells are thawed and infused according to local standard operating procedures. The number of CD34+ cells to be reinfused should be $\geq 2.0 \times 10^{6} / \mathrm{kg}$, residual T cell content is targeted at $\leq 1.0$ $\times 10^{5} \mathrm{~T}$ cells $/ \mathrm{kg}(17)$. Exceptional release according to local practice is allowed and will be registered in the eCRF.

Arm B. Cyclophosphamide followed by mycophenolate mofetil and HSCT as rescue option Immunosuppressive therapy in arm B consists of 12 monthly intravenous pulses of cyclophosphamide $750 \mathrm{mg} / \mathrm{m}^{2}$ (= $9 \mathrm{~g} / \mathrm{m}^{2}$ cumulative) followed by at least 12 months of oral mycophenolate mofetil daily (3 grams as maximum daily dosage) or mycophenolic acid (up to 2.160 grams daily), according to local practice. Hyperhydration, alkalinisation of urine and Mesna is recommended during the 12 monthly intravenous pulses cyclophosphamide, and will be given according to local protocols in order to prevent haemorrhagic cystitis.

\section{Supportive care}

Supportive care measures, including prophylactic or therapeutic antibiotics, anti-viral or anti-fungal agents, cell replacement therapy and anti-emetic agents will be taken according to local standard operating procedures for such patients. In case of HSCT, particular attention will be paid to the risk of EBV and CMV-reactivation. EBV and CMV-load will be monitored by PCR weekly in the first three months following transplantation, then monthly for the next 9 months. In case of reactivation, the patient will be treated according to standard of care guidelines.

Initiation of an ACE-inhibitor prior to HSCT is strongly recommended (i.e. enalapril $5 \mathrm{mg}$ once daily) to prevent scleroderma renal crisis based on the clinical experience from the ASTIStrial (8).

\section{Study outline}

An overview of the study outline is shown in Figure 1 (study flow diagram). After randomisation, concurrent immunosuppressive therapy will be discontinued.

Glucocorticoids may be continued at the lowest possible dose. Either treatment is to be initiated within six weeks after randomisation, i.e. mobilisation in patients randomised to $\operatorname{Arm} A$, and the first pulse of cyclophosphamide in patients randomized to Arm B. Rescue therapy may be considered in both arms in case of insufficient response or clinically relevant flare, but preferably not within the first 6 months after randomisation. For patients from Arm A methotrexate, mycophenolate mofetil or mycophenolic acid, or rituximab can be (re)instituted, according to local preference. Based on earlier studies, the clinical benefits of i.v. pulse cyclophosphamide may take between 6-12 months. Therefore it is recommended to then switch patients from arm B to HSCT only in case of rapidly progressive disease, which is arbitrarily defined as $\geq 30 \%$ increase in $m R S S$ or $\geq 20 \%$ relative decline in FVC, TLC, or DLCO predicted. 
Figure 1. Study flow diagram

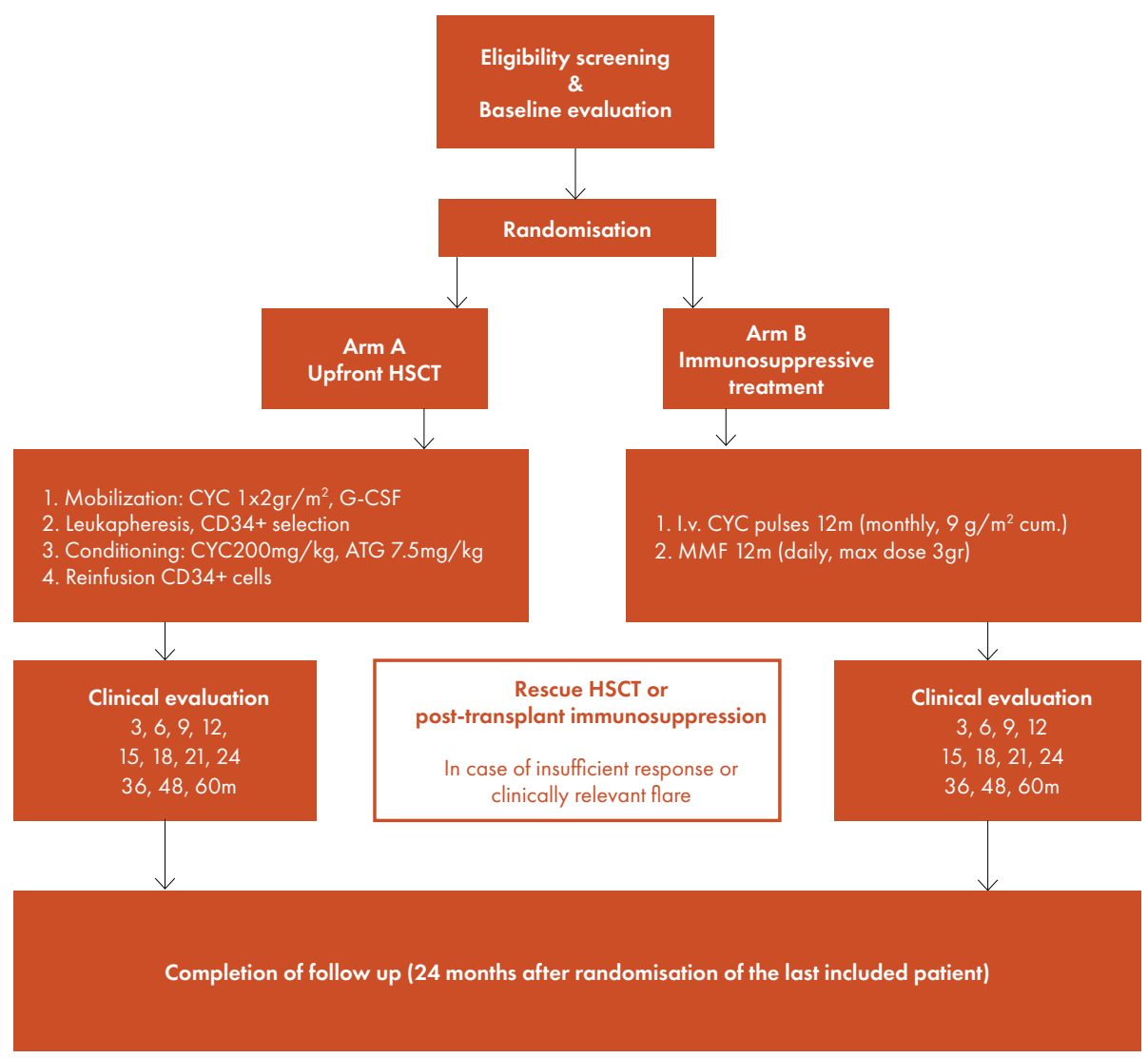

\section{Outcomes and follow-up}

The primary endpoint of the study will be event-free survival. Event-free survival is defined as the time in days from the day of randomisation until the occurrence of death due to any cause or the development of persistent major organ failure (heart, lung, kidney) defined as follows:

- Heart: left ventricular ejection fraction $<30 \%$ by cardiac MR (or cardiac echo)

- Lungs: respiratory failure = resting arterial oxygen tension $\left(\mathrm{PaO}_{2}\right)<8 \mathrm{kPa}(<60 \mathrm{mmHg})$ and/ or resting arterial carbon dioxide tension $\left(\mathrm{PaCO}_{2}\right)>6.7 \mathrm{kPa}(>50 \mathrm{mmHg})$ without oxygen supply, or need of oxygen supply.

- Kidney: need for renal replacement therapy (i.e. dialysis) 
Secondary outcome measures include:

1. Progression-free survival, defined as the time in days since the day of randomisation until any of the following relative changes from baseline has been documented: death, $\geq 10 \%$ drop in (F)VC predicted and/or $\geq 15 \%$ drop in DLCO predicted (18), $\geq 15 \%$ drop in LVEF by echo or cardiac MR, $\geq 15 \%$ drop in body weight, $\geq 30 \%$ drop in creatinine clearance, $\geq 25 \%$ and $\geq 5$ points increase in skin score, $\geq 0.5$ increase in SHAQ.

2. Treatment related mortality, defined as any death during the study period following randomisation that cannot be attributed to progression of the disease according to the consensus opinion of the Data and Safety Monitoring Board (DSMB).

3. Overall Survival

4. Treatment toxicity and adverse events, using Common Terminology Criteria for Adverse Events toxicity parameters version 5.0 ( $\geq$ grade 3 toxicity). Viral infections will be graded according to the Bone Marrow Transplant Clinical Trials Network.

5. The area under the curve (AUC) of the combined response index for systemic sclerosis (CRISS) over time, measuring the 'predicted probability of being improved' over 2 years. This AUC is calculated based on 4 repeated measures (6,12,18 and 24 months) with back translation to the original scale between 0 and 1 .

6. Change from baseline over time (i.e. during follow-up) of the following parameters: modified Rodnan Skin Score (mRSS), pulmonary involvement: diffusion capacity for carbon monoxide (DLCO and DLCO/VA), (forced)vital capacity ((F)VC), total lung capacity (TLC), residual volume (RV), mean pulmonary artery pressure by cardiac echo (or right heart catheterization), lung density measurement by thoracic CT and 18 FDG-PET scan lung, renal involvement: urine portion: creatinine/ protein ratio, myocardial involvement: left ventricular function as measured by cardiac MR, body weight (kg), changes in nailfold capillaroscopy, quality-of-life (EuroQol (EQ-5D-5L)), SHAQ including visual analogue scales (VAS) for scleroderma-specific symptoms, gastrointestinal symptom scale (UCL-SCTC GIT 2.0 questionnaire), sexual functioning (short IIEF-5 questionnaire (in men) and SFQ-28 (in women)), fatigue score (FACIT questionnaire), productivity losses due to health issues (customised iPCQ questionnaire), characteristics of the immune system: autoantibody concentration and avidity targeting host nuclear antigens, primarily focusing on anti-ATA, anti-RNAPIII and anti-CENP, isotype usage, isotype levels, Fc-glycosylation profiles of antitopoisomerase and skewing of T cell receptor repertoire and determination of HLA profiles, composition of the microbiome in the gut and skin, inflammatory and fibrotic characteristics of the skin, levels of ATG in relation with changes in lymphocyte subsets and outcomes. Follow-up appointments will be according to regular care: monthly the first half year, then three-monthly until two years after randomisation, followed by annual appointments for three years (Table 3).

\section{Statistical analyses}

\section{Sample size}

The sample size is determined assuming a median event-free survival of 2 years in the control group and an (approximate) exponential survival curve based on the survival observed in the HSCT arm of the ASTIS trial (7). We expect our proposed intervention to result in a considerable improvement (assumed hazard ratio of 0.5 ) and take a total study period of 5 years with 2 years follow up of the last patient enrolled ( 3 years for recruiting patients at 
a constant rate), $10 \%$ loss to follow up after 5 years in both groups and an alpha of 0.05 into account. Based on the above, we will need 60 patients per group to have at least $80 \%$ power to detect a difference as calculated using the SAS power procedure (two sample survival, log rank test). Based on the incidence of dcSSc and the collective treatment experience of the 15 trial sites, we anticipate we can enrol the required 120 patients (60 per group) within 3 years and complete the trial within 5 years $(19,20)$.

\section{Primary outcome}

Data will be analysed on an intention-to-treat basis. Data regarding adverse events and SAEs will be provided using descriptive statistics and tables. Population characteristics will be provided using descriptive statistics. To compare event free survival (the primary endpoint) and other time-to-event outcomes between treatment groups, Kaplan Meyer (KM) curves will be constructed (based on first event) and tested using the log-rank test and Cox regression to take important prognostic covariates (sex, age, smoking status, cardiac function) and centre (stratification factor for randomisation), as determined a priori (before database lock) in SAP, into account. For all time-to-event outcome data is censored at the last visit. Based on a visual inspection of the KM curves also a treatment $x$ time interaction will be modelled in the Cox regression analysis to allow for non-constant hazards over time. An intention to treat (ITT) analysis (primary) and per protocol (PP) analysis will be performed. In the primary analysis for patients leaving the study early (early dropout) this last visit will be treated as the censoring date, a multiple-imputation method for sensitivity analyses of time-to-event data accounting for possible informative censoring will also be performed.

\section{Secondary outcomes}

Secondary continuous outcomes (i.e. change from baseline in CRISS score)(21) measured over time will be analysed using mixed modelling approaches if needed based on graphical inspection including a treatment $x$ time interaction, controlling for important prognostic covariates (sex, age, smoking habit) and centre (stratification factor for randomisation). For binary outcomes at a fixed timepoint, frequencies and proportions will be calculated and differences tested using Chi-square or Fisher exact tests. The effects of covariates will be evaluated using logistic regression. An intention to treat (ITT) analysis (primary) and per protocol (PP) analysis will be performed. A cost effectiveness analyses will be performed from a societal perspective including direct medical and non-medical and productivity costs. Cost-per-QALY gained as well as costs per life year and per event-free life year gained will be calculated. The economic evaluation will be done at 5 years in line with the duration of the trial and the evaluation will be performed in line with the Dutch guidelines for economic evaluations (22).

\section{Interim analysis}

There will be an interim analysis at 12 months after the first inclusion and/or after 60 patients have been included, whatever comes first, and at the DSMB request. Formal statistical methods for evaluating interim efficacy and toxicity results will be used as guidelines rather than absolute rules. An alpha spending function (O'Brien-Fleming) will be used. Reasons for DSMB decisions will be recorded. 
Table 3. Data collection

\begin{tabular}{|c|c|c|c|c|c|c|c|c|c|c|c|}
\hline & D. & 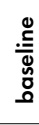 & 3 & 6 & 9 & 12 & 15 & 18 & 21 & 24 & 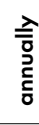 \\
\hline Survival status & \multicolumn{11}{|c|}{ Continuous registration } \\
\hline Toxicity according to CTC criteria (=/>grade 3$)$ & $x$ & $x$ & $x$ & $x$ & $x$ & $x$ & $x$ & $x$ & $x$ & $x$ & $x$ \\
\hline mRSS & $x$ & $x$ & $x$ & $x$ & $x$ & $x$ & $x$ & $x$ & $x$ & $x$ & $x$ \\
\hline $\begin{array}{l}\text { Laboratory } \\
\text { A. ESR, Hb, WBC with differential, platelet count, } \\
\text { C3, C4, Clq } \\
\text { B. Electrolytes, renal, liver function tests, albumin } \\
\text { C. Autoantibody titers (ANA, Scl70, RNA pllI) } \\
\text { D. Urine portion: creatinin/ protein ratio } \\
\text { E. Serology CMV, EBV, HBV, HCV, HIV, HSV, } \\
\text { HTLV- 1,2, VDRL, VZV } \\
\text { F. Immunophenotyping by FACS of PBMCs: CD3+, } \\
\text { CD4+, CD8+, CD4+ CD45RA, CD4+ CD45RO, } \\
\text { CD3- CD56+ CD 16+, CD 19+, CD 14+; IgG, IgA, } \\
\text { IgM). } \\
\text { G. Women: FSH, anti-Müllerian hormone } \\
\text { Men: TSH, testosterone, prolactin } \\
\text { H. Blood and urine samples for immunologic } \\
\text { studies and ATG levels }\end{array}$ & $\begin{array}{l}x \\
x \\
x \\
x \\
x\end{array}$ & $x$ & $x$ & $x$ & $x$ & $\begin{array}{l}x \\
x \\
x\end{array}$ & & $x$ & & $\begin{array}{l}x \\
x \\
x \\
x\end{array}$ & $\begin{array}{l}x \\
X \\
X\end{array}$ \\
\hline $\begin{array}{l}\text { Image studies } \\
\text { A. HRCT } \\
\text { B. Pulmonary function studies } \\
\text { C. } 24 \text { hour ECG Holter } \\
\text { D. Cardiac echo } \\
\text { E. Cardiac MR } \\
\text { F. Right heart catheterization } \\
\text { G. } 18 \text { F FDG-PET scan from the thorax } \\
\text { H. Nailfold capillaroscopy }\end{array}$ & $\begin{array}{l}X \\
X \\
X \\
X \\
X\end{array}$ & $\begin{array}{l}x \\
x\end{array}$ & & $x$ & & $\begin{array}{l}x \\
x \\
x \\
x \\
x \\
x\end{array}$ & & $x$ & & $\begin{array}{l}x \\
x\end{array}$ & $\begin{array}{l}x \\
x\end{array}$ \\
\hline $\begin{array}{l}\text { Sampling } \\
\text { A. Two skin biopsies from affected skin } \\
\text { B. Stool sample for microbiome studies }\end{array}$ & & $\begin{array}{l}x \\
x\end{array}$ & & & & $\begin{array}{l}X \\
X\end{array}$ & & & & & \\
\hline $\begin{array}{l}\text { Other scores } \\
\text { A. Physician global assessment } \\
\text { B. Modified HAMIS }\end{array}$ & & $\begin{array}{l}x \\
X\end{array}$ & & $x$ & & $\begin{array}{l}X \\
X\end{array}$ & & & & $\begin{array}{l}x \\
x\end{array}$ & $\begin{array}{l}x \\
x\end{array}$ \\
\hline $\begin{array}{l}\text { PROMS } \\
\text { A. Patient global assessment } \\
\text { B. S-HAQ } \\
\text { C. VAS } \\
\text { D. EQ-5D-5L } \\
\text { E. UCL SCTC GIT } 2.0 \\
\text { F. SFQ-28 (women) or IIEF-5 (men) } \\
\text { G. FACIT } \\
\text { H. Customized iPCQ }\end{array}$ & & $\begin{array}{l}x \\
X \\
X \\
x \\
X \\
x \\
x \\
x\end{array}$ & & $\begin{array}{l}x \\
x \\
x \\
x \\
x \\
x \\
x \\
x\end{array}$ & & $\begin{array}{l}x \\
x \\
x \\
x \\
x \\
x \\
x \\
x\end{array}$ & & $\begin{array}{l}x \\
x \\
x \\
x \\
x \\
x \\
x \\
x\end{array}$ & & $\begin{array}{l}x \\
x \\
x \\
x \\
x \\
x \\
x \\
x\end{array}$ & $\begin{array}{l}x \\
x \\
x \\
x \\
x \\
x \\
x \\
X\end{array}$ \\
\hline
\end{tabular}

Abbreviations: ANA: antinuclear antibody, CMV: cytomegalovirus, CTC: common toxicity criteria, DLCO: diffusion capacity carbon monoxide, EBV: Ebstein Barr virus, ECG: electrocardiogram, EQ5D5L: EuroQol five dimensions, five levels, ESR: estimated sedimentation rate, FACIT: Functional Assessment of Chronic Illness Therapy, FDG-PET: fluorodeoxyglucose-positron emission tomography, FSH: follicle stimulating hormone, HAMIS: Hand Mobility in Scleroderma, HAQ-DI: Health Assessment Questionnaire Disability Index, Hb: hemoglobulin, HBV: hepatitis B virus, HCV: hepatitis C virus, HIV: human immunodeficiency virus, HRCT: high resolution computerized tomography, HSV: herpes simplex virus, HTLV-1,2: human T-cell lymphoma virus type, IIEF-5: International Index of Erectile Function, iPCQ: iProductivity Cost Questionnaire. MR: magnestic resonance, mRSS: modified Rodnan Skin Score, PBMCs: peripheral blood mononuclear cells, PROMs: patient reported outcome measure, RNA pIII: RNA polymerase, RV: residual volume, SFQ-28: Sexual Functioning Questionnaire, TLC: total lung capacity, TSH: thyroid stimulating hormone, UCL SCTC GIT: University College London Scleroderma Clinical Trials Consortium Gastrointestinal Tract, VAS: visual analogue scale, VC: vital capacity, VDRL: venereal disease research laboratory, VZV: varicella zoster virus, WBC: white blood count. 


\section{Safety}

The UPSIDE Trial will be overseen by an international DSMB. The DSMB consists of clinicians (including experts on SSc and on stem cell transplantation) and a biostatistician. Every 6 months, the DSMB will review the status and conduct of the clinical trial, evaluate all causes of death and adverse events and make recommendations to the clinical research group concerning the trial's continuation and modification.

Data collection in the study will be monitored by an independent monitor within Julius Centre, UMC Utrecht, the Netherlands. There will be five scheduled visits per centre, the first visit will be the initiation visit and thereafter once a year visits will be performed. The last visit is combined with the close-out visit.

\section{Patient participation}

Our research question originates from clinical practice. The lack of evidence to support the decision-making process in choosing the right treatment strategy is a burden for patients and caretakers. A patient panel (international panel of representatives of patient organizations and patient partners) was involved in the design of this study and development of the patient information. The panel will continue to be involved in the study preparation and evaluation. After completion of the study, we intend to write a patient summary and publish and disseminate the results using media accessible by patients (e.g. magazine of the patient organizations, social media, study website). The Dutch patient organization for systemic sclerosis (NVLE) recognizes the importance of the research question and supports this study.

\section{Ethics}

The study will be performed according to the principles of the Declaration of Helsinki (Adopted by the 18th World Medical Association (WMA) General Assembly, Helsinki, Finland, June 1964 and amended by the 64th WMA General Assembly, Fortaleza, Brazil, October 2013) and in accordance with the Dutch Medical Research Involving Human Subjects Act (WMO).

Patient information will be handled with care, taking into consideration the required confidentiality as stated by the Law for the Protection of Personal Information, the Law Common Treatment Agreement, the EU General Data Protection Regulation and the Dutch Act on Implementation of the General Data Protection Regulation (GDPR). All data will be stored in a pseudonymized database (CASTOR). A limited number of people have access to the data. These are the principal investigator, coordinating investigator and data manager. Personal data are only processed by the researchers or by those who fall directly under their authority. In addition, the study monitor (Clinical Research Associate), auditors, employees from the Medical Research Ethics Committee (MREC) and the Health Care Inspectorate of the Ministry of Health, Welfare and Sport have access to the source data. All are subject to the pledge of confidentiality. The data are directly imputed in CASTOR and securely stored. Research data will be kept up to 15 years after ending the research.

\section{Dissemination}

The results will be presented on scientific conferences, and through publication of articles in peer-reviewed and patient journals. After publication of the main study results, study data will be made available upon request. The study protocol, statistical analysis plan and the informed consent form will be made available as well. 


\section{References}

1. Denton CP, Khanna D. Systemic sclerosis. Lancet. 2017; 390:1685-1699.

2. Elhai M, Meune C, Boubaya M, Avouac J, Hachulla E, Balbir-Gurman A et al. Mapping and predicting mortality from systemic sclerosis. Ann Rheum Dis 2017; 76:1897-1905.

3. Tyndall AJ, Bannert B, Vonk M, Airò P, Cozzi F, Carreira PE et al. Causes and risk factors for death in systemic sclerosis: A study from the EULAR Scleroderma Trials and Research (EUSTAR) database. Ann Rheum Dis 2010; 69:1809-1815.

4. Ioannidis JPA, Vlachoyiannopoulos PG, Haidich AB, Medsger TA, Lucas M, Michet CJ et al. Mortality in systemic sclerosis: An International meta-analysis of individual patient data. Am J Med. 2005;118:210.

5. Altman RD, Medsger TA, Bloch DA, Michel BA. Predictors of survival in systemic sclerosis (Scleroderma). Arthritis Rheum. 1991; 34:403-413.

6. Bulpitt KJ, Clements PJ, Lachenbruch PA, Paulus HE, Peter JB, Agopian MS et al. Early undifferentiated connective tissue disease: III. Outcome and prognostic indicators in early scleroderma (systemic sclerosis). Ann Intern Med. 1993; 118:602-609.

7. Burt RK, Milanettib F. Hematopoietic stem cell transplantation for systemic sclerosis: History and current status. Curr Opin Rheumatol. 2011; 23:519-529.

8. Van Laar JM, Farge D, Sont JK, Naraghi K, Marjanovic Z, Larghero J et al. Autologous hematopoietic stem cell transplantation vs intravenous pulse cyclophosphamide in diffuse cutaneous systemic sclerosis: A randomized clinical trial. JAMA. 2014;311:2490-2498.

9. Assassi S, Wang X, Chen G, Goldmuntz E, Keyes-Elstein L, Ying J et al. Myeloablation followed by autologous stem cell transplantation normalises systemic sclerosis molecular signatures. Ann Rheum Dis. 2019;78:1371-1378.

10. Eyraud A, Scouppe L, Barnetche T, Forcade E, Lazaro E, Duffau P, et al. Efficacy and safety of autologous haematopoietic stem cell transplantation in systemic sclerosis: a systematic review of the literature. $\mathrm{Br}$ J Dermatol. 2018; 178:650-658.

11. Shouval R, Furie N, Raanani P, Nagler A, Gafter-Gvili A. Autologous Hematopoietic Stem Cell Transplantation for Systemic Sclerosis: A Systematic Review and Meta-Analysis. Biol Blood Marrow Transplant. 2018; 24:937-944.

12. Host L, Nikpour M, Calderone A, Cannell P, Roddy J. Autologous stem cell transplantation in systemic sclerosis: A systematic review. Clin. Exp. Rheumatol. 2017; 35:S198-207.

13. Smith V, Scirè CA, Talarico R, Airo P, Alexander T, Allanore Y et al. Systemic sclerosis: State of the art on clinical practice guidelines. RMD Open. 2018; 4(Suppl 1):e000782.

14. Kowal-Bielecka O, Fransen J, Avouac J, Becker M, Kulak A, Allanore Y et al. Update of EULAR recommendations for the treatment of systemic sclerosis. Ann Rheum Dis. 2017; 76:1327-1339.

15. Van Bijnen S, De Vries-Bouwstra J, Van Den Ende CH, Boonstra M, Kroft L, Geurts B et al. Predictive factors for treatment-related mortality and major adverse events after autologous haematopoietic stem cell transplantation for systemic sclerosis: Results of a long-term follow-up multicentre study. Ann Rheum Dis. 79(8), 1084-1089.

16. Farge D, Burt RK, Oliveira MC, Mousseaux E, Rovira M, Marjanovic Z et al. Cardiopulmonary assessment of patients with systemic sclerosis for hematopoietic stem cell transplantation: Recommendations from the European Society for Blood and Marrow Transplantation Autoimmune Diseases Working Party and collaborating partners. Bone Marrow Transplant. 2017; 52:1495-1503.

17. Carreras E, Mohty M, Kroger M. Hematopoietic Stem Cell Transplantation and Cellular Therapies. In: The EBMT Handbook. Springer Nature Switzerland AG 2019.

18. Distler O, Assassi S, Cottin V, Cutolo M, Danoff SK, Denton CP et al. Predictors of progression in systemic sclerosis patients with interstitial lung disease. Eur Respir J. 2020; 55:1902026.

19. Andréasson K, Saxne T, Bergknut C, Hesselstrand R, Englund M. Prevalence and incidence of systemic sclerosis in southern Sweden: Population-based data with case ascertainment using the 1980 ARA criteria and the proposed ACR-EULAR classification criteria. Ann Rheum Dis. 2014; 73:1788-1792.

20. Vonk MC, Broers B, Heijdra YF, Ton E, Snijder R, Van Dijk APJ et al. Systemic sclerosis and its pulmonary complications in The Netherlands: An epidemiological study. Ann Rheum Dis. 2009;68:961-965.

21. Khanna D, Berrocal VJ, Giannini EH, Seibold JR, Merkel PA, Mayes MD et al. The American College of Rheumatology Provisional Composite Response Index for Clinical Trials in Early Diffuse Cutaneous Systemic Sclerosis. Arthritis Rheumatol. 2016;68:299-311.

22. Guideline for economic evaluations in healthcare. https://english.zorginstituutnederland.nl/ publications/reports/2016/06/16/guideline-for-economic-evaluations-in-healthcare 
The UPSIDE Study protocol 


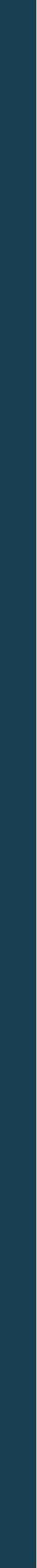


chapter 12

General discussion 


\section{General Discussion}

\section{Optimising outcomes of patients with systemic sclerosis}

Despite advances in supportive care in systemic sclerosis (SSc), outcomes are still dismal in terms of morbidity and mortality. In this thesis, I zoom in on organisation of health care and autologous stem cell transplantation (HSCT) as potential targets to improve outcomes. $\mathrm{SSc}$ is a complex condition. Due to its infrequent occurrence, non-specific early symptoms and an unevenly present level of expertise among health care professionals, diagnosis and initiation of the best treatment strategy can be delayed. Moreover, the variety of symptoms and multiorgan involvement requires a dedicated multidisciplinary team. In order to provide care at the appropriate place - centralisation for advanced cases, shared care and decentralisation for low complexity care - extensive collaboration across hospitals is needed. This is particularly true for HSCT, which is a complex treatment, requiring timely referral of eligible patients to tertiary centres where experienced health care professionals are working together closely. Besides the challenges on the organisational level of SSc care, more attention should be paid to support and education of patients and caregivers. Finally, more insight in the best therapeutic approach is necessary to improve outcomes of patients with SSc.

\section{Quality of health care in systemic sclerosis}

\section{How is quality of care defined?}

By assessing quality of health care, points for improvement can be identified and centres can be benchmarked. This makes it possible to identify best practices of care from which other centres can learn. There are multiple definitions of quality of care. Generally these definitions include values and goals of medical care systems in society $(1,2)$. The way quality of care is evaluated is variable, and also depends on the perspective (patient, caregiver, physician, policy maker).

In chapter two, quality of care was evaluated from a patient perspective. In the absence of defined patient reported quality indicators for care in SSc, the consumer quality (CQ) index was used, which is validated for other chronic rheumatic conditions (3). Our study pointed out that patients were quiet satisfied with the provided care (4). Although we can be pleased with this outcome, this only reflects one dimension of quality of care.

The CQ-index evaluates the experience of patients visiting doctors and nurses, and collaboration between health care professionals. This experience can be influenced by aspects that have no connection with the medical care or clinical outcome though (i.e. state of mind, parking facilities, communicative skills of the health care professional). Secondly, some patients might accept the care they are offered and might not have a comparator, which makes them satisfied with their care anyway. Also, only patients who were able to participate in our online survey could join the survey. Deceased or severely ill patients might have prioritized outcomes as survival or quality of life.

On the other hand, the CQ-index does evaluate two aspects that are most valued by patients, 
since SSc patients prioritized the indicators 1) good patient-physician interaction (80\%), 2) absence of disease progression (66\%) and 3) structural multidisciplinary collaboration (46\%)(4). In contrast, rheumatologists preferred outcomes like quality of life and absence of internal organ involvement (5), and structured screening on disease complications $(6,7)$. This illustrates the different points of view on quality of care in SSc. Ideally, definition of good SSc care should be based on a combination or agreement between both perspectives. Furthermore, while assessing quality of care, not only patient reported outcomes should be included, but also other outcome measures for SSc i.e. those proposed in literature (7), and prioritized by Dutch rheumatologists in a survey conducted by the ARCH systemic sclerosis working group in 2018 (5).

\section{How is SSc expertise defined?}

Notably, in chapter two, no significant differences between regional and expert centres were observed in the perceived quality of care (4). We hypothesized that quality of care would vary across centres with different levels of experience, facilities and case load, as this was reported in literature in other diseases (8-10). However, we observed that the perceived quality of care in SSc across thirteen centres did not differ in the Netherlands. This can be explained, amongst others, by the high overall standard of care in our country and the fact that most participants were treated in large hospitals, but also the applied outcome measure, because the experienced quality of collaboration, communication with physicians and nurses might not necessarily depend on the level of knowledge and facilities in specialized centres.

Yet, it can be helpful to differentiate levels of expertise of SSc centres and determine which medical care could be facilitated by a specialized centre or a local hospital. Collaboration between all types of centres ensures sharing of knowledge and accessibility of the level of care patients need at every stage of the disease. In chapter four requirements for two types of SSc centres are defined, since clear disease-specific criteria for expert centres were still lacking. A Delphi consensus study was conducted among rheumatologists in the Netherlands, and resulted in a list of requirements that can be used to transparently categorize centres with regard to facilities and collaborations present.

Currently, there are organisations that already certify hospitals to be expert centre in systemic autoimmune diseases. The Netherlands Federation of University Medical Centres (NFU), for instance, certifies Dutch university hospitals as "Expert centres for rare diseases" and "Top-reference care centres" for specific conditions, including SSc. The first is based on European agreements and the second is developed by a committee in the Netherlands. Secondly, for non-university hospitals, a certification created by the STZ (the collaborative association of top-clinical teaching hospitals) exists. The requirements for certification for all the existing SSc expert qualifications, are however, rather unspecific with regard to SSc. Furthermore, the approval process is not transparent. Although adding a fourth definition of SSc expert centres, like we did, might only complicate things further, the list described in chapter four could also be regarded as a translation of these existing requirements into practice. Also, the definition of SSc treatment centres enables a more balanced distribution of care and, importantly, intends to encourage collaboration between centres. Future initiatives could focus on discussing the requirements with all stakeholders, and aligning and publishing both requirements and certifications in such a way that patients and 
physicians get insight in the facilities and experience of every hospital in the Netherlands.

\section{Overarching goals and challenges}

The significance of collaboration in SSc care in the Netherlands, was emphasized in chapter three. In the multidisciplinary mixed-method study and working conference in which medical specialists, health professionals and patients discussed ways to optimise SSc care in the Netherlands, it was concluded that shared care and multidisciplinary collaboration are ideal ways to organise SSc care (11). Arthritis Research and Collaboration Hub (ARCH), an initiative from ReumaNederland, aiming to create a nationwide platform that brings together medical expertise on rare autoimmune diseases in the Netherlands. This project can potentially boost collaboration between centres and navigate patients in health care. Yet, many challenges can be faced in the process, particularly with regard to effective medical data exchange between centres, which is key in shared care. Despite the fact that we currently experience a digital revolution that seems to have no real boundaries in other sectors, in health care we still face the limitations of cumbersome centre-specific electronic Patient Record Systems that are not accessible for other hospitals. Privacy and data protections regulations, but also reimbursement strategies in health care block the way of desired innovations like network medicine, shared care and multidisciplinary e-health. These hurdles cannot be overcome by clinicians alone, but should be prioritized by policy makers and insurance companies on a national level.

\section{Navigation and support}

SSc has a major impact on quality of life and daily functioning $(12,13)$. Both physical impairment and psychological distress are frequently reported by patients $(14,15)$. Support from close relationships in activities and, importantly, in coping processes is pivotal (16). Yet, providing help on different levels, including informational, emotional and instrumental support, can be complex and demanding for caregivers. Chapter five describes the burden of the disease on caregivers (17). Caregivers reported that the relationship, their social lives and emotional wellbeing was affected due to the disease of their loved-one. Providing support was sometimes hindered by a lack of knowledge about the disease, insight in the overall treatment strategy and skills in order to optimise communication with their lovedone(s) and cope with their own psychological distress. Accordingly, health care professionals should involve caregivers in educational and supportive sessions as well.

In addition, patient peers can potentially play a role in the support for patients with SSc on an individual (18), or group level (19). Peers can socially support patients, advise on selfcare and share experiences and may be less personally involved than loved-ones (20). In order to further develop a successful peer support programme for patients, peers should be trained in communication, ways of providing support and education about SSc (21).

Another way of helping patients is to make information about SSc more accessible, and to provide advice about self-management. Surprisingly, these needs are currently not sufficiently met in The Netherlands (22,23). In line with this need identified in previous studies, one of the main suggestions in the working conference outlined in chapter three, was the creation of a national information platform (11).

\section{Patient involvement in decision-making}

Importantly, accessible information for patients also increases empowerment and strengthens patients' position in decision-making processes (24). Moreover, effective 
patient-physician communication is crucial for this, yet lacking in current care (25). Patients with SSc believe they should play a bigger part in their health care and in the decisionmaking process (chapter three)(11). Likewise, rheumatologists reported that measures are needed to further involve patients with SSc in care planning and decision-making. This is particularly the case in the context of a complex treatment modality such as HSCT. In the absence of strong evidence on the exact place of HSCT in the course of the disease, treatment decision-making rests on the shoulders of patients and their doctors. The available treatment options in early dcSSc carry different risks and benefits, moreover, outcomes remain unpredictable on an individual level. Patient reported that this treatment decision-making process can be very difficult, as was shown in the qualitative study described in chapter seven (26). Many factors influence this process, such as health status, expectations, education and work, social contacts and family and values, but also knowledge about the disease and alternative treatment options, risk perception and interaction with the doctor. The troublesome circumstances of patients with rapidly progressive disease, might hamper a balanced decision. Especially, when clear and SSc specific information about treatment options is lacking. This could also explain why patients don't mind the leading role of their doctor. Health care professionals should therefore be aware of the values, preferences and expectations of patients, when guiding them in the decision process. Furthermore, optimal content and ways to provide information should be further explored (chapter eight).

\section{Autologous HSCT in SSc: timing and refining}

Rapidly progressive disease can lead to severe morbidity and premature death (27). In order to prevent this, immunomodulating therapies can be considered, including methotrexate, mycophenolate mofetil, cyclophosphamide and HSCT (28-30). In chapter six, a summary of the current evidence of the efficacy of autologous HSCT in SSc was provided (31). We pointed out in this chapter that this treatment is effective and, as a consequence, increasingly performed in SSc (32-34). Yet, the relatively high complication and relapse rate, leaves room for improvement.

Firstly, it is unclear whether HSCT should be positioned as upfront therapy or as rescue treatment in case of refractory disease. Given the risks and costs associated with HSCT, it may be preferable to evaluate the patient's response to immunosuppressive therapy before proceeding to HSCT. This approach could significantly delay the need for a potentially harmful treatment and would be an efficient approach from a health economic point-ofview. On the other hand, if immunosuppressive therapy fails, organ damage may develop, possibly leading to a contra-indication for HSCT. We hypothesize that early HSCT may even lead to less toxicity and medical costs in the long run. In order to determine the best treatment strategy, we designed a multicentre randomized open label trial in chemotherapy naive patients with early progressive dcSSc (chapter eleven). The study design allows patients who deteriorate, despite administration of the allocated treatment, to switch to rescue HSCT or post-transplantation immunosuppression. In this way the study follows clinical practice and, moreover, we expect more patients are willing to participate. The latter is essential, as recruitment of 120 eligible patients with early dcSSc in a randomized trial, will be the main challenge. A disadvantage of this design is the risk of losing statistical power needed for the primary outcome, if many patients switch (the differences in event free survival between both groups will probably be smaller). Still, if this will happen, findings will be valuable for clinical practice, as this is a study investigating optimal strategies. Also, the 


\section{Chapter 12}

need to switch will be included as secondary outcome.

A second area of interest is posttransplant management: prevention and management of relapse and supportive care.

Currently, no guidelines exist on the use of post-HSCT immunosuppressants in SSc. HSCT is believed to reset the autoreactive immune system of patients (35). Following HSCT, autoreactive cells and auto-antibodies seem not completely eradicated (36-38). Yet, numbers of CD4+ CD25+ Foxp3+ T cells (39) and the repertoire of T cell receptors increase $(40,41)$, suggesting an immunotolerant state. Therefore, no additional immunosuppressive treatment is generally initiated after HSCT. Still, a considerable number of patients develop disease progression or relapse post-HSCT (42).

Chapter nine describes a case with severe relapse within one year after successful HSCT(43). A repeat autologous HSCT was eventually indicated due to failure of immunosuppressive therapies. After the second HSCT, immunosuppressive medication was added directly after reinfusion of the CD34+ stem cells, in order to maintain the effect. After four years, this patient is doing well and experiences minimal symptoms related to SSc. Still, the long-term safety of repeated HSCT is unknown, i.e. the high cumulative dose of cyclophosphamide increases the risk of malignancies (44). Therefore, second HSCT should be reserved for refractory cases. Alternatively, the use of posttransplant immunosuppressive therapies could be considered to prevent relapse. This concept is currently evaluated in a prospective, observational, European study (NISSC-2, NCT03444805) and the phase II, North-American STAT trial with mycophenolate mofetil at 3 months post-HSCT (NCT01413100). Ideally, patients at risk for relapse should be identified prior to transplantation or shortly after in order to determine which patient needs posttransplant immunosuppressive therapies. Potential predictors, i.e. T-cell receptor repertoire, reconstitution rate of T-cells and anti-thymocyte globulin (ATG) concentrations should be studied in future research.

Alongside the fine-tuning of the medical aspects of HSCT, more attention needs to be given to non-pharmacological care after transplantation. In chapter ten, we described that HSCT has a large physical and psychological impact on patients, which are not adequately addressed in current health care (45). In line with chapter 3, 8 and 9, information about expected recovery and treatment outcomes is insufficiently provided. Also, a rehabilitation program, including physiotherapy and psychological support, as already exists for patients with other conditions treated with HSCT $(46,47)$, is indicated for patients with dcSSc too.

\section{Early action and new directions}

In this thesis we discussed the importance of smooth collaboration, modern technologies, clear and accessible patient education and optimal transplant strategies in order to improve outcomes in SSc.

Also, by recognising the early stages of disease (48-51), the way has been paved to evolve processes required for timely diagnosis, referral and management. However, awareness of first symptoms and presentation of SSc is still coming up short (chapter two)(4) resulting in delayed referral and initiation of treatment (52). Identification and stratification of patients within the first years of symptoms, based on autoantibody profile, cardiopulmonary screening and skin involvement, allows appropriate treatment and counselling (53). New initiatives are therefore needed, i.e. fast-track Raynaud's clinics in collaboration with general practitioners and other specialties and research that investigate ways to determine risk profiles for individual patients in terms of organ complications and subsequent tailormade 
follow-up programs, and the effects of early interventions, i.e. methylprednisolone pulse therapy in very early SSc (54) or early treatment for ILD or PAH in asymptomatic patients. In addition, novel sustainable therapies are needed to enhance quality of life and survival rates for the full spectrum of SSc patients. HSCT is a potentially beneficial treatment for only a selection of patients, besides, this treatment is expensive and carries high-risks for complications. Many trials have been undertaken to identify more targeted, safe and equally effective therapies. Several biologic disease modifying antirheumatic drugs (bDMARDs) have been demonstrated to be successful in other autoimmune diseases. Unfortunately, many trials with bDMARDs in SSc did not show a significant effect (55), although tocilizumab, a sIL$6 \mathrm{R}$ antibody did preserve lung function better than placebo in two trials. More recent studies, however, showed promising results for some new kids on the block, like protein kinase inhibitor nintedanib in patients with interstitial lung disease (56) and cannabinoid receptor type 2 agonist lenabasum in diffuse skin and interstitial lung disease (57). Further research on combination therapies with immunosuppression and i.e. antifibrotic drugs in SSc-ILD and $\mathrm{PAH}$ could also help to establish potentially new treatment approaches. So, considering the ongoing developments at this bumpy road, there might be a promising outlook for this once believed to be untreatable disease. 


\section{Chapter 12}

\section{References}

1. Donabedian A. Evaluating the quality of medical care. Milbank Q. 2016; 94(2):237-241

2. Donabedian A. Some basic issues in evaluating the quality of health care. NLN Publ. 1987; (21-2194):328.

3. Zuidgeest M, Sixma H, Rademakers J. Measuring patients' experiences with rheumatic care: the consumer quality index rheumatoid arthritis. Rheumatol Int. 2009; 30(2):159-167.

4. Spierings J, van den Ende CHM, Schriemer RM, Moens HJB, van der Bijl EA, Bonte-Mineur F, et al. How do patients with systemic sclerosis experience currently provided healthcare and how should we measure its quality? Rheumatology. 2020; 59(6):1226-1232.

5. van den Ende $\mathrm{CH}$, de Pundert L, de Vries-Bouwstra JK, Schriemer R, Spierings J. Rapport route naar hoogwaardige, toegankelijke zorg voor alle mensen met systemische sclerose. 2018 www.ARCH.nl

6. Gazi H, Pope JE, Clements P, Medsger TA, Martin RW, Merkel PA, et al. Outcome measurements in scleroderma: results from a delphi exercise. J Rheumatol. 2007; 34(3):501-509.

7. Khanna D, Kowal-Bielecka O, Khanna PP, Lapinska A, Asch SM, Wenger N, et al. Quality indicator set for systemic sclerosis. Clin Exp Rheumatol. 2011;29(2 SUPPL. 65):S33.

8. Mahadeva R, Webb K, Westerbeek RC, Carroll NR, Dodd ME, Bilton D, et al. Clinical outcome in relation to care in centres specialising in cystic fibrosis: Cross sectional study. Br Med J. 1998; 13;316(7147):17711775 .

9. Markar SR, Mackenzie H, Wiggins T, Askari A, Karthikesalingam A, Faiz O, et al. Influence of national centralization of oesophagogastric cancer on management and clinical outcome from emergency upper gastrointestinal conditions. Br J Surg. 2018;1;105(1):113-120.

10. Lemmens VEPP, Bosscha K, Van Der Schelling G, Brenninkmeijer S, Coebergh JWW, De Hingh IHJT. Improving outcome for patients with pancreatic cancer through centralization. Br J Surg. 2011; 98(10):1455-1462.

11. Spierings J, van den Ende C, Schriemer R, de Pundert L, Moens HB, van Laar J, et al. Optimal care for systemic sclerosis patients: recommendations from a patient-centered and multidisciplinary mixedmethod study and working conference. Clin Rheumatol. 2019;38(4):1007-1015

12. Park EH, Strand V, Oh YJ, Song YW, Lee EB. Health-related quality of life in systemic sclerosis compared with other rheumatic diseases: A cross-sectional study. Arthritis Res Ther. 2019;21(1).

13. Hudson M, Thombs BD, Steele R, Panopalis P, Newton E, Baron M, et al. Health-related quality of life in systemic sclerosis: A systematic review. Arthritis Rheum. 2009; 61(8):1112-1120

14. Sierakowska M, Doroszkiewicz H, Sierakowska J, OlesiDska M, Grabowska-Jodkowska A, Brzosko M, et al. Factors associated with quality of life in systemic sclerosis: a cross-sectional study. Qual Life Res. 2019; 1;28(12):3347-3354.

15. Gumuchian ST, Peláez S, Delisle VC, Carrier ME, Jewett LR, El-Baalbaki G, et al. Exploring sources of emotional distress among people living with scleroderma: A focus group study. PLoS One. 2016; 11(3):e0152419.

16. Milette K, Thombs BD, Dewez S, Körner A, Peláez S. Scleroderma patient perspectives on social support from close social relationships. Disabil Rehabil. 2020; 42(11):1588-1598.

17. Schriemer MR, Spierings J, de Vries-Bouwstra JK, de Pundert LAJ, van den Ende CH, Vonk MC. Living with systemic sclerosis: exploring its impact on caregivers. Disabil Rehabil. 2020;42(11):1632-1633.

18. Graham-Wisener L, Dempster M. Peer advice giving from posttreatment to newly diagnosed esophageal cancer patients. Dis Esophagus. 2017;30:1-7

19. Rice DB, Thombs BD. Support Groups in Scleroderma. Curr Rheumatol Rep. 2019; 21(4):9.

20. Gumuchian ST, Delisle VC, Kwakkenbos L, Pépin M, Carrier ME, Malcarne VL, et al. Reasons for attending support groups and organizational preferences: the European scleroderma support group members survey. Disabil Rehabil. 2019;10;41(8):974-982.

21. Spierings J, van Laar JM. Choosing a treatment: how can patients be guided through the labyrinth? Lancet Rheumatol. Lancet Rheumatol. 2020; 2;3:e130-e131

22. Schouffoer AA, Zirkzee EJM, Henquet SM, Caljouw MAA, Steup-Beekman GM, Van Laar JM, et al. Needs and preferences regarding health care delivery as perceived by patients with systemic sclerosis. Clin Rheumatol. 2011;30(6):815-824.

23. Schouffoer AA, Ndosi ME, Vliet Vlieland TPM, Meesters JJL. The educational needs of people with systemic sclerosis: a cross-sectional study using the Dutch version of the Educational Needs Assessment Tool (D-ENAT). Rheumatol Int. 2016; 1;36(2):289-294.

24. Coulter A, Entwistle VA, Eccles A, Ryan S, Shepperd S, Perera R. Personalised care planning for adults 
with chronic or long-term health conditions. Cochrane Database Syst Rev. 2015; 2015(3):CD010523.

25. Denton CP, Laird B, Moros L, Flores JLL. Challenges in physician-patient communication for optimal management of systemic sclerosis-associated interstitial lung disease: a discourse analysis. Clin Rheumatol. 2020; 10.1007/s10067-020-05063-x.

26. Spierings J, van Rhijn-Brouwer FCC, de Bresser CJM, Mosterman PTM, Pieterse AH, Vonk MC, et al. Treatment decision-making in diffuse cutaneous systemic sclerosis: a patient's perspective. Rheumatology. 2020; 1;59(8):2052-2061.

27. Ioannidis JPA, Vlachoyiannopoulos PG, Haidich AB, Medsger TA, Lucas M, Michet CJ, et al. Mortality in systemic sclerosis: An International meta-analysis of individual patient data. Am J Med. 2005; 118(1):210.

28. Fernández-Codina A, Walker KM, Pope JE. Treatment Algorithms for Systemic Sclerosis According to Experts. Arthritis Rheumatol. 2018; 1;70(11):1820-1828.

29. Herrick AL, Pan X, Peytrignet S, Lunt M, Hesselstrand R, Mouthon L, et al. Treatment outcome in early diffuse cutaneous systemic sclerosis: The European Scleroderma Observational Study (ESOS). Ann Rheum Dis. 2017; 1;76(7):1207-1218.

30. Kowal-Bielecka O, Fransen J, Avouac J, Becker M, Kulak A, Allanore Y, et al. Update of EULAR recommendations for the treatment of systemic sclerosis. Ann Rheum Dis. 2017; 1;76(8):1327-1339.

31. Spierings J, Van Rhijn-Brouwer FCC, Van Laar JM. Hematopoietic stem-cell transplantation in systemic sclerosis: An update. Curr Opin Rheumatol. 2018; 30(6):541-547

32. Sullivan KM, Wigley FM, Denton CP, Van Laar JM, Furst DE. Haemopoietic stem-cell transplantation for systemic sclerosis. Lancet. 2012; 379(9812):219-220.

33. Burt RK, Shah SJ, Dill K, Grant T, Gheorghiade M, Schroeder J, et al. Autologous non-myeloablative haemopoietic stem-cell transplantation compared with pulse cyclophosphamide once per month for systemic sclerosis (ASSIST): An open-label, randomised phase 2 trial. Lancet. 2011; 6;378(9790):498506.

34. Van Laar JM, Farge D, Sont JK, Naraghi K, Marjanovic Z, Larghero J, et al. Autologous hematopoietic stem cell transplantation vs intravenous pulse cyclophosphamide in diffuse cutaneous systemic sclerosis: A randomized clinical trial. JAMA. 2014;311(24):2490-2498.

35. van Rhijn-Brouwer FCC, Spierings J, van Laar JM. Autologous hematopoietic stem cell transplantation in systemic sclerosis: A reset to tolerance? Immunol Lett. 2018; 195:88-96

36. Bohgaki T, Atsumi T, Bohgaki M, Furusaki A, Kondo M, Sato-Matsumura KC, et al. Immunological reconstitution after autologous hematopoietic stem cell transplantation in patients with systemic sclerosis: Relationship between clinical benefits and intensity of immunosuppression.J Rheumatol. 2009; 36(6):1240-1248.

37. Hiroshi Tsukamoto, Koji Nagafuji, Takahiko Horiuchi, Hiroki Mitoma, Hiroaki Niiro, Yojiro Arinobu, Yasushi Inoue, Kentaro To, Toshihiro Miyamoto, Hiromi Iwasaki, Takanori Teshima, Mine Harada KA. Analysis of immune reconstitution after autologous CD34+ stem/progenitor cell transplantation for systemic sclerosis: predominant reconstitution of Th1 CD4+ T cells. Rheumatology. 2010; 50(5):944-952.

38. Jörg Henes, Lennard Glaeser, Ina Kötter, Wichard Vogel, Lothar Kanz RK. Analysis of Anti-Topoisomerase I Antibodies in Patients With Systemic Sclerosis Before and After Autologous Stem Cell Transplantation. Rheumatology. 2017;1(56):451-456.

39. Baraut J, Grigore El, Jean-Louis F, Khelifa SH, Durand C, Verrecchia F, et al. Peripheral blood regulatory T cells in patients with diffuse systemic sclerosis (SSc) before and after autologous hematopoietic SCT: A pilot study. Bone Marrow Transplant. 2014; 49(3):349-354.

40. Arruda LCM, Malmegrim KCR, Lima-Junior JR, Clave E, Dias JBE, Moraes DA, et al. Immune rebound associates with a favorable clinical response to autologous HSCT in systemic sclerosis patients. Blood Adv. 2018; 23;2(2):126-141.

41. Farge D, Arruda LCM, Brigant F, Clave E, Douay C, Marjanovic Z, et al. Long-term immune reconstitution and $T$ cell repertoire analysis after autologous hematopoietic stem cell transplantation in systemic sclerosis patients. J Hematol Oncol. 2017;19;10(1):21.

42. Spierings J, van Laar JM. Is There a Place for Hematopoietic Stem Cell Transplantation in Rheumatology? Rheum Dis Clin North Am. 2019; 45(3):399-416

43. Van Rhijn-Brouwer FCC, Spierings J, Van Rhenen A, Kuball J, Van Laar JM. Second autologous haematopoietic stem cell transplantation in systemic sclerosis - A case report. Rheumatolology. 2019; 58(7):1305-1307

44. Heydari K, Shamshirian A, Lotfi-Foroushani P, Aref A, Hedayatizadeh-Omran A, Ahmadi M, et al. The risk of malignancies in patients receiving hematopoietic stem cell transplantation: a systematic review and 


\section{Chapter 12}

meta-analysis. Clin Transl Oncol. 2020;10.1007/s12094-020-02322-w.

45. Spierings J, de Bresser JM, van Rhijn- Brouwer FCC, Pieterse AH, Vonk MC, Voskuyl AE, de VriesBouwstra JK, van Laar JM KM. From "being at war" to "getting back on your feet": an exploratory qualitative study in patients with systemic sclerosis treated with hematopoietic stem cell transplantation. J Scleroderma Relat Dis. 2020; 5(3), 202-209

46. Laine J, D'Souza A, Siddiqui S, Sayko O, Brazauskas R, Eickmeyer SM. Rehabilitation referrals and outcomes in the early period after hematopoietic cell transplantation. Bone Marrow Transplant. 2015; 1;50(10):1352-1357.

47. Park J, Wehrlen L, Mitchell SA, Yang L, Bevans MF. Fatigue predicts impaired social adjustment in survivors of allogeneic hematopoietic cell transplantation (HCT). Support Care Cancer. 2019; 1;27(4):1355-1363.

48. Bellando-Randone S, Matucci-Cerinic M. From Raynaud's Phenomenon to Very Early Diagnosis of Systemic Sclerosis- The VEDOSS approach. Curr Rheumatol Rev. 2014;20;9(4):245-248.

49. Guiducci S, Bellando-Randone S, Matucci-Cerinic M. A New Way of Thinking about Systemic Sclerosis: The Opportunity for a Very Early Diagnosis. Isr Med Assoc J. 2016;18(3-4):141-143.

50. NHG. Behandelrichtlijn Fenomeen van Raynaud. NHG standaarden. 2018;9.

51. Minier T, Guiducci S, Bellando-Randone S, Bruni C, Lepri G, Czirják L, et al. Preliminary analysis of the Very Early Diagnosis of Systemic Sclerosis (VEDOSS) EUSTAR multicentre study: Evidence for puffy fingers as a pivotal sign for suspicion of systemic sclerosis. Ann Rheum Dis. 2014; 1;73(12):2087-2093.

52. Oliver Distler, Yannick Allanore, Christopher P Denton, Marco Matucci-Cerinic, Janet E Pope, Barbara Hinzmann, Siobhan Davies, Janethe de Oliveira Pena DK. Factors influencing early referral, early diagnosis and management in patients with diffuse cutaneous systemic sclerosis. Rheumatology. 2018; 57(5):813-817.

53. Roofeh D, Khanna D. Management of systemic sclerosis: the first five years. Curr Opin Rheumatol. 2020; $1 ; 32(3): 228-37$.

54. van den Hombergh WMT, Kersten BE, Knaapen-Hans HKA, Thurlings RM, van der Kraan PM, van den Hoogen FHJ, et al. Hit hard and early: Analysing the effects of high-dose methylprednisolone on nailfold capillary changes and biomarkers in very early systemic sclerosis: Study protocol for a 12-week randomised controlled trial. Trials. 2018; 22;19(1).

55. Denton CP, Khanna D. Systemic sclerosis. Lancet. 2017;390(10103):1685-1699.

56. van den Hoogen LL, van Laar JM. Targeted therapies in systemic sclerosis, myositis, antiphospholipid syndrome, and Sjögren's syndrome. Best Pract Res Clin Rheumatol. 2020;34(1):101485.

57. Spiera R, Hummers L, Chung L, Frech TM, Domsic R, Hsu V, et al. Safety and efficacy of lenabasum in a phase 2 randomized, placebo-controlled trial in adults with systemic sclerosis. Arthritis Rheumatol. 2020; 10.1002 /art.41294. 


\section{General discussion}




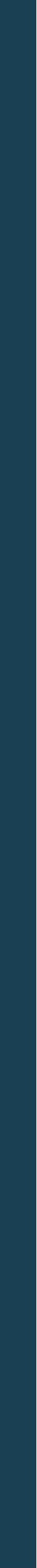




\section{Summary}

This thesis is divided into two parts. The first part focused on quality of health care in systemic sclerosis (SSc) in the Netherlands, the second part investigates care in the context of autologous stem cell transplantation (HSCT).

Chapter 1, provides an introduction in the epidemiology, pathogenesis, clinical presentation, treatment options and health care organisation of SSc. SSc is a rare systemic autoimmune connective tissue disease affecting 1 in 10000 people globally. The disease is characterized by inflammation, vasculopathy, and fibrosis of the skin and visceral organs, yet clinical presentation of SSc is heterogeneous, ranging from limited skin thickening to generalized skin involvement with severe internal organ damage. Two disease subtypes can be distinguished: patients with skin involvement restricted to the face and the distal part of the elbows and knees (limited cutaneous SSc (lcSSc)) and patients with generalized skin thickening (diffuse cutaneous SSc (dcSSc)).

Despite improvement in health care and increased understanding of pathophysiological processes, SSc is still associated with increased mortality rates and high morbidity. Major complications are digital vasculopathy, joint contractures, gastrointestinal complications, cardiac and pulmonary failure and scleroderma renal crisis. Due to the heterogeneous character of the disease, multiorgan involvement and relatively limited therapeutic options, treating patients with SSc can be challenging. Immunomodulating therapies are widely used in patients with diffuse inflammatory and fibrotic disease. Additionally, intensive immunomodulating therapy with haemopoietic autologous stem-cell transplantation (HSCT) can be initiated in patients with progressive SSc, although the optimal selection of patients and timing of this high-risk treatment has not been established yet.

\section{Part 1}

In chapter 2, the results of a survey evaluating quality of care in thirteen hospitals in the Netherlands are discussed. The aim of this study was to gain insight into the patients' perspective of quality of care in SSc and to investigate their preferred quality indicators. In total, 650 patients completed the questionnaire (mean age 59 years, $75 \%$ women, 32\% IcSSc, $20 \%$ dcSSc). Patients reported they were treated in a SSc expert centre in $58 \%$, a regional centre in $29 \%$ or in both in $39 \%$. Interestingly, $13 \%$ of patients was not aware if their hospital was specialized in SSc. The perceived quality of care was rated fair to good, with a mean score of 3.2 (SD 0.5) (range 1.0 - 4.0). No relevant differences between expert and regional centres were observed. The three prioritized process indicators were: good patientphysician interaction (80\%), structural multidisciplinary collaboration (46\%) and treatment according to SSc guidelines (44\%). Absence of disease progression (66\%), organ involvement (33\%) and digital ulcers (27\%) were the three highest rated outcome indicators.

In chapter $\mathbf{3}$ the results of a multidisciplinary, mixed-method study are described. The goal of this study was to identify preferences and priorities among patients and health 
professionals regarding care for SSc patients in the Netherlands, and to develop ideas to improve quality of care. The study consisted of multiple steps: qualitative analysis of focus group interviews and interviews with medical specialists, nurses and health professionals, a survey among patients ( $n=650)$, rheumatologists $(n=167)$, nurses $(n=51)$ and health professionals $(n=85)$, and a consensus meeting $(n=77)$. At the consensus meeting, results from the qualitative studies and survey were discussed and ideas to improve care were addressed and prioritized using nominal group technique. Five key themes were identified: 1. Shared care and multidisciplinary collaboration, 2. Medical data exchange, 3. Education about the disease for all stakeholders, 4. Patient empowerment and 5. Non-pharmacological care. Suggestions for improvement for shared care and collaboration were: guidelines for referral, clear task division between medical specialists and centres, treatment coordination, and exploration of novel ways to exchange medical records. The creation of a national web-based information hub was highly prioritised.

In order to support establishing a nationwide structure for optimal and transparent organization of care, requirements for two type of SSc expert centres in the Netherlands were determined. This three-round Delphi-study is described in chapter 4. The study was conducted among 47 Dutch rheumatologists and immunologists and twenty-two patient representatives. Based on existing criteria for other conditions, five categories were created, including medical care, case load, collaboration, research and training of staff. Items were derived from literature and supplemented with criteria suggested by participants. Every item was evaluated as a requirement for SSc expert centre and/or SSc treatment centres. Consensus (when $>85 \%$ of the rheumatologist panel agreed) was reached for the requirements of SSc expert ( 45 items) and SSc treatment centres (29 items).

Chapter 5 reports on the results of a study that explored the impact of SSc on caregivers (partners, children, family members). Several challenges for caregivers were identified. Firstly, the diagnosis and uncertainty about the course of the disease had a large impact on caregivers. The deteriorating health of their loved-ones was an emotional and physical burden, because of a changing appearance of their partner, declining mobility and increasing dependence on their support. They saw relationships, family life and future plans change. Furthermore, not only social activities of patients diminished, they noticed that their social network dwindled as well. Caregivers mentioned they needed to cope with the diagnosis and its consequences themselves, but experienced difficulties discussing this with their companions and received little to no support from the health care professionals. Moreover, caregivers noticed they were barely involved in the discussion about treatment options and prognosis, which they believed would also help them to cope and support their loved-ones. In conclusion, caregivers are key in the wellbeing of patients, therefore, more attention should be paid to support of caregivers.

\section{Part 2}

Chapter 6 provides an overview of recent literature on autologous HSCT in SSc. Superiority of HSCT versus intravenous cyclophosphamide pulses was already demonstrated in two randomized trials and several observational studies. This observation was recently supported by the randomized controlled SCOT trial $(n=75)$. In SCOT, total body irradiation 
(TBI) was used instead of the nonmyeloablative regimens used in other trials, and considered safe during a follow-up time of 4.5 years. Transplant related toxicity and mortality remain critical issues in HSCT. Cardiac complications, either treatment or disease related, require special attention, but are still not always predictable. So, optimal patient selection, pretransplantation workup and post-transplant management, need to be optimised.

Likewise, the exact working mechanism of HSCT remains unknown. In recent studies changes in regulatory $T$ cells and diversity of T cell receptor repertoire post-HSCT were observed and correlations with treatment response were described, yet, more research is needed to draw further conclusions and to identify predictors for response that can be used in clinical practise.

In chapter $\mathbf{7}$ the results of a qualitative, exploratory study about the experiences of treatment decision-making in the context of HSCT are presented. Semi-structured, face-toface interviews were obtained and analysed thematically. Twenty-five patients participated in this study, five patients were about to undergo HSCT, sixteen were post-HSCT and four were treated otherwise. Making a treatment decision is an intensive and difficult process for patients with dcSSc. When selecting a treatment, many factors played a role: family, work, expectations of the treatment, health at the time of the choice, available information about the treatment and the doctor-patient relationship. The interviews showed that patients had different expectations of treatments with regard to outcomes and risks. Furthermore, half of the patients did not feel they had a choice other than to opt for HSCT, because their health was rapidly deteriorating. Shared decision-making (SDM) was assessed with the 9-item Shared Decision Making Questionnaire (SDM-Q-9). The decision making process was overall perceived as a shared process (median score 81/100 (range 49-100)). On the other hand, patients reported that decision-making was strongly guided by the rheumatologist. Patients did not disapprove this, because they trusted their doctor, but also because they could not oversee all treatment options to make a balanced decision themselves. Patients could be involved more in decision making but need uniform and clear information about the available options to be able to participate in the decision making process.

Chapter 8 reflects on treatment decision making and ways to support patients in this process, as an extension of the study described in chapter 7 . In the context of this complex decision, leaflets and verbal information will not be sufficient. Furthermore, information excess can be a pitfall, as is a selection bias of information that is believed to be relevant from the doctor's perspective. Accordingly, information priorities of patients and doctors should be investigated and unmet information needs should be identified before developing information materials. Furthermore, another potential source of information for patients, which can help them weigh all treatment options, are patient peers.

Apart from patient education, guiding a patient in making a treatment decision can be improved if doctors are more aware of the interaction with their patients and the large influence they have on their decisions.

Chapter 9 describes a patient with dcSSc who underwent a second HSCT. Approximately $25 \%$ of patients treated with HSCT, experience a relapse. This relapse mostly occurs within the first two years. There are no guidelines on how to treat relapses but often immunosuppressive therapy sufficiently suppresses disease activity. We describe a case of a female dcSSc patient who responded very well on the first HSCT. She, however, 
relapsed within the first year following transplantation, and was refractory to two different immunosuppressive therapies. She underwent a second HSCT which resulted in sustained resolution of skin thickening and musculoskeletal complaints. Post-HSCT immunosuppression was initiated to maintain this treatment effect, which was discontinued after two years. This first case report underscores the potential benefit of a second HSCT with post-HSCT immunosuppression in SSc patients who relapse after HSCT. Still, caution should be taken regarding possible toxicity and long-term side-effects.

Chapter 10 describes the results of a qualitative study aiming to gain more insight into the experiences of patients with dcSSc during and after HSCT. Semi-structured interviews were conducted with patients who underwent HSCT in four university hospitals in the Netherlands.

Nine male and seven female patients were interviewed. Patients mentioned their life was severely disrupted before HSCT. Additionally HSCT had a major physical and psychological impact on patients with dcSSc. Uncertainty because of disease progression, loss of control over health and the sense of time and fear of adverse events were common during hospitalization. After HSCT, life remained unsettled for a long time, as patients experienced more physical limitations than they had expected, and recovery took longer and was mentally draining. Going back to work and finding a new balance in personal relations and social life was complicated. Various strategies to deal with challenges were identified in this study.

Importantly, patients reported that aftercare focused on medical aspects rather than on psychological wellbeing and social issues. Also, patients would have preferred to be prepared better on what to expect after discharge, and lacked information about selfmanagement, prognosis, optimal recovery, work, sexuality, and family planning.

Chapter 11 provides the design of the UPSIDE (Upfront autologous hematopoietic Stem cell transplantation versus Immunosuppressive medication in early Diffus E cutaneous systemic sclerosis) trial, a study assessing the optimal treatment strategy in early dcSSc. Currently, there are several treatments available in early dcSSc to change the course of disease, including immunosuppressive agents and HSCT. HSCT has been implemented in treatment guidelines and is offered in several expert centres worldwide. However, optimal timing and patient selection for HSCT are still unclear. In particular, it is unclear whether HSCT should be positioned as upfront therapy or as rescue treatment for patients refractory to immunosuppressive therapy. We hypothesize that upfront HSCT results in less toxicity and medical costs in the long run. Therefore, we propose this multicentre randomized open-label trial which aims to determine the optimal treatment strategy in early dcSSc by comparing two treatment strategies: A. upfront autologous HSCT versus B. immunosuppressive therapy (intravenous cyclophosphamide pulse therapy followed by mycophenolate mofetil) with rescue HSCT in case of treatment failure.

In total, 120 patients with early dcSSc will be randomised in fifteen European centres. The primary outcome is event free survival at two years after randomisation. Secondary outcomes include (serious) adverse events, functional status, quality of life, evaluation of correlation between disease activity and immunological parameters and cost-effectiveness. Follow-up visits will be scheduled 3-monthly for 2 years and annual follow-ups in the following 3 years for the assessment of survival, efficacy and adverse events. 


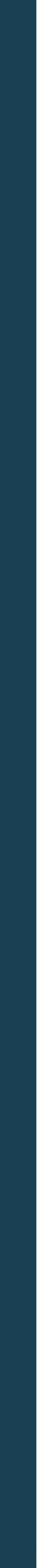




\section{Samenvatting}

Dit proefschrift bestaat uit twee delen. Het eerste deel is gericht op de kwaliteit van de gezondheidszorg voor systemische sclerose (SSc) in Nederland, in het tweede deel wordt de zorg in het kader van autologe stamceltransplantatie (HSCT) onderzocht.

Hoofdstuk 1 geeft een inleiding in de epidemiologie, pathogenese, klinische presentatie, behandelingsmogelijkheden en zorgorganisatie van SSc. SSc is een zeldzame systemische auto-immuunziekte die wereldwijd 1 op de 10.000 mensen treft. De ziekte wordt gekenmerkt door ontsteking, vaatproblemen en fibrose van de huid en interne organen. De klinische presentatie van SSc is heterogeen, variërend van beperkte huidverstrakking tot gegeneraliseerde huidbetrokkenheid en ernstige orgaanschade. Er worden twee ziektesubtypen onderscheiden: patiënten met huidbetrokkenheid beperkt tot het gezicht en distaal van de ellebogen en knieën (gelimiteerde cutane SSc (lcSSc)) en patiënten met gegeneraliseerde huidverdikking (diffuse cutane SSc (dcSSc)). Ondanks verbetering van de gezondheidszorg en beter begrip van pathofysiologische processen, kent SSc nog steeds een verhoogde mortaliteit en hoge morbiditeit. Belangrijke complicaties zijn vaatschade, gewrichtscontracturen, hart- en longfalen en renale schade. Het behandelen van patiënten met SSc kan een uitdaging zijn, vanwege het heterogene karakter van de ziekte, de betrokkenheid van meerdere organen en beperkte therapeutische opties. Van oudsher worden patiënten met het diffuse subtype behandeld met afweeronderdrukkende medicijnen, of met hemopoëtische autologe stamceltransplantatie (HSCT) als patiënten onvoldoende verbeteren op behandeling met afweeronderdrukkende medicijnen of aan snel progressieve ziekte lijden. Echter, de optimale patiëntselectie en de timing van deze hoog-risico behandeling is nog niet vastgesteld.

\section{Deel 1}

In hoofdstuk 2 worden de resultaten van een onderzoek naar de kwaliteit van zorg in dertien Nederlandse ziekenhuizen besproken. Het doel van dit onderzoek was inzicht te krijgen in het patiëntperspectief, en om kwaliteitsindicatoren te identificeren en prioriteren. In totaal namen 650 patiënten deel aan de vragenlijst. De gemiddelde leeftijd van deze patiënten was 59 jaar, $75 \%$ was vrouw, 32\% had lcSSc, $20 \%$ dcSSc. $58 \%$ van de patiënten gaf aan behandeld te worden in een expertise centrum voor SSc, $29 \%$ in een regionaal ziekenhuis of in beide (39\%). Een opvallende bevinding was dat $13 \%$ van de patiënten niet wist of hun ziekenhuis gespecialiseerd was in SSc. De ervaren kwaliteit van zorg werd als redelijk tot goed beoordeeld. Er werden geen relevante verschillen in deze beoordeling tussen expert- en regionale centra.

De drie geprioriteerde procesindicatoren waren: goede interactie tussen patiënt en arts (80\%), structurele multidisciplinaire samenwerking (46\%) en behandeling volgens SScrichtlijnen (44\%). Afwezigheid van ziekteprogressie (66\%), orgaanbetrokkenheid (33\%) en digitale ulcera (27\%) waren de drie hoogst gewaardeerde uitkomstindicatoren. 
In hoofdstuk 3 worden de resultaten van een multidisciplinaire studie beschreven. Het doel van dit onderzoek was het identificeren van voorkeuren en prioriteiten bij patiënten en zorgprofessionals met betrekking tot zorg voor SSc-patiënten in Nederland, en het ontwikkelen van ideeën om de kwaliteit van zorg te verbeteren. De studie bestond uit meerdere stappen: kwalitatieve analyse van focusgroep interviews en interviews met medisch specialisten, verpleegkundigen en gezondheidswerkers, een enquête onder patiënten ( $n=650)$, reumatologen $(n=167)$, verpleegkundigen $(n=51)$ en gezondheidswerkers $(n=85)$ en een consensusvergadering $(n=77)$.

Tijdens de consensusvergadering werden de resultaten van de kwalitatieve studies en de enquête besproken en werden ideeën om de zorg te verbeteren verzameld en geprioriteerd met behulp van de nominale groepstechniek (NTG). Er werden vijf hoofdthema's onderscheiden: 1. Gedeelde zorg en multidisciplinaire samenwerking, 2. Uitwisseling van medische gegevens, 3. Educatie over de ziekte, 4. Patiënt empowerment en 5. Nietmedicamenteuze zorg.

Suggesties voor verbetering voor gedeelde zorg en samenwerking waren: het opstellen van richtlijnen voor verwijzing, een duidelijkere taakverdeling tussen medisch specialisten en tussen centra, coördinatie van behandelingen en verkenning van nieuwe manieren om medische informatie uit te wisselen.

De oprichting van een landelijk online informatieplatform kreeg hoge prioriteit.

Om het opzetten van een landelijke structuur voor een optimale en transparante zorgorganisatie te ondersteunen, zijn criteria vastgesteld waaraan SSc-expertisecentra in Nederland moeten voldoen. Deze Delphi-studie wordt beschreven in hoofdstuk 4. De studie is uitgevoerd onder 47 Nederlandse reumatologen en internisten en 22 patiëntvertegenwoordigers. Op basis van bestaande criteria voor andere aandoeningen zijn vijf categorieën gecreëerd, waaronder medische zorg, casusbelasting, samenwerking, onderzoek en opleiding van personeel. De items waarmee de eerste ronde gestart werd, waren ontleend uit de literatuur en konden aangevuld worden met door deelnemers voorgestelde criteria. Elk item werd beoordeeld als een vereiste voor een SScexpertisecentrum en / of SSc-behandelcentra. Er werd overeenstemming bereikt met vereisten voor SSc-expert (45 items) en SSc-behandelcentra (29 items) voor Nederland.

Hoofdstuk 5 rapporteert de resultaten van een onderzoek dat de impact van SSc op naasten (partners, kinderen, familieleden) onderzocht. In dit onderzoek werden verschillende uitdagingen geïdentificeerd waar naasten mee te maken krijgen. Ten eerste hadden de diagnose en onzekerheid over prognose een grote impact op naasten. De verslechterende gezondheid van hun dierbaren was een emotionele en fysieke belasting, vanwege een veranderend uiterlijk, afnemende mobiliteit en toenemende afhankelijkheid van hun steun. Ze zagen relaties, gezinsleven en toekomstplannen veranderen. Bovendien namen niet alleen de sociale activiteiten van patiënten af, ze merkten ook dat hun sociale netwerk afnam. Naasten gaven aan dat ze zelf de diagnose en de gevolgen ervan moesten verwerken, maar ondervonden moeilijkheden om dit te bespreken en kregen weinig tot geen steun van de zorgverleners. Ook merkten naasten dat ze nauwelijks betrokken waren bij de discussie over behandelingsopties en prognose. Concluderend zijn naasten van groot belang voor patiënten, daarom moet er meer aandacht worden besteed aan ondersteuning van naasten. 


\section{Deel 2}

Hoofdstuk 6 geeft een overzicht van recente literatuur over autologe HSCT bij SSc. De toegevoegde waarde van HSCT ten opzichte van intraveneuze cyclofosfamide pulse therapie werd al aangetoond in twee gerandomiseerde onderzoeken en verschillende observationele studies. Onlangs werd deze bevinding ondersteund door de gerandomiseerde gecontroleerde SCOT-studie $(n=75)$. Transplantatie-gerelateerde toxiciteit en mortaliteit blijven echter struikelblokken bij de implementatie van HSCT. Cardiale complicaties, zowel door de behandeling als door de ziekte zijn nog steeds niet goed voorspelbaar. Optimale patiëntselectie, pre-transplantatie behandeling en screening en post-transplantatiebeleid moeten daarom worden geoptimaliseerd.

Daarnaast is het exacte werkingsmechanisme van HSCT grotendeels onbekend. In recente studies werden veranderingen in regulatoire T-cellen en de diversiteit van het T-cel receptor repertoire na HSCT waargenomen en werden correlaties met respons op de behandeling beschreven. Echter, er is meer onderzoek nodig om verdere conclusies te trekken uit de studies en voorspellers voor respons te identificeren die in klinische praktijk gebruikt kunnen worden.

In hoofdstuk 7 worden de resultaten van een kwalitatieve, exploratieve studie naar de ervaringen van het besluitvormingsproces voor de behandeling in dcSSc gepresenteerd. Vijfentwintig patiënten namen deel aan dit onderzoek. Het onderzoek laat zien dat het maken van een behandelbeslissing een intensief en moeilijk proces is voor patiënten met dcSSc. Bij de keuze van een behandeling speelden veel factoren een rol: gezin, werk, verwachtingen van de behandeling, gezondheid op het moment van de keuze, beschikbare informatie over de behandeling en de arts-patiëntrelatie. Uit de interviews bleek dat patiënten verschillende verwachtingen hadden van behandelingen met betrekking tot uitkomsten en risico's. Bovendien vond de helft van de patiënten dat ze geen andere keuze hadden dan te kiezen voor HSCT, omdat hun gezondheid snel achteruit ging. Het besluitvormingsproces werd over het algemeen beoordeeld als een gedeeld proces, in een hiervoor gevalideerde vragenlijst. Opmerkelijk vonden patiënten ook dat het besluit sterk werd gestuurd door de reumatoloog. Dit vonden de meeste patiënten overigens niet erg, omdat ze vertrouwen hadden in hun arts, maar ook omdat ze niet alle behandelingsmogelijkheden konden overzien. Hieruit concluderen we dan ook dat patiënten nog meer bij de besluitvorming betrokken kunnen worden, maar dat daar wel uniforme en duidelijke informatie over de beschikbare opties voor nodig is.

Hoofdstuk 8 reflecteert op de besluitvorming over behandeling en manieren om patiënten te ondersteunen in besluitvormingsproces rond HSCT. Traditioneel worden hiervoor zowel folders als mondelinge informatie verstrekking gebruikt maar aan beide kleven bezwaren. Er is een risico op informatie overkill of juist verkeerde informatie door de arts. Meer inzicht in de prioriteiten en behoeften van patiënten wat betreft informatievormen en onderwerpen met betrekking tot aspecten van de verschillende behandelopties dienen onderzocht te worden zodat informatiemateriaal ontwikkeld kan worden dat aansluit bij de patiënt. Daarnaast ligt er een waardevolle rol in informatieverstrekking en ondersteuning voor patiëntpartners (ook wel 'buddies' genoemd). Ook kan de begeleiding van patiënten in het besluitvormingsproces worden verbeterd als artsen zich meer bewust zijn van de interactie met hun patiënten en de grote invloed die zij op hun beslissingen hebben. 
Hoofdstuk 9 beschrijft een patiënt met dcSSc met een ernstige recidief na HSCT, die een tweede HSCT heeft ondergaan. Ongeveer 25\% van de patiënten behandeld met HSCT ontwikkelt een recidief binnen de eerste jaren na de behandeling. Er zijn echter geen richtlijnen voor het behandelen van recidieven, maar vaak is immunosuppressieve therapie voldoende. We beschrijven een casus waarbij na goed respons op HSCT, binnen een jaar een ernstig recidief optrad, waarbij twee verschillende afweer onderdrukkende therapieën onvoldoende effect hadden. Zij onderging uiteindelijk een tweede HSCT die resulteerde in volledige remissie. Post-HSCT immunosuppressiva werden gestart om het behandelingseffect te behouden. Dit is de eerste casus in literatuur beschreven van een tweede HSCT bij dcSSc.

Hoofdstuk 10 beschrijft de resultaten van een kwalitatief onderzoek over de ervaringen van zestien patiënten met dcSSc tijdens en na HSCT. Patiënten rapporteerden dat HSCT een grote fysieke en psychologische impact had. Angst voor ziekteprogressie of een recidief, verlies van controle over gezondheid en angst voor bijwerkingen kwamen vaak voor tijdens ziekenhuisopname. Na HSCT beschreven ze dat hun leven lange tijd ontwricht bleef, omdat er toch meer fysieke beperkingen waren dan ze hadden verwacht, en het herstel langer duurde. Hervatting van werk, een nieuwe balans vinden in persoonlijke relaties en oppakken van een sociale leven werd als ingewikkeld ervaren. In deze studie werden verschillende strategieën geïdentificeerd die patiënten gebruikten om met uitdagingen om te gaan. Een belangrijk bevinding was dat patiënten meldden dat de huidige nazorg meer gericht is op medische aspecten dan op psychisch welbevinden en sociale kwesties. Patiënten hadden ook liever beter voorbereid willen zijn op wat ze na ontslag konden verwachten, en hadden geen informatie over zelfmanagement, prognose, optimaal herstel, werk, seksualiteit en gezinsplanning.

Hoofdstuk 11 beschrijft het design van de UPSIDE studie (Upfront autologe hematopoëtische stamceltransplantatie versus immunosuppressieve medicatie in vroege DiffusE cutane systemische sclerose), een studie die de optimale behandelstrategie in vroege dcSSc onderzoekt. HSCT voor dcSSc is geïmplementeerd in behandelrichtlijnen en wordt aangeboden in verschillende centra wereldwijd. De optimale timing en patiëntselectie voor HSCT zijn echter nog steeds onduidelijk. Het is met name niet bekend of HSCT moet worden gepositioneerd als eerstelijns therapie of als laatste redmiddel voor patiënten die niet reageren op immunosuppressieve therapie. We veronderstellen dat eerstelijns HSCT leidt tot minder toxiciteit en medische kosten op de lange termijn. Daarom ontwikkelden we deze multicenter gerandomiseerde open-label studie, die als doel heeft de optimale behandelstrategie in vroege dcSSc te bepalen, door twee behandelstrategieën te vergelijken: A. Eerstelijns autologe HSCT versus B. immunosuppressieve therapie (intraveneuze cyclofosfamide-pulsen gevolgd door mycofenolaat mofetil) met als escape HSCT bij refractaire ziekte. In totaal zullen 120 patiënten met vroege dcSSc worden gerandomiseerd in veertien Europese centra. De primaire uitkomstmaat is ziektevrije overleving twee jaar na randomisatie. Secundaire uitkomsten zijn onder meer ernstige toxiciteit, dagelijks functioneren, kwaliteit van leven, evaluatie van correlatie tussen ziekteactiviteit en immunologische parameters en kosteneffectiviteit. 


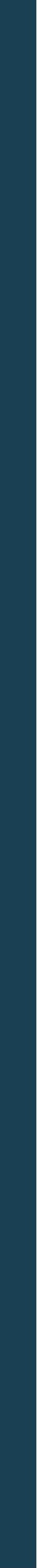




\section{Dankwoord}

Dit proefschrift gaat voor een belangrijk deel over samenwerking, en de studies die in dit werk beschreven worden, zijn eveneens tot stand gekomen door gezamenlijke inspanningen van patiënten en collega's. Er zijn dan ook enorm veel mensen die ik hier wil noemen.

Allereerst dank ik alle patiënten en collega's voor deelname aan de onderzoeken in dit proefschrift.

Prof. dr. Van Laar, beste Jaap (2), je hebt mij geïntroduceerd in de wereld van systemische sclerose, je hebt me de fijne kneepjes van de kliniek geleerd en me het vertrouwen en de ruimte gegeven de wonderlijke en weerbarstige onderzoekswereld te exploreren. Ik kon ervan op aan dat je kritisch over mijn schouder meekeek, en probeerde bij te sturen met de vraag: "Wil je mijn eerlijke mening horen...?" Successen leerde je me vieren met softijs uit het ziekenhuisrestaurant. Tot slot wil ik je danken voor de kansen die je mij biedt. Ik hoop dat we nog lang zullen samenwerken.

Dr. Vonk, beste Madelon, jij hebt vanaf het begin een grote rol gespeeld in de onderzoeken binnen ARCH en mijn promotietraject. Jouw enthousiasme, doorzettingsvermogen en kennis zijn inspirerend. Veel dank voor je betrokkenheid en begeleiding en voor je hulp om mij letterlijk weer op de been te krijgen. Ik heb genoten van onze samenwerking, die na dit promotietraject gelukkig niet zal eindigen.

Dr. Kars, beste Marijke, jij hebt me laten zien dat kwalitatief onderzoek zeer waardevolle inzichten en kennis opleveren. Hartelijk dank voor je eindeloze geduld en indrukwekkende kennis, je hebt me vanaf het ontwerp van onze studie tot het schrijven van de manuscripten fantastisch begeleid.

Dr. De Vries-Bouwstra, beste Jeska, veel dank voor de leuke en constructieve samenwerking in de ARCH- en stamceltransplantatieonderzoeken. Ik ben blij dat je het UPSIDE team versterkt!

Prof. dr. Voskuyl, beste Alexandre, ik waardeer je betrokkenheid en adviezen enorm. Bedankt voor de samenwerking bij vele studies.

Geachte leden van de leescommissie, Prof. dr. Wulffraat, Prof. dr. Oldenburg, Prof. dr. Denton, Prof. dr. Voskuyl, dr. van Wijk, veel dank voor het beoordelen van dit proefschrift. Ik kijk er naar uit om tijdens de verdediging met u over de inhoud te discussiëren.

Prof. dr. Prakken, beste Berent, als mijn mentor heb je mij de afgelopen drie jaar gesteund en bemoedigd, waarvoor hartelijk dank.

Dr. Bernelot Moens, beste Hein, door de duik in het ARCH avontuur heb ik de afgelopen drie jaar mijn tanden kunnen zetten in leuke en soms taaie uitdagingen. Ik heb hier ontzettend 
veel van geleerd. Jouw liefde voor nieuwe technologie is vooruitstrevend, maar ik geloof niet dat ik nog snel zelf een app ga bouwen... Dank ook voor jouw rust en wijsheid. En, wat een mooi netwerk vormt zich in Nederland!

Werkgroep ARCH systemische sclerose. Dr. Van den Ende, beste Els, ik heb genoten van de plezierige samenwerking, jouw kritische blik en unieke kijk op de onderzoeken waren zeer waardevol.

Beste Rita, of we nu op een lawaaierig station in Utrecht, in de trein of op een terras in Pisa zitten, het werkt altijd. Ik bewonder je scherpe blik, je humor en zorgzaamheid. Het is fantastisch met jou samen te werken. Beste Sonja, ik was blij dat jij bij het ARCH Systemische sclerose team aansloot en met jouw ervaring in dit veld kon helpen bij de evaluatie van de app en bij andere projecten. Beste Lian, dank voor de fijne samenwerking in het ARCH Systemische sclerose team.

Beste Alja, Anne, Egon, Femke, Judith, Hanneke, Marieke, Meeke, Thea, Udo en Ward, dank voor jullie medewerking aan de ARCH studies beschreven in dit proefschrift.

Team Clearfields, beste Nicole, Lieke en Loes, dank voor het schakelen, terugkoppelen, inregelen, opleveren, agendapunten aftikken, prio's stellen en smart maken. Ik kon altijd iets tegen jullie aanhouden. Dank voor jullie ondersteuning bij de processen binnen $\mathrm{ARCH}$. Projectmanagement is iets anders dan geneeskunde, maar het is verfrissend hoe verschillende invalshoeken synergistisch werken.

Ook wil ik alle leden van de Nationale vereniging voor lupus, APS, sclerodermie en MCTD (NVLE) en Stichting Sclerodermie Nederland bedanken voor hun betrokkenheid bij de ARCH projecten.

Betrokkenen bij de kwalitatieve studies. Dr. Pieterse, beste Arwen, jouw kennis en invalshoek op besluitvormingsprocessen en arts-patiënt communicatie waren een essentiële toevoeging aan mijn onderzoeken. Dank voor de prettige samenwerking. Beste Femke, wat een geluk heb ik gehad met jou als onderzoek maatje. Je toewijding en enthousiasme zijn aanstekelijk! Ik wil je bedanken voor de fijne samenwerking en ik weet zeker dat we elkaar weer vinden als ik terug ben uit Londen en jij weer in het UMC. Succes met de laatste loodjes van jouw proefschrift en de opleiding tot reumatoloog.

Beste Carolijn, veel dank voor jouw hulp bij de kwalitatieve studie. Het urenlange typewerk heeft je gelukkig nooit af geschrokken, sterker nog, je bleef enthousiast mee denken. Succes met het afronden van de studie en de keuzes die daarna komen (reumatologie?).

Beste Petra, wat patiënten belangrijk vinden zou de basis moeten zijn van alle klinisch wetenschappelijk onderzoek. Dit kan alleen als je het samen met patiënten uitvoert. Ik kan altijd rekenen op jouw eerlijke en kritische blik op mijn werk, hartelijk dank daarvoor.

De UPSIDE groep. Dr. Van Rhenen, beste Anna, dank voor je hulp bij de hematologische details voor de UPSIDE studie en de soepele samenwerking in de transplantatie zorg voor onze patiënten met systemische sclerose. Dr. Welsing, beste Paco, hartelijk dank voor de brainstormsessies en geduldige uitleg over studie designs en statistiek.

De UPSIDE klankbordgroep, met vertegenwoordigers vanuit de NVLE, Stichting het Sclerodermie fonds, de Belgische vereniging voor Sclerodermie en CIB Liga wil ik danken 
voor de waardevolle bijdrage aan het ontwerp van de UPSIDE studie.

Dear Prof. dr. De Langhe, Prof. dr. Del Papa, Prof. dr. Dierickx, dr. Gheorghe, dr. Henes, dr. Hesselstrand, Prof. dr. Kerre, Prof. dr. Ljungman, Prof. dr. Van de Loosdrecht, dr. Marijt, dr. Mayer, dr. Schmalzing, Prof. dr. Schroers, Prof. dr. Smith, Prof. dr. Voll, Prof. dr. Walker, dr. Wuttge, thank you for your collaboration in the UPSIDE study and contribution to the UPSIDE design paper. It is a pleasure working with you.

Beste Dr. Marijnissen, Anne Karien, dank voor je ondersteuning bij de studies in dit proefschrift: je geduld, structuur en precisie zijn buitengewoon. Ik heb genoten van onze samenwerking binnen het Clinical Study Team en ik ben je nu al oneindig dankbaar voor al jouw hulp bij de UPSIDE studie. Ik kijk uit naar de jaren die we nog gaan samenwerken. Beste Anneloes en Karin, ik kwam altijd graag langs in jullie kamertje, voor een update van de studies, jullie praktische kijk op organisatorische zaken van mijn onderzoeken of gewoon een kop koffie. Jullie zijn een geweldig team!

Beste Marieke, wat is het ongelofelijk fijn om met iemand zoals jij samen te werken. Ondanks de hoeveelheid ideeën en vragen waarmee ik bij je aanklop, blijf je me enthousiast helpen. Ik waardeer dit zeer!

Beste Mw. Van de Sanden-Koolen, ontzettend bedankt voor het vertrouwen in mij, de interesse in mijn onderzoek en de bijdragen aan mijn werk. Ik kom u graag weer eens bijpraten.

Beste collega stafleden Reumatologie en Klinische Immunologie in het UMC Utrecht, als nieuwkomer op een afdeling in verandering was het soms zoeken naar mijn plek. Ik heb de afgelopen jaren jullie steeds beter leren kennen en ik prijs me gelukkig dat ik in zo'n kleurrijk team mag werken.

Dr. Heijstek, beste Marloes, dank voor je steun en vrolijkheid, ik kijk uit naar onze verdere samenwerking, als team op de afdeling en in ons vasculitis project. Dr. Kruize, beste Aike, dank voor je vertrouwen en wijsheid. Prof. dr. Lafeber, beste Floris, dank voor jouw betrokkenheid en eerlijke commentaar op de organisatorische en financiële kanten van onderzoek doen (echt waar). Dr. Leavis, beste Helen, jouw gedrevenheid en kennis zijn grenzeloos. Het was me een genoegen samen te werken aan de COVID-19 studie. Ik hoop dat we na crisistijd ook op andere vlakken elkaar kunnen vinden in onderzoek. Dr. Limper, beste Maarten, wat ontzettend leuk om met jou aan ARCH te werken.Daarnaast ben je ook een fantastische collega, met wie ik graag praat, lunch en een kruk deel. Die laatste hebben we gelukkig niet meer nodig. Dank voor de gezelligheid en steun! Dr. Tekstra, beste Janneke, dank voor jouw humor, relativeringsvermogen en openheid. Beste Evelien, dank voor je betrokkenheid en hulp bij het Raynaud zorgpad en zoveel andere zaken. Ik kijk ernaar uit om met je te brainstormen over CTD zorg en onderwijs met de nieuwe inspiratie die ik nu in het Royal Free Hospital opdoe. Beste Carien, dank voor je interesse en enthousiasme. Beste Martijn, ik kijk ernaar uit om samen met jou de echografie op de afdeling verder vorm te geven. Beste Jeffrey, dank voor je hulp en vrolijke noot.

Dr. Jacobs, beste Hans, dank dat ik je altijd wat mocht vragen. Maar vooral ook voor het delen van je kennis en enthousiasme in echografie, en voor je legendarische diacollectie.

Dr. Van der Goes, beste Marlies, je bent helaas maar kort mijn maatje in het UMC geweest, 
maar je werkt gelukkig niet ver weg. Ik vind je een geweldig arts en onderzoeker en bovenal lieve collega waar ik graag mee spar. Laten we dat snel weer doen!

Beste AIOS reumatologie UMCU, dank voor de leuke tijd en jullie inzet, en bovenal jullie hulp bij de organisatie van de vrijdagmiddagborrels en het hartverwarmende afscheidsfeestje (de fles Pimm's wacht hier geduldig op een Friday Night Drinks met jullie).

Beste reumaverpleegkundigen, Etienne, Lucy, Sanne, Suzan en Wil dank voor de fijne samenwerking. Alison, Elles, Elly, Judy, Joyce, Saime, bedankt voor de ondersteuning op de polikliniek. Beste Diana, dank voor de organisatorische ondersteuning bij onder andere de UPSIDE studie.

Prof. dr. Denton, dear Chris, it is an incredible honor to visit the Scleroderma Centre at the Royal Free Hospital and collaborate with you on several exciting research projects. I am particularly grateful that you were found willing to be a member of the Doctoral Examination Committee.

Lieve vrienden, dank voor jullie steun en goede raad, boswandelingen, fietstochten, culinaire uitspattingen, picknicks, filmavonden en reizen. Jullie zijn een fantastische inspiratie voor mij.

Lieve Beatrijs, al vanaf groep 4 van de basisschool in Breda, lachen, feesten, koken we samen, en voel en leef je mee. Ik zou niet eens weten waar ik moet beginnen als ik zou moeten samenvatten wat onze vriendschap allemaal omvat. Daarnaast ben je briljant en creatief, en ben ik je zeer dankbaar dat je dit proefschrift onder handen wilde nemen en het gemaakt hebt tot wat het nu is.

Lieve Lies, paranimf, vanaf het begin van onze studie geneeskunde zijn we samen opgetrokken. Wat hebben we veel meegemaakt, al was het alleen al op de talloze reizen die we samen ondernomen hebben. Jij met richtingsgevoel en kaartleeskwaliteiten terwijl ik de excursies naar de lokale spoedeisende hulp verzorgde. Gelukkig ben jij er tijdens de verdediging om me voor ongelukken te behoeden.

Lieve Maud, paranimf, partner in crime, we zijn tegelijk aan de opleiding in het Maxima Medisch Centrum in Veldhoven begonnen en naast de talloze gezamenlijke diensten, afdelingsperikelen, AIOS commissie, duo co-assistentenbegeleiding, jeu-de boules toernooien, was het rollenspellen met immuuncellen toch wel een bescheiden hoogtepunt in al die jaren. Ik ben blij dat we de liefde voor systeemziekten delen!

Lieve schoonfamilie, Ankie en Jan-Maarten, Lies en Erik, veel dank voor jullie interesse en betrokkenheid bij mijn promotie en bij alle andere life-events.

Charlotte, geweldige zus, dank voor alle spontane avondjes uit of thuis, de weekenden in Eindhoven, Amsterdam of Rotterdam, samen met Steven. Deze worden ook altijd zeer gewaardeerd door je twee nichtjes.

Casper, je bent een ongelofelijk lieve en sterke broer. Dank je wel voor je betrokkenheid. 
Lieve mama en papa, dank voor jullie tomeloze interesse en goede raad. Jullie enthousiasme en hulp met de draken tijdens lange werkdagen waren zeer welkom.

Jaap, liefste Jaap (1), je bent fantastisch.

Olivia en Valerie, samen barsten jullie van fantasie en energie, en verwonderen me elke dag weer. Wat een leuke en mooie momenten beleven we samen, ik kijk uit naar meer! 


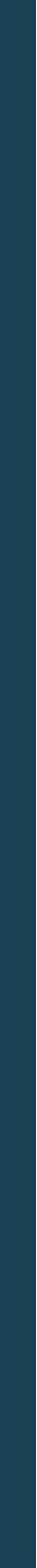




\section{Curriculum vitae}

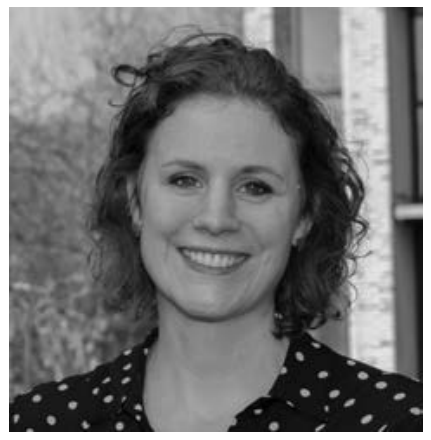

Julia Spierings was born on October 25th, 1985 in Breda, the Netherlands. After graduating high school in 2004 at the Mencia Mendoza Lyceum in Breda she started studying Medicine at the University of Maastricht. In November 2010 she obtained her medical degree. In January 2011 she started with her rheumatology specialisation. She was a resident in Internal Medicine at the Maxima Medical Centre in Eindhoven from 2011 to 2014. In 2014, she started her Rheumatology fellowship at the Maastricht University Medical Center, followed by a year residency at the Zuyderland Medical Centre in Heerlen. She did a fellowship in systemic autoimmune diseases during her last year of residency at the University Medical Centre Utrecht.

She was trained in musculoskeletal ultrasound in Heerlen, and obtained the IRON certification (Imaging RheumatOlogy in the Netherlands) in October 2016. In 2018, she became musculoskeletal ultrasound trainer and acquired the international EULAR level 1 recognition.

From October 2017 to June 2020 she worked as a rheumatologist at the department of Rheumatology \& Clinical Immunology at the University Medical Centre Utrecht. She initiated the Raynaud's outpatient clinics, coordinated the scleroderma transplant program and took part in the Clinical Study Team. Additionally, she worked as a project coordinator at the national ARCH (Arthritis Research and Collaboration Hub) project.

The PhD project "Optimizing outcomes in systemic sclerosis" was started at the Department of Rheumatology \& Clinical Immunology at University Medical Center Utrecht under supervision of prof. dr. J.M. van Laar and dr. M.C. Vonk in February 2018. The result of her research is described in this thesis, has been published in peer-reviewed international journals and led to several presentations at (inter)nationals congresses.

Julia was chair of the JNVR (Junior Dutch Society of Rheumatology), chair of the EMEUNET (Emerging EULAR NETwork) subgroup Global Affairs and Visibility, and is currently leader of 
the subgroup on Clinical Science of the EUSTAR Young Investigators Group.

She is a member of the Dutch Society of Reumatology (NVR), the Scleroderma Clinical Trials Consortium (SCTC) and the European Reference Networks group ReCONNET (Rare and Complex Connective Tissue and Musculoskeletal diseases).

Julia received research grants from the Vrienden van het UMCU, Boehringer Ingelheim, Stichting Het Sclerodermie Fonds and was co-applicant of a ZonMW research grant (round 8, Goed Gebruik Geneesmiddelen). She was awarded with travel stipends from EUSTAR (European Scleroderma Trials and Research) and EULAR (European League against Rheumatism).

In July 2020, she moved to London, United Kingdom, to dedicate her time to systemic sclerosis care and research, as a honorary clinical research fellow at the Royal Free Hospital - University College London, under supervision of Prof.dr. Christopher Denton and dr. Voon Ong. 


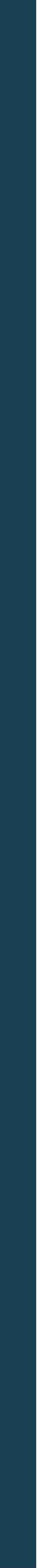




\section{List of publications}

\section{This thesis}

Spierings J, van Rhenen A, Welsing PMJ, Marijnissen ACA, De Langhe E, Del Papa N, Dierickx D, Gheorghe KR, Henes J, Hesselstrand R, Kerre T, Ljungman P, van de Loosdrecht AA, Marijt WAF, Mayer M, Schmalzing M, Schroers R, Smith V, Voll RE, Vonk MC, Voskuyl AE, de VriesBouwstra JK, Walker UA, Wuttge DM, van Laar JM. A randomized, open-label trial to assess the optimal treatment strategy in early diffuse cutaneous systemic sclerosis: the UPSIDE Study protocol. Submitted to BMJ Open

Spierings J, Schriemer MR, Dittmar S, de Pundert AJ, de Vries-Bouwstra JK, van den Ende $\mathrm{CH}$, Vonk MC. On behalf of the ARCH study group. Requirements for systemic sclerosis expert centres in the Netherlands: a Delphi consensus study. J Scleroderma Relat Disord. 2020. OnlineFirst doi.org/10.1177/2397198320953063

Spierings J, de Bresser JM, van Rhijn- Brouwer FCC, Pieterse AH, Vonk MC, Voskuyl AE, de Vries-Bouwstra JK, van Laar JM, Kars MC. From "being at war" to "getting back on your feet": an exploratory qualitative study in patients with systemic sclerosis treated with hematopoietic stem cell transplantation. J Scleroderma Relat Disord. 2020 5(3), 202-209 doi. org/10.1177/2397198320920436

Spierings J, van Laar JM. Choosing a treatment: how can we guide patients through the labyrinth? Lancet Rheumatology 2020; 2(3):130-131 doi.org/10.1016/S2665-9913(20)300266

Spierings J, van Rhijn- Brouwer FCC, de Bresser JM, Vonk MC, Voskuyl AE, de VriesBouwstra JK, Pieterse AH, Kars MC, van Laar JM. Treatment decision-making in hematopoietic stem cell transplantation in patients with poor prognosis diffuse cutaneous systemic sclerosis. Rheumatology. 2020; 59(8):2052-2061. doi: 10.1093/rheumatology/ kez579.

Spierings J, van den Ende CH, Schriemer MR, Bernelot Moens HJ, van der Bijl AE, BonteMineur F, de Buck PDM, de Kanter MAE, van Laar JM, Mulder DJ, Potjewijd J, van de Pundert AJ, Schoonbrood THM, Schouffoer AA, Vercoutere W, Voskuyl AE, de Vries-Bouwstra JK, Vonk MC. Quality of care from the patient's perspective: how do patients with systemic sclerosis experience health care and how should we measure its quality? Rheumatology. 2020; 59(6):1226-1232. doi:10.1093/rheumatology/kez417.

van Rhijn-Brouwer FCC, Spierings J, van Rhenen A, Kuball JHE, van Laar JM. Second autologous hematopoietic stem cell transplantation in systemic sclerosis - a case report. Rheumatology 2019; 58(7):1305-1307. doi: 10.1093/rheumatology/kez010 
Schriemer MR, Spierings J, de Vries-Bouwstra JK, de Pundert AJ, van den Ende CH, Vonk MC. On behalf of the ARCH study group. Living with systemic sclerosis: exploring its impact on caregivers. Disabil Rehabil. 2019; 1-2. doi:10.1080/09638288.2019.1608320.

Spierings J, van den Ende CH, Schriemer MR, de Pundert AJ, Bernelot Moens HR, van Laar JM, de Vries-Bouwstra JK, Vonk MC. Optimal care for patients with systemic sclerosis: recommendations from a patient-centered and multidisciplinary mixed-method study and working conference. Clin Rheumatol. 2019; 38(4):1007-1015. doi: 10.1007/s10067-0184358-x.

Spierings J, van Rhijn-Brouwer FCC, van Laar JM. Hematopoietic stem cell transplantation in systemic sclerosis: an update. Curr Opin Rheumatol 2018; 30(6):541-547. doi: 10.1097/ BOR.0000000000000541.

\section{Other publications}

Shah A, Spierings J, van Laar JM, Sullivan KM. Reevaluating transplant inclusion criteria: three case reports of successful autologous hematopoietic stem cell transplant in advanced systemic sclerosis. Submitted.

Boers N, Ekkelenkamp M, Hindriks-Keegstra A, Kruyt M, Spierings J. Cutibacterium acnes and autoinflammatory bone disease: case series of three patients. Clin Immunol. $2020 \mathrm{Jul}$ 15:108540. doi:10.1016/j.clim.2020.108540.

Klein Haneveld MJ, Lemmen CHC, Brunekreef TE, Bijl M , Jansen AJG, de Leeuw K, Spierings J, Limper M, for the ARCH study group. Diagnosis and treatment of patients with antiphospholipid syndrome: a mixed-method evaluation of care in the Netherlands. Rheumatology Advances in Practice June 2020. rkaa021. doi.org/10.1093/rap/rkaa021

Stöcker JK, Vonk MC, van den Hoogen FHJ, Nijhuis-van der Sanden MWG, Spierings J, Staal $\mathrm{JB}$, Satink T, van den Ende CHM, Room for improvement in non-pharmacological systemic sclerosis care? - A cross-sectional online survey of 650 patients. BMC Rheumatology 2020 Jul 31;4:43. doi: 10.1186/s41927-020-00142-7.

van Bijnen STA, de Vries-Bouwstra JK, van den Ende CH, Boonstra M, Kroft LJM, Geurts BHJ, Snoeren M, Schouffoer AA, Spierings J, van Laar JM, Huizinga T, Voskuyl AE, Marijt WAF, van der Velden WJFM, van den Hoogen FHJ, Vonk MC. Predictive factors for treatment related mortality and major adverse events after autologous hematopoietic stem cell transplantation for systemic sclerosis. Ann Rheum Dis. 2020 May 14:annrheumdis-2020-217058. doi:10.1136/annrheumdis-2020-217058.

Spierings J, Sloeserwij A, Vianen ME, de Boer JH, Sigurdsson V, van de Wijgert JHHM, van Laar JM, Health related quality of life in patients with immune mediated inflammatory diseases. Clin Immunol. 2020 May;214:108392. doi:10.1016/j.clim.2020.108392. 
Servaas NH, Spierings J, Pandit A, van Laar JM. The role of innate immune cells in systemic sclerosis in the context of autologous hematopoietic stem cell transplantation. Clin Exp Immunol. 2020; 201(1):34-39. doi:10.1111/cei.13419.

Spierings $\mathbf{J}$, van Laar JM. Is there a place for hematopoietic stem cell transplantation in rheumatology? Rheum Dis Clin North Am. 2019; 45(3):399-416. doi:10.1016/j. rdc.2019.04.003.

Limper M, de Leeuw K, Lely AT, Westerink J, Teng YKO, Eikenboom J, Otter S, Jansen AJG, V D Ree M, Spierings J, Kruyt ND, van der Molen R, Middeldorp S, Leebeek FWG, Bijl M, Urbanus RT. Diagnosing and treating antiphospholipid syndrome: a consensus paper. Neth J Med. 2019; 77(3):98-108. PMID: 31012427

Spierings J, Lutter L, van Rhijn-Brouwer FCC, van Laar JM, van Wijk F. Resetting the T cell compartment in autoimmune diseases with autologous hematopoietic stem cell transplantation: an update. Front Immunol. 2018; 20;9:767. doi:10.3389/fimmu.2018.00767

van Rhijn-Brouwer FCC, Spierings J, van Laar JM. Autologous hematopoietic stem cell transplantation in systemic sclerosis: a reset to tolerance? Immunol Lett. 2018; 195:88-96. doi: 10.3389/fimmu.2018.00767.

Spierings J, Bours S, Peeters HRM. Regional Migratory Osteoporosis. Osteoporos Int. 2018; 29(2):507-510. doi: 10.1007/s00198-017-4240-8

Spierings $\mathbf{J}$, van Eden W. Heat shock proteins and their immunomodulatory role in inflammatory arthritis. Rheumatology. 2017; 56(2):198-208. doi: 10.1093/rheumatology/ kew266.

Spierings J, Vosse D, Verstraeten V. Nodular scleroderma. Arthritis Rheumatol. 2015; 67(12):3157. doi: 10.1002/art.39325.

Spierings J, van der Linden AN, Kuijper PH, Tick LW, Nijziel MR. Incidentally detected diffuse signal alterations of bone marrow on MRI: is bone marrow biopsy indicated? Neth J Med. 2014; 72(7):345-8. PMID: 25178767

Wolfs TG, Kallapur SG, Knox CL, Thuijls G, Nitsos I, Polglase GR, Collins JJ, Kroon E, Spierings J, Shroyer NF, Newnham JP, Jobe AH, Kramer BW. Antenatal ureaplasma infection impairs development of the fetal ovine gut in an IL-1-dependent manner. Mucosal Immunol. 2013; 6(3):547-56. doi: 10.1038/mi.2012.97.

Wolfs TG, Kallapur SG, Polglase GR, Pillow JJ, Nitsos I, Newnham JP, Chougnet CA, Kroon E, Spierings J, Willems $\mathrm{CH}$, Jobe AH, Kramer BW. IL-1 $\alpha$ mediated chorioamnionitis induces depletion of FoxP3+ cells and ileal inflammation in the ovine fetal gut. PLoS One. 2011; 6(3):e18355. doi:10.1371/journal.pone.0018355. 


\section{Book chapters}

Spierings J, van Rhijn-Brouwer FCC, van Laar JM. The Microbiome in Systemic Sclerosis. Chapter in: The Microbiome in Rheumatic Diseases and Infection 2018. Springer Nature 2018, ISBN 978-3-319-79026-8

Van Laar JM, Spierings J, Vonk MC. How to assess a patient for HSCT.

Chapter in: Practical Management of Systemic Sclerosis in Clinical Practice. Springer (2021). ISBN: 9783030537357. doi:10.1007/978-3-030-53736-4.

Tyndall A, Spierings J, van Laar JM. Chapter 85. Stem cell therapies.

Chapter in: Oxford Textbook of Rheumatology 4th Edition 2019. ISBN: 978-0199642489

Spierings J, Ulf Müller-Ladner. The gastrointestinal tract in systemic sclerosis.

In: EULAR SSc Online course 2020

van Rhijn-Brouwer FCC, Spierings J, van Laar JM. Autologous stemcel transplantation. In: EULAR SSc Online course 2020

\section{In Dutch}

Spierings J. Dure wondzorg, praktijkperikel. Medisch Contact, Mei 2015

Kuipers S, Herenius M, Spierings J.Vitaliteit AIOS reumatologie;resultaten AIOS enquête. NTVR 2018-2

Spierings J, Boone N, Peeters HRM, Landewé R. Methotrexaat: Spuiten of slikken? NTVR 2017-3

Spierings J, Brunekreef B, Dirikgil E, Bernelot Moens HR. Overdaad aan ICD-10 diagnosen belemmert zorgevaluatie en wetenschappelijk onderzoek. Medisch Contact, March 2020

Schriemer R, Spierings J, van den Ende, E. Leven met systemische sclerose: verkenning van de impact op mantelzorgers en aanbevelingen voor de zorg. NTVR 2020-2

Schriemer R, Spierings J, van den Ende CH, Dittmar S, Bernelot-Moes H, van Laar JM, de Pundert AJ, de Vries-Bouwstra JK en Vonk MC. Wat kan het expertise platform voor zeldzame vormen van reuma bieden aan mensen met systemische sclerose? Resultaten van de multidisciplinaire ACRH werkgroep systemische sclerose. NTVR 2020-3 


\section{Oral presentations}

Health related quality of life in patients with immune mediated inflammatory diseases.

Annual meeting of the Dutch Society of Rheumatology 2019.

From "being at war" to "getting back on your feet": an exploratory qualitative study in patients with systemic sclerosis treated with hematopoietic stem cell transplantation.

Annual meeting of the Dutch Society of Rheumatology 2019.

Shared decision-making around hematopoietic stem cell transplantation in patients with poor prognosis diffuse cutaneous systemic sclerosis.

Annual meeting of the Dutch Society of Rheumatology 2019.

Patients' evaluation of dutch health care in systemic sclerosis: unmet needs and preferences.

Annual meeting of the Dutch Society of Rheumatology 2018.

Presentation of the results of the evaluation of dutch health care in systemic sclerosis. ARCH SSc working conference 2018.

\section{Invited speaker}

Autologe stamcel transplantatie in systemische sclerose

Landelijk congress NVLE, 2020.

Workshop management Raynaud's phenomenon.

Landelijke contactdag NVSP, 2019.

Improving quality of care in systemic sclerosis, project $\mathrm{ARCH}$.

Landelijk congress NVLE, 2019.

Pulmonary hypertension in systemic sclerosis

Regionale refereeravond cardiologen, 2019.

Post EULAR session on fibrotic connective tissue disease.

Post EULAR congress, 2018.

\section{Posters presentation}

How do patients with systemic sclerosis experience health care and how should we measure its quality?

World Scleroderma Congress 2020. P155

Treatment decision-making in diffuse cutaneous systemic sclerosis: a patients' perspective. World Scleroderma Congress 2020. P156 
Shared decision-making around hematopoietic stem cell transplantation in patients with poor prognosis diffuse cutaneous systemic sclerosis.

Annual meeting of the Dutch Society of Rheumatology 2019.

Health values, treatment preferences and shared decision making around hematopoietic stem cell transplantation in patients with poor prognosis diffuse cutaneous systemic sclerosis.

BSR 2019. E070

Patients' evaluation of dutch health care in systemic sclerosis: unmet needs and preferences.

EULAR 2018. THU0655.

\section{Courses}

- Klinische epidemiologie (2020, Boerhaave, Leiden University)

- Good Clinical Practice/BROK certificate (2019)

- Course on Writing a scientific paper online (2019, Utrecht University)

- EUSTAR international course (2019, Nijmegen)

- Course on Clinical Epidemiology (2018, Coursera, Utrecht University)

- EULAR Systemic sclerosis online course (certificate 2017, EULAR)

\section{Supervision of students in research projects}

Julia supervised six medical students who worked on her research projects.

\section{Educational activities}

- University lectures: osteoarthritis, autoimmunity and clinical cases

- Clinical lectures for residents: systemic sclerosis, stem cell transplantation, Raynaud's phenomenon, nailfold capillaroscopy

- Trainer in Musculoskeletal ultrasound (three residents) 


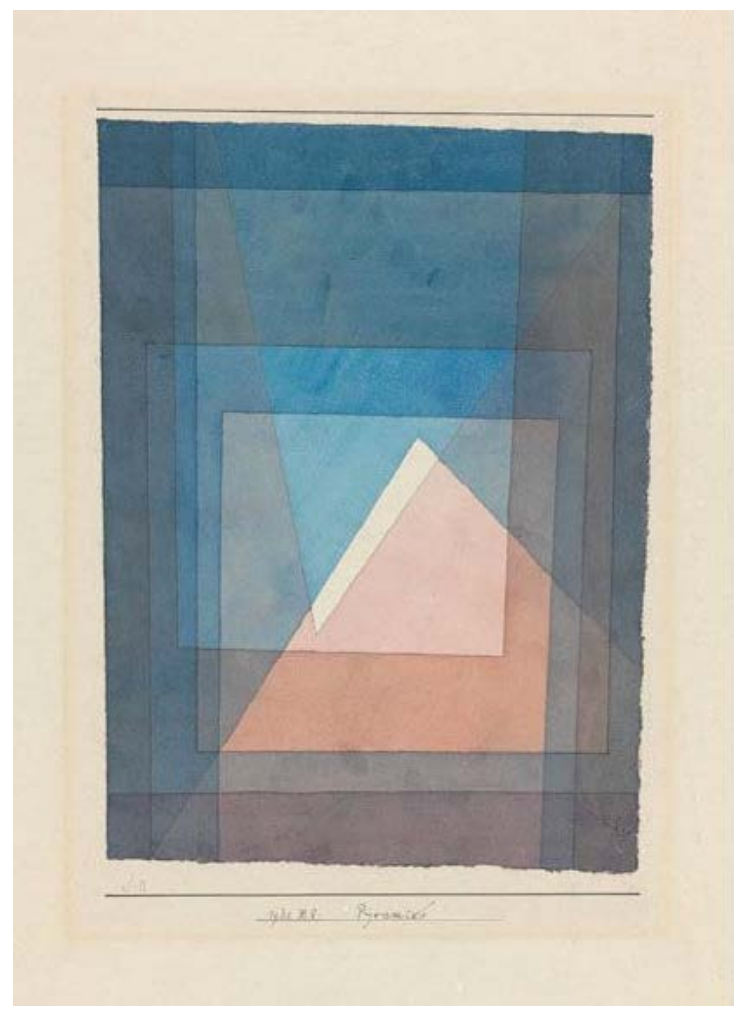

\section{'Pÿramide' by Paul Klee, 1930}

The cover of this thesis was inspired by Paul Klee's Pÿramide. The arrangement of shapes and colours form a complex in which individual objects can be observed, and simultaneously different perspectives and depths are created.

In 1935 Klee started to suffer from a mysterious disease, which influenced his work tremendously. Only 10 years after his death, the illness was recognized as 'scleroderma'. 
